
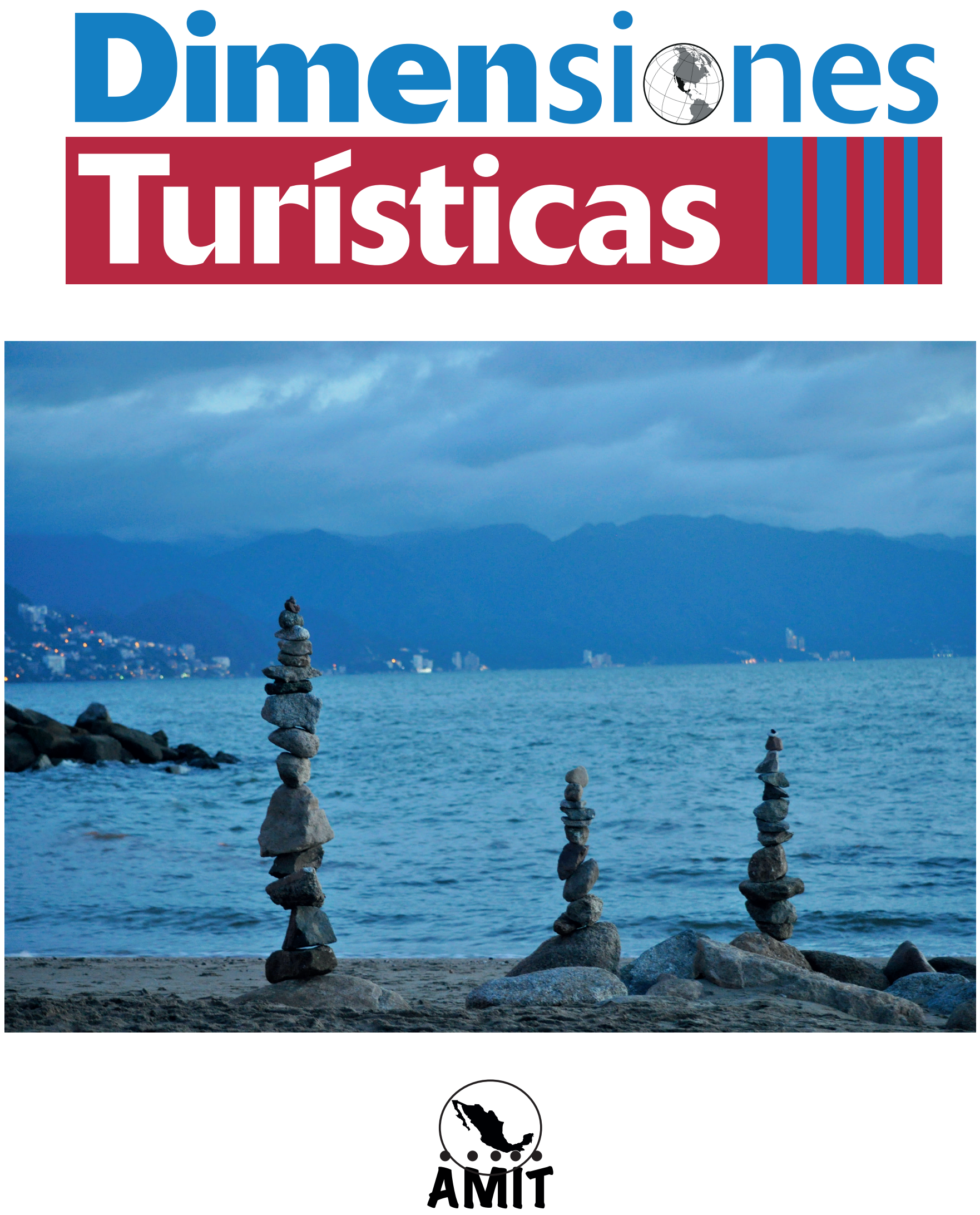

Academia Mexicana de Investigación Turística, A. C.

Publicación semestral • Vol. 4 • Núm. 7 • julio-diciembre 2020 e-ISSN: 2594-2069 

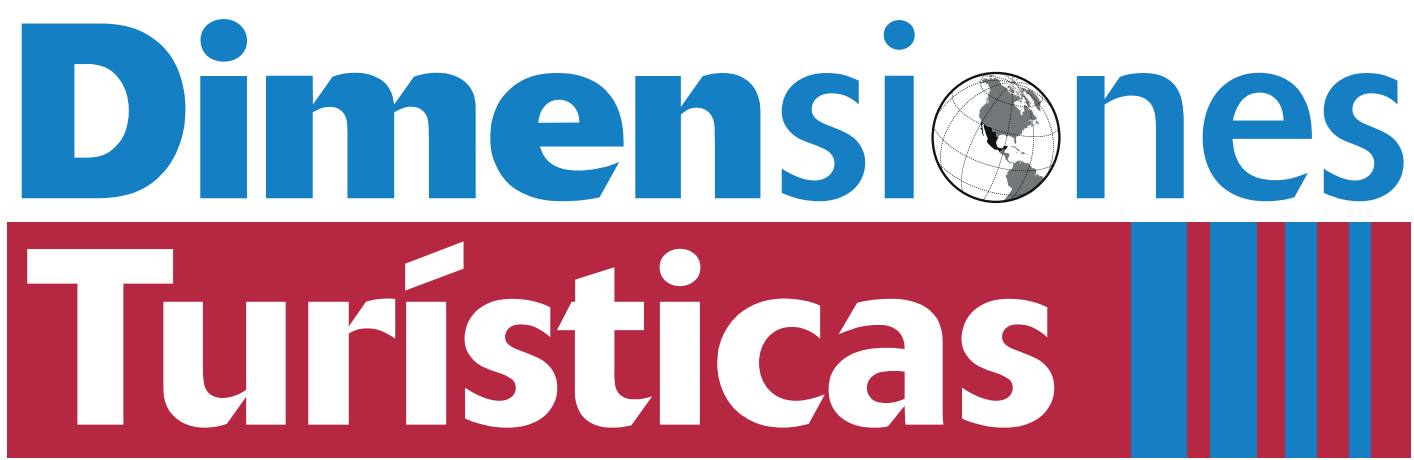

Publicación semestral • Vol. 4 • Núm. 7 • julio-diciembre 2020 •-ISSN: 2594-2069

https://doi.org/10.47557/HSSW8363

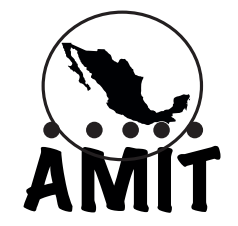

Academia Mexicana de Investigación Turística, A. C. 
Academia Mexicana de Investigación Turística, A. C.

La Academia Mexicana de Investigación Turística, A.C. (AMIT), de acuerdo con sus estatutos es una sociedad sin fines de lucro cuyos miembros, adscritos a universidades, centros de investigación u otro tipo de entidades públicas y privadas, proceden del campo de estudio del turismo, así como de disciplinas como la geografía, economía, sociología, comunicación, antropología, psicología, administración, ciencia política, demografía, ecología, entre otras. La AMIT pretende generar un espacio de trabajo colegiado entre los (las) investigadores(as) dedicados a los estudios del turismo.

Directora de Dimensiones Turísticas

Nora Leticia Bringas Rábago

Teléfono: +52 (664) 6316300 ext. 1306

Correo electrónico: amit.dimentur@gmail.com

Contacto de asistencia

Teresa López Avedoy

Teléfono: +52 (664) 6316300 ext. 1315

Correo electrónico: amit.dimentur@gmail.com

Diseño, formación y cuidado de la edición

Miguel Ángel Ávila García

Irma Leticia Bermúdez Aceves

Fotografía de la portada

Jorge L. López R.

Dimensiones Turísticas, Vol. 4, Núm. 7, julio-diciembre 2020, es una publicación semestral, editada por la Academia Mexicana de Investigación Turística, Villa Costa Azul núm. 55, Mediterráneo Club Residencial, Mazatlán, Sinaloa, C. P. 82113, tel.: +52 (664) 6316300 ext. 1306, https:// dimensionesturisticas.amiturismo.org, amit.dimentur@gmail.com. Editora responsable: Nora Leticia Bringas Rábago. Reserva de Derechos al Uso Exclusivo: 04-2018-082217054200-203, e-ISSN: 2594-2069, ambos otorgados por el Instituto Nacional de Derechos de Autor. Responsable de la última actualización de este número, administrador web de la Academia Mexicana de Investigación Turística: Carlos Vladimir Ruelas González, Carretera Escénica Tijuana-Ensenada Km 18.5, San Antonio del Mar, Tijuana, Baja California, C. P. 22560. Fecha de última modificación: 27 de noviembre de 2020.

Las opiniones expresadas por los autores no necesariamente reflejan la postura del editor de la publicación. 


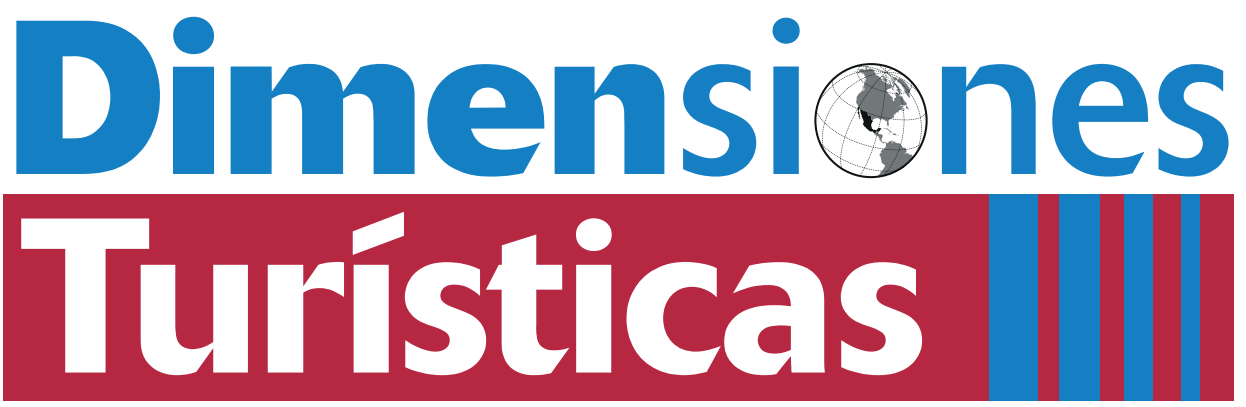

Publicación semestral • Vol. 4 • Núm. 7 • julio-diciembre 2020 e-ISSN: 2594-2069

Nora Leticia Bringas Rábago

DIRECTORA

\section{Consejo Científico}

Cayetano Espejo Marín · Universidad de Murcia, España

Salvador Gómez Nieves · Universidad de Guadalajara, México

Daniel Hiernaux-Nicolas · Universidad Autónoma de Querétaro, México

Raquel Huete Nieves · Universidad de Alicante, España

Antonina Ivanova Boncheva - Universidad Autónoma de Baja California Sur, México

Alfonso de Jesús Jiménez Martínez - Universidad del Caribe, México

Tomás López Guzmán • Universidad de Córdoba, España

Alejandro Palafox Muñoz · Universidad de Quintana Roo, México

Agustín Santana Talavera · Universidad de La Laguna, Canarias, España

Regina G. Schlüter · Centro de Investigación y Estudios Turísticos, Argentina

Rocío del Carmen Serrano Barquín - Universidad Autónoma del Estado de México

Pablo Szmulewicz · Universidad Austral de Chile, Chile

José Fernando Vera Rebollo · Universidad de Alicante, España

\section{COMITÉ EDITORIAL}

Alfonso González Damián · Universidad de Quintana Roo, México

Maximiliano E. Korstanje · Universidad de Palermo, Argentina

Álvaro López López · Universidad Nacional Autónoma de México

Andrea Muñoz Barriga · Pontificia Universidad Católica del Ecuador, Ecuador

Maribel Osorio García · Universidad Autónoma del Estado de México, México

Ana Pricila Sosa Ferreira • Universidad del Caribe, Quintana Roo, México

Basilio Verduzco Chávez - Universidad de Guadalajara, México

Lilia Zizumbo Villarreal · Universidad Autónoma del Estado de México, México 
NoRA LETICIA BRINGAS RÁBAgO

7-8 Presentation

ARTICLES

ALEJANDRo MANTECóN

GONZALO CRUZ

José GuadaluPe Magdaleno Elizondo

ISMaEl Manuel RodríGuez HeRRera

Diana ElizABEth HeRnÁNDEZ-OCHOA

ARELY AlCÁZAR GUZMÁN

ELIZABETH OLMOS-MARTíNEZ

OMAR ISMAEl RamíREZ HeRnándeZ

ROCíO JARAMILLO JARAMILLO

RICARDO SONDA DE LA ROSA

DAMAYANTI ESTOLANO CRISTERNA

SANDRA GUERRA MONDRAGÓN

\section{ESSAY}

Jesús Antonio Madera Pacheco

BOOK REVIEW

GABRIEL INOSTROZA

$191-194$

Planning and management cases tour. Behaviors, problems and advances

Bringas-Rábago, N. L., Osorio-García, M. y Sosa-Ferreira, A. P. (Coords.)

Víctor Manuel López Guevara

93-124 State of knowledge on sustainable development in Pueblos Mágicos

125-150 Management of natural resources in the community of El Peñón, Temascaltepec: an ecotourism route for the diversification of the offer

151-180 Centennials job expectations for Cancún tourism businesses. Approach based on McClelland's theory of needs

181-190 Rural tourism: challenges of rural communities in the context of COVID-19

Nature tourism in indigenous communities

\section{INDEX} in México

López-Pardo, G. y Palomino-Villavicencio, B. 


\section{Dimensiones Turísticas \\ Publicación semestral \\ Vol. 4, Núm. 7 \\ julio - diciembre 2020 \\ e-ISSN: 2594-2069}

NoRa Leticia BRINGAS RÁBAgO

ARTí́CULOS

AlejANDRo Mantecón

GONZALO CRUZ

José Guadalupe Magdaleno Elizondo Ismael Manuel Rodríguez Herrera DiANA ELIZABETH HERNÁNDEZ-OCHOA

ARELY ALCÁZAR GUZMÁN

ElizABETH OLMOS-MARTíneZ

OMAR ISMAel Ramírez HeRnández

ROCíO JARAMILLO JARAMILLO

RICARDO SONDA DE LA ROSA

DAMAYANTI ESTOLANO CRISTERNA

SANDRA GUERRA MONDRAGÓN

NOTA CRÍTICA

Jesús Antonio Madera Pacheco

RESEÑA

GABRIEL INOSTROZA

191-194

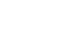

ÍNDICE

\section{de la oferta de McClelland}

7-8 Presentación

9-28 Ética y política en la investigación del turismo

29-62 Movilización social y turismo: el conflicto por la privatización del espacio costero en la ciudad de Mar del Plata, Argentina

63-92 Efectividad de la comunicación en las pequeñas y medianas empresas del sector turístico en un entorno altamente competitivo

93-124 Estado del conocimiento sobre el desarrollo sustentable en Pueblos Mágicos

125-150 Aprovechamiento de los recursos naturales en la comunidad El Peñón, Temascaltepec: una ruta ecoturística para la diversificación

151-180 Expectativas laborales de los centennials para los negocios turísticos de Cancún. Enfoque basado en la teoría de las necesidades

181-190 Turismo rural: desafíos de las comunidades rurales en el contexto del COVID-19
Casos de planeación y gestión turística.
VÍctor MANuel LóPEZ GueVARA

Comportamientos, problemas y avances. Bringas-Rábago, N. L., Osorio-García, M. y Sosa-Ferreira, A. P. (Coords.)

Turismo de naturaleza en comunidades indígenas en México.

López-Pardo, G. y Palomino-Villavicencio, B. 


\section{Presentación}

- n este número se presenta una amplia diversidad en temas, comenzando con un recorrido desde los principios éticos en torno a la investigación en el turismo, el análisis del activismo social en defensa de un destino de playa y los marcos en que se construye, el estudio de la efectividad de la comunicación como elemento que impulsa a las Pymes del sector, la propuesta de diversificar la oferta turística con productos innovadores en las comunidades, la revisión de la literatura enfocada en desarrollo sustentable y Pueblos Mágicos, cerrando con el panorama laboral en las empresas de turismo al recibir a la Generación Z.

Así, Alejandro Mantecón diserta respecto a la ética y la política en la investigación turística, con un enfoque crítico hacia la Academia de Esperanza y las dificultades que enfrentan los nuevos paradigmas, haciendo un llamado a los investigadores a defender sus convicciones éticas, con una reflexión de las nuevas perspectivas y metodologías que contribuyan a su labor.

Gonzalo Cruz examina la situación en Mar del Plata, con relación a las movilizaciones sociales a causa de la privatización de los espacios costeros bajo la perspectiva de los marcos de acción colectiva, además de dedicar una visión hacia el desarrollo sustentable, compatible con los requerimientos de los residentes.

Retomando el tópico de la economía y la competitividad, José Guadalupe Magdaleno, Ismael Rodríguez y Diana Hernández plantean que las pequeñas y medianas empresas del sector turismo en Aguascalientes, México, pueden mejorar su desempeño en la medida en que integren el concepto de efectividad de la comunicación en sus modelos internos, desde una investigación descriptiva-correlacional.

En el marco de la sustentabilidad, Arely Alcázar y Elizabeth Olmos Martínez analizan el programa Pueblos Mágicos, haciendo un recorrido a través de los trabajos académicos realizados bajo este enfoque y su relación con las dimensiones socioculturales, medioambientales y económicas.

Bajo el enfoque de que los habitantes de una comunidad pueden incrementar sus ingresos, por medio del aprovechamiento consciente de los recursos naturales, Omar Ramírez y Rocío Jaramillo proponen una ruta ecoturística para la oferta en la localidad de El Peñón, Temascaltepec, municipio del Estado de México. 
Asimismo, Ricardo Sonda, Damayanti Estolano y Sandra Guerra, determinan las expectativas laborales de los centennials, en un estudio centrado en identificar las motivaciones que dicha generación mantiene en su vida profesional, las cuales impactan en los índices de rotación de personal de las organizaciones turísticas.

Desde la visión de los residentes, Jesús Madera establece en su nota crítica los desafíos de las comunidades rurales en el contexto del COVID-19, en un ejercicio que profundiza en la importancia de romper con la imagen idílica del turismo en dichas regiones, que lo vende como una panacea en tiempos pandémicos.

En cuanto a las reseñas, en esta ocasión Gabriel Inostroza dedica sus comentarios al libro Casos de planeación y gestión turística. Comportamientos, problemas y avances, obra coordinada por Nora L. Bringas Rábago, Maribel Osorio García y Ana Pricila Sosa Ferreira, editada por PASOS bajo el sello Colección PASOS Edita.

Víctor Manuel López hace lo propio con el libro Turismo de naturaleza en comunidades indígenas en México, de Gustavo López Pardo y Bertha Palomino, al brindar una apreciación que discurre el abordaje de los autores sobre el desarrollo, la naturaleza y las políticas públicas afines.

Como afirma Alejandro Mantecón en el primer artículo de este número, las diversas perspectivas y metodologías "contribuyen a enriquecer la comprensión del turismo", de manera que las múltiples visiones aquí plasmadas convergen para recordarnos la infinita pluralidad de aquello que creemos conocer. 


\section{ÉTICA Y POLÍTICA EN LA INVESTIGACIÓN DEL TURISMO}

ALEJANDRO MANTECÓN alejandro.mantecon@ua.es Universidad de Alicante, España

El cuestionamiento de las lógicas positivistas, dominantes en la investigación del turismo, favoreció en el umbral del siglo XXI el desarrollo del llamado giro crítico de los estudios turísticos y el intento de construcción de un nuevo paradigma con rasgos distintivos: la Academia de Esperanza. Se revisa este proceso y se critican las bases teóricas y los supuestos ético-políticos en los que se sostiene. Finalmente, se discute el tipo de relación que debe establecer el análisis crítico del turismo con la reflexión moral sobre sus efectos.

Palabras clave: reflexividad, empirismo abstracto, acumulación de conocimiento, giro crítico, epistemología.

\section{ETHICS AND POLITICS IN TOURISM RESEARCH}

The questioning of positivist logics, dominant in tourism research, drove to the so-called critical turn in tourism studies, on the threshold of the twenty-first century. As a result, the Academy of Hope is an attempt to build a new paradigm with distinctive features. This process is reviewed, with a critic of the theoretical basis and ethic-political foundations. Finally, the relationship that must be established between the critical tourism analysis and the moral reflection on its effects is discussed.

Keywords: reflexivity, abstract empiricism, knowledge accumulation, critical turn, epistemology. 


\section{Introducción}

a investigación y la reflexión acerca de las repercusiones de la actividad turística fueron empresas intelectuales poco frecuentes, hasta que, una vez concluida la Segunda Guerra Mundial, la expansión de las sociedades de consumo en la Europa capitalista y Norteamérica propició la eclosión del turismo de masas.

En los años 50 y 60 se produjo un tímido impulso, gracias a la publicación, todavía muy ocasional, de libros introductorios o de revistas como Tourism: an International Interdisciplinary Journal (fundada en 1953), Estudios Turísticos (de 1964) o Journal of Travel Research (de 1968). No obstante, es difícil encontrar artículos de esa época que presenten el turismo como un fenómeno conflictivo.

En la década de los 70, un grupo de pioneros bosqueja otros enfoques, ajenos a los discursos apologéticos emitidos por los organismos oficiales. Estos se concretan en ensayos redactados desde perspectivas antropológicas y sociológicas críticas (De Kadt, 1979; Estivill, 1979; Gaviria, 1974; Galán et al., 1977; Greenwood, 1977; Jurdao, 1979; Nash, 1977; Turner y Ash, 1975), algunas influenciadas por distintas corrientes neomarxistas (teorías de la dependencia o pensamiento urbano de Henri Lefebvre).

La profusión de publicaciones de los años 80 y 90 del siglo pasado trastoca la situación anterior, con dos efectos evidentes: a) la legitimación del turismo como un objeto de estudio complejo y relevante para las ciencias sociales, y b) su creciente incorporación a las universidades a través de la implementación de programas formativos, la creación de grupos de trabajo y un incremento de las líneas de financiación. Por supuesto, el proceso se extiende de diversas maneras y con ritmos muy dispares, reconociéndose hoy dinámicas consolidadas junto a otras apenas incipientes.

La institucionalización académica de la investigación turística queda asociada a debates epistemológicos y, sobre todo, a disputas corporativistas que reivindican la apropiación del turismo por parte de las áreas de conocimiento, departamentos o facultades con más arraigo e influencia. Así, entre las aspiraciones de unos y las demostraciones de poder de otros, se originan discusiones recurrentes a propósito de si el turismo posee una entidad disciplinaria genuina o si, más bien, es un espacio distinto que se abre a la indagación geográfica, antropológica, mercadotécnica, entre otras (Leiper, 2000; Tribe, 1997; 2000). 
Al volver la vista atrás y observar los caminos transitados durante las dos primeras décadas del nuevo milenio, es posible advertir cómo el examen del turismo se adentra en una nueva etapa con rasgos distintivos. En su intento por trascender los problemas de identidad de los estudios turísticos, las aproximaciones más vanguardistas proponen esquemas interpretativos posdisciplinares (Coles et al., 2006), capaces de configurar redes (de investigadores, ideas, conceptos) conectadas entre sí con el fin de desarrollar proyectos que encaren el turismo no como un sistema más o menos determinante, sino como una dimensión constitutiva de las sociedades modernas (Darbellay y Stock, 2012).

La realidad turística se convierte entonces en un campo de trabajo central y paradigmático en el que, junto a las miradas más convencionales, confluyen y se interpenetran enfoques como los estudios de género (Aitchison, 2005; Cole, 2018; Figueroa-Domecq et al., 2015), la ecología (Becken y Hay, 2007; Scott, 2008), la investigación de las emociones (Picard y Robinson, 2012), la teoría del actor-red y el estudio de los vínculos que los turistas establecen con los objetos materiales (Beard et al., 2016; Muecke y Wergin, 2014), el paradigma de la movilidad (Sheller y Urry, 2006; Urry, 2007), los análisis sobre la digitalización de la vida social (Huete, 2019; Wang et al., 2002, 2012), o la filosofía y la ética del turismo (Fennell, 2006; Tribe, 2009).

Estas perspectivas tienden a empapar los modos en los que se plantea el entendimiento tanto de las prácticas turísticas tradicionales como de la infinidad de formas emergentes; además, atraviesan los grandes temas que han focalizado la curiosidad de los expertos: los tipos de turistas (motivaciones, comportamientos), los impactos de la actividad turística (económicos, socioculturales, geoambientales), las interacciones entre los visitantes y los residentes en las sociedades receptoras (y las percepciones e imaginarios que de ellas resultan), o la evolución de la industria que promueve el negocio del ocio y el viaje (cambios en las estructuras empresariales y laborales).

Sin duda, la comprensión del hecho turístico se ha incrementado y refinado. A la vez, surgen nuevos retos como consecuencia de las transformaciones experimentadas por el contexto tecnológico, las crisis recurrentes del capitalismo, los riesgos inherentes al calentamiento global o, en el momento de escribir estas líneas, el desastre provocado por la pandemia del COVID-19. Otro tipo de dificultades aluden a asuntos que se vienen arrastrando por décadas y que, más que resolverse, se adap- 
tan a los nuevos tiempos. También se hace referencia a tensiones ligadas al envoltorio político-ideológico que interviene en la producción de conocimiento sobre el turismo.

Una de esas tensiones es analizada por Claudio Milano (2017), quien aborda los motivos que explican el carácter subalterno de la literatura redactada en español y portugués acerca de la antropología del turismo, frente a aquella escrita en inglés. Los argumentos expuestos por Milano son extrapolables a otras disciplinas, y se enmarcan en la panorámica de desafíos examinados por Maribel Osorio y Maximiliano Korstanje (2017), muchos de los cuales están emparentados con los objetivos de este texto, pues también explora la construcción social del conocimiento.

\section{Objetivo}

En las próximas páginas, se invita a pensar acerca del modo en el que los estudios turísticos se ven afectados debido a una tensión consustancial al trabajo científico en general y al científico-social en particular: la influencia de la reflexividad en la investigación. Por reflexividad se entiende la cualidad de las personas de dotar de diferentes significados a las acciones que emprenden, así como las circunstancias que las influyen y, en consecuencia, modificar sus actitudes y conductas.

Esta vieja cuestión es gestionada de distintas maneras en unos y otros entornos. Para el caso del turismo, ha sido revisada desde distintos ángulos; por ejemplo, son destacables las contribuciones de Tobar-Bustamante et al. (2015) o las de Castillo-Nechar y Panosso (2010). Aquí se atrae la atención a algunos de los problemas derivados de:

a) La pretensión de dotar a los estudios turísticos de un estatus científico, sostenido en supuestos positivistas simplificadores, que obvian las implicaciones de la reflexividad en el análisis científico-social.

b) La manera en que el denominado giro crítico (critical turn) de los estudios turísticos ha intentado superar el fetichismo metodológico y el reduccionismo analítico inherentes a una aplicación radical de los supuestos positivistas en la investigación del turismo. 


\section{La aspiración científica}

La ciencia es una estrategia de producción de conocimiento creada por los seres humanos en su deseo por entender el funcionamiento de ciertos aspectos de la realidad. Asume que existe una realidad cognoscible, que posee pautas de orden y regularidad descifrables, cuyo esclarecimiento nos proporciona la sensación de no vivir en un caos aleatorio y carente de sentido. A pesar de ser un proyecto social $y$, por lo tanto, de hallarse expuesto a múltiples contingencias, muestra una sorprendente eficacia a la hora de generar explicaciones sólidas de la realidad a la que pertenecemos.

Los hallazgos científicos parecen disociarse de los valores y las interpretaciones subjetivas, hasta convertirse en referentes de gran utilidad para organizar la vida. Por ejemplo, al unir dos átomos de hidrógeno con uno de oxígeno se forma una molécula de agua; en ausencia de elementos perturbadores la repetición de esta operación, guste o no, ofrecerá el mismo resultado.

Según la ortodoxia, el secreto de tal eficacia explicativa reside en una observación disciplinada, guiada por la aplicación del método científico. No importaría que la ciencia fuese una construcción colectiva, pues un individuo aislado, aplicando con rigurosidad el método científico, obtendría los mismos resultados que otro en condiciones idénticas de replicabilidad experimental.

Los problemas de esta concepción fueron desmenuzados por Thomas S. Kuhn (1962; 1977), y están relacionados con el hecho de que las decisiones que los científicos toman están mediadas por las estructuras grupales en las que se hallan insertos, a propósito de la definición de su objeto de estudio (¿qué es y qué no es un problema de investigación?) y de la posición que frente a él adoptan (¿qué parte de la realidad es accesible en términos científicos? y ¿cómo materializar ese acceso?). Es decir, la validez y fiabilidad del discurso científico no se sustenta en la aplicación aséptica de un método unívoco, sino en un conjunto de operaciones articuladas por compromisos cognoscitivos socialmente condicionados.

Las disputas relativas a estos planteamientos han hecho correr ríos de tinta (Popper, Lakatos, Feyerabend, Latour y un largo etcétera). En las ciencias sociales los problemas se multiplican, porque la naturaleza de las relaciones que se establecen entre el sujeto y el objeto de la investigación, así como los contextos que determinan esas 
relaciones, amplifican de tal modo las inquietudes que, desde algunos ámbitos, se cuestiona que las ciencias sociales merezcan el calificativo de ciencias.

A continuación, se exponen algunas ideas sobre la relación sujeto-objeto (y sus repercusiones en los estudios turísticos), enlazadas posteriormente con los factores contextuales.

Florian Znaniecki (1927) Ilamó coeficiente humanístico a la propiedad de los sistemas culturales en virtud de la cual el conocimiento de la realidad social solo podría alcanzarse si el investigador admite que su objeto de estudio no posee una independencia (una resistencia al cambio) comparable a la de los objetos a los que se enfrentan los científicos naturales. En el análisis de una situación social, el experto tendría que abordar las claves interpretativas (subjetivas y volubles) que construyen los diferentes actores en ella involucrados, y distinguir esas interpretaciones de la suya.

Ahondando en esta cuestión, Henry A. Landsberger (1958) acuña la expresión efecto Hawthorne, al revisar los estudios dirigidos por Elton Mayo en la planta industrial Western Electric's Hawthorne Works de Chicago, realizados entre 1924 y 1932. El efecto Hawthorne se refiere a la distorsión que se produce en la investigación debido al conocimiento que tienen los sujetos estudiados del hecho de serlo (y la consiguiente variación en sus actitudes y comportamientos).

Estos factores, la subjetividad y la autoconciencia, son la base en la que se asienta la reflexividad característica de las interacciones humanas. Aceptar su existencia hace casi imposible edificar unas ciencias sociales equiparables a las ciencias naturales, pues las expectativas de acumulación de conocimiento (de acuerdo con la lógica de lo que Kuhn llamó ciencia normal) se ven muy restringidas. Pero esa acumulación es nada menos que la manifestación del progreso de la actividad científica en un campo dado (Kuhn, 1962).

Sin embargo, ni las ciencias sociales en general, ni los estudios turísticos en particular, encajan de buen grado las implicaciones de este dictamen. La matematización a la que se expusieron las ciencias sociales durante la centuria pasada constituye un monumental esfuerzo de afirmación de su estatus científico que, finalmente, cristaliza en una proliferación de estudios de caso sustentados en análisis estadísticos más o menos sofisticados. 
Estos estudios, en sus versiones más afortunadas, ofrecen teorías de alcance medio: modelos teóricos con una validez temporal determinada, útiles para explicar realidades en contextos concretos (Merton, 1949). En sus versiones más exasperantes, desembocan en un torrente de lo que Wright Mills (1959) denominó empirismo abstracto. En la investigación del turismo, esta dinámica acumulativa se puede apreciar con nitidez gracias a los estudios dedicados a analizar la valoración del turismo por parte de la sociedad receptora a la luz de la Teoría del Intercambio Social.

La idea central de este enfoque sugiere que los residentes apoyarán el desarrollo turístico, siempre y cuando perciban que los beneficios esperados serán mayores que los costos. Esta línea no ha producido generalizaciones empíricas relevantes, aparte de constatar que en los estudios de opinión sobre los efectos del turismo se identifica una mayor concentración de valoraciones positivas alrededor de las repercusiones económicas, a la par de una apreciación más crítica de los impactos medioambientales y socioculturales (Mantecón, 2016).

Además de amasar certezas estadísticas de dudosa relevancia y amontonar estudios de caso sin apenas conexión, en las inercias observadas se advierte una suerte de isomorfismo teórico, ajeno a cualquier cuestionamiento crítico de la literatura existente (aunque, desde luego, han alcanzado un éxito notable facilitando la vida a quienes buscan un catalizador de publicaciones).

El exceso de confianza que la Teoría del Intercambio Social deposita en la racionalidad individual, su infravaloración de los aspectos emocionales, la escasa atención que presta al cambio social, su dificultad para articular los análisis cuantitativos con diseños cualitativos, así como el desinterés por explicar la influencia que las relaciones de poder ejercen en la formación de la opinión pública, invitan a explorar vías alternativas que ayuden a entender las distintas maneras en que las personas se enfrentan al turismo (Mantecón y Velasco, 2020).

Las corporaciones empresariales y las administraciones públicas (por separado o en convergencia, al margen de disquisiciones epistemológicas) afinan su habilidad para combinar el empirismo abstracto con la practicidad liberal, reconvirtiendo a investigadores aparentemente independientes en una suerte de consultores (o de productores de una supuesta legitimidad científico-académica) dedicados no ya a elaborar estudios de mercado, sino a ensamblar microinformes con fines publicitarios o para facilitar corrientes de opinión. 
Dicho estado de las cosas parece abocar a una reproducción acrítica de las realidades ya conocidas y a una contención de las propuestas innovadoras. El desarrollo científico-social resultante de la lógica acumulativa causa decepción, y su proyección como impulsor de progreso no acaba de reconocerse. En la investigación del turismo, esta percepción provoca y justifica el llamado giro crítico en los estudios turísticos. En el siguiente apartado se discute este asunto.

\section{La promesa de un mundo mejor}

Hace un tiempo, quien firma estas líneas asistió a un seminario universitario en el que un acreditado conferenciante, investigador del turismo, afirmaba estar cansado de la ciencia convencional. A continuación, compartía con los oyentes la decisión de aprovechar su posición, a fin de implicarse en los siguientes años solo en proyectos que sirvieran para hacer un mundo mejor. El hartazgo de este académico había derivado en inquietudes existenciales: ¿y si la ciencia y sus estructuras sociales no sirven para desplegar el modelo ético de vida en el que le gustaría verse reflejado?, ¿no sería más conveniente invertir el orden de las prioridades?, ¿acaso no sería más pragmático pensar el orden moral deseable y, después, poner la ciencia al servicio de su consecución?

En el umbral del siglo XXI, el giro crítico de los estudios turísticos surge en un contexto intelectual y político orientado por la esperanza de ensanchar las fronteras de la justicia social y de frenar la influencia del neoliberalismo. Este movimiento se concreta en publicaciones en las que se razona la pertinencia de liberarse de una ciencia subordinada a las prácticas consumistas y organizada por burocracias universitarias que reproducen valores masculinos. Dicha contestación se materializaría en el turismo en la promoción de formas de conocimiento y prácticas participativas, transformadoras, emancipadoras, comprometidas, trascendentales, igualitarias, sostenibles, etcétera (ver, por ejemplo, Ateljevic et al., 2007a; Pritchard et al., 2011; Wilson et al., 2012).

Un texto ilustrativo de esta corriente es el de John Tribe (2007), que entronca el giro crítico de los estudios turísticos con la teoría crítica de la Escuela de Frankfurt, aludiendo a Max Horkheimer, Theodor Adorno, Herbert Marcuse y Jürgen Habermas, así como al interés de estos por profundizar en los aspectos ético-morales que intervienen en la actividad investigadora. Lo que no precisa es que la forma en la que este 
asunto es abordado por los autores a los que hace referencia difiere bastante y tiene efectos prácticos casi antagónicos. Los denominadores comunes mencionados por Tribe: la preocupación por las relaciones de poder, el papel de las ideologías y la manipulación cultural o la conciencia emancipadora, son gestionados de forma desigual.

En líneas generales, aquí se concuerda con la distinción que Axel Honneth (1987) propone entre el círculo interior de la teoría crítica (integrado por Horkheimer, Adorno y, de un modo más ambiguo, por Marcuse) y el círculo exterior (Franz Neumann, Otto Kirchheimer, Walter Benjamin y Erich Fromm). Este último, con planteamientos mucho más optimistas que el primero, desemboca en la obra de Habermas (1981), donde se muestra una firme confianza en las alternativas que pueden resultar de la liberación del potencial racionalizador que la acción comunicativa guarda en su seno, siempre y cuando las personas sean capaces de crear espacios de interacción que permitan su desarrollo (no en vano es reconocida una deuda con su trabajo por Pritchard et al., 2011).

Por el contrario, las ideas nucleares del primer círculo, contenidas en sus libros más relevantes (Horkheimer, 1947; Horkheimer y Adorno, 1947), no concluyen en ninguna praxis colectiva destinada a transformar la realidad, más allá de la resistencia que cada individuo pueda ofrecer a los cantos de sirena coreados por la alienante industria cultural (el último gran sistema productor de conformismo creado por el capitalismo).

En clara oposición a las tesis posteriores de Habermas, para Horkheimer y Adorno (1947) la racionalidad humana solo habría probado una convincente eficacia histórica a la hora de expresar su dominio sobre la naturaleza y, al fin y al cabo, sobre la propia humanidad. Ante este diagnóstico, cualquier propuesta emancipadora pasaría por la redefinición (reconciliación) de las relaciones que los seres humanos entablan con la naturaleza.

En la introducción al libro que contiene el texto de Tribe, sus editoras (Ateljevic et al., 2007b) manifiestan la voluntad de promover una Academia de Esperanza desde la cual desarrollar estudios críticos del turismo superadores de las limitaciones asociadas a la tradición de la Escuela de Frankfurt, a su juicio deudora en exceso de las teorías marxistas y, por lo tanto, poco apta para dar el salto desde el way of knowing al way of being; esto es, del análisis de la realidad a la adquisición de un compromiso en el que la investigación se supedite a la subversión de las estructuras opresoras que coartan las dinámicas igualitarias y la justicia social. 
Al tener en cuenta que el conjunto de la obra busca asentar los principios teóricos del giro crítico, estas argumentaciones merecen algunos comentarios: por un lado, se invoca la herencia del pensamiento frankfurtiano porque hace hincapié en el análisis crítico de los factores ideológico-culturales, frente al mayor determinismo económico-materialista del marxismo clásico; pero, por otro, se pretende afirmar una autonomía ante esa misma herencia, ya que se cuestiona su potencial transformador a causa de su encadenamiento al referido marxismo. Efectivamente, la Escuela de Frankfurt presta una mayor atención a la influencia de la superestructura cultural; sin embargo, como se explicaba, sus propuestas prácticas distan de ser homogéneas.

En cuanto a las dudas acerca de la voluntad transformadora de los enunciados marxistas originales, puede recordarse la famosa sentencia en la que Marx declara que el tiempo para interpretar el mundo debe dejar paso al momento de su transformación (Marx, 1888). Asimismo, en relación con el alcance del cambio propuesto, quizá a la Academia de Esperanza le parezca poco ambicioso un plan en el que toda la actividad intelectual se pone al servicio de la abolición de la propiedad privada, el derrocamiento del régimen burgués y la conquista del poder por el proletariado (Marx y Engels, 1848).

Ateljevic et al. (2007b) y Pritchard et al. (2011) expresan su interés por desligarse de etiquetas frankfurtianas o marxistas y, en su lugar, las reemplazan por otras de cosecha propia (critical turn, hopeful tourism enquiry, co-transformative learning, academy of hope o spiritual activism).

Aunque Pritchard et al. (2011) hacen una mención muy puntual a algunos de los estudios realizados en la década de los 70 desde enfoques críticos (citados en el tercer párrafo de este ensayo), prefieren desmarcarse de ellos y afirmarse como impulsoras de un cambio de paradigma que enfatiza el interés por los elementos simbólico-discursivos, propuestas contestatarias inequívocas y una terminología apropiada para causar impacto en los restringidos círculos académicos donde hoy se decide qué debe y qué no tenerse en cuenta.

Tribe (2007) espera hasta los años 90 para localizar los escasos antecedentes que le son de utilidad a fin de mostrar la herencia de la teoría crítica en los estudios turísticos. Una de esas publicaciones es la de Keith Hollinshead (1999), donde los conflictos vinculados a la actividad turística quedan diluidos en un estilo narrativo más cercano a la crítica literaria que al análisis crítico del turismo. En todo caso, el argumento que Hollinshead propone tiene más interés si se enmarca en una reflexión 
sobre los márgenes de libertad en los que se mueve el turista moderno (o posmoderno), que en la comprensión de las repercusiones del turismo en los destinos.

Es verdad que en otros trabajos referidos por Tribe se exponen críticas a los enfoques etnocentristas occidentales (Hollinshead, 1992); no obstante, en su afán por ensalzar los factores de la superestructura ideológica, queda desplazado a un segundo plano el análisis crítico de la influencia que el turismo ejerce en, por ejemplo, la destrucción de ecosistemas, la expansión de dinámicas urbanizadoras carentes de una adecuada planificación, el (mal) desarrollo de las economías agrarias locales, la precarización de las condiciones laborales de quienes trabajan en el sector (y no solo en las regiones del llamado Sur Global), o en la configuración de economías ilícitas que, en los casos más lamentables, fomentan la explotación sexual.

Asimismo, en su interés por distinguirse de los esquemas clásicos del marxismo, de afirmar unas señas de identidad libres de etiquetas pasadas, de adaptarse a la estética discursiva de los tiempos presentes y de situar la transformación de la sociedad en la cúspide de su proyecto (exorcizando cualquier sustrato metodológico de raíces positivistas), el giro crítico de los estudios turísticos sustituye unos determinismos por otros, sin lograr articular entre medias una crítica del turismo tan transgresora y renovadora como pretende.

Cualquier esfuerzo encaminado a formular una crítica tan radical como para autodenominarse progresista, debe cuestionar las bases de sus principios y, para el caso que nos ocupa, esto tiene que ver con la consideración de la viabilidad del propio hecho turístico.

Como señalaban Horkheimer y Adorno (1947), solo el pensamiento que ejerce violencia sobre sí mismo es lo suficientemente duro como para quebrar los mitos. En un mundo en el que la estabilidad social se persigue a través del cambio incesante y la acumulación convulsiva (Rosa, 2010), la emancipación a la que se refiere con tanta insistencia la Academia de Esperanza se logra transformando la agresiva relación que establecemos con la naturaleza.

La interiorización de la falsa dicotomía naturaleza-cultura hace que olvidemos que las personas también somos naturaleza, y que si no la salvamos a ella tampoco nos salvamos nosotros. En el discurso del llamado por Honneth círculo interior de la Escuela de Frankfurt, valorado por el propio Honneth, y por tantos otros, como un pensamiento pesimista y carente de esperanza, se abordan los problemas cruciales 
y se encuentran las soluciones implícitas para encarar el mayor desafío del siglo XXI: garantizar un planeta habitable para los seres humanos del siglo XXII.

Al respecto, es inaceptable que en la economía turística mundial, articulada por una industria de los transportes tan contaminante y dependiente de la extracción de recursos no renovables, pueda justificarse la sostenibilidad de una actividad que en 2019 registró mil quinientos millones de desplazamientos internacionales.

El uso interesado que se ha hecho de la expresión desarrollo sostenible ha favorecido que con los años se aproxime más a un concepto político y mercadotécnico que a uno científico (Igoe et al., 2010). Entre las formas de turismo tradicional y la pluralidad de tipologías emergentes, existe un denominador común: la contaminación y la perturbación de ecosistemas a causa de un gigantesco flujo de movimientos motivados por la búsqueda de experiencias de ocio.

La crítica del orden social existente va unida a la implantación de medidas en virtud de las cuales el turismo tendría que gestionarse según principios de decrecimiento, o ser sustituido por otro tipo de actividades económicas que no generen impactos tan agresivos. Pero el esfuerzo que requeriría la aplicación de esas medidas es percibido como absurdo o contraproducente por, quizá, demasiados actores del sistema turístico, y las pautas de consumo objeto de críticas están interiorizadas como no problemáticas por, quizá también, demasiados millones de individuos. Los límites de tolerancia que las personas están dispuestas a asumir poseen una flexibilidad portentosa.

Ante esta situación, diferentes organismos reguladores se dedican a poner parches en un proceso de degradación en el que propuestas como la de la Academia de Esperanza y su giro crítico se autoproclaman en alternativas salvíficas, cuya principal característica es la insustancialidad y el solipsismo académico.

El análisis de los discursos, muy necesario para entender las razones profundas que orientan los puntos de vista de unos y otros actores, se diluye en reflexiones en torno al envoltorio simbólico del turismo, a la vez que se encapsula en un marco analítico culturalista, desconectado en exceso de las realidades sociales concretas a las que esos discursos se supone que aluden.

En este sentido, se está en pleno acuerdo con Daniel Hiernaux (2006; 2018) cuando, tomando como referencia el diagnóstico que Carlos Reynoso (2000) hace de los estu- 
dios culturales, advierte de la escasa efectividad de estos en su pretensión de confluir con aproximaciones interesadas en aportar conocimiento sólido sobre el turismo.

Igualmente, se comparte en líneas generales con Hiernaux (2018) su apreciación acerca de la necesidad de distinguir entre el proceso (el turismo) y su aplicación. Aunque en este caso se apuntan dudas: por lo que toca a los impactos ambientales causados por la industria turística internacional, ¿una variación significativa de su modus operandi, acaso no implicaría una completa redefinición no ya de prácticas concretas, sino del propio hecho turístico? No se quiere incurrir en un tipo de sinécdoque por la cual se enjuicie el todo a partir de una fracción, pero si de verdad se tomara en serio la censura y erradicación de las dinámicas perniciosas ocasionadas por esa parte: ¿qué quedaría entonces del todo?

\section{Conclusión}

Cuando la definición del contexto se convierte en un asunto más político que científico, pues de su conquista depende qué obtendrá cada uno de los actores implicados, las ciencias sociales se arriesgan a prostituir sus principios en entornos en los que la opinión no se estudia, se fabrica. Penetradas por influencers y emisores de fake news, las sociedades modernas enfrentan la investigación del turismo ante retos de envergadura:

a) La posibilidad de salvaguardar espacios de independencia desde los cuales llevar a cabo análisis rigurosos e innovadores, es decir, capaces de cuestionar el orden presentado como inevitable. Se requiere asumir que la apuesta unilateral por las lógicas del trabajo acumulativo, comentadas más arriba, no se adaptan bien a la naturaleza de la investigación científico-social, y esto afecta a la calidad y originalidad de los estudios turísticos.

b) Revisar, criticar y adoptar, cuando sea conveniente, nuevas perspectivas y metodologías que contribuyan a enriquecer la comprensión del turismo, como hecho social total, aglutinador de procesos económicos, políticos, culturales y ecológicos de alcance global. Por eso, se sugiere promover una formación transdisciplinar que integre (y supere) las tradicionales oposiciones micromacro, cualitativo-cuanti-tativo, elementos simbólicos-estructuras materiales, naturaleza-cultura, estabilidad-cambio, por mencionar algunas. 
c) Defender las convicciones éticas del investigador, pero no instrumentalizarlas como prescripciones morales o ideológicas del trabajo científico-social. Es decir, se recomienda vincular el principal compromiso ético de la investigación con su función desenmascaradora del entramado de relaciones de poder, mentiras, intereses privados, convenciones o costumbres justificadoras del statu quo, que emanan del actual contexto sociotécnico y que, como si de una nube tóxica se tratara, lo encapotan.

Como en el relato bíblico, hay que confiar en que la verdad traerá la libertad, aunque no necesariamente la justicia social, o al menos no de manera inmediata. Dicho de otro modo, los resultados obtenidos con la investigación del turismo pueden ayudar a pensar con más claridad y autonomía la dinámica del entramado turístico ( $y$, dada su actual relevancia, del conjunto del sistema social), pero no habilitan para prescribir cambios y alternativas irrefutables de este sistema.

La constatación empírica del sufrimiento objetivo provocado por determinados comportamientos (turismo sexual, explotación laboral en el sector, entre otros), así como la difusión de esos hallazgos, tienen una poderosa capacidad transgresora, agitando conciencias e, indirectamente, modificando la opinión pública sobre problemas antes invisibilizados. De esa manera, quienes se benefician de esos comportamientos tendrán más problemas a la hora de obtener los inputs de legitimidad social requeridos para perpetuar sus conductas.

La aspiración de una sociedad más justa pertenece al ámbito de la lucha y la reivindicación política, la cual sería deseable que se sostuviera en argumentaciones racionales, ancladas en conocimiento procedente de prácticas investigadoras honestas y rigurosas. Se propone, en definitiva, aceptar que el discernimiento de lo que está bien o mal, de lo que es estimable o repudiable, hermoso o feo, no deriva de los hallazgos obtenidos a través del trabajo científico, sino de la contraposición de juicios morales que, en el mejor de los casos, mantienen un diálogo constructivo, tomando como referencia tales descubrimientos.

Lo anterior no debe soslayar la responsabilidad del investigador cuando define y acota la realidad que conforma su objeto de estudio, establece un tipo de relación cognoscitiva con esa realidad y planifica el acceso a la misma, pues de los compromisos adquiridos dependerá la clase de luz que proyecten sus hallazgos y las partes de la realidad que se iluminen (en un segundo momento, esas decisiones tendrán repercusiones éticas y políticas). 
El argumento desarrollado no considera que la política y la investigación del turismo sean esferas independientes, todo lo contrario, el poder impregna la mayoría de las interacciones sociales. Lo que afirma es que la acción política, al margen de que se exprese por medio de estrategias subversivas más o menos beligerantes, se encauce por canales institucionalizados y transparentes, o se gestione desde grupúsculos restringidos y opacos, debe disociarse de la praxis científico-social.

El investigador, por supuesto, debe comunicar sus hallazgos, asesorar y formular recomendaciones, en coherencia con los resultados obtenidos en sus estudios. Así, enriquecerá la calidad de los debates que han de mantener los actores implicados en el espacio influido por el turismo, pero en esa tarea no debe olvidar las limitaciones con las que se topa el discurso científico; si lo hiciese, tendría enseguida que renunciar a la autonomía y la credibilidad conferida por el hecho de ser productor de un tipo de explicaciones que, por definición, pretenden reducir en la medida de lo posible el ruido ideológico y la parcialidad política.

Orientado por sus convicciones, también puede optar por implicarse en los procesos de transformación social, pero entonces su rol de investigador se diluiría tras el de activista o gestor, y esos sí son dos ámbitos que han de separarse.

La instrumentalización (manipulación) política y propagandística que las élites del poder han hecho (y siguen haciendo) del trabajo científico, y del científico-social con especial énfasis, no debe combatirse con una contra-instrumentalización dirigida por sectores organizados de la sociedad civil. La primera víctima de esa disputa sería la legitimidad de las ciencias sociales y de los estudios turísticos.

Otra cuestión es aceptar que esa pérdida resulta asumible, si a cambio se incrementan las opciones de expansión de la justicia social. En ese caso, el disimulo (el hacer pasar una cosa por otra) puede entenderse como parte de una estrategia política más amplia. Cada uno puede hacer su personal valoración al respecto. Se concluye entonces con algunas aclaraciones finales y limitaciones relativas a todo lo expuesto.

Las alusiones realizadas a corrientes positivistas y posmarxistas son susceptibles de ser sometidas a infinidad de matices. La distancia que separa a unas y otras no forma un continuo $y$, en consecuencia, no se quiere dar a entender que los desarrollos teórico-metodológicos que agrupan estos enfoques agoten las muy variadas propuestas epistemológicas de las ciencias sociales y de los estudios turísticos, simplemente la atención que se les ha prestado ha sido útil para construir un hilo 
conductor. De hecho, la apuesta por la transdisciplinariedad surge de una confianza (asumida a priori) en la capacidad de las posiciones holísticas y eclécticas para confluir con miradas en las que se reconozca un espíritu crítico (y esa asunción, se admite, puede identificarse como un sesgo de la exposición).

El carácter ensayístico de este texto no está dirigido por una voluntad pontificadora, desde luego no es esa la intención del autor; al contrario, trata de alimentar una discusión ya existente, de gran interés, en la que tienen cabida diversas sensibilidades acerca de la naturaleza de la investigación en turismo. Se invita a los lectores a participar en este debate abierto, planteando razonamientos y soluciones diferentes.

\section{Referencias}

Aitchison, C.C. (2005). Feminist and gender perspectives in tourism studies: the social-cultural nexus of critical and cultural theories. Tourist Studies, 5(3), 207-224. https://doi.org/10.1177/1468797605070330

Ateljevic, I., Pritchard, A. y Morgan, N. (Eds.). (2007a). The critical turn in tourism studies: innovative research methodologies. Elsevier.

Ateljevic, I., Pritchard, A. y Morgan, N. (Eds.). (2007b). Editors' introduction: promoting an academy of hope in tourism enquiry. En I. Ateljevic, A. Pritchard y N. Morgan (Eds.), The critical turn in tourism studies: innovative research methodologies (pp. 1-8). Elsevier.

Beard, L., Scarles, C. y Tribe, J. (2016). Mess and method: using ANT in tourism research. Annals of Tourism Research, 60, 97-110. https://doi.org/10.1016/ j.annals.2016.06.005

Becken, S. y Hay, J. (2007). Tourism and climate change. Risks and opportunities. Channel View Publications.

Castillo-Nechar, M. y Panosso, A. (2010). Epistemología del turismo. Estudios críticos. Editorial Trillas.

Cole, S. (Ed.). (2018). Gender equality and tourism. Beyond empowerment. University of the West of England.

Coles, T., Hall, C. M. y Duval, D. T. (2006). Tourism and post-disciplinary enquiry. Current Issues in Tourism, 9(4-5), 293-319. https://doi.org/10.2167/cit327.0 
Darbellay, F. y Stock, M. (2012). Tourism as complex interdisciplinary research object. Annals of Tourism Research, 39(1), 441-458. https://doi.org/10.1016/j.annals.2011.07.002

De Kadt, E. (1979). Tourism: passport to development? Perspectives on the social and cultural effects of tourism in developing countries. Oxford University Press.

Estivill, J. (1979). Lloret de Mar: destruccions i resistencies d'un poble en mans del turisme. Papers, Revista de Sociologia, 10, 175-201. https://doi.org/10.5565/ rev/papers/v10n0.1107

Fennell, D. (2006). Tourism ethics. Channel View Publications.

Figueroa-Domecq, C., Pritchard, A., Segovia-Pérez, M., Morgan, N. y Villacé-Molinero, T. (2015). Tourism gender research: a critical accounting. Annals of Tourism Research, 52, 87-103. https://doi.org/10.1016/j.annals.2015.02.001

Galán, J.J., Martín, A., Ruiz, J. y Mandly, A. (1977). Costa del Sol. Retrato de unos colonizados. Cuadernos de Campo Abierto Ediciones.

Gaviria, M. (1974). España a go-go: turismo charter y neocolonialismo del espacio. Turner.

Greenwood, D. J. (1989). Culture by the pound: an anthropological perspective on tourism as cultural commoditization. En V. Smith (Ed.), Hosts and guests: the anthropology of tourism (pp. 171-186). University of Pennsylvania Press. https://doi.org/10.9783/9780812208016

Habermas, J. (1981). Theorie des kommunikativen Handelns. Suhrkamp.

Hiernaux, D. (2006). Geografía del turismo. En D. Hiernaux y A. Lindón (Coords.), Tratado de geografía humana (pp. 397-428). Anthropos y Universidad Autónoma Metropolitana-Iztapalapa. https://bit.ly/3cUH9|4

Hiernaux, D. (2018). Más de tres décadas de investigación turística en México: algunas reflexiones. Dimensiones Turísticas, 2(2), 123-132. https://doi.org/10.47557/ RIEX6572

Hollinshead, K. (1992). 'White' gaze, 'red' people. Shadow visions: the disidentification of 'Indians' in cultural tourism. Leisure Studies, 11(1), 43-64. https://doi. org/10.1080/02614369100390301 
Hollinshead, K. (1999). Surveillance of the worlds of tourism: Foucault and the eyeof-power. Tourism Management, 20(1), 7-23. https://doi.org/10.1016/S02615177(98)00090-9

Honneth, A. (1987). Critical theory. En A. Giddens y J. Turner (Eds.), Social theory today (pp. 347-382). Stanford University Press.

Horkheimer, M. (1947). Eclipse of reason. Oxford University Press.

Horkheimer, M. y Adorno, Th. (1947). Dialektik der Aufklärung. Querido.

Huete, R. (2019). La digitalización de la economía y el fin del turismo. En A. Álvarez-Sousa, A. Mantecón e I. Puertas-Cañaveral (Eds.), Sociología del turismo (pp. 299-321). Centro de Investigaciones Sociológicas. https://bit.ly/3naoA0R

Igoe, J., Neves, K. y Brockington, D. (2010). A spectacular eco-tour around the historic bloc: theorizing the convergence of biodiversity conservation and capitalist expansion. Antipode, 42(3), 486-512. https://doi.org/10.1111/j.14678330.2010.00761.x

Jurdao, F. (1979). España en venta. Compra de suelos por extranjeros y colonización de campesinos en la Costa del Sol. Ayuso.

Kuhn, T.S. (1962). The structure of scientific revolutions. University of Chicago Press.

Kuhn, T.S. (1977). The essential tension. Selected studies in scientific tradition and change. University of Chicago Press.

Landsberger, H. A. (1958). Hawthorne revisited: management and the worker, its critics, and developments in human relations in industry. Cornell University.

Leiper, N. (2000). An emerging discipline. Annals of Tourism Research, 27(3), 805-809. https://doi.org/10.1016/S0160-7383(99)00118-8

Mantecón, A. (2016). La opinión pública sobre el turismo. Crítica y propuesta para una nueva orientación. Estudios y Perspectivas en Turismo, 25(2), 110-123. https://bit.ly/3cmaG76

Mantecón, A. y Velasco, M. (2020). Beyond tourismphobia: conceptualizing a new framework to analyze attitudes towards tourism. En C. Ribeiro-de-Almeida, A. Quintano, M. Simancas, R. Huete y Z. Breda (Eds.), Handbook of research on the impacts, challenges, and policy responses to overtourism (pp. 60-74). IGI Global. https://bit.ly/3ld0Jfp

Marx, K. (1888). Thesen über Feuerbach. J. H. W. Dietz. 
Marx, K. y Engels, F. (1848). Manifest der Kommunistischen Partei. Bildungs-Gesellschaft für Arbeiter.

Merton, R. K. (1949). Social theory and social structure: toward the codification of theory and research. Free Press.

Milano, C. (2017). Otherness anthropologies: toward ibero-american anthropologies of tourism. American Anthropologist, 119(4), 736-741. https://doi. org/10.1111/aman.12957

Mills, C. W. (1959). The sociological imagination. Oxford University Press.

Muecke, S. y Wergin, C. (2014). Materialities of tourism in the twenty-first century: a very brief introduction. Tourist Studies, 14(3), 227-230. https://doi. org/10.1177/1468797614536307

Nash, D. (1977). Tourism as a form of imperialism. En V. Smith (Ed.), Hosts and guests: the anthropology of tourism (pp. 37-52). University of Pennsylvania Press. https://doi.org/10.9783/9780812208016.37

Osorio, M. y Korstanje, M. E. (2017). Reflexiones en torno a la situación de la investigación turística. Dimensiones Turísticas, 1(1), 13-30. https://doi.org/10.47557/ JJLL9743

Picard, D. y Robinson, M. (2012). Emotion in motion: tourism, affect and transformation. Routledge.

Pritchard, A., Morgan, N. y Ateljevic, I. (2011). Hopeful tourism: a new transformative perspective. Annals of Tourism Research, 38(3), 941-963. https://doi. org/10.1016/j.annals.2011.01.004

Reynoso, C. (2000). Apogeo y decadencia de los estudios culturales. una visión antropológica. Gedisa. https://bit.ly/3n9U33k

Rosa, H. (2010). Alienation and acceleration: towards a critical theory of late-modern temporality. Nova Southeastern University Press.

Scott, D. (Coord.). (2008). Climate change and tourism. Responding to global challenges. The United Nations Environment Program \& World Meteorological Organization. https://bit.ly/33oZ4wW

Sheller, M. y Urry, J. (2006). The new mobilities paradigm. Environment and Planning A: Economy and Space, 38(2), 207-226. https://doi.org/10.1068/a37268 
Tobar-Bustamante, L. E., Castillo-Nechar, M., Mendoza-Valdés, R. y Tamayo-Salcedo, A. L. (2015). La visión crítica en el construir del conocimiento turístico. Revista de Análisis Turístico, 19, 33-44. https://bit.ly/3kCCKpr

Tribe, J. (1997). The indiscipline of tourism. Annals of Tourism Research, 24(3), 638657. https://doi.org/10.1016/S0160-7383(97)00020-0

Tribe, J. (2000). Indisciplined and unsubstantiated. Annals of Tourism Research, 27(3), 809-813. https://doi.org/10.1016/S0160-7383(99)00122-X

Tribe, J. (2007). Critical tourism: rules and resistance. En I. Ateljevic, A. Pritchard y N. Morgan (Eds.), The critical turn in tourism studies (pp. 29-39). Elsevier. https://doi.org/10.1016/B978-0-08-045098-8.50007-6

Tribe, J. (2009). Philosophical issues in tourism. Channel View. https://doi.org/ $10.21832 / 9781845410988$

Turner, L. y Ash, J. (1975). The golden hordes: international tourism and the pleasure periphery. Constable.

Urry, J. (2007). Mobilities. Polity Press.

Wang, Y., Yu, Q. y Fesenmaier D. R. (2002). Defining the virtual tourist community: implications for tourism marketing. Tourism Management, 23(4), 407-417. https://doi.org/10.1016/S0261-5177(01)00093-0

Wang, D., Park, S. y Fesenmaier, D. R. (2012). The role of smartphones in mediating the touristic experience. Journal of Travel Research, 51(4), 371-387. https://doi.org/ $10.1177 / 0047287511426341$

Wilson, E., Small, J. y Harris, C. (2012). Editorial introduction: beyond the margins? The relevance of critical tourism and hospitality studies. Journal of Hospitality and Tourism Management, 19(1), 48-51. https://doi.org/10.1017/jht.2012.2

Znaniecki, F. (1927). The object matter of sociology. American Journal of Sociology, 32(4), 529-584. https://doi.org/10.1086/214184 


\title{
MOVILIZACIÓN SOCIAL Y TURISMO: EL CONFLICTO POR LA PRIVATIZACIÓN DEL ESPACIO COSTERO EN LA CIUDAd de MAR dEl Plata, ARgentina
}

\author{
GONZALO CRUZ \\ gonzalocruz83@hotmail.com \\ Universidad Nacional de Mar del Plata, Argentina
}

Se aborda el conflicto de la privatización de los sectores playeros en la ciudad de Mar del Plata, Argentina, con enfoque en las organizaciones que buscan advertir sobre sus perjuicios. La tarea se realiza a partir de los aportes teóricos de Benford y Snow para el análisis de los marcos de acción colectiva de diagnóstico, pronóstico y campos de identidad. Se plantea un trabajo de tipo cualitativo en el que se interpreta el discurso de los activistas en medios de prensa y en sus plataformas de difusión. También se realiza una revisión de la normativa que corresponde a los reclamos. La postura de las organizaciones involucra una consideración de la playa que va más allá de sus posibilidades productivas, se destaca su valor ambiental y cultural. Es posible identificar una conexión entre los argumentos y el marco jurídico, la existencia de flexibilidad en su aplicación y la necesidad de encauzar un modelo de desarrollo turístico compatible con los requerimientos y valoraciones de la población residente.

Palabras clave: Mar del Plata, movilización social, turismo, playas, privatización.

\section{SOCIAL MOBILIZATION AND TOURISM: THE CONFLICT OVER THE PRIVATIZATION OF COASTAL SPACE in THE CITY OF MAR DEL PlatA, ARgentina}

This paper addresses the conflict over the privatization of the beach sectors in the city of Mar del Plata, Argentina, focusing on the organizations that seek to warn about the problems caused by this. The task is carried out considering the theoretical contributions of Benford and Snow for the analysis of diagnostic, prognostic and motivational collective action frames. A qualitative type of work is proposed in which the discourse of the activists in the press media and their own diffusion platforms is interpreted. A revision of the regulations corresponding to each of the claims is also carried out. The position of the organizations involves a consideration of the beach that goes beyond its productive possibilities, its environmental and cultural value is highlighted. It is possible to identify a correspondence between the arguments and the legal framework, the existence of flexibility in their application and the need to channel a tourism development model compatible with the requirements and values of the resident population.

Keywords: Mar del Plata, social mobilization, tourism, beaches, privatization. 


\section{Introducción}

a ciudad argentina de Mar del Plata ha tenido una estrecha relación con el turismo desde su fundación; según explica Mantero (1997) adquirió un rol preponderante en los procesos de urbanización y en la configuración del espacio litoral, circunstancia que se intensificó en los años 90, a partir de la proliferación de medidas neoliberales que promovieron el retraimiento del Estado en la organización del territorio.

Cicalese (2005) indica que se migró del plan público al plan privado, hecho que dio lugar a la expansión de la privatización de los sectores de playa, a través de la instalación de nuevos balnearios destinados a brindar servicios especiales para sus clientes. Así, la valoración de la playa quedó relegada casi exclusivamente en torno a su potencial productivo. Se redujeron y desatendieron los sitios públicos no arancelados y se profundizó un modelo que subestima los impactos negativos producidos por la expansión privada.

Con el correr de los años los problemas sociales y medioambientales se hicieron cada vez más notorios. Los beneficios de la explotación comercial no se vieron reflejados en un incremento de la calidad de vida de los habitantes, además de la reducción del espacio público no arancelado, a causa de la acción erosiva del mar.

Es así como a principios de la década actual emergieron una serie de organizaciones que buscan advertir sobre las consecuencias de la privatización de las playas. La Asamblea por los Espacios Públicos y la Organización No Gubernamental (ONG) En Defensa de las Playas Públicas han liderado un proceso de movilización a través del desarrollo de acciones de carácter colectivo, que han servido para que la problemática se visibilice y se incorpore a la agenda.

Teniendo presente lo anterior, en este trabajo se aborda el escenario de conflictos desarrollado, enfocándose en la perspectiva de dichas organizaciones. Para ello, el análisis se realiza a partir de las consideraciones teóricas para el abordaje de los movimientos sociales realizadas por Snow y Benford (1988), principalmente aquellas acerca de los marcos de acción colectiva: de diagnóstico y de pronóstico. El primero hace referencia a la identificación del conflicto y los agentes responsables de la situación, el segundo refleja las propuestas para solucionar la situación de injusticia previamente identificada. 
Para el marco de diagnóstico se observan los principales reclamos y la legislación existente en cada cuestión. En el caso del marco de pronóstico, se consideraron las soluciones planteadas por los activistas, en torno a los reclamos en particular y la problemática en general. Finalmente, se realiza la identificación de los distintos campos de identidad: protagonistas, antagonistas y espectadores. Se adopta un enfoque cualitativo que involucra la interpretación del discurso de los activistas, a partir de un análisis de contenido de fuentes diversas: artículos periodísticos, plataformas de difusión de las organizaciones y normativa vigente.

Resulta oportuno mencionar que la bibliografía que analiza los conflictos generados por el desarrollo turístico y la perspectiva teórica para el abordaje de los movimientos sociales, es aún incipiente. De esta manera, el presente artículo busca contribuir en este campo del conocimiento y considera la importancia de las distintas voces y concepciones de los diferentes actores presentes en los destinos turísticos. Los resultados también pueden ser de utilidad en los procesos de toma de decisiones y el diseño de políticas públicas.

\section{Consideraciones teóricas con respecto a los marcos de acción colectiva y antecedentes}

Las perspectivas teóricas para el análisis de los movimientos sociales pueden clasificarse en tres corrientes principales: las visiones clásicas, la Teoría de la Movilización de Recursos (TMR) y el enfoque de los Nuevos Movimientos Sociales (NMS). Las visiones clásicas enfatizan los factores psicosociales que dan lugar a la participación en los procesos de movilización; esta corriente adquiere su mayor auge a mediados del siglo XX, con estudios de autores como Blumer (1951), Turner y Killian (1957) y Smelser (1962).

Por su parte, la TMR se refiere al contexto político en el cual se desarrollan los movimientos sociales, su estructura organizacional y la forma en la que los recursos son distribuidos. Algunos de los autores de mayor relevancia para esta corriente son: Tilly (1978), McCarthy y Zald (1977), McAdam (1996) y Tarrow (1997).

Por último, el enfoque de los NMS se centra en aspectos macroestructurales, que dan lugar a la emergencia de la acción colectiva e incorporan la identidad de grupo como un factor relevante para la participación. Se destacan los trabajos de Touraine (1987) y Melucci (1996). En el mismo sentido, Cruz (2019) realiza una revisión deta- 
Ilada sobre las distintas corrientes de pensamiento y su incorporación en el campo de la investigación en turismo.

El enfoque de los marcos de acción colectiva se desarrolla como una línea al interior de la TMR. Según Jasper (2010) esta circunstancia implica la consideración de factores culturales involucrados en los procesos de movilización, que en un principio no se habían tomado en cuenta en profundidad. Dicho autor indica que esta apertura hacia una visión más compleja de los movimientos sociales se encuentra plasmada en obras como las de Snow y Benford (1988; 1992) y McAdam et al. (1996), entre otras.

En general esta perspectiva es considerada dentro de las vertientes constructivistas en el análisis de los procesos de movilización social, junto con el enfoque de los NMS. De hecho, las dos corrientes comparten algunas presunciones que no son objeto de este repaso teórico; sin embargo, resulta oportuno destacar que en ambos casos se busca ir más allá de los enfoques estructuralistas planteados por la TMR.

Benford y Snow (2000) explican que el término marco fue utilizado primero por Goffman (1974), para hacer alusión a los esquemas interpretativos que permiten a los individuos localizar, percibir, identificar y etiquetar ocurrencias dentro de su espacio vital y el mundo en general. Chihu Amparán (1999) expone que el enmarcado, en el contexto de la acción colectiva, involucra una observación de las dimensiones culturales de los movimientos sociales, puesto que se consideran productores de significado.

Según establece Tricot (2011), la producción de discursos o significados por parte de los movimientos sociales implica una interpretación de la realidad, que "permite que la gente defina de manera colectiva su situación de agravio o conflicto, potencie su sentido de pertenencia y la viabilidad del accionar colectivo" (pp. 185-186). Estos significados se plasman en los marcos, buscando generar adhesión y participación a los procesos de movilización, al proporcionar no solo una determinada interpretación de la realidad, sino que adquieren una función de coordinación entre los intereses individuales y colectivos, es decir, se pretende alinear la identidad de las personas con la de la organización.

Chihu Amparán (1999) indica que el surgimiento de la acción colectiva se encuentra vinculada a la conformación de un marco de injusticia compartido por los individuos con respecto a una determinada situación. El mismo autor señala que dicha circunstancia constituye el punto de partida para la aparición de múltiples marcos, 
los cuales son considerados "conjuntos de creencias, a través de las cuales se significan las situaciones y a través de las cuales se legitiman las acciones de los movimientos sociales" (p. 43).

Como se mencionó previamente, Benford y Snow (2000) establecen la existencia de tres marcos centrales de acción colectiva: el marco de diagnóstico, el de pronóstico y el de motivación. El primero remite a la identificación del conflicto y a los agentes responsables de la situación. El segundo se refiere a la propuesta para la solución de la situación de injusticia previamente identificada, formula un plan y las estrategias para llevarlo a cabo. Los autores explican que es en este marco donde pueden observarse las mayores diferencias entre las organizaciones que componen un movimiento. Finalmente, el marco de motivación incluye la justificación que hace necesaria la participación de la población para modificar la realidad.

De acuerdo con Chihu Amparán (1999) durante el desarrollo de la acción colectiva es posible reconocer tres campos de identidad, con base en la posición que los distintos actores toman: los protagonistas, los antagonistas y los observadores. Los primeros son los activistas, participantes cuyos valores se encuentran alineados con los del movimiento. Los antagonistas son aquellos que se oponen a la lucha llevada a cabo por los activistas, poseen valores distintos y no concuerdan con los objetivos perseguidos. Por último, los observadores son quienes no tienen una posición definida con respecto al conflicto.

Ahora bien, a pesar de los avances que esta perspectiva ha logrado en el estudio de los movimientos sociales, ha sido objeto de diversas críticas provenientes de autores como Jasper (2010), Cefaï (2001) o el propio Benford (1997). Della Porta y Diani (2006) señalan la tendencia de este tipo de análisis a generar explicaciones ad hoc, cuestión que no solo es atribuida a los estudios de los marcos de acción colectiva, sino que constituye también una deficiencia de la TMR en general.

Los autores indican que, si bien es posible estudiar las implicaciones culturales y simbólicas bajo las cuales se alinean los actores movilizados en casos específicos, existe aún una carencia en el desarrollo de estudios sistemáticos. No se formulan hipótesis orientadas a determinar una vinculación entre la producción simbólica y el éxito de las movilizaciones.

Otro tema planteado por Della Porta y Diani (2006) es el tratamiento de los marcos como estructuras cognitivas estáticas. Este problema se atribuye principalmente 
a la falta de atención de los académicos a las maneras en las que los marcos se construyen y evolucionan a través del tiempo. La forma de subsanarlo implica la adopción de una perspectiva dinámica de la práctica discursiva, y considerar cómo se modifican los marcos en las diferentes etapas que la movilización atraviesa. También se mencionan trabajos que hacen hincapié en la transformación de los valores de las comunidades, al establecer una vinculación entre los procesos de movilización social y el cambio cultural.

Finalmente, se cuestiona el carácter estratégico del enfoque, los marcos y las habilidades de enmarcado que constituyen un recurso desde esta visión. Se presupone que los activistas poseen la capacidad de construirlos y manipularlos con el objetivo de captar nuevos participantes. Tal postura omite los procesos intermedios a través de los cuales los sujetos deciden ser parte de la acción colectiva. Se obvia principalmente el componente emocional que incide en la decisión de las personas a participar. La ira, el sentimiento de injusticia o la solidaridad, son elementos no considerados que aquí adquieren un rol relevante.

Desde el punto de vista metodológico, la crítica involucra la tendencia a realizar estudios basados en fuentes secundarias como artículos periodísticos. No obstante, Jasper (2010) explica la necesidad de dar un giro hacia formas de recolección de información centradas en los actores, con el objetivo de dejar de lado los análisis de contenidos tradicionales. En ese sentido, el autor presupone que esta tarea puede ser alcanzada a través de entrevistas, biografías de vida o la observación participante, entre otras.

Algunas de estas reflexiones son aplicables al modelo clásico de la TMR, que proponía como ejes de estudio las oportunidades políticas, las estructuras movilizadoras, los repertorios de acción y los marcos de acción colectiva. Los principales referentes de esta corriente realizaron un intento por superar especialmente el carácter estático del modelo, a partir de la constitución de uno nuevo centrado en las relaciones y el dinamismo de sus componentes.

McAdam et al. (1996) desarrollaron el modelo de la contentius politcs (política contenciosa), que busca poner en relación los componentes del modelo clásico. Según Jasper (2012), este intento solo constituyó una nueva forma de presentar los elementos anteriores; el esquema de política contenciosa no logró generar un abordaje que pudiese escapar del sesgo estratégico y estático, en tanto otorga un lugar secundario a los procesos culturales y a las emociones involucradas en la acción colectiva. 
A pesar de las críticas expuestas, la perspectiva de marcos aún se encuentra vigente en la literatura científica que tiene como propósito estudiar los movimientos sociales. Esto se evidencia en trabajos desarrollados en los últimos cinco años, como los de Chihu Amparán (2016), Winstead (2017), Nulman, (2017), Aslanidis (2018), Terríquez et al. (2018), Zhou y Yang (2018), Menke (2019), Hansen y Nicolini (2019), y Salim (2019), entre otros.

Los autores citados previamente rescatan el concepto de marcos de acción colectiva, al establecer la posibilidad de conocer la postura de los actores movilizados, con respecto a una determinada situación que consideran injusta y en la que es preciso actuar. El abordaje de las visiones e interpretaciones involucra además un acercamiento a los significados que se producen y promueven la adhesión de nuevos miembros.

En general, se adopta una estrategia metodológica de estudio de caso. Se analiza un movimiento en particular y se detallan las consideraciones específicas que le competen. Si bien la construcción de los análisis varía en cuanto a detalle y niveles de desarrollo, se observa como una cuestión relevante la identificación de los marcos de diagnóstico y pronóstico.

En el campo de la investigación en turismo, la inclusión de las perspectivas teóricas que analizan los movimientos sociales es todavía incipiente. Algunos trabajos en donde es posible observar esto son los desarrollados por Kousis (2009), Vianello (2016), Zizumbo-Villarreal et al. (2009), McGehee (1999; 2002; 2012), McGehee y Santos (2005) y Monterrubio (2017). A pesar de que en la literatura mencionada es posible advertir referencias a las distintas corrientes de pensamiento (visiones psicosociales, TMR, enfoque de los NMS), en ningún caso se ha trabajado en relación con los marcos de acción colectiva.

\section{Articulación teórica y metodológica}

En este apartado se establece el modo en el que se aborda el problema, al señalar su articulación con la teoría referida y la estrategia metodológica propuesta. En primera instancia, se realiza una exposición del diagnóstico con las demandas de los activistas. Dichas demandas y el discurso a través de los cuales se exponen constituyen un elemento central para conocer la interpretación del problema y las cues- 
tiones consideradas injustas, como puede observarse en los trabajos previamente mencionados. En este punto se identifica el conflicto central y los responsables.

Posteriormente, con el objetivo de generar un análisis más completo, se incorporan las normas en las cuales el discurso se apoya y le otorgan legitimidad, más allá del posicionamiento de sus interlocutores. Así, en el presente estudio se expone una combinación de información discursiva basada en la subjetividad de los activistas con elementos vinculados al marco jurídico, externos a las organizaciones.

La elaboración del marco de pronóstico se fundamenta en el discurso de los activistas, relacionado con las formas en las que estos sugieren que se debería solucionar el conflicto (ver figura 1). Enseguida, se hace referencia a la asignación de identidades que se realiza en el proceso de enmarcado. Son considerados los tres campos: los protagonistas, los antagonistas y los observadores.

Figura 1. Análisis de marcos

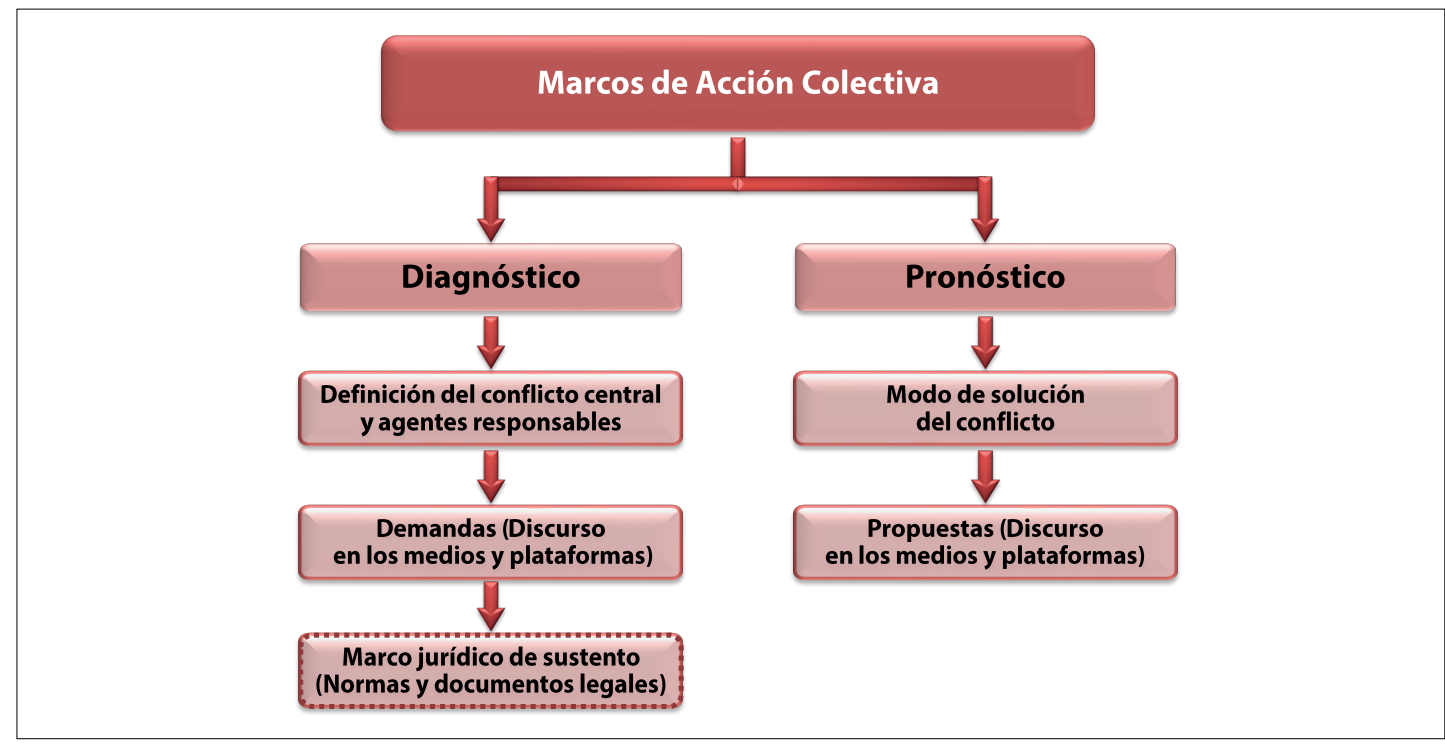

Fuente: Elaboración propia.

Se incorporan al trabajo otras cuestiones que exceden el análisis de marcos, como elementos que permiten comprender mejor el enfoque adoptado y contextualizar el análisis central. En un primer punto, se hace referencia al desarrollo turístico en la ciudad, con la identificación de las etapas y distintas circunstancias que incidieron en la emergencia del conflicto. Enseguida, se describen las organizaciones que protagonizan el proceso de movilización (unidades de análisis), y se indican las distin- 
tas administraciones de los bienes en pugna. En la figura 2 se observa el contenido y los apartados correspondientes.

Desde el punto de vista metodológico, para realizar el análisis central se adopta una estrategia cualitativa en la que la interpretación de la información adquiere un rol preponderante. Las fuentes de información incluyen artículos periodísticos en rotativos y portales de noticias locales (Diario 0223, La Capital, Qué Digital y MDP Hoy), así como plataformas digitales de comunicación (Facebook). También se incluyen entrevistas realizadas a los activistas en programas televisivos y radiales. Para dar cuenta del sustento jurídico de las demandas se retoman ordenanzas, pliegos de bases y condiciones, así como la normativa provincial y nacional vigente.

Al valorar las críticas mencionadas en el apartado anterior, se considera que en la medida que se busque realizar un estudio con mayor profundidad en los procesos culturales que dan lugar a la participación, es preciso utilizar otras técnicas para recolectar información útil, como la entrevista a profundidad o la observación in situ.

Figura 2. Estructura de los contenidos

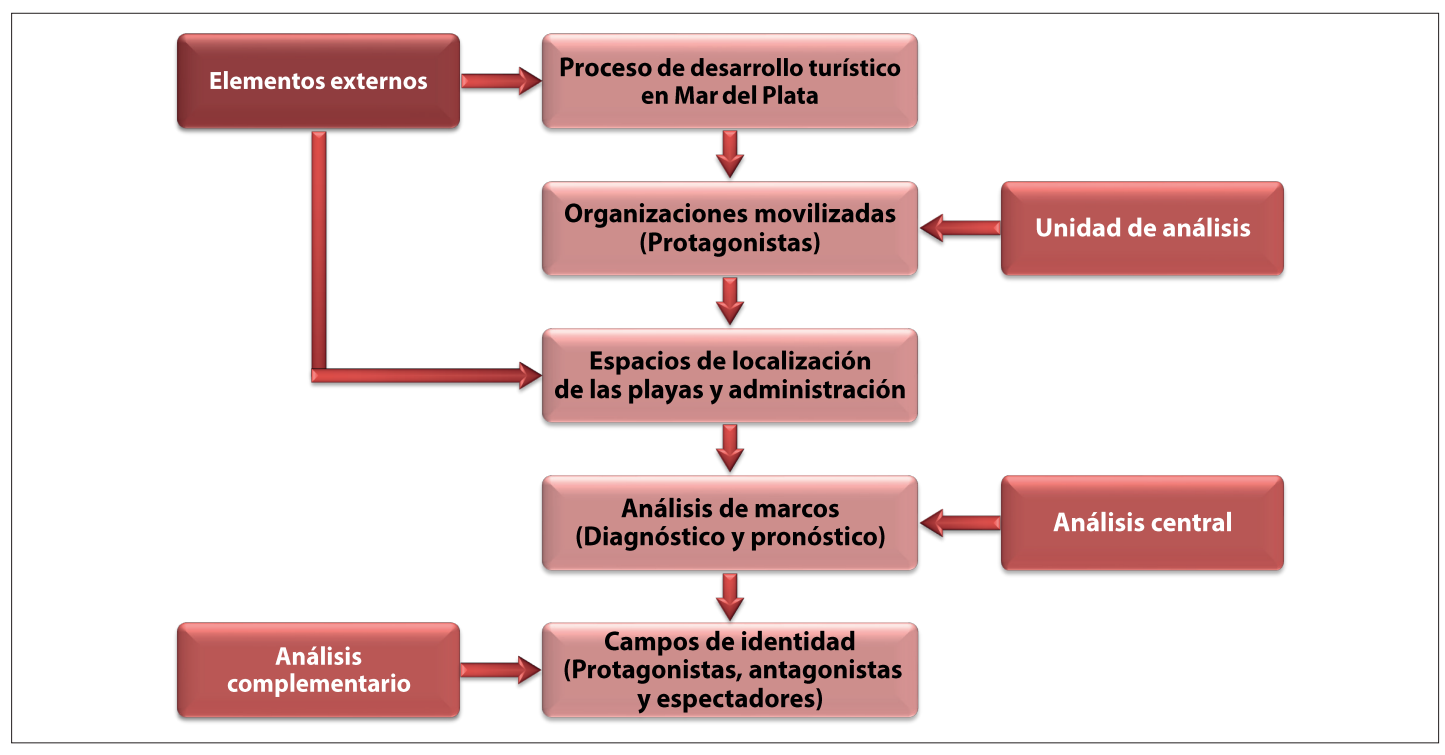

Fuente: Elaboración propia.

Se trabajó con aproximadamente 65 artículos periodísticos publicados entre 2009 y 2018, lapso en el que las organizaciones objeto de estudio adquieren relevancia en la problemática. Para la construcción del marco de diagnóstico se generaron categorías que permitieron agrupar los reclamos. Esta clasificación se realizó a par- 
tir del análisis del discurso de los miembros de las agrupaciones en las fuentes ya mencionadas.

La misma estrategia se aplicó para la construcción del marco propositivo. La sistematización de las demandas se llevó a cabo mediante una matriz de datos, al ordenar las citas textuales en categorías temáticas, de acuerdo con su contenido. Cabe señalar que en la exposición de los resultados no fue posible identificar una explicación unívoca de las causas de participación o la emergencia del movimiento.

En las páginas siguientes se intenta dar un panorama general sobre la forma en la que los activistas perciben la realidad con base en su discurso. Igualmente, se hace alusión a las cuestiones que estos consideran injustas y que en cierta medida definen su posicionamiento en el contexto espacio temporal en el que se encuentran. El trabajo constituye así un primer paso en el análisis de los procesos de movilización social, en torno al conflicto convocante.

Si bien existen otros aspectos y dimensiones para examinar en futuros análisis, es necesario generar un acercamiento inicial, a raíz del cual sea posible construir un horizonte completo del fenómeno en cuestión. También se abre una puerta para el abordaje dinámico del caso. A medida que el tiempo pase será factible observar las modificaciones en los marcos de acción relacionadas con la aparición de nuevos discursos y la evolución del conflicto, tarea que por ahora es poco viable debido al carácter reciente de la movilización.

\section{El turismo en la ciudad de Mar del Plata}

Es importante dar cuenta de la evolución de Mar del Plata como destino turístico y de las condiciones que dieron lugar al conflicto actual. Mantero (1997) establece etapas para analizar la relación entre el turismo y la ciudad, al hacer referencia al contexto macroeconómico, los tipos de visitantes, las transformaciones territoriales y las repercusiones del desarrollo del sector para la comunidad local. Se centra en los sucesos ocurridos desde principios del siglo XX hasta mediados de la década de los 90 .

La primera etapa va de 1885 a 1915. Se caracteriza por la presencia de visitantes en su mayoría provenientes de la ciudad de Buenos Aires, con un nivel socioeconómico elevado. Constituyen una burguesía que adquiere su posicionamiento en el marco de un modelo económico orientado a la exportación agrícola. Mantero 
(1997, p. 139) indica que en esta primera etapa el turismo configura la disposición urbana de la ciudad: "el espacio urbano se produce y reproduce en función del valor de cambio de su puesta en consumo turístico inmediato, al impulso de los propietarios del suelo".

La segunda etapa, que va desde 1915 a 1945, Mantero (1997) la llama de "transición" y se caracteriza por la convivencia del turismo de élite con otro compuesto por visitantes de clase media. Esta nueva afluencia está dada por la distribución de los beneficios, producida por el viraje en la política económica hacia la industrialización sustitutiva.

La tercera etapa (1945-1975) se identifica por el apogeo del turismo en la ciudad y la expansión de los servicios afines en la zona litoral. En este periodo la demanda está constituida principalmente por visitantes pertenecientes a los sectores socioeconómicos medios. Mantero (1997) atribuye esta circunstancia a la gestión de un Estado social y a los procesos de industrialización y urbanización, que van de 1956 a 1960. En este momento se advierten las primeras consecuencias negativas de la consolidación del turismo masivo en la calidad de vida de los residentes.

La desmesura de la expansión, traducida en la intensa ocupación del área central, a niveles de saturación, se realiza en deterioro de la invocada calidad de vida del turista, residente periódico de la ciudad, y en la extensa afectación urbana del área litoral, en perjuicio de una racional política de extensión urbana, consecuencia del creciente rol de promotores inmobiliarios y empresas constructoras. (Mantero, 1997, p. 143).

La cuarta etapa comprende los años de 1975 a 1995, durante los cuales se produce nuevamente un cambio en la orientación de las políticas macroeconómicas, en este caso hacia el libre mercado. En este contexto, aunque el turismo continúa su desarrollo, se reduce la capacidad de los sectores de nivel socioeconómico medio y bajo. Esto se traduce en el declive gradual del número de visitantes y de la duración de la temporada alta. Mantero (1997) revela el predominio de la orientación productiva en el desarrollo de la ciudad, que se ve reflejada en la construcción de los complejos La Perla y El Sur. Al mismo tiempo, señala nuevamente que estas acciones no representan un incremento positivo de la calidad de vida de los residentes.

El último período comienza en 1995, en este caso el autor se refiere a las posibilidades de Mar del Plata, en función del contexto de la época en el que destaca la globa- 
lización económica, la exclusión social, la desigualdad, el retraimiento del Estado y el predominio de valores individuales, en concordancia con una lógica basada en el mercado. En este marco, Mantero (1997) explica la necesidad de reorientar el desarrollo del turismo, adecuándolo a las necesidades de la comunidad, con el objetivo de mejorar sus condiciones de vida.

De acuerdo con Cicalese (2005) esta reorientación no se produjo, sino que se profundizó el plan privado en detrimento del plan público. El autor afirma que desde el punto de vista jurídico se facilitaron las condiciones para la inversión privada; esto surgió en el marco de una búsqueda por modernizar la oferta, en concordancia con las nuevas tendencias del turismo e implicó la desprotección de espacios públicos y el medio ambiente en la zona litoral. Así, la configuración del paisaje costero de la ciudad quedó primordialmente en manos de actores privados. Este modelo basado fundamentalmente en la voluntad empresarial trajo consigo la ocupación privada de la playa, además del desplazamiento de residentes y turistas que no deseaban o no podían pagar por unidades de sombra hacia sectores cada vez más reducidos.

La erosión del frente costero por causas antrópicas y naturales constituyó también un factor decisivo en la disminución de los sectores mencionados. Bajo estas condiciones, a principios de la década actual emergieron una serie de organizaciones que se enfrentan al despojo de la costa marplatense. Nace una nueva valoración del territorio que considera a la playa como un bien con valor cultural y ecológico, en desafío a las visiones predominantes ancladas en la perspectiva mercantil. A través del desarrollo de diversas labores colectivas, los activistas han logrado una visibilidad relevante en los medios de comunicación y en la opinión pública.

\section{Las organizaciones movilizadas}

El movimiento que atiende la problemática en cuestión se compone de diversas organizaciones: aquellas que se conformaron específicamente para tratar el tema de la privatización del espacio costero en Mar del Plata (Asamblea por los Espacios Públicos y la ONG En Defensa de las Playas Públicas) y otras que poseen objetivos más amplios o reducidos, pero también se involucran activamente.

La Asamblea por los Espacios Públicos se creó en el año 2015, por iniciativa de un grupo de vecinos de la zona sur. Uno de los primeros temas tratados fue la expulsión de residentes de los sectores de playa aledaños a los balnearios. Si bien se enfoca 
principalmente en temas concernientes al territorio sureño, se involucran también en situaciones consideradas injustas en el resto de la ciudad. Esta organización fue una de las impulsoras de las primeras manifestaciones públicas de descontento: las sombrilleadas, una movilización en defensa de las playas como espacio público.

En Defensa de las Playas Públicas se constituyó inicialmente como una página de Facebook creada en el año 2012, en la que se denunciaban los problemas relacionados a la ocupación del espacio público por parte del sector privado, sobre todo en las Unidades Turísticas Fiscales (UTF). Años más tarde, ante el incremento de usuarios, los administradores decidieron conformar una ONG. Además de efectuar reclamos a través de Facebook, participó de las sombrilleadas y desarrolló otro tipo de acciones colectivas destinadas a modificar la situación de las playas.

Otra de las estructuras involucradas en el movimiento es Surfrider Argentina. Aunque la organización no se fundó para tratar particularmente la problemática de la privatización del espacio costero, afronta cuestiones relacionadas con la preservación de los ecosistemas marinos. En esta situación se encuentran otros organismos como la Asamblea Verde Mundo, Remadores-Playas Limpias y la Asociación Vecinal de Fomento Los Acantilados. Algunos de sus objetivos y reclamos coinciden con los que persiguen la Asamblea por los Espacios Públicos y la ONG En Defensa de las Playas Públicas. Así el desarrollo de la acción colectiva involucra una serie de participantes que, a pesar de pertenecer a distintas organizaciones, coordinan sus esfuerzos en una causa común.

\section{Espacios de localización de las playas y administración}

El proceso de privatización del espacio se ha desarrollado a lo largo de toda la costa de la ciudad; sin embargo, es posible advertir realidades distintas en función de los actores responsables de la administración y explotación de las playas. Por este motivo, la regulación de la actividad de los balnearios y la delimitación de los espacios arancelados puede variar entre los diferentes sectores.

El primer sector por considerar es aquel en el cual se emplazan las ya mencionadas UTF. En este territorio el municipio tiene a su cargo la administración y explotación, y cada unidad es otorgada para su manejo a través de concesiones públicas. Por esta razón es posible identificar áreas de uso arancelado y áreas de uso público. EI concesionario es responsable de la manutención de ambas. En este caso los plie- 
gos de bases y condiciones determinan las obligaciones de los concesionarios, y se fijan las proporciones de cada una de las áreas públicas y aranceladas, entre otras cuestiones.

Según el Ente Municipal de Turismo (EMTUR), a lo largo de los 47 kilómetros de costa marplatense se emplazan 47 UTF$^{1}$. A su vez, estas se agrupan según su ubicación geográfica: Norte (3), La Perla (8), Centro (8), Playa Grande (14), Punta Cantera (4), Sur (10) (ver figura 3).

El segundo sector es donde el territorio costero es propiedad privada. Estos terrenos están ubicados al sur de la ciudad, específicamente desde el faro Punta Mogotes hasta el paraje Los Acantilados, propiedad de los familiares del fundador de Mar del Plata, Patricio Peralta Ramos. Administran ese espacio a través de la empresa Playas del Faro SAI y cuentan con aproximadamente 30 balnearios. A diferencia de las UTF, en este caso la actividad en la zona es principalmente regulada (normas territoriales, administrativas y de manejo) por la ordenanza 8434/91. Adicionalmente, la ordenanza 21090/12 establece el régimen para las servidumbres administrativas de paso, en el uso y el interés público.

El tercer sector es el del complejo Punta Mogotes, compuesto por 24 balnearios. En este caso la administración y explotación se encuentra predominantemente en manos del Estado provincial. Según lo establecido en la Ley 10233, tales funciones son ejercidas específicamente por la Administración de Punta Mogotes, una entidad pública interjurisdiccional cuyo patrimonio es $70 \%$ de la Provincia de Buenos Aires y 30\% de la Municipalidad del Partido de General Pueyrredón. En este caso, los concesionarios son regidos por lo estipulado en los pliegos de bases y condiciones.

Ahora bien, a pesar de la existencia de normas específicas para cada sector (pliegos de bases y condiciones a cargo del municipio o del Estado provincial y las ordenanzas 8434/91 y 21090/12), existen normativas transversales que pueden ser de origen nacional, provincial o local, cuyo alcance puede incluir a más de un sector o incluso a todos ellos.

\footnotetext{
Las Unidades Turísticas Fiscales son en su mayoría balnearios integrales con alquiler de unidades de sombra y otros servicios como gastronomía, estacionamientos, etcétera. Sin embargo, existen otras figuras como los complejos o centros integrales, que proveen una variedad de servicios en las zonas de playa, sin alquiler de unidades de sombra.
} 
Figura 3. Playas de Mar del Plata

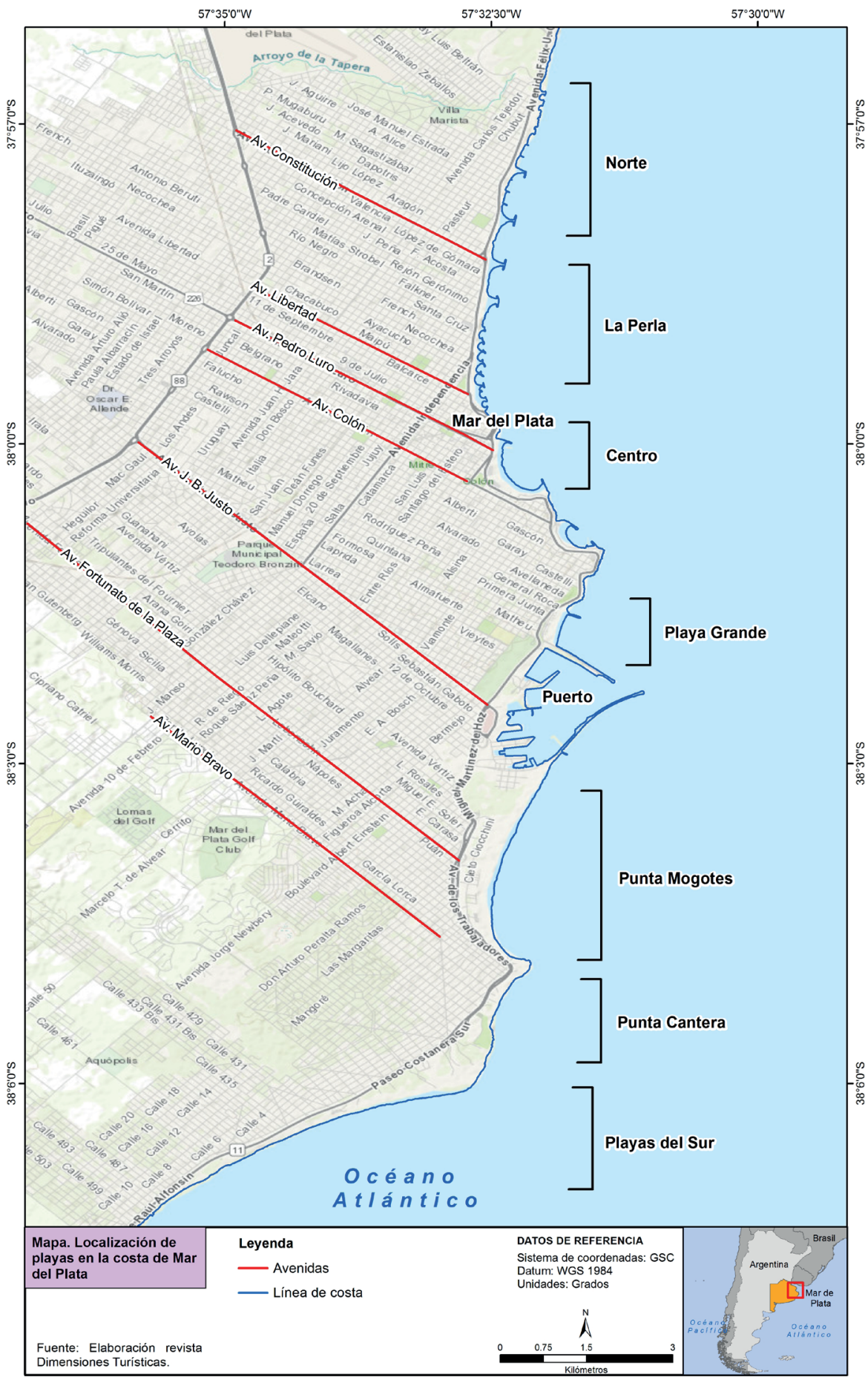

Fuente:Ver interior figura 3. 


\section{Diagnóstico: el conflicto central, los reclamos y la normativa de apoyo}

El conflicto central se erige en la disputa sobre el territorio. Esta circunstancia no sorprende si se observan las reflexiones de Svampa (2009), a propósito de las luchas latinoamericanas y de los movimientos socioambientales. Según el autor, la territorialidad constituye una dimensión transversal a los movimientos que emergieron en la región, en un contexto en que el desarrollo ha quedado supeditado a las visiones neoliberales. Mientras que la lógica predominante de acumulación del capital establece una valoración del territorio solo en función de sus posibilidades productivas, los movimientos adoptan una postura más amplia, que incluye aspectos sociales, culturales y ambientales.

En este caso, la puja territorial se refleja en el reclamo de distintas organizaciones por la privatización del espacio costero. Por una parte, se concibe a la playa primordialmente como recurso turístico, orientado a satisfacer las necesidades de sus clientes. Desde esta óptica, la oferta de servicios y la instalación de facilidades de uso exclusivo constituyen el eje a través del cual se valoriza el espacio. La otra postura, además de considerar los beneficios que las actividades productivas otorgan, pone énfasis en la playa como espacio natural a conservar, en el que se desarrollan procesos de socialización y se construye la identidad colectiva de un pueblo.

En este conflicto central convergen una serie de agravios denunciados por las diferentes organizaciones, a través de los cuales se articula y se le confiere sentido a la movilización. A continuación, se enumeran y explican cada una de las situaciones consideradas injustas desde la perspectiva de los protagonistas. El discurso expuesto y los reclamos manifestados conforman el marco a partir del cual se intenta visibilizar la causa y orientar la opinión pública, a favor de una determinada concepción de la realidad.

\subsection{Restricciones de permanencia y usurpación del espacio público}

Resulta significativo hacer alusión a la expulsión, en algunos casos violenta, de residentes y turistas del espacio comprendido entre los límites de los balnearios y el mar, en la zona sur de la ciudad ${ }^{2}$. Esta circunstancia es vista por los activistas como

2 Se entiende por zona sur el territorio que se encuentra entre el Faro Punta Mogotes al norte y el Paraje Los Acantilados al sur; desde el Mar Argentino al este, hasta las tierras fiscales que lindan con la Ruta Provincial número 11 hacia el oeste. 
el detonante que dio origen a las primeras reuniones entre vecinos y organizaciones para tratar la problemática, sentando las bases para el surgimiento general del movimiento y la acción colectiva:

A mí lo que me pasó cuando me mudé al barrio en el 2008 (...) es que no podía comprender cómo no me dejaban estar en la playa, no lo podía creer, entonces esa era la parte más difícil. Que uno termina naturalizando un tema, diciendo -ah esto es privado me corro, me dijeron que acá no se puede, me lo creo y lo hago-. Entonces esa fue la parte más chocante por la que comenzamos a trabajar, porque veíamos también que la gente cerraba las sombrillas, cerraba su carpa, agarraba a su hijo y se iba... y no tenía que ser así. (Karina Huarte, Asamblea por los Espacios Públicos, comunicación personal, 10 de marzo de 2017).

Estas prácticas de restricción a la permanencia se observaron en el sur de la ciudad de Mar del Plata, donde los balnearios se emplazan en terrenos privados. Ante esta circunstancia, el reclamo se sustenta en lo establecido en el artículo 2340 del Código civil argentino (Ministerio de Justicia y Derechos Humanos, 2014) y en el decreto provincial 10391/87.

El referido artículo determina que las playas marítimas son efectivamente de dominio público. Ahora bien, en el texto se apunta que las playas marítimas constituyen "la porción de tierra que las mareas bañan y desocupan durante las más altas y más bajas mareas normales". Este segmento no es estático, el incremento del nivel del mar y la acción humana constituyen factores capaces de modificarlo, lo que vuelve indispensable su medición y delimitación de manera frecuente.

Según lo establecido en el decreto provincial 10391/87, dicha tarea incluye el trazado de la línea de la ribera. Esta línea permite identificar qué parte de la arena corresponde al uso público y su determinación está a cargo de la Autoridad del Agua de la Provincia de Buenos Aires, con las indicaciones presentes en el Código de aguas (Gobierno de la Provincia de Buenos Aires, s. f.), en sus artículos 18 al 21.

Los activistas advierten que la línea de la ribera no ha sido determinada desde 1997, y exigen que el Estado provincial se ocupe del asunto:

El Código civil determina que las playas son un bien público y en Mar del Plata se nos sigue sacando playa cuando en el resto del mundo ese espacio es de todos. Por eso, es fundamental que se vuelvan a realizar las mediciones de la 
línea de que determina dónde empieza lo público y dónde lo privado en las playas. Se pidió el año pasado a través de la Defensoría del Pueblo y nosotros lo solicitamos en junio a la Provincia. Hasta ahora sin respuestas. (Karina Huarte, Asamblea por los Espacios Públicos, citada en Diario 0223, 2016b).

Por otra parte, el decreto provincial 9196/50 se refiere a esta cuestión y contempla la existencia de la ribera externa, la cual constituye una franja paralela a la playa marítima (definida por el Código civil), considerada como espacio para el uso público. Este documento ya no se encuentra en vigencia, pero representa un antecedente de la búsqueda por la preservación de los espacios públicos de la provincia.

En la actualidad, la ribera externa se encuentra ocupada por unidades de sombra. Esta circunstancia se contempla en el artículo 9 de la ordenanza 8434/91 en donde, contrariamente a lo expresado en el decreto mencionado, se otorga permiso a los balnearios para levantar instalaciones removibles, como carpas sombrillas y puestos abiertos.

Los documentos legales y antecedentes que sustentan los reclamos por la expulsión de usuarios en la zona sur son también referenciados por los activistas para denunciar la usurpación de espacios públicos por parte de los concesionarios en el resto de las playas de la ciudad. Si bien no se han hecho visibles prácticas intimidatorias destinadas a desalojar residentes y turistas, se han observado acciones que dan cuenta de la ocupación de la playa marítima.

Se trata de una problemática que afecta a toda la franja costera, pero especialmente a la zona sur, donde los privados directamente expulsan de la playa pública a quienes no son clientes y se instalan con sombrillas. En los balnearios de la zona céntrica, en tanto, la soga está cada vez más cerca del mar, por lo cual la gente puede establecerse solo sobre arena mojada, lo cual no es admisible. (Karina Huarte, Asamblea por los Espacios Públicos, citada en La Capital Mar del Plata, 2016).

Los activistas observan incumplimientos de los concesionarios de las UTF, en relación con lo estipulado en los pliegos de bases y condiciones, a propósito del número de unidades de sombra permitidas. Si bien la ordenanza 22536/15 determina la obligatoriedad de publicar la cantidad de unidades de sombra autorizadas por el EMTUR, la ONG En Defensa de las Playas Públicas denuncia excesos. En este caso, se hace alusión directa a los balnearios ubicados en el centro de la ciudad, corres- 
pondientes al complejo La Perla, y se exige mayor intervención al municipio. "En los balnearios de La Perla ha habido exceso de carpas y sombrillas, y no hay controles salvo cuando se mediatizan (...)" (Mariano Gemín, En Defensa de las Playas Públicas, citado en Radio Mega, 2016).

\subsection{Restricciones de acceso y falta de balnearios públicos}

La segunda cuestión atañe a la falta de accesos y balnearios públicos, así como el mantenimiento de los existentes. Desde las organizaciones se sostiene que los empresarios no realizan las obras necesarias, pese a la existencia de legislación destinada a garantizar el libre acceso a las playas, en la que se asigna un responsable para su mantenimiento.

Para la zona sur, el reclamo se sustenta en la ordenanza 8434/91, en la cual se establecen los indicadores urbanísticos para el sector que corresponde a Playas del Faro SAI. En el artículo $6^{\circ}$ queda expreso que debe construirse un balneario público por cada tres privados. Asimismo, la ordenanza 21090/12 determina que debe garantizarse una bajada mínima por cada balneario o explotación turística; además, cada uno de estos pasos públicos debe contener baños de uso libre.

Es necesario abrir expedientes con estos temas, nos faltan bajadas públicas, nos faltan playas públicas, faltan controles para los concesionarios y lo único que queda, para los turistas y marplatenses que no queremos o no podemos tener una carpa o una sombrilla, es arena húmeda. (Karina Huarte, Asamblea por los Espacios Públicos, citada en Qué Digital, 2016).

Este reclamo se extiende al resto de la ciudad, en donde las UTF se emplazan sobre terrenos pertenecientes al estado, con la reglamentación de la actividad de los concesionarios expresa en los pliegos de bases y condiciones. A propósito de esta circunstancia, los actores movilizados en torno a la problemática se alinearon a la denuncia formal de un particular, en la que se advierte que la posibilidad de acceso al espacio público de las playas se encuentra limitada.

En el 2016, desde el poder judicial se dictó una medida cautelar en la que se ordenó a 32 balnearios de la ciudad y a la Municipalidad del Partido de General Pueyrredón garantizar el acceso irrestricto al espacio público. En la denuncia se establece que desde el Estado municipal y provincial no se realizaron los debidos controles de accesos y baños públicos, de acuerdo con lo que se postula en las ordenanzas 
$8434 / 91$ y 21090/12. Sin embargo, tras la apelación de los concesionarios y del propio municipio, la medida quedó sin efecto.

En el dictamen de los jueces se determina que la alusión a las ordenanzas 8434/91 y 21090/12, como sustento para la denuncia a las UTF, no corresponde, puesto que su injerencia no alcanza a las zonas referidas (legislación que sí puede ser aplicable para los terrenos privados concesionados al sur de la ciudad). Ante tales circunstancias, la Asamblea por los Espacios Públicos manifestó su inconformidad, sobre todo por la falta de controles municipales a los concesionarios y la ausencia de apoyo a la ciudadanía en sus reclamos.

Nosotros estimábamos que con la medida tomada por el juez se iban a inspeccionar los balnearios y de allí se podían generar multas o la baja de las concesiones, pero si es el municipio el que la apela, no nos queda otra que salir a pelear por nuestros derechos. (Karina Huarte, Asamblea por los Espacios Públicos, citada en Diario 0223, 2016a).

Otra de las situaciones denunciadas, en este caso por la ONG En Defensa de las Playas Públicas, se focaliza en la situación de las playas del centro de la ciudad, en particular en la concesión de Las Toscas y Paseo Hermitage, respecto al mantenimiento de las estructuras de las unidades de sombra en temporada baja. Esto adquiere relevancia para la ONG debido a que: en primer lugar, obstruye el acceso para el disfrute del espacio público y, en segundo término, distorsiona el paisaje en la zona más emblemática de la ciudad. Para los activistas, esta modificación del panorama costero plantea una imagen de la ciudad despojada de su espacio natural, y cumple la función de naturalizar la privatización de la playa.

El tema de la privatización de los espacios costeros es algo que está en debate y cuando pasan estas cosas da bronca; hoy en día el nivel de impunidad con el que se manejan los concesionarios que ni siquiera se molestan en retirar las estructuras fuera de la época estival, hace que tengan la playa principal de la ciudad cerrada en temporada baja. (Mariano Gemín, En Defensa de las Playas Públicas, citado en Qué Digital, 2015).

\subsection{Prácticas que acentúan el deterioro ambiental}

Aunque el proceso general de urbanización en el entorno costero constituye un factor de deterioro ambiental relevante, en este apartado se hace referencia a prác- 
ticas particulares que lo acentúan: la deforestación, la extracción ilegal de arena y las construcciones no removibles. Según explican Veneziano y García (2014), estas prácticas aumentan los procesos erosivos; señalan que pueden ser causados por circunstancias tanto naturales como antrópicas. Entre las primeras, destacan la acción de tormentas y sudestadas, a la par del incremento del nivel del mar, mientras que en las segundas aparecen la construcción de vías de circulación próximas a la costa, los desagües pluviales, la minería extractiva en las playas, así como la actuación urbanística y de servicios sobre la costa y áreas inmediatas.

En cuanto al primer punto, se observan denuncias por la actividad de los concesionarios en la zona de la reserva Paseo Costanera Sur. El caso más señalado en fechas recientes ha sido el del balneario Horizonte del Sol, que durante 2016 realizó una tala en el espacio de la reserva, con el fin de incrementar su capacidad para instalar equipamiento.

Nuevamente los vecinos de la zona sur integrantes de Asamblea Verde Mundo, Asamblea Vecinos por los Espacios Públicos y esta Asamblea detectamos deforestación y movimientos de arena y tierra en NUESTRA Reserva Forestal Paseo Costanero Sur. (Asamblea por los Espacios Públicos, 2018).

Las otras dos cuestiones que atañen a los empresarios son la extracción de arena y las construcciones ilegales en las playas. Con respecto a la construcción de estructuras no permitidas (por contener cemento) en las playas de la ciudad, resulta oportuno indicar que la ordenanza 8434/91 especifica que las construcciones sobre la ribera deben ser removibles. El caso paradigmático que ha tenido una fuerte repercusión en los medios es el del balneario Abracadabra, ubicado en la zona sur de la ciudad (ver tabla 1).

Desde hace tres semanas venimos visibilizando conjuntamente [sic] con los vecinos la situación en Abracadabra y a raíz de las denuncias efectuadas, se labraron dos actas de constatación, pero si bien el Tribunal de faltas 2 dispuso la clausura que se hizo efectiva este jueves por la mañana, pasamos por el balneario a la tarde y vimos que los operarios habían reanudado los trabajos en la obra. (Karina Huarte, Asamblea por los Espacios Públicos, citada en MDP Hoy, 2016).

A pesar de que en un principio la denuncia realizada por la Asamblea por los Espacios Públicos no logró detener los trabajos de construcción, tras la insistencia en los 
reclamos y con el trabajo de la Comisión de turismo y el Defensor del pueblo, en 2018 el Tribunal de faltas ordenó la demolición de las edificaciones. A pesar de que el caso resultó favorable para los denunciantes, se observa que este tipo de edificaciones no sustentables continúan realizándose en distintos puntos de la costa marplatense.

La situación siempre es igual del norte hacia el sur, venimos viendo los mismos escenarios a pesar de lo que planteamos las comunidades. Se construye, se pasan por encima ordenanzas, leyes provinciales, leyes nacionales y ambientales, leyes de construcción y de uso de suelo. Una vez hecho se empieza con la lucha de defensa y disputa y la verdad es que muy pocas veces se tiran abajo esos lugares, a pesar de estar construidos ilegalmente. (Karina Huarte, Asamblea por los Espacios Públicos, citada en MDP Ya, 2018).

Por otra parte, a medida que pasan los años el tema de la arena en las costas de la ciudad adquiere mayor relevancia. La erosión del frente trae como consecuencia una reducción de la playa y, por lo tanto, existe menor espacio para montar las unidades de sombra de cada balneario. Según explica En Defensa de las Playas Públicas, ante esta situación los concesionarios extraen arena de los espacios libres y la depositan en el sector destinado a la instalación de las carpas y sombrillas. Sostienen que esta acción, además de causar mayor deterioro del frente costero, reduce el espacio público.

Ahí los concesionarios lo que hicieron fue una extracción de arena del sector público, prácticamente de la orilla de la playa para arrojarla al sector de la playa privada, para defender sus intereses más que nada. Eso en teoría no debería estar avalado por el Organismo Provincial para el Desarrollo Sostenible. (Mariano Gemín, Asamblea por los Espacios Públicos, citado en Qué Digital, 2019).

También se acusa a los empresarios y al grupo que los reúne, Cámara de Empresarios de Balnearios, Restaurantes y Afines (CEBRA) de realizar el refulado, que implica la extracción de arena ubicada mar adentro y deposición en las playas, para contrarrestar los efectos de la erosión. Esta práctica resulta muy costosa y se realiza con cargo al Estado, lo que beneficia primordialmente al sector privado.

A propósito de esta cuestión, la resolución 2623/08, emanada desde el Consejo Deliberante del Municipio de General Pueyrredón, declara a la arena como "recurso turístico fundamental". En el documento se expresa la necesidad de protección y 
conservación, puesto que constituye uno de los pilares del desarrollo económico local. En este contexto se insta al Estado provincial a realizar las inversiones necesarias para evitar la pérdida de este recurso (ver tabla 1).

\section{Tabla 1. Síntesis del diagnóstico}

\begin{tabular}{|c|c|c|c|c|c|}
\hline \multicolumn{6}{|c|}{ Diagnóstico } \\
\hline $\begin{array}{c}\text { Problemáticas } \\
\text { generales }\end{array}$ & $\begin{array}{c}\text { Problemáticas } \\
\text { específicas }\end{array}$ & $\begin{array}{l}\text { Año de } \\
\text { información } \\
\text { referenciada }\end{array}$ & $\begin{array}{c}\text { Zonas } \\
\text { referenciadas }\end{array}$ & $\begin{array}{l}\text { Normativa } \\
\text { referenciada }\end{array}$ & $\begin{array}{l}\text { Ejes del } \\
\text { discurso }\end{array}$ \\
\hline \multirow{2}{*}{$\begin{array}{l}\text { Restricciones } \\
\text { de permanencia } \\
\text { y usurpación del } \\
\text { espacio público }\end{array}$} & Expulsiones & $2016 / 2017$ & Zona sur & $\begin{array}{c}\text { Código civil } \\
\text { Art. } 2340 \\
\text { Decreto provincial } \\
10391 / 97\end{array}$ & \multirow{2}{*}{$\begin{array}{l}\text { Valoración } \\
\text { productiva } \\
\text { vs. valoración } \\
\text { ecológica y } \\
\text { cultural }\end{array}$} \\
\hline & $\begin{array}{c}\text { Excesos en la } \\
\text { instalación de } \\
\text { unidades de } \\
\text { sombra }\end{array}$ & 2019 & Zona norte & $\begin{array}{l}\text { Pliegos de bases } \\
\text { y condiciones } \\
\text { Ordenanza } \\
22536 / 15\end{array}$ & \\
\hline \multirow{3}{*}{$\begin{array}{l}\text { Restricciones } \\
\text { de acceso y falta } \\
\text { de balnearios } \\
\text { públicos }\end{array}$} & Bajadas públicas & 2016 & Zona sur & Ordenanzas & \multirow{3}{*}{$\begin{array}{l}\text { Privatización } \\
\text { excesiva } \\
\text { vs. reivindicación } \\
\text { de lo público }\end{array}$} \\
\hline & Acceso limitado & 2018 & Todas las zonas & $\begin{array}{c}8434 / 91 \\
\text { y } 21090 / 12\end{array}$ & \\
\hline & $\begin{array}{l}\text { Mantenimiento } \\
\text { de estructuras en } \\
\text { temporada baja }\end{array}$ & 2015 & Zona centro & & \\
\hline \multirow{3}{*}{$\begin{array}{l}\text { Prácticas } \\
\text { que acentúan } \\
\text { el deterioro } \\
\text { ambiental }\end{array}$} & Deforestación & 2018 & Zona sur & $\begin{array}{c}\text { Ordenanza } \\
19111 / 09\end{array}$ & \multirow{3}{*}{$\begin{array}{l}\text { Flexibilidad } \\
\text { jurídica } \\
\text { vs. regulación } \\
\text { y control }\end{array}$} \\
\hline & $\begin{array}{c}\text { Extracción de } \\
\text { arena }\end{array}$ & 2019 & No se especifica & $\begin{array}{l}\text { Resolución } \\
\text { 2623/09 }\end{array}$ & \\
\hline & $\begin{array}{l}\text { Estructuras no } \\
\text { removibles }\end{array}$ & 2018 & Zona sur & $\begin{array}{c}\text { Ordenanzas } \\
21090 / 12 \\
\text { y } 8434 / 91\end{array}$ & \\
\hline
\end{tabular}

Fuente: Elaboración propia.

Como se señala a lo largo del texto, las problemáticas no son exclusivas de una determinada zona. Los años mencionados dan cuenta de los momentos en los que se expuso el discurso analizado, pero no significa que no existan otras instancias en las que este tuviese exposición. La privatización afecta a la costa marplatense en general, y las denuncias se han producido y tomado notoriedad mediática a lo largo de la última década. 


\section{Pronóstico: propuestas y posibles soluciones desde las organizaciones}

Las organizaciones ven esencial la participación del Estado para regular la actividad de los concesionarios. Una de las principales cuestiones que las movilizaciones buscan que se defina son las acciones del sector público provincial, respecto a la demarcación de la línea de la ribera, a fin de establecer los límites del espacio que puede ser ocupado por los balnearios.

Para otras cuestiones como la falta de accesos y balnearios públicos, el exceso del factor ocupacional, la construcción de estructuras no permitidas y el mantenimiento de los espacios no arancelados que son parte de las concesiones, los activistas advierten la necesidad de ejercer mayores controles por parte del Estado municipal. Además, en el caso de las UTF, se busca que las infracciones constatadas tengan un peso definitivo a la hora de renovar las concesiones.

Los activistas explican que los permisos se otorgan por plazos excesivamente largos, sin tener en cuenta la dinámica costera. En los pliegos de bases y condiciones queda establecido el área a ocupar por el balneario, pero no se considera la posibilidad de que el mar avance sobre la playa, con la consecuente reducción al espacio público. Este punto es central en el conflicto. Cuando desde el sector privado o desde el municipio se desestiman los reclamos de las organizaciones, se argumenta que la zona arancelada se encuentra fijada en los pliegos de bases y condiciones.

No hay multas porque cuando el Municipio autoriza concesiones, que son de entre 20 y 30 años, son por una cantidad determinada de unidades de sombra y no se tiene en cuenta la dinámica del mar y ese es el problema que estamos teniendo ahora. Las concesiones no se pueden modificar porque es un documento legal y los empresarios están avalados por ellas mientras el mar avanza. (Mariano Gemín, En Defensa de las Playas Públicas, citado en Qué Digital, 2019).

A través de las exigencias que recaen sobre actores públicos y privados, las organizaciones buscan obtener mayor transparencia en los procesos de toma de decisiones, con respecto a los temas enunciados y al desarrollo turístico en general. Se pretende mejor acceso a los expedientes, informes y pliegos de bases y condiciones, para incrementar las posibilidades de control ciudadano sobre la explotación de la costa. El hecho de que estos documentos sean elaborados entre los empresarios y los organismos públicos, con una escasa participación comunitaria, refuerza la idea 
de una planificación de los espacios costeros centrada en determinadas expectativas e intereses.

Desde la Asamblea por los Espacios Públicos se reivindica también la posibilidad de gestión comunitaria en determinados sectores del sur de la ciudad. El Balneario Verde Mundo es un caso exitoso de autogestión en el que los vecinos estructuran formas innovadoras hacia el manejo sustentable del espacio de playa, para el disfrute de turistas y residentes. En definitiva, si bien las posturas con respecto a la gestión de la playa pueden variar en el marco de la heterogeneidad del movimiento, se trata siempre de una búsqueda por plasmar la voluntad y las valoraciones de la comunidad sobre el territorio.

Se destaca que la movilización no demanda eliminar la posibilidad de desarrollo de actividades productivas vinculadas al turismo de Mar del Plata; su intención es exigir aspectos soslayados en el modelo actual, que son importantes para mejorar la calidad de vida de los residentes y turistas. Ante ello, se observa la necesidad de un nuevo entramado turístico en el que la playa en particular y el territorio en general, adquieran una valoración más amplia. A pesar de que existe legislación local, provincial y nacional que respalda esta postura compleja y superadora, los hechos indican que su implementación es aún deficiente.

\section{Campos de identidad}

La correlación a los campos de identidad implica la asignación de determinados roles a los actores que se encuentran involucrados en la problemática abordada. En primer lugar, el grupo protagonista está compuesto por las organizaciones previamente descritas. Es relevante considerar que la identificación de los protagonistas se construye, en cierta medida, a partir de la diferenciación con los otros. En este caso los otros, los antagonistas, representan una visión que se opone al discurso de los actores movilizados, con respecto a la valoración de la playa. Los antagonistas son referenciados principalmente en el marco de diagnóstico.

Así, los actores que se encuentran en conflicto con los protagonistas son el estado y los empresarios del sector de balnearios. Según los activistas, los concesionarios realizan prácticas que impactan negativamente en diversos ámbitos. En este contexto, el ente gobernante no regula ni controla adecuadamente en función de los intereses comunitarios. Esta observación coincide con la mirada de Harvey (2008), 
quien postula al Estado como facilitador de los procesos de expansión territorial del capital, a través de la flexibilización de los marcos normativos.

Finalmente, el grupo de los espectadores está compuesto por residentes y turistas. Se busca crear conciencia sobre la situación de las playas en los marplatenses, al insistir sobre el carácter público de los bienes naturales y su importancia para la comunidad. A su vez, los turistas constituyen otro sector al que los activistas buscan advertir. Aquí entra en juego la posibilidad de disfrute para el turismo que queda excluido del modelo de desarrollo orientado a un determinado perfil.

A modo de cierre del análisis, se presenta a continuación un esquema basado en el modelo planteado por Chihu Amparán (2016) en el que es posible visualizar los campos de identidad, así como los marcos de diagnóstico y pronóstico.

Figura 4. Marcos e identidades

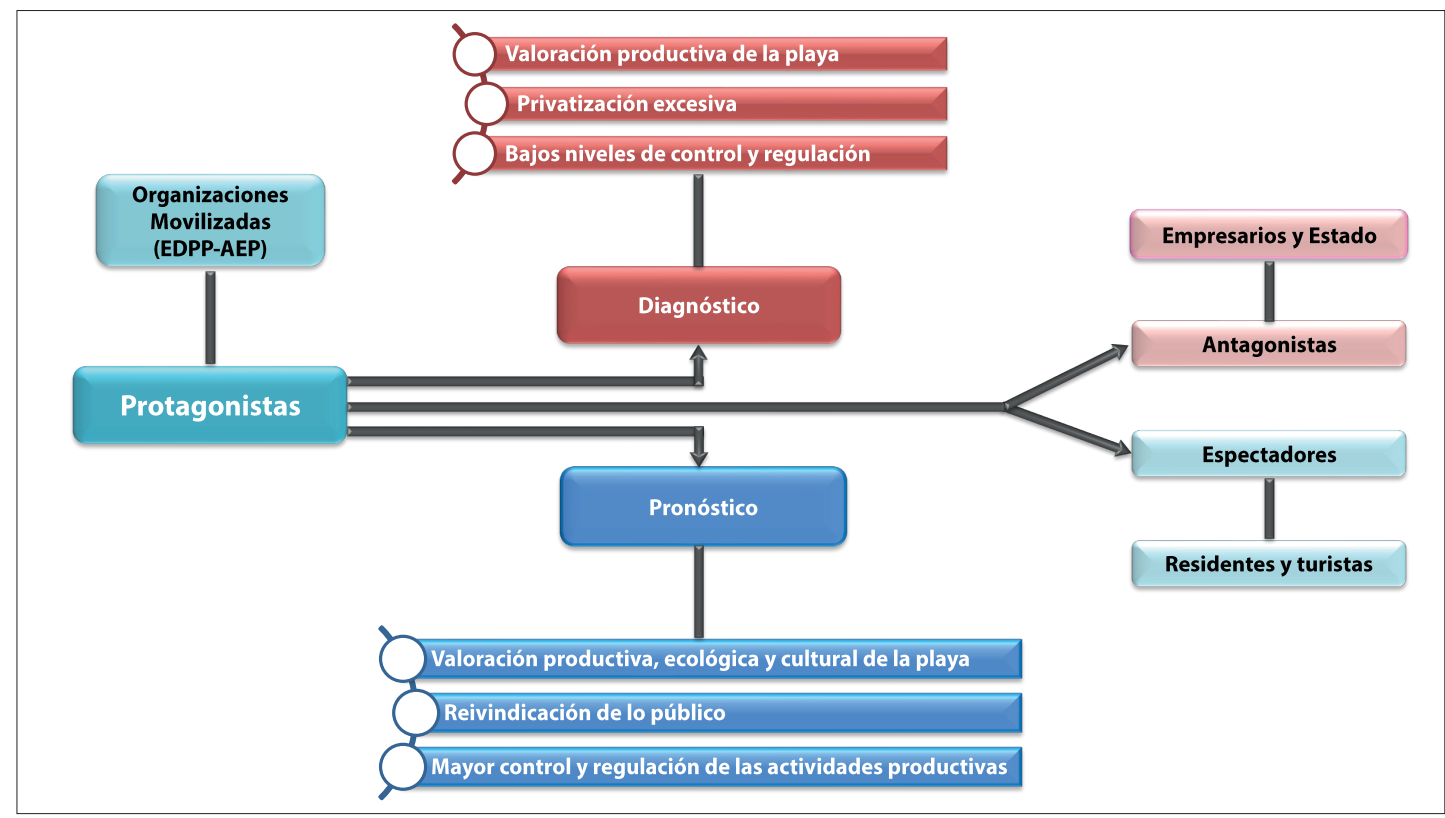

Fuente: Elaboración propia con base en el modelo de Chihu Amparán (2016).

\section{Conclusiones}

Con el abordaje del devenir de Mar del Plata como destino turístico se ha podido visualizar el proceso de apropiación del espacio litoral, a partir de la instalación de balnearios con infraestructuras y servicios orientados a las necesidades de los 
clientes. Esta expansión se produjo en el marco de una valoración del territorio en términos productivos, que a través del tiempo ha comprimido los espacios de esparcimiento y socialización de la comunidad. La reducción de la playa para los residentes y turistas se acentuó con la expansión privada y también como resultado de los procesos erosivos por causas naturales y antrópicas.

Las movilizaciones sociales en la primera década del siglo XXI dejan en evidencia la existencia de una valoración distinta del territorio, basada en su carácter natural, cultural y patrimonial. En este sentido, la defensa de las playas implica la reivindicación del carácter público de los bienes, ante el despojo producido por el proceso de privatización y las prácticas que lo sostienen.

Al revisar las demandas de los movilizados, se observó la existencia de tres cuestiones fundamentales que dan cuenta de lo establecido: a) las restricciones de permanencia y la usurpación del espacio público, b) las limitaciones de acceso y la falta de balnearios públicos, y c) el desarrollo de prácticas que acentúan el deterioro ambiental.

El discurso de los activistas busca plasmar las ideas del movimiento con enfoque en la defensa del espacio público. Se pretende generar conciencia sobre el dominio público de las playas y los derechos de los residentes y romper con la naturalización de un entorno en el que los ciudadanos no poseen voz en las decisiones sobre el propio territorio. Se hace referencia al Estado como responsable del sostenimiento de las bases de un statu quo considerado injusto para la comunidad, y se promulga la necesidad de armonizar el crecimiento económico derivado de la explotación de la zona costera con las necesidades de la población local.

Al analizar la legislación aplicable a cada una de las problemáticas, se advirtió que la mayor parte de las cuestiones que se reclaman tienen un sustento jurídico. Es decir, que la visión de las organizaciones coincide con los ideales plasmados en las ordenanzas, leyes, decretos, resoluciones, y pliegos de bases y condiciones. A pesar de esta circunstancia, proliferan prácticas que pasan por alto las normas. Si bien desde el Estado se ejerce cierto control para su cumplimento, este resulta insuficiente.

En este contexto, las organizaciones objeto de análisis presentan sus propuestas de modificación de la situación actual, ante la necesidad de reorientar la actividad pública en función de objetivos más amplios, que incluyan una valoración distinta del territorio. Asimismo, no se descarta la posibilidad de incursionar en proyectos 
de gestión comunitaria de determinados sectores, en los que la escala lo permita. Como se mencionó anteriormente, el proyecto no implica una desmercantilización absoluta de la costa, se trata de construir un nuevo modelo de desarrollo turístico, de carácter incluyente y sustentable.

Además de los hallazgos que emergieron producto del análisis específico, el estudio presentó una posibilidad de articulación entre la teoría generada para el abordaje de la acción colectiva y las problemáticas, en las que la gestión y evolución del turismo adquieren un rol protagónico. Así, se plantea una posibilidad de investigación útil para nuevos casos en los que se identifiquen situaciones conflictivas de este tipo.

Actualmente, es posible observar procesos de movilización social respecto a los efectos del turismo masivo en ciudades como Barcelona, Venecia, Ibiza, Roma, MaIlorca, San Sebastián, Dubrovnik, entre otras. A pesar de la existencia de dicha disposición a nivel mundial, aún son escasos los estudios que adoptan una perspectiva centrada en las organizaciones y los movimientos que realizan o dan impulso a las acciones colectivas.

Para cerrar, es importante dejar en claro que este trabajo representa un panorama inicial de la problemática y el proceso de movilización social. Se advierte que la amplitud del tema otorga la posibilidad de generar nuevos trabajos, desde diferentes perspectivas y disciplinas. En lo que se refiere al análisis del movimiento y las organizaciones que lo componen, queda pendiente la indagación en referencia a su estructura organizativa, sus repertorios de acción y los procesos de conformación de la identidad colectiva.

\section{Referencias}

Asamblea por los Espacios Públicos (2018, 30 de octubre) Publicaciones [página de Facebook]. Facebook. https://bit.ly/2RQAJtm

Aslanidis, P. (2018). Populism as a collective action master frame for transnational mobilization. Sociological Forum, 33(2), 443-464. https://doi.org/10.1111/ socf. 12424 
Benford, R. D. (1997). An insider's critique of the social movement framing perspective. Sociological Inquiry, 67(4), 409-430. https://doi.org/10.1111/j.1475682X.1997.tb00445.x

Benford, R. D. y Snow, D. A. (2000). Framing processes and social movements: an overview and assessment. Annual Review of Sociology, 26(1), 611-639. https:// doi.org/10.1146/annurev.soc.26.1.611

Blumer, H. (1951). Collective behavior. En A. McClung y R. E. Park (Eds.), New Outline of the Principles of Sociology (pp. 166-222). Barnes \& Noble.

Cefaï, D. (2001). Les cadres de l'action collective. Définitions et problèmes. En C. Daniel y D. Trom (Eds.), Les formes de l'action collective. Mobilisations dans des arènes publiques (pp. 51-97). Editions de l'École des Hautes Études en Sciences Sociales. https://doi.org/10.2307/3322890

Chihu Amparán, A. (1999). Estrategias simbólicas y marcos para la acción colectiva. Revista Polis, 1(1), 41-66. https://bit.ly/3kIOW83

Chihu Amparán, A. (2016). Marcos de acción colectiva en el movimiento de El Barzón. Región y Sociedad, 28(66), 321-337. https://bit.ly/3klYobP

Cicalese, G. (2005, 11-13 de mayo). Territorios críticos y propiedad privada de recursos turísticos valiosos. Las playas privadas del sur de Mar del Plata, 19912005 [conferencia]. Taller Internacional: desplazamientos, contactos, lugares. La experiencia de la movilidad y la construcción de otras geografías, Buenos Aires, Argentina.

Consejo Profesional de Agrimensura. (1987, 30 de noviembre). Decreto Provincia de Buenos Aires 10391/87. Boletín Oficial Provincia de Buenos Aires No. 21148. https://bit.ly/2Ho4YWN

Cruz, G. (2019). Perspectivas teóricas para el abordaje de los movimientos sociales y su incorporación en el campo de la investigación en turismo. Turismo y Sociedad, 25, 195-216. https://bit.ly/3iUxj4U

Della Porta, D. y Diani, M. (2006). Social movements: an introduction. Publishing Limited.

Diario 0223. (2016a, 20 de enero). Tras la apelación del municipio, se viene una nueva sombrilleada. https://bit.ly/3iUrDI6 
Diario 0223. (2016b, 8 de septiembre). No es que falta arena, sino que hay más carpas. https://bit.ly/35Uvu4l

Gobierno de la Provincia de Buenos Aires. (s. f.). Ley 12257. Código de aguas. https:// bit.ly/3kHktrk

Gobierno de la Provincia de Buenos Aires. (1950, 11 de mayo). Decreto Provincia de Buenos Aires 9196/50. https://bit.ly/3mJaXFW

Gobierno de la Provincia de Buenos Aires. (1984, 6 de diciembre). Decreto Provincia de Buenos Aires 7297/1984. Ley 10233. Boletín Oficial Provincia de Buenos Aires No. 20403. https://bit.ly/3iTuq4j

Goffman, E. (1974). Frame analysis: an essay on the organization of experience. Harvard University Press.

Hansen, S. S. y Nicolini, K. M. (2019). No longer just a protest: how women's march strategic messaging for collective action mobilizes a movement. Public Relations Journal, 13(1). https://bit.ly/3kDfYh7

Harvey, D. (2008). El derecho a la ciudad. New Left Review, 53(4), 23-39. https://bit. $\mathrm{ly} / 36 \mathrm{rOA3B}$

Jasper, J. M. (2010). Cultural approaches in the sociology of social movements. En B. Klandermann y C. Roggeband (Eds.), Handbook of social movements across disciplines (pp. 59-109). Springer. https://doi.org/10.1007/978-0-387-709604_3

Jasper, J. M. (2012). ¿De la estructura a la acción? La teoría de los movimientos sociales después de los grandes paradigmas. Sociológica México, 27(75), 7-48. https://bit.ly/2ZUpkxh

Kousis, M. (2000). Tourism and the environment: a social movements perspective. Annals of Tourism Research, 27(2), 468-489. https://doi.org/10.1016/ S0160-7383(99)00083-3

La Capital Mar del Plata. (2016, 9 de enero). Exigen que se garantice el acceso y uso de las playas públicas. https://bit.ly/3hSAOCA

Mantero, J. C. (1997). Mar del Plata: devenir urbano y desarrollo turístico. FACES, 3(4), 135-152. https://bit.ly/2Gwhram 
McAdam, D. (1996). Political opportunities: conceptual origins, current problems, future directions. En D. McAdam, J. D. McCarthy, M. N. Zald y N. Z. Mayer (Eds.), Comparative perspectives on social movements: political opportunities, mobilizing structures, and cultural framings (pp. 23-40). Cambridge University Press.

McAdam, D., McCarthy, J. D., Zald, M. N. y Mayer, N. Z. (Eds.). (1996). Comparative perspectives on social movements: political opportunities, mobilizing structures, and cultural framings. Cambridge University Press. https://doi.org/10.1017/ CBO9780511803987

McCarthy, J. D. y Zald, M. N. (1977). Resource mobilization and social movements: a partial theory. American Journal of Sociology, 82(6), 1212-1241. https://bit. ly/3cRvkMk

McGehee, N. G. (1999). Alternative tourism: a social movement perspective [tesis de doctorado, Virginia Tech]. https://bit.ly/3iUslj8

McGehee, N. G. (2002). Alternative tourism and social movements. Annals of Tourism Research, 29(1), 124-143. https://doi.org/10.1016/S0160-7383(01)00027-5

McGehee, N. G. (2012). Oppression, emancipation, and volunteer tourism: research propositions. Annals of Tourism Research, 39(1), 84-107. https://doi. org/10.1016/j.annals.2011.05.001

McGehee, N. G. y Santos, C. A. (2005). Social change, discourse and volunteer tourism. Annals of Tourism Research, 32(3), 760-779. https://doi.org/10.1016/j. annals.2004.12.002

MDP Hoy. (2016, 16 de diciembre). Balneario Abracadabra: denuncian obra ilegal y violación de clausura. https://bit.ly/2G3gk1S

MDP Ya. (2018, 7 de agosto). Construcción en Playa Grande: Mar del Plata no posee conciencia ambiental. https://bit.ly/3iSqWyU

Melucci, A. (1996). Challenging codes: collective action in the information age. Cambridge University Press. https://doi.org/10.1017/CBO9780511520891

Menke, L. (2019). What strikes a chord? the construction of resonance in collective action frames on missing and murdered indigenous women and girls in $\mathrm{Ca}$ - 
nada [tesis de maestría, Utrecht University]. Utrecht University Repository. https://bit.ly/3mlc3Bw

Ministerio de Justicia y Derechos Humanos. (2014). Código civil y comercial de la nación argentina. https://bit.ly/2RLKBVm

Monterrubio, C. (2017). Protests and tourism crises: a social movement approach to causality. Tourism Management Perspectives, 22, 82-89. https://doi. org/10.1016/j.tmp.2017.03.001

Municipalidad del Partido de General Pueyrredón. (1991, 28 de noviembre). Ordenanza 8434/91. Expediente H.C.D.: 1482/1991. https://bit.ly/3mGpq5j

Municipalidad del Partido de General Pueyrredón. (2008, 13 de noviembre). Resolución $N^{\circ}$ 2623/08 del Honorable Concejo Deliberante. Expediente H.C.D.: 2113 LETRA U. https://bit.ly/35Xb6PW

Municipalidad del Partido de General Pueyrredón. (2009, 22 de abril). Ordenanza 19111/09. Expediente H.C.D.:2076-D-07. https://bit.ly/2Es71bg

Municipalidad del Partido de General Pueyrredón. (2012, 25 de octubre). Ordenanza 21090/12. Expediente H.C.D.: 1920-D-2012. https://bit.ly/301AsIN

Municipalidad del Partido de General Pueyrredón. (2015, 18 de diciembre). Ordenanza 22536/15. Expediente H.C.D.: 1937-FV-15. https://bit.ly/33U3ICc

Nulman, E. (2017). Neo-imperialism in solidarity organisations' public discourses: coIlective action frames, resources and audiences. Third World Quarterly, 38(11), 2464-2481. https://doi.org/10.1080/01436597.2017.1368011

Qué Digital. (2015, 14 de mayo). Denuncian abandono en las playas del centro. https:// bit.ly/32SmquM

Qué Digital. (2016, 8 de enero). Sombrillas en la municipalidad para que el gobierno actúe. https://bit.ly/2G2ERnn

Qué Digital. (2019, 3 de enero). Playas públicas: no falta arena sino que sobran carpas. https://bit.ly/3j5U9GA

Radio Mega. (2016, 28 de agosto). Aseguran que en Mar del Plata el 92\% de las playas se encuentran privatizadas. https://bit.ly/3hYISGS 
Salim, A. (2019). Save Indonesia with Sharī 'Ah and KhilāFah: a study on the collective action frame of Hizbut Tahrir Indonesia. Sulthan Thaha Journal of Social and Political Studies, 1(2), 136-170. https://bit.ly/35WEQfl

Smelser, N. (1962). Theory of collective behavior. The Free Press.

Snow, D. A. y Benford, R. D. (1988). Ideology, frame resonance, and participant mobilization. International Social Movement Research, 1(1), 197-217. https://bit. ly/3ckG85m

Snow, D. A. y Benford, R. D. (1992). Master frames and cycles of protest. En A. Morris y C. McClurg (Eds.), Frontiers in social movement theory (pp. 133-155). Yale University Press. https://bit.ly/3isD6xv

Svampa, M. (2009). Protesta, movimientos sociales y dimensiones de la acción colectiva en América Latina [ponencia]. Jornadas de Homenaje a C. Tilly, Madrid, España.

Tarrow, S. (1997). El poder en movimiento: los movimientos sociales, la acción colectiva y la política. Alianza Editorial.

Terríquez, V., Brenes, T. y López, A. (2018). Intersectionality as a multipurpose collective action frame: the case of the undocumented youth movement. Ethnicities, 18(2), 260-276. https://doi.org/10.1177/1468796817752558

Tilly, C. (1978). From mobilization to revolution. Addison-Wesley.

Tricot, T. (2011). El movimiento mapuche en Chile y Argentina. Una aproximación desde las teorías de la acción colectiva y los movimientos sociales [tesis de doctorado, Universidad de Salamanca]. Repositorio institucional de la Universidad de Salamanca. https://bit.ly/3iTtBIB

Touraine, A. (1987). Actores sociales y sistemas políticos en América Latina. Prealc.

Turner, R. y Killian, L. (1957). Collective behavior. Prentice-Hall.

Veneziano, M. F. y García, M. C. (2014, 19-21 de noviembre). Protección costera y regeneración de playas en el sur de municipio de Gral. Pueyrredón, Provincia de Buenos Aires [conferencia]. Il Jornadas Nacionales de Ambiente, Tandil, Argentina. 
Vianello, M. (2016). The No Grandi Navi campaign. En C. Comb y J. Novy-Oxon (Eds.), Protest and resistance in the tourist city (pp. 171-191). Routledge.

Winstead, K. C. (2017). Black catholicism and black lives matter: the process towards joining a movement. Ethnic and Racial Studies, 40(11), 1855-1863. https://doi. org/10.1080/01419870.2017.1334932

Zizumbo-Villarreal, L., Pérez-Ramírez, C. y Quintanilla Montoya, A. (2009). La construcción social de la acción colectiva y los desafíos del medio rural en el contexto del desarrollo turístico [ponencia]. VIII Jornadas de sociología de la Universidad de Buenos Aires, Buenos Aires, Argentina.

Zhou, Y. y Yang, Y. (2018). Mapping contentious discourse in China: activists' discursive strategies and their coordination with media. Asian Journal of Communication, 28(4), 416-433. https://doi.org/10.1080/01292986.2018.1434803 


\title{
EFECTIVIDAD DE LA COMUNICACIÓN EN LAS PEQUEÑAS Y MEDIANAS EMPRESAS DEL SECTOR TURÍSTICO EN UN ENTORNO ALTAMENTE COMPETITIVO
}

\author{
José GUADALUPE MAGDALENO ELIZONDO \\ jose.magdaleno@edu.uaa.mx \\ ISMAel MANUEl Rodríguez HeRRERA \\ imrodri@correo.uaa.mx \\ Diana ElizABETH HERNÁNDEZ-OCHOA \\ dianahernande37@hotmail.com \\ Universidad Autónoma de Aguascalientes, México
}

La situación económica global vuelve cada vez más difícil la tarea de mantener competitivas a las pequeñas y medianas empresas (Pymes). El objetivo de este artículo es determinar la relación entre el Tiempo y Entrega de la Información (TEl), el Acceso a la Información (Al), el Uso de la Información (UI) y el Intercambio de la Información (II), con respecto de la efectividad de la comunicación (EC). Se analizan 260 Pymes turísticas mediante un modelo de regresión. Los resultados indican que todas las variables son influyentes en la $E C$, se destaca que el II es la variable con mayor influencia, mientras que el TEl es la menos influyente. Se concluye sobre la importancia de la EC para el desempeño de dichas organizaciones.

Palabras clave: Pymes turísticas, comunicación organizacional, efectividad empresarial, México, competitividad.

\section{COMMUNICATION EFFECTIVENESS}

\section{IN SMALL AND MEDIUM-SIZED ENTERPRISES IN THE TOURISM SECTOR IN A HIGHLY COMPETITIVE ENVIRONMENT}

The global economic situation makes it increasingly difficult to keep small and medium-sized enterprises (SMEs) competitive. The objective of this article is to determine the relationship between Time and Delivery of Information (TDI), Access to Information (AI), Use of Information (UI) and Exchange of Information (EI), regarding their Communication Effectiveness (CE). 260 tourist SMEs are analyzed using a regression model. The results indicate that all the variables are influential to $\mathrm{CE}$, it stands out that $\mathrm{El}$ is the variable with the greatest influence on $C E$, while TDI is the least influential. It concludes on the importance of CE for the performance of these organizations.

Keywords: tourism SMEs, organizational communication, business effectiveness, Mexico, competitiveness. 


\section{Introducción}

E I interés por el estudio de la Efectividad de la Comunicación (EC) se ha incrementado desde hace muchos años en el ámbito organizacional; no obstante, en la actualidad es posible identificar que el desarrollo de investigaciones que involucran elementos de la EC en las empresas turísticas aún tiene terreno por explorar, debido a que todavía se analizan diversos aspectos dentro del proceso de la comunicación en contextos nuevos y con distintos grados de competencia.

Se ha establecido que no considerar la EC en las empresas puede causar problemas en el desempeño del individuo y de la organización, puesto que su falta podría provocar diversas limitantes que afecten el desempeño particular y de los grupos (Snyder y Morris, 1984). Para evitar esto, es importante conocer aquellos factores que mayor impacto tienen en la EC, con la finalidad de fomentar los comportamientos que permitan obtener mejores resultados durante los procesos comunicativos (Al-Tokhais, 2016).

Este enfoque permitió identificar en múltiples ocasiones que los tipos de comunicación (verbales y no verbales) son insuficientes para que el receptor pueda comprender lo que el emisor pretende notificar (Stiff et al., 1994). Lo que lleva a considerar la importancia de todas las partes que intervienen durante el proceso, para que el intercambio de la información se pueda dar de manera correcta. Factores como las emociones y actitudes (Lundqvist, 2008), al igual que aquellos referentes a la dirección en la que se dé el intercambio dentro de la estructura (Fisher et al., 1997), han demostrado ser algunos de los componentes responsables que afectan el resultado de la comunicación.

El estudio de la EC en las Pymes turísticas es una corriente de investigación relativamente nueva (en comparación con otras variables y sectores económicos), misma que se cree es producto de la transición global hacia una nueva economía, la cual reconoce el impacto de la comunicación organizacional, ya que esta pretende aportar significado a diversos elementos que subyacen en lo más profundo de los organismos (valores, misión, visión, cultura, entre otros) (Kahle, 2002); además, parece claro que las organizaciones buscan que su gestión pueda llevarse a cabo de forma sencilla y clara. Para ayudar con dicha tarea, la EC ha probado ser una gran aliada, al posibilitar que el intercambio de información se pueda dar fácil y efectivamente (Nordin et al., 2014). 
En los últimos años ha existido un crecimiento exponencial de las Pymes turísticas dentro del estado de Aguascalientes, México, mismo que es producto tanto del desarrollo del turismo de negocios como de la ampliación del sector manufacturero (considerado como la actividad económica principal de la entidad). Esto ha causado la incursión de empresas de mayor tamaño u operación en ese entorno, lo que propicia que las Pymes se vean en problemas en el desempeño de sus trabajadores y en la generalidad.

Sin embargo, existe una brecha en el desarrollo de recursos científicos que permiten que estas empresas puedan operar de una manera óptima (en términos de comunicación); inclusive se ha puesto en evidencia la importancia que tiene esta variable dentro de las Pymes del sector turístico, ya que por medio de ella pueden impulsar su verdadero potencial para tratar de aumentar su ejercicio en términos de competencia (Mbatha, 2012).

En este contexto, la presente investigación tiene por objetivo determinar la relación entre las variables independientes relacionadas con la información: Uso (UI), Tiempo y Entrega (TEI), Acceso (Al) y finalmente, el Intercambio (II), con respecto a la EC. Lo anterior bajo el fundamento propuesto por Yazici (2002), en el que se establece que dichas variables independientes son necesarias para estimular a la EC y de esta manera sentar las bases hacia la obtención de un mejor desempeño individual y organizacional. Para responder esto, se ejecuta un modelo de regresión lineal múltiple en el que se analiza la relación entre las variables referidas.

En la revisión de trabajos, se detectó una brecha en la relación teorética y empírica entre las variables, al igual que con el vínculo que guardan en el contexto de las Pymes del sector turístico dentro del estado de Aguascalientes. Para dar soporte a ello, en primera instancia se realiza un análisis de la literatura existente, con mayor relevancia en cada una de las variables establecidas, así como en la explicación del modelo y de los factores que lo integran. En segundo lugar, se desarrolla el diseño y propuesta de descripción del modelo de investigación. Finalmente, las últimas dos secciones constan del análisis de los resultados, una breve discusión sobre estos, así como las conclusiones. 


\section{Marco teórico}

A lo largo de las últimas décadas, diversos estudios han concentrado sus esfuerzos en la observación de los principales elementos de la comunicación y cómo esta se desarrolla dentro del sector empresarial (Snyder y Morris, 1984; Clampitt y Downs, 1993; Lievens y Moenaert, 2000; Adler y Marquardt, 2005; Mazzei, 2010; Robbins y Judge, 2013; Bucăţa y Rizescu, 2017), donde se ha puesto en evidencia que el grado de efectividad que tengan las organizaciones durante sus procesos de comunicación puede determinar su desempeño (Brownell, 1992). Con ello, es preciso reiterar que la EC es el producto del proceso de la comunicación entre individuos o grupos (Bhattacherjee, 1998; Lundqvist, 2008).

Dentro del presente apartado se detalla el concepto de la comunicación, así como la manera en la que adquirió importancia, tanto para la comunidad científica como para las organizaciones, con respecto de las estrategias y las herramientas que les permitan obtener un desempeño superior.

Por último, se atienden aspectos esenciales sobre los principales componentes de la EC, así como los múltiples beneficios que pueden derivarse de la optimización de sus factores, al involucrar distintos atributos que permitan:

a) Mejorar el intercambio de comunicación interfuncional (Abdullah y Antony, 2012).

b) Aumentar los sistemas, a fin de que la estructura organizacional tenga a su disposición información relevante y pertinente (AI) (Dennis, 1967).

c) Ampliar los mecanismos de control a los canales de comunicación y en el desarrollo de las interacciones interpersonales (UI) (Houman, 2001).

d) Emplear la forma de comunicación más adecuada al tipo de datos que se desea compartir (II) (Yazici, 2002).

Lo anterior, con la finalidad de obtener mejores resultados en términos de la EC.

\subsection{La comunicación efectiva y su relación con el desempeño de las organizaciones}

El interés por el estudio de la comunicación como una variable organizacional ha estado presente desde hace tiempo, prueba de ello se encuentra en la investigación de Scott y Mitchell (1976), en la cual se identifica que el control, la motivación, 
la expresión emocional y de información son inherentes a la comunicación y que por medio de estos es posible mejorar el desempeño tanto de individuos como de las empresas.

Lo anterior no fue ajeno al rubro de los servicios en general, donde no era considerado un elemento aislado, debido a que ya se abordaba la necesidad de observar diferentes fenómenos propios de dicho sector, al tener en cuenta que en esa época las investigaciones de carácter científico predominaban dentro del ramo industrial.

La noción de comunicación como variable tiene presencia en la mente de investigadores y administradores, gracias a la incursión en el ámbito organizacional de teorías como la de los recursos y capacidades, la cual se convirtió en una gran aliada para el referido concepto, como un elemento cuantificable. Esto permitió identificar el verdadero potencial que tiene la comunicación dentro de ciertos procesos de la operación de las organizaciones (Kuratko, 2009), aunque inicialmente el principal problema giró en torno a la unificación de su propio significado, mismo que ocasionaba ciertas precondiciones. La problemática fue abordada por Trelles (2001, p. 7), quien señala:

En tanto algunos conciben la comunicación desde el punto de vista de su papel únicamente trasmisor, con funciones concentradas en el mejoramiento de la elaboración de mensajes, y el perfeccionamiento de canales de transmisión, otros proponen aproximaciones más complejas, al ver la comunicación como parte orgánica de la organización.

Por su parte, Pérez-Rolo $(2012$, p. 1) indica que la comunicación organizacional "es la disciplina encargada de analizar, diagnosticar, planificar y evaluar la comunicación interna y externa para alcanzar los objetivos empresariales previstos". Mientras que Price $(1997$, p. 349) señala que esta es "el proceso mediante el cual fluye la información acerca del trabajo y de las tareas que desempeña el trabajador dentro de la empresa."

Esas orientaciones establecen a la comunicación como un elemento que puede ser utilizado de diversas maneras: en primer lugar, aplicarse con la finalidad de controlar el comportamiento del recurso humano, mediante la comunicación formal e informal dentro del área de trabajo. También, puede emplearse con la intención de proporcionar diversos planteamientos necesarios durante la toma de decisiones. Así, la comunicación se encuentra presente en cualquier proceso, por ello es imposible concebir que una empresa opere de forma eficiente sin ella, de manera efecti- 
va, en virtud de que esta subyace en la interacción de la estructura organizacional. Ante esto, Segredo Pérez et al. (2017, p. 30) afirman:

A los dirigentes, las organizaciones y su entorno, sin un flujo continuo de información novedosa y de inteligencia, les es imposible tomar decisiones seguras, mantener el curso de una acción o variarlo, progresar con seguridad y mantener la continuidad necesaria para triunfar, para responder a los cambios del medio y los competidores.

Por ello es fundamental que la comunicación sea oportuna y efectiva, para lograrlo es indispensable que exista un propósito (compartir datos), puesto que es fundamental la necesidad por comunicar algo. No contar con dicho objetivo desencadena la posibilidad de caer en confusiones o malinterpretaciones dentro del proceso comunicativo (Adler y Marquardt, 2005; Robbins y Judge, 2013) (ver figura 1).

Figura 1. Modelo del proceso de comunicación

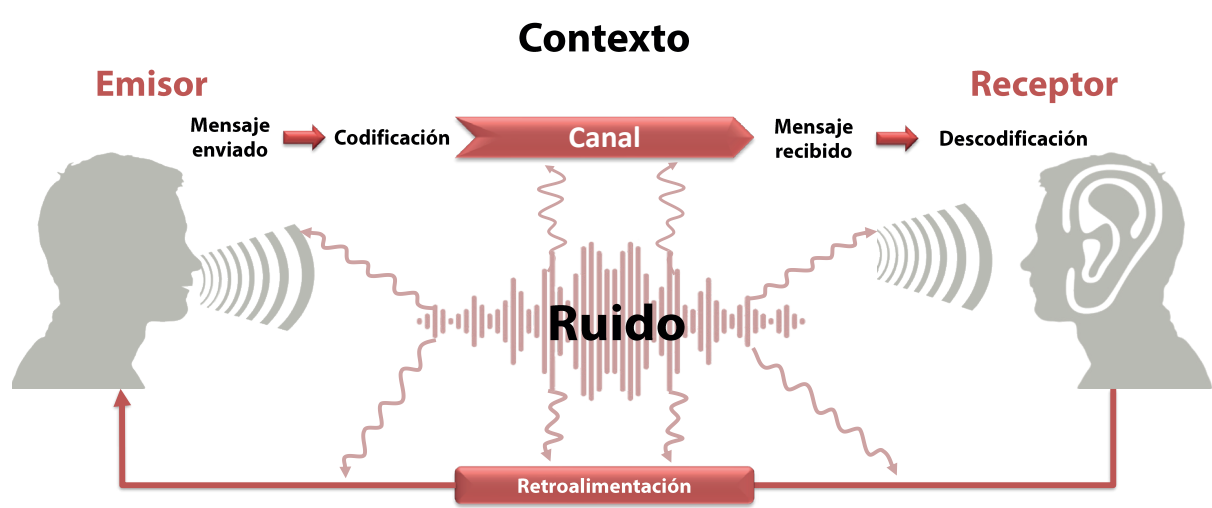

Fuente: Elaboración propia con base en las obras de Adler y Marquardt (2005) y Robbins y Judge (2013).

En dicho modelo, Robbins y Judge (2013) señalan que dentro del proceso se presenta un emisor, quien es el que emite una señal denominada mensaje, el cual se construye bajo una codificación y que es transmitido mediante un canal, por donde el mensaje transita hasta llegar al receptor, encargado de descodificar el mensaje y, una vez comprendido, debe retroalimentar al emisor; solo de esta manera se puede completar de forma correcta el proceso de comunicación. Adler y Marquardt (2005) agregan que es importante considerar la existencia del ruido como una de las principales barreras, puesto que puede entorpecer la comprensión del mensaje.

En el caso de las empresas turísticas, la observación del proceso de comunicación ha estado presente desde hace varios años y se entiende como un componente 
fundamental dentro de la gestión y la conexión, ya que brinda mejores resultados si se realiza un adecuado manejo/intercambio de información, se consideran actitudes y comportamientos, a la par que se unifican significados y mejoran las relaciones sociales (Yildiz, 2015).

Ese enfoque permite que las organizaciones concentren sus esfuerzos por mejorar los canales comunicativos, puesto que son esenciales para transmitir la información (Gee, 1994); incluso, se ha evidenciado que por medio del aumento en la efectividad que tiene la comunicación organizacional es posible que la empresa genere valor. Por lo tanto, este elemento debe ser considerado para que las Pymes del sector turístico puedan obtener ventajas con respecto de su competencia (Verčič et al., 2012).

\subsection{La comunicación efectiva en el ámbito organizacional}

Para comprender la EC basta entender de dónde proviene. Se identifica que es producto de la interacción cotidiana entre individuos o grupos, misma que comúnmente se atribuye a la operación diaria de la organización (Lundqvist, 2008). Inclusive, existen otras aproximaciones a la conceptualización de la EC en las que se le atribuyen diversas aptitudes: "la EC refiere al intercambio formal e informal de información significativa y oportuna" (Sharma y Patterson, 1999, p. 158), esto se traduce en que la información contenida en el mensaje debe presentarse cuando se le solicite.

Otra aproximación sugiere que la EC se puede identificar como una actividad, es decir, "el acto humano de transferir un mensaje a otros y hacer que se entienda de manera significativa" (Houman, 2001, p. 168), aquí se enfatiza la importancia de que el receptor pueda entender el mensaje codificado.

Aunado a ello, otras corrientes de investigación atribuyen características propias de un producto a la EC:"[...] combinación de qué tan bien se entrega, accede, comparte y utiliza la información" (Yazici, 2002, p. 542), así como "la EC representa el logro de un resultado previsto de comunicación" (Park et al., 2014, p. 322). Sin lugar a duda, tiempo atrás ya se tenía claro que estos elementos propios de la EC podrían actuar entre sí por medio de una acción, misma que era preconcebida como "el acto humano de transferir un mensaje a otros y hacer que se entienda de manera significativa" (Patterson, 2016, p. 168). 
En el ámbito de las empresas dedicadas al servicio, en especial aquellas con actividades relacionadas al turismo, ha sido posible establecer vínculos entre diversos elementos inherentes a la comunicación y su efectividad dentro de las organizaciones. Esto se encuentra soportado por múltiples investigaciones con diversas aproximaciones y diferentes métodos de recopilación. Trabajos como el de Sharma y Patterson (1999) establecen que la EC incide en la calidad, así como en el compromiso y la confianza de los miembros de la empresa. Por su parte, Lievens y Moenaert (2000) encuentran que la comunicación entre individuos/grupos impacta ciertos puntos relacionados con el proceso de innovación.

Lo anterior permite identificar los beneficios que pueden obtener las empresas turísticas de la relación entre múltiples atributos de la EC, en sus distintos contextos y tamaños de operación. Esto es posible puesto que dichas variables propiamente anteceden a diversos componentes generadores de ventajas competitivas (Tucker et al., 1996; Wang y Huang, 2020), al igual que aquellos relacionados con la creación de valor (Stenroos y Jaakkola, 2010) y con la productividad (Clampitt y Downs, 1993), al entender que la EC es una forma de comunicación en la que el receptor es capaz de comprender el mensaje que envía el emisor, indistintamente de la forma o el canal que use para enviarlo.

\subsection{Factores que integran a la comunicación efectiva}

Antes de abordar los factores de la EC es menester indicar que deben existir ciertas precondiciones, dirigidas a aumentar las posibilidades de obtener resultados favorables del proceso de comunicación, acorde con Nosnik (1996; 1998). El autor recalca que la comunicación debe ser: a) abierta, puesto que el objetivo es llegar al exterior, b) evolutiva, porque pone énfasis al interior de la empresa, c) flexible, ya que habilita una relación formal e informal oportuna, d) multidireccional, pues fluye en distintas trayectorias; y finalmente, e) instrumentada, debido a que hace uso de distintas herramientas para transitar por la estructura organizacional. Al cumplirse esas condicionantes las posibilidades de aumentar la EC serán mayores.

Aunado a ello, otras investigaciones han identificado varios componentes que integran a la EC, en particular, la exploración realizada por Sharma y Patterson (1999), quienes proponen que la EC está compuesta por factores como: el intercambio de información, su flujo y disponibilidad, la frecuencia y la naturaleza de los datos, además de su claridad. Mientras que en la investigación de Park et al. (2014) se integra- 
ba a la EC por características de la comunicación como: la frecuencia, la bidireccionalidad y la calidad.

Por su parte, Massey y Kyriazis (2007) analizaron a la EC en el ámbito de las empresas del sector servicios y encontraron que estaba conformada por: a) la frecuencia de la comunicación, referida al número de eventos de comunicación por unidad de tiempo, b) la comunicación bidireccional, representada por el grado en que el proceso de comunicación de dos vías ocurre entre los departamentos; y, finalmente, por c) la calidad, como la medida en que se proporciona información apropiada y útil. Los autores concluyen que es posible obtener buenos resultados en términos de la EC, siempre y cuando se tenga una alta fiabilidad en el medio y en lo que se intercambie.

En ese mismo sector, pero en diferente contexto, Patterson (2016) indica que es posible desarrollar la EC por medio de los estilos de comunicación, los comportamientos presentes en la interacción entre individuos/grupos, los canales de distribución de información, además de su intercambio/flujo y calidad. De igual manera, Kwofie et al. (2017) precisan que la EC puede ser influenciada por factores como: la exactitud, la oportunidad, la baja y la sobrecarga de información, la comprensión, las barreras, la distorsión, el mantenimiento de los canales de distribución, y, finalmente, los procedimientos de diseminación.

Ante ello, Yazici (2002) propone que una EC positiva debe considerar aspectos dentro del mensaje, así como aquellos otros factores presentes en todo el proceso de comunicación. El autor plantea que la EC puede ser alcanzada por medio del tiempo y entrega de la información, de su acceso, uso e intercambio, puesto que estos puntos consideran particularidades tanto del mensaje como del emisor y receptor, a la par de la codificación y la retroalimentación.

Esto puede completarse por diversos medios y con el uso de distintas herramientas. Las actitudes y comportamientos pueden afectar el resultado de dicho proceso, tanto en niveles de mayor envergadura (entiéndase el ambiente o los grupos), como los de menor magnitud (los individuos). Por esto es importante hacer énfasis específicamente en aquellos componentes que integran este concepto, ya que permitiría identificar con claridad cuáles elementos tienen relevancia para la EC en una organización. 


\subsubsection{El Tiempo y la Entrega de la Información (TEI) y su relación con la EC}

Conforme al momento en el que se encuentra una organización dentro de su ciclo de vida, comúnmente tiende a generar diversos procesos de comunicación, con la finalidad de poder interconectar la estructura organizacional y que esta sea consciente de lo que acontece en la operación diaria de la empresa.

Este aspecto ha propiciado que diversas investigaciones establezcan relación entre el TEl y la eficiencia dentro del proceso comunicativo. Ciertas líneas de investigación señalan que la manera en la que la información pueda ser diseminada hacia aquella parte de la estructura que la necesite de forma oportuna y de buena calidad, permitirá obtener una ventaja competitiva mediante el incremento en el desempeño y la efectividad de sus miembros, así como de la organización en el corto plazo (Adeosun et al., 2008).

Adicionalmente, se observa que la relación entre variables va de la mano con el uso de las tecnologías de la información y de la comunicación. Inclusive, se ha demostrado que en correspondencia con la efectividad en el desarrollo y la implementación de sistemas y estrategias, es posible obtener un desempeño grupal y organizacional superior (Azhar et al., 2015). Aunado a ello, se establece que las prácticas que fomentan comportamientos relacionados con el intercambio de datos, de manera adecuada y oportuna, tienden a obtener mejores resultados en términos de sus prácticas de comunicación intra e interfuncional dentro de la estructura (Abdullah y Antony, 2012).

Uno de los principales factores en el desarrollo de la EC es la entrega de la información, misma que permite la apertura de nuevos sistemas (canales de comunicación), cuyo enfoque comúnmente se centra en el desarrollo tecnológico, ya que estos contribuyen a la creación de conciencia y facilitan la interacción, con un mayor nivel de efectividad dentro del ámbito organizacional (Mbatha, 2012).

Además, el autor encuentra que por medio de dichos sistemas es posible aumentar la conciencia de los miembros del organismo, con respecto a objetivos organizacionales específicos, al igual que la alta participación de estos en cuanto a lo compartido. De la misma manera, identifica que existe un aumento en el desarrollo de las relaciones interpersonales, producto de la implementación de los sistemas.

Es necesario realizar un proceso de entrega de información adecuado, ya que la efectividad en el desempeño de una empresa puede estar relacionada con la ma- 
nera en la que esta es compartida y utilizada (Vimarlund et al., 2008), lo que supone una de las principales barreras para el desarrollo de relaciones entre los individuos. Por tanto, la primera hipótesis de investigación se plantea de la siguiente manera:

H1: existe relación positiva significativa entre el TEl y la EC en las empresas del sector turístico del estado de Aguascalientes.

\subsubsection{El Acceso a la Información (Al) y su relación con la EC}

Se ha demostrado que uno de los elementos esenciales para los procesos operativos es la manera en la que interactúa la estructura, puesto que de ello se obtienen diversos resultados (positivos o negativos), en términos de información que concierne a otras variables. Esta suposición permite comprender que las empresas hacen uso de los canales de comunicación, a fin de mantener significados compartidos (Adams et al., 2005).

Esto ya era conocido desde finales de la década de los 60 , cuando se identificaba que el Al era un elemento que permitía un buen desempeño por parte de la estructura (Dennis, 1967). Dennis incluso registró la necesidad de aprovechar los sistemas multiacceso ya que hacen posible que toda la empresa obtenga informes relevantes y pertinentes al alcance, cuando los necesite. También se ha demostrado que limitar el Al puede ser negativo en términos de la cohesión y la colaboración, en especial si un elemento de jerarquía alta es quien lo hace (Dourish y Bellotti, 1992; Mantei, 1988).

En la investigación de Dourish y Bellotti (1992) se recalca la importancia del Al, pues permite que los miembros de la estructura ganen conciencia (unifiquen significados) y de esta manera se beneficie el desempeño del proceso de la toma de decisiones. En el trabajo de Mantei (1988) se aconseja el uso de nodos (redes de comunicación grupales) que habilitan una codificación específica para cada nivel jerárquico, lo cual abre un uso personalizado e independiente en cada grupo.

Sin embargo, se advierte sobre la importancia de la igualdad en el Al, ya que es posible obtener múltiples beneficios en términos del desempeño de las personas y grupos, permitiendo así el desarrollo de ventajas a nivel organizacional (Austin et al., 1990). 
De igual manera se ha demostrado que el Al puede darse por medio del intercambio de información, de forma implícita y conexa a los tipos y canales de comunicación, donde los primeros pueden ejercer cierta influencia sobre los efectos que derivan de dicho intercambio (Gkorezis et al., 2015). En caso de no existir significados compartidos se cae en la posibilidad de que cada grupo organice sus acciones comunicativas de manera inconexa, sin coordinación entre sí, ni orientación central, lo que se revierte en incoherencias y hasta contradicciones en el discurso, al igual que con la duplicación de esfuerzos y gastos innecesarios de recursos (Arciniega, 2011).

En cuanto a las empresas de servicios turísticos, se ha destacado la importancia que tiene el Al, como en la investigación de Heymann (1992), en la que se reconoce la calidad del desarrollo de los equipos de trabajo, como un medio para la adecuada actuación de una organización. Este autor recalca la necesidad de unificar significados, así como la creación de sistemas compartidos, que admitan que todos los miembros de la empresa tengan a su disposición los datos de manera pertinente y relevante, con la finalidad de reducir los conflictos de eficacia y calidad en los procesos operativos. Es por ello, que la segunda hipótesis de investigación se plantea de la siguiente manera:

H2: existe relación positiva significativa entre el Al y la EC en las empresas del sector turístico del estado de Aguascalientes.

\subsubsection{EI Uso de la Información (UI) y su relación con la EC}

Una de las primeras aproximaciones sobre el UI, en el contexto de las Pymes, fue la desarrollada por Johannessen et al. (1999); en ella se establece la importancia del Ul y el uso de las tecnologías de la información. En dicho estudio longitudinal, se señala que el UI tiene un impacto positivo y significativo en diversas variables, al hacer hincapié en la efectividad, en diversos términos de la calidad, el desempeño, en características generadoras de ventajas competitivas (aspectos económicos), así como el incremento en diferentes tipos de comunicación y el acceso a la información que adquieren los empleados.

Por lo anterior, se establece que unidades como la calidad y la cantidad de la información que es transmitida, determinan en buena parte el éxito en el UI (Mohr y Spekman, 1994). Así, es importante cuidar el progreso de los medios de comunicación, puesto que juegan un rol preciso en el desarrollo de las interacciones interpersonales y determinan el éxito del Al y del UI (Houman, 2001). 
En específico, tanto los medios directos (verbales) como aquellos menos directos (escritos) y de ciertos canales de comunicación pueden ofrecer distinto grado de riqueza (según la ocasión), puesto que algunos ofrecen mayor capacidad para usar información diferente de manera simultánea, mientras que otros brindan mayor grado de retroalimentación y son más personales (Robbins y Judge, 2013).

Sin lugar a duda, los beneficios de un adecuado UI se han evidenciado dentro del contexto organizacional, donde se le asocia con un aumento en el ejercicio y la efectividad de ciertas metodologías de gestión (Khan et al., 2011), al igual que con el éxito en el desarrollo de nuevos productos (Pentina y Strutton, 2007) y un mejor resultado en la planificación para el desarrollo sostenible (Taghavi et al., 2014).

De tal manera, es indispensable cuidar los aspectos internos ligados al receptor, al igual que las habilidades interpersonales e interfuncionales, además de factores externos referidos al contexto, puesto que son estos los elementos que intervienen dentro del UI y su diseminación. Lo anterior cobra especial atención porque en ambos se pueden encontrar puntos de frecuencia y formalidad (Nordin et al., 2014).

Incluso dentro de las empresas del sector turístico se ha logrado establecer la importancia del UI como una variable capaz de mejorar la EC, ya que este tipo de organismos tiende a desarrollar una fuerte correlación con el ajuste de la tecnología en las tareas (Ratna et al., 2020). Autores demuestran que aquellos miembros cuyo desempeño es superior a los demás y tienden a hacer un mayor UI. Por lo anterior, la tercera hipótesis de investigación se plantea de la siguiente forma:

H3: existe relación positiva significativa entre el UI y la EC en las empresas del sector turístico del estado de Aguascalientes.

\subsubsection{El Intercambio de la Información (II) y su relación con la EC}

Si se considera que el Il es producto de la interacción entre individuos o grupos, es menester señalar que es indispensable cuidar la calidad, tanto de la información como del proceso de intercambio, ya que son factores determinantes del éxito en las relaciones interpersonales. Por ello, es importante establecer y unificar las normas de la empresa, porque regulan el curso de la interacción y el comportamiento de los agentes preponderantes (Mohr y Spekman, 1994). 
De manera general, el Il puede darse a través de distintos tipos de interacción entre individuos o grupos. El intercambio de tipo formal se caracteriza por estar sujeto a un conjunto de normas preestablecidas por la jerarquía, mismas que conllevan ciertas actitudes y comportamientos, mientras que el de tipo no formal suele darse en ambientes con un nivel alto de control, y normalmente ocurre entre miembros de la misma jerarquía (Baron et al., 1992).

Otro elemento importante para considerar dentro del proceso del II, es el medio de transmisión, debido a que también impacta en las percepciones individuales. Una de las condicionantes para que la comunicación sea considerada efectiva es que se realice por contacto directo, de otra manera se corre el riesgo de ocasionar problemas hacia el II (King y Xia, 1997; Yazici, 2002).

Tal como se ha podido constatar, es común que el proceso del II se facilite por medios verbales (Chandon et al., 1997); sin embargo, también se ha identificado que un buen porcentaje de la interacción entre individuos es dado por medios no verbales (Gkorezis et al., 2015). El primer caso involucra al lenguaje en sus múltiples modalidades, mientras que el segundo integra todo tipo de comunicación que no haga uso del lenguaje, generalmente con señas, expresiones, ademanes, entre otros (Burgoon et al., 1990).

Es posible reconocer que la EC es un elemento fundamental dentro de las organizaciones dedicadas a cualquier actividad económica referente al servicio, más aún cuando la efectividad se encuentra íntimamente relacionada con los procesos de interacción que tiene la estructura, en especial con los clientes/consumidores, tomando en cuenta que la finalidad de las organizaciones es la de brindar la mejor experiencia de servicio (Jung y Yoon, 2011).

Finalmente, es claro que al incrementarse la frecuencia de la comunicación dentro de la empresa, la participación en el intercambio de ideas será mayor entre los departamentos. Lo anterior detona la eficiencia, debido a que así se unifican significados y se admite un mejor UI que se comparte, aumentando las posibilidades de obtener un desempeño superior en la EC (Vimarlund et al., 2008). Con ello, se llega a la cuarta hipótesis de investigación:

H4: existe relación positiva significativa entre el II y la EC en las empresas del sector turístico del estado de Aguascalientes. 


\section{Metodología}

El análisis estadístico desarrollado en el presente artículo involucra diversas condiciones organizacionales, además de la manera en que estas interactúan en las Pymes del sector turístico de Aguascalientes. La investigación es de tipo descriptivo-correlacional, puesto que aborda únicamente el análisis sobre la situación referente a la relación causal entre los factores $\mathrm{TEl}, \mathrm{Al}$, $\mathrm{UI}$ e II y la EC, en el contexto establecido.

La muestra se obtuvo mediante la técnica de muestreo aleatorio simple, con la fórmula del cálculo de poblaciones finitas, para obtener el 95\% de confiabilidad y con un error admitido de $\pm 5 \%$, la cual se aplicó al universo $(N=574)$ de las Pymes turísticas en Aguascalientes, que preferentemente estuvieran adscritas al Registro Nacional del Turismo y cuya actividad económica tuviera alguna relación con el sector turístico dentro del contexto determinado.

Se analizó así un total de 260 Pymes turísticas, de las cuales 81 son hoteles, 75 son agencias de viaje, 84 son empresas dedicadas a la preparación de alimentos y bebidas; además de 20 organismos que realizan otras actividades relacionadas con el turismo.

La información correspondiente se obtuvo mediante la aplicación de un instrumento confiable y validado, que proviene de la línea de investigación propuesta por Yazici (2002). Dicho instrumento establece que la EC es un elemento organizacional, que puede ser medido a través de cuatro factores y un total de siete ítems, con el objeto de indagar sobre su percepción con respecto de las variables determinadas. La encuesta contiene un rango de respuestas en escala Likert a 5 puntos (desde $1=$ Totalmente en desacuerdo, hasta $5=$ Totalmente de acuerdo).

El modelo de investigación se compone de los siguientes factores: 1) el TEl está compuesto por dos ítems, los cuales se encuentran relacionados con el flujo de la información, sus enunciados versan sobre si se recibe y si llega a tiempo. El 2) Al, se refiere a la disponibilidad y a la calidad de los datos y sus enunciados tratan sobre si estos mantienen su significado a través de la estructura y si el acceso a ellos es sencillo. Con respecto al 3) UI, se integran ítems que abordan si la información se presenta de manera esperada, así como si la que se recibe es precisa y pertinente. Finalmente, el último corresponde al 4) II, representado por un ítem, mismo que alude a si se tiene conciencia sobre lo que se comparte. 
Cabe destacar que previo al análisis de la información, se revisó la consistencia interna de las variables mediante el alfa de Cronbach, con un valor combinado de 0.93. Se resalta que dicho alcance es superior en comparación con el obtenido por Yazici (2002), que llegó a un valor del igual a 0.74, matizando la buena consistencia interna de los ítems. Una vez que se tuvo el fundamento correspondiente, se contó con una base de datos con los parámetros necesarios para realizar un análisis estadístico comprensivo

Dicha base fue integrada al software SPSS v.23, para su posterior revisión y el futuro contraste de las hipótesis de investigación. El estudio realizado comprende los lineamientos de una regresión lineal múltiple (Hair et al., 2010; Malhotra, 2008), y hace uso del método denominado por pasos (también conocido como paso a paso, o pasos sucesivos). Esta técnica pretende revelar qué porcentaje de la EC es explicada por TEl, Al, Ul y II.

Se resalta el desarrollo del presente trabajo de investigación, puesto que una amplia cantidad de literatura se enfoca únicamente en algunos de los factores delimitados, así como su interacción con respecto de alguna variable en específico. Esta escasez plantea una problemática sobre los apoyos empíricos que puedan soportar las relaciones encontradas (Dennis, 1967; Johannessen et al., 1999; Adeosun et al., 2008; Jung y Yoon, 2011). Este artículo aborda esa brecha mediante el planteamiento de diversas hipótesis, con el propósito de establecer la incidencia de las variables determinadas en el mencionado contexto.

\subsection{Modelo de regresión múltiple}

El modelo de regresión planteado permite dar respuesta a las hipótesis de investigación, así como conocer la relación y el grado de influencia que ejercen las variables TEl, Al, Ul e II con respecto de la EC, en las Pymes del sector turístico del estado de Aguascalientes. Una vez que el modelo sea planteado, se espera un aumento de la variable dependiente con respecto de las independientes, mismas que deberán tener valores positivos y significativos.

Los factores utilizados para estimar el modelo de regresión se integran por las siguientes variables ( $v$ ); el primer factor (TEI), se entiende como el periodo que tarda en trasladarse la información del emisor al receptor, así como la tasa de entrega que efectivamente alcanza su destinatario original. 
El segundo factor (Al), es la dimensión que está integrada por las variables de filtración jerárquica y acceso a la información. La primera representa aquellos tamices por los que pasan los datos conforme recorren la estructura organizacional, acción que realiza el personal en una posición de poder jerárquico, con la finalidad de limitar lo que se comparte dentro de la estructura (comúnmente cuando se da en orden descendente). La segunda variable representa la facilidad con la que se encuentra disponible para quien la necesite, comúnmente identificada en el caso en que un miembro de la empresa requiere algún tipo (particular o no) a fin de desarrollar alguna tarea/trabajo.

El tercer componente (UI), se refiere a las variables formato de representación y cantidad/calidad de la información. La primera de ellas representa el medio por el cual la información será enviada al receptor, comprendida en la tipología de la comunicación formal e informal; la segunda variable asienta las cualidades de intercambio, como el grado de fiabilidad, si está completa o no, entre otras. Finalmente, el cuarto factor (II), variable que se entiende como la disposición para transmitir la información del punto $a$ al $b$, enlazada con las actitudes por parte de los individuos y la inclinación de estos para compartirla.

Con lo anterior, la ecuación de regresión se representa de la siguiente manera:

$$
\gamma_{e}=\beta_{0}+\beta_{1} x_{11}+\beta_{2} x_{21}+\beta_{3} x_{31}+\beta_{4} x_{41}+e_{1}
$$

Donde los indicadores representados para $\beta$ evalúan la intensidad de las medias sobre los efectos de las variables TEI, Al, Ul y II, en torno a la variable a explicar (EC), producto de los valores parciales derivados y con respecto de cada variable explicativa. Mientras que $\gamma_{\text {e }}$ representa al valor estimado de predicción de la EC en las Pymes del contexto determinado. El valor $\beta_{0}$ simboliza aquellos elementos desconocidos, mientras que los valores para $\mathrm{X}_{11} \cdots \mathrm{X}_{41}$ son estimaciones para las variables independientes (TEI, Al, Ul y II) sobre la EC. Por último, los valores e, son los términos de residuos o errores, que representan una variable aleatoria cuya distribución normal tiende a tener una media igual a cero y una varianza constante.

\section{Resultados del modelo de regresión}

Como se mencionó previamente, a fin de realizar el análisis se utilizó el paquete estadístico SPSS v.23. Así, de acuerdo con los resultados obtenidos del modelo de 
regresión', se establece que: 1) el primer modelo considera únicamente a la variable UI. 2) El segundo modelo agrega la variable Al; con ello, el modelo contempla ambas variables UI, AI. 3) El tercer modelo integra la variable II, con las variables UI, Al. Finalmente, 4) el cuarto modelo añade la variable TEl, de modo que se incluyen las cuatro variables. Esto sienta las bases para presentar la comparación de los datos estadísticos de la regresión (ver tabla 1).

Tabla 1. Comparación de los datos estadísticos de regresión para cada modelo

\begin{tabular}{|c|c|c|c|c|}
\hline Indicadores & Modelo & Modelo & Modelo & Modelo \\
$\mathbf{1}^{\mathbf{a}}$ & $\mathbf{2}^{\mathbf{b}}$ & $\mathbf{3}^{\mathbf{c}}$ & $\mathbf{4}$ \\
\hline Coeficiente de correlación múltiple & 0.922 & 0.965 & 0.986 & 1.000 \\
\hline Coeficiente de determinación $\mathrm{R}^{2}$ & 0.850 & 0.932 & 0.972 & 1.000 \\
\hline $\mathrm{R}^{2}$ ajustado & 0.849 & 0.931 & 0.972 & 1.000 \\
\hline Error típico & 0.33218 & 0.22390 & 0.14286 & 0.00000 \\
\hline Número de observaciones & 260 & 260 & 260 & 260 \\
\hline
\end{tabular}

Nota: Valores correspondientes a los modelos de regresión:

a) $\operatorname{Var}=U \mathrm{Ul}$; b) Var=Ul y Al; c) $\mathrm{Var}=\mathrm{UI}$, Al e Il; d) Var= UI, Al, II y El. Con respecto de la EC.

Fuente: Elaboración propia.

Se muestran los valores obtenidos para cada uno de los modelos regresión; el ajuste del modelo final es perfecto, lo que indica que todas las variables en conjunto representan a la EC de manera cabal. Sin embargo, trasciende que el modelo 1 , representado únicamente por el $\mathrm{UI}$ destaque con un valor de $\mathrm{R}^{2}$ ajustado igual al 84.9\% (tabla 1), lo que se traduce en que únicamente esa variable representa en tal proporción a la EC. Dichos valores, de acuerdo con Cohen et al. (2003), se consideran efectos de gran tamaño. Esto demuestra que existe una derivación efectiva de regresión altamente significativa entre las variables UI, Al, II, TEl y la EC. Ello tiene especial importancia al observar el análisis de la varianza de cada uno de los modelos de regresión (ver tabla 2).

\footnotetext{
1 Cabe destacar que el ajuste del último modelo de regresión es perfecto (el cual se integra por todas las variables independientes); por tal motivo, y con fundamento en los criterios de probabilidad para la muestra de $F$, cuyos parámetros oscilan en el rango que va de 0.05 hasta 0.10 , para cada una de las variables. Para tener mayor referencia de los resultados, se desglosan los valores obtenidos para todos los modelos arrojados dentro del método de regresión paso a paso.
} 
Tabla 2. Análisis de la varianza para cada modelo de regresión

\begin{tabular}{|c|c|c|c|c|c|}
\hline Valores & $\begin{array}{l}\text { Suma de } \\
\text { cuadrados }\end{array}$ & GI & Media cuadrática & $\mathbf{F}$ & Sig. \\
\hline $\begin{array}{l}\text { Modelo } 1 \text { a } \\
\text { Regresión } \\
\text { Residuo } \\
\text { Total }\end{array}$ & $\begin{array}{r}161.041 \\
28.468 \\
189.509 \\
\end{array}$ & $\begin{array}{c}1 \\
258 \\
259\end{array}$ & $\begin{array}{r}161.041 \\
.110\end{array}$ & 1459.487 & .000 \\
\hline $\begin{array}{l}\text { Modelo } 2^{\text {b }} \\
\text { Regresión } \\
\text { Residuo } \\
\text { Total }\end{array}$ & $\begin{array}{r}176.626 \\
12.883 \\
189.509\end{array}$ & $\begin{array}{c}2 \\
257 \\
259\end{array}$ & $\begin{array}{r}88.313 \\
.050\end{array}$ & 1761.700 & .000 \\
\hline $\begin{array}{l}\text { Modelo } 3^{c} \\
\text { Regresión } \\
\text { Residuo } \\
\text { Total }\end{array}$ & $\begin{array}{r}184.285 \\
5.224 \\
189.509\end{array}$ & $\begin{array}{c}3 \\
256 \\
259\end{array}$ & $\begin{array}{r}61.428 \\
.020\end{array}$ & 3010.057 & .000 \\
\hline $\begin{array}{l}\text { Modelo } 4^{\mathrm{d}} \\
\text { Regresión } \\
\text { Residuo } \\
\text { Total }\end{array}$ & $\begin{array}{r}189.509 \\
.000 \\
189.509\end{array}$ & $\begin{array}{c}4 \\
255 \\
259\end{array}$ & $\begin{array}{r}47.377 \\
.000\end{array}$ & $\cdot$ & $\cdot$ \\
\hline
\end{tabular}

Nota:Valores correspondientes a los modelos de regresión:

a) $\mathrm{Var}=\mathrm{Ul}$; b) $\mathrm{Var}=\mathrm{Ul}$ y Al; c) $\mathrm{Var}=\mathrm{UI}$, Al e Il; d) $\mathrm{Var}=\mathrm{UI}$, Al, II y El. Con respecto de la EC.

Fuente: Elaboración propia.

Se identifica que todos los modelos de regresión obtenidos mediante la prueba tienen un valor positivo, correspondiente al apartado $F$, observando que para todas las variables independientes (UI, Al, II y TEI) existe una influencia en la EC. Esto significa que todos los factores poseen el mismo comportamiento que la variable dependiente. Además, los valores contenidos en la columna Sig., correspondientes a los diversos modelos, coinciden en tener un valor positivo significativo $(p<0.005)$.

Al observar los valores contenidos en la tabla 1, es posible establecer que el modelo que mejor ajusta es el 4; por tanto, solo se plantea la ecuación de regresión en función de dichos valores. Con ello en mente, se indica que el modelo de regresión propuesto permite predecir que, si se parte del origen ubicado en $-6.661 \mathrm{E}-16$, por cada incremento en las variables UI (0.275), Al (0.274), II (0.302) y TEI (0.267) respectivamente, se incide en la EC en esa misma proporción. Considerando lo anterior, así como los resultados obtenidos de la aplicación del modelo, la ecuación de la regresión se presenta de la siguiente manera:

$$
Y_{e}=-6.661 E-16+(0.275) U I+(0.274) A I+(0.302) I I+(0.267) \mathrm{TEI}+\text { ei }
$$


Los coeficientes estandarizados de $ß$ para las variables independientes (ver tabla 3), muestran de manera general que las variables $\mathrm{UI}, \mathrm{Al}$, TEl e II tienen grados de influencia similar (con respecto de la influencia ejercida sobre la EC). Sin embargo, el factor II (4) mantiene una mayor fuerza (al considerar únicamente los valores obtenidos en el modelo final) para el coeficiente $(\beta)$ con un valor de $\beta=0.302$, mientras que los factores UI (3) y AI (2) cuentan con una influencia similar $\beta=0.275$ y $\beta=0.274$ respectivamente. Por último, el factor TEI (1) es el elemento con menor influencia en $\beta=0.267$. Se destaca que los cuatro componentes no difieren sustancialmente.

Esto resulta interesante, pues se deduce que una Pyme turística del estado de Aguascalientes cuya estrategia de gestión se enfoca en aumentar su EC, lo puede conseguir por medio del uso de prácticas que fomenten el desarrollo de cualquiera de las variables independientes (TEl, Al, UI e II). No obstante, obtendrá un mejor resultado si se enfoca en el desarrollo de prácticas de inyección de capital, uso de herramientas y metodologías, entre otras, que fomenten el II como principal elemento. Igualmente, podría lograr resultados positivos si se enfoca en el Ul y el Al, dejando al final aquellas prácticas relacionadas con el TEl, por ser la que menor beneficio representa para la EC. Por ello, se aconseja incluir las cuatro variables en las estrategias.

Tabla 3. Coeficientes del modelo de regresión

\begin{tabular}{|c|c|c|c|c|c|c|c|c|c|c|c|c|}
\hline \multirow{2}{*}{$\begin{array}{c}\text { Modelo } \\
4^{*}\end{array}$} & \multicolumn{2}{|c|}{$\begin{array}{l}\text { Coeficientes no } \\
\text { estandarizados }\end{array}$} & \multirow{2}{*}{$\begin{array}{c}\text { Coeficientes } \\
\text { estandarizados } \\
\text { Beta }\end{array}$} & \multirow[b]{2}{*}{$\mathbf{t}$} & \multirow[b]{2}{*}{ Sig. } & \multicolumn{2}{|c|}{$\begin{array}{c}\text { Intervalo de } \\
\text { confianza para } \\
\text { B // } 95.0 \%\end{array}$} & \multicolumn{3}{|c|}{ Correlaciones } & \multicolumn{2}{|c|}{$\begin{array}{l}\text { Estadísticos de } \\
\text { colinealidad }\end{array}$} \\
\hline & B & $\begin{array}{l}\text { Error } \\
\text { estándar }\end{array}$ & & & & $\begin{array}{l}\text { Límite } \\
\text { inferior }\end{array}$ & $\begin{array}{l}\text { Límite } \\
\text { superior }\end{array}$ & $\begin{array}{l}\text { Orden } \\
\text { cero }\end{array}$ & Parcial & Parte & Tolerancia & VIF \\
\hline Constante & $-6.661 \mathrm{E}-16$ & .000 & & 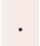 & . & .000 & .000 & & & & & \\
\hline UI & .250 & .000 & .275 & . & . & .250 & .250 & .922 & 1.000 & .141 & .262 & 3.822 \\
\hline Al & .250 & .000 & .274 & . & . & .250 & .250 & .913 & 1.000 & .145 & .281 & 3.559 \\
\hline ॥ & .250 & .000 & .302 & . & . & .250 & .250 & .875 & 1.000 & .190 & .396 & 2.523 \\
\hline TEI & .250 & .000 & .267 & . & . & .250 & .250 & .866 & 1.000 & .166 & .386 & 2.590 \\
\hline
\end{tabular}

Nota: Variables dentro del modelo $=\mathrm{UI}$, Al, II y El. Con respecto de la EC. Fuente: Elaboración propia.

Con base en lo presentado en las tablas anteriores, al igual que con los valores obtenidos del análisis de regresión, sobre la percepción del personal directivo/gerencial de las Pymes del sector turístico dentro del estado de Aguascalientes, es posible in- 
dicar que las hipótesis de investigación se cumplen, al observar que cada uno de los factores (1) TEl, (2) Al, (3) Ul e (4) II inciden positiva y significativamente con respecto de la EC en el contexto determinado. Se establece la importancia de las variables II, UI, Al y TEI, respectivamente, para estimular a la EC en el contexto.

Lo anterior sienta las bases para la posible relación de las variables determinadas, con respecto de otros factores organizacionales, que de forma conjunta pudieran impactar en el desarrollo, desempeño, efectividad organizacional, productividad y competitividad de estos negocios, lo cual podría ser analizado en un futuro trabajo.

En la literatura se encuentran diversas recomendaciones dirigidas a estimular la EC. Pérez-Rolo (2012) menciona que puede perfeccionarse por medio de mejoras dentro del proceso de interacción de la estructura, puesto que ello supone un adelanto dentro de la planeación estratégica (comunicación descendente), al igual que progresos dentro del desarrollo de los procesos operativos (comunicación lateral). De tal manera, es importante comprender que el proceso comunicativo es un elemento que moldea el comportamiento de los trabajadores, ya que es una de las principales herramientas que pueden ser utilizadas con los individuos y los grupos por igual (Mazzei, 2010).

Esto supone múltiples beneficios en términos de eficacia laboral (Bucăţa y Rizescu, 2017), al igual que ciertos elementos dentro de la calidad del servicio (Patterson, 2016; Sharma y Patterson, 1999), el desempeño (Adeosun et al., 2008; Azhar et al., 2015), la productividad (Clampitt y Downs, 1993; Yazici, 2002), el fortalecimiento del compromiso que posee el cliente/consumidor con respecto de la organización (Park et al., 2014; Patterson, 2016), así como aspectos inherentes a la creación de ciertas ventajas competitivas (Brownell, 1992; Stenroos y Jaakkola, 2010; Verčič et al., 2012).

\section{Discusión}

Los resultados obtenidos permiten vislumbrar la importancia que tiene la EC dentro de las organizaciones, aún más en el sector de las Pymes turísticas del estado de Aguascalientes, principalmente porque la mayoría de las organizaciones considera que es viable aumentar la efectividad en el proceso de comunicación por medio del TEl, del Al, del Ul y del II. 
Esos hallazgos apuntan en el mismo sentido que la literatura, con la demostración de que es posible mejorar el grado de la EC en diversos contextos y sectores económicos, si se cumplen los siguientes aspectos: a) considerar la dirección de la información compartida y los sistemas que se utilizan para ello (TEI) (Abdullah y Antony, 2012); b) que el intercambio sea relevante y pertinente y que no se encuentre filtrado (AI) (Dennis, 1967); c) incrementar los puntos de control en los canales de comunicación y en las interacciones entre individuos o grupos (UI) (Houman, 2001); y d) emplear la forma (verbal - no verbal) de comunicación más adecuada, según el tipo de información que se desea compartir (II) (Chandon, et al., 1997; Gkorezis et al., 2015). De tal manera, será factible aumentar las posibilidades de éxito en el uso de la EC, como un medio para mejorar el desempeño de la organización (Yazici, 2002).

\section{Conclusiones}

Actualmente el estado de Aguascalientes se enfrenta a distintos retos inherentes a la demanda de la globalización por el uso de servicios turísticos, lo que se traduce en una alta oferta en la materia. Tal condición no es ajena a las Pymes turísticas porque, dadas las condiciones de vulnerabilidad en las que se encuentran, el contar con una vasta cantidad de variables organizacionales para el desarrollo de ventajas competitivas mejora sus capacidades de supervivencia, indistintamente del contexto/mercado en el que estas operan.

Aunque se considera que la creación de recursos científicos en torno a diversos factores organizacionales en el sector de las empresas turísticas podría parecer una mera transferencia de conocimientos (Hjalager, 2010), esto ofrece la ventaja de poder aplicar escalas consolidadas y adaptarlas a las necesidades propias de una industria o sector específico (Cújar et al., 2013). Para la EC no es diferente, aunque se ha observado que existe un interés por abordarla dentro de ese sector es importante tratar de cerrar las brechas con respecto a las variables y a distintos contextos específicos.

Este trabajo de investigación se desarrolló bajo el supuesto de que los problemas actuales de las Pymes turísticas pueden ser resueltos, o al menos ampliar el panorama de dichas organizaciones en referencia al tema planteado. Los resultados obtenidos permiten identificar que aquellas empresas cuyas prácticas y estrategias de gestión consideren algunos de los componentes presentes en el II, UI, Al y TEl, podrían obtener mejores resultados en términos de su EC. 
Se considera que la EC es el producto del proceso de comunicación y que la mejor manera de poder entenderlo es a través del análisis en la interacción de la estructura organizacional. Por ello, es menester reconocer que mientras mejor comprensión tenga el receptor sobre el mensaje que envía el emisor, mayor grado de EC. Ciertas investigaciones (Fisher et al., 1997; Sharma y Patterson, 1999) cuyos resultados apuntan en el mismo sentido que los obtenidos en la presente investigación, señalan la necesidad de cuidar aspectos de la tipología de la comunicación (Byron, 2008).

Si bien la comunicación per se no ofrece beneficios directos sobre variables tan complejas como la competitividad (Dupeyras y MacCallum, 2013), es viable establecer que el potencial de la EC en las Pymes turísticas del estado de Aguascalientes puede tener un impacto en ámbitos como la cultura organizacional (Keyton, 2010), la innovación (Tjosvold y McNeely, 1988), la motivación de los trabajadores (Krivonos, 1978) y el desempeño (Hollingshead et al., 1993).

Con apoyo de dichas variables y demás características estructurales, se puede encaminar a las empresas a obtener mejores resultados en términos de desempeño organizacional (Thitthongkam et al., 2010), ya que esto les permitirá competir en cualquier mercado (Camisón y Monfort-Mir, 2012; Camisón y Forés, 2015).

Finalmente, tanto en lo global como en un entorno altamente competitivo, se vuelve importante que en los próximos años se adopte un compromiso serio, por la unificación de objetivos en materia de estrategias administrativas y de cultura organizacional, en los que se busque un sentido de cooperación y se invierta en el desarrollo de los recursos humanos, mismos que comúnmente son ignorados (Robbins y Judge, 2013). Importante recordar que, en el sector servicios, diversos aspectos de la comunicación pueden determinar el éxito o fracaso de la empresa (Jung y Yoon, 2011).

\section{Referencias}

Abdullah, Z. y Antony, C. A. (2012). Perception of employees on internal communication of a leading five-star hotel in Malaysia. Asian Social Science, 8(2), 17-26. https://doi.org/10.5539/ass.v8n2p17

Adams, A., Blandford, A., Budd, D. y Bailey, N. (2005). Organizational communication and awareness: a novel solution for health informatics. Health Informatics Journal, 11(3), 163-178. https://doi.org/10.1177/1460458205052357 
Adeosun, O. O., Adeosun, T. H., Adetunde, I. A. y Adagunodo, E. R. (2008, 20-22 de diciembre). Strategic application of information and communication technology for effective service delivery in banking industry [ponencia]. International Conference on Computer and Electrical Engineering, Phuket, Thailand. https://doi.org/10.1109/ICCEE.2008.1

Adler, R. B. y Marquardt, J. (2005). Comunicación organizacional: principios y prácticas para negocios y profesiones. Mcgraw-Hill - Interamericana.

Al-Tokhais, A. (2016). The relationship between communication effectiveness and multicultural employees; job outcomes [tesis de maestría, Kent State University]. https://bit.ly/34hUZtX

Arciniega, R. S. (2011). Hacia la caracterización de culturas organizacionales. Debates en Sociología, 36, 5-25. https://bit.ly/2RSg9sQ

Austin, L. C., Liker, J. K. y McLeod, P. L. (1990, octubre). Determinants and patterns of control over technology in a computerized meeting room [ponencia]. ACM Conference on Computer-Supported Cooperative Work, San Francisco, EUA. https://bit.ly/3iTw8Tm

Azhar, N., Kang, Y. y Ahmad, I. (2015). Critical look into the relationship between information and communication technology and integrated project delivery in public sector construction. Journal of Management in Engineering, 31(5). https://doi.org/10.1061/(ASCE)ME.1943-5479.0000334

Baron, R., Kerr, N. y Miller, N. (1992). Group process, group decision, group action. Brooks/Cole Publishing Company. https://bit.ly/3mNVVie

Bhattacherjee, A. (1998). Managerial influences on intraorganizational information technology use: a principal-agent model. Decision Sciences, 29(1), 139-162. https://doi.org/10.1111/j.1540-5915.1998.tb01347.x

Brownell, J. (1992). Hospitality managers' communication practices. International Journal of Hospitality Management, 11(2), 111-128. https://doi. org/10.1016/0278-4319(92)90005-G

Bucăţa, G. y Rizescu, A. M. (2017). The role of communication in enhancing work effectiveness of an organization. Land Forces Academy Review, 22(1), 49-57. https://doi.org/10.1515/raft-2017-0008 
Burgoon, J., Birk, T. y Pfau, M. (1990). Nonverbal behaviors, persuasion, and credibility. Human Communication Research, 17(1), 140-169. https://doi. org/10.1111/j.1468-2958.1990.tb00229.x

Byron, K. (2008). Carrying too heavy a load? The communication and miscommunication of emotion by email. Academy of Management Review, 33(2), 309-327. https://doi.org/10.5465/amr.2008.31193163

Camisón, C. y Monfort-Mir, V. M. (2012). Measuring innovation in tourism from the Schumpeterian and the dynamic-capabilities perspectives. Tourism Management, 33(4), 776-789. https://doi.org/10.1016/j.tourman.2011.08.012

Camisón, C. y Forés, B. (2015). Is tourism firm competitiveness driven by different internal or external specific factors? New empirical evidence from Spain. Tourism Management, 48, 477-499. https://doi.org/10.1016/j.tourman.2015.01.001

Chandon, J., Leo, P. y Philippe, J. (1997). Service encounter dimensions - a dyadic perspective: measuring the dimensions of service encounters as perceived by customers and personnel. International Journal of Service Industry Management, 8(1), 65-86. https://doi.org/10.1108/09564239710161088

Clampitt, P. G. y Downs, C. W. (1993). Employee perceptions of the relationship between communication and productivity: a field study. The Journal of Business Communication, 30(1), 5-28. https://doi.org/10.1177/002194369303000101

Cohen, J., Cohen, P., West, S. G. y Aiken, L. S. (2003). Applied multiple regression/correlation analysis for the behavioral sciences. Lawrence Erlbaum Associates.

Cújar, A., Ramos, C., Hernández, H. y López, J. (2013). Cultura organizacional: evolución en la medición. Estudios Gerenciales, 29(128), 350-355. https://doi. org/10.1016/j.estger.2013.09.009

Dennis, J. B. (1967). A position paper on computing and communications. Proceedings of the first ACM Symposium on operating system principles, 6.1-6.10. https://doi.org/10.1145/800001.811671

Dourish, P. y Bellotti, V. (1992). Awareness and coordination in shared workspaces [ponencia]. ACM conference on computer-supported cooperative work (CSCW '92). Association for Computing Machinery, Nueva York, Estados Unidos. https://doi.org/10.1145/143457.143468 
Dupeyras, A. y MacCallum, N. (2013). Indicators for measuring competitiveness in tourism. A guidance document. OECD Tourism Papers, 2. https://doi. org/10.1787/5k47t9q2t923-en

Fisher, R. J., Maltz, E. y Jaworski, B. J. (1997). Enhancing communication between marketing and engineering: the moderating role of relative functional identification. Journal of Marketing, 61(3), 54-70. https://doi. org/10.1177/002224299706100304

Gee, C. Y. (1994). International hotels, development and management. Educational Institute of the American Hotel \& Motel Association.

Gkorezis, P., Bellou, V. y Skemperis, N. (2015). Nonverbal communication and relational identification with the supervisor: evidence from two countries. Management Decision, 53(5), 1005-1022. https://doi.org/10.1108/MD-11-2014-0630

Hair, J. F., Black, W. C., Babin, J. B. y Anderson, R. E. (2010). Multivariate data analysis. Pearson - Prentice Hall.

Heymann, K. (1992). Quality management: a ten-point model. Cornell Hospitality Quarterly, 33(5), 51-60. https://doi.org/10.1177/001088049203300526

Hjalager, A. M. (2010). A review of innovation research in tourism. Tourism Management, 31(1), 1-12. https://doi.org/10.1016/j.tourman.2009.08.012

Hollingshead, A. B., Mcgrath, J. E. y O'Connor, K. M. (1993). Group task performance and communication technology: a longitudinal study of computer-mediated versus face-to-face work groups. Small Group Research, 24(3), 307-333. https://doi.org/10.1177/1046496493243003

Houman, P. A. (2001). Relationship development and marketing communication: an integrative model. Journal of Business \& Industrial Marketing, 16(3), 167-183. https://doi.org/10.1108/08858620110389786

Johannessen, J., Olaisen, J. y Olsen, B. (1999). Strategic use of information technology for increased innovation and performance. Information Management \& Computer Security, 7(1), 5-22. https://doi.org/10.1108/09685229910255133

Jung, H. S. y Yoon, H. H. (2011). The effects of nonverbal communication of employees in the family restaurant upon customers' emotional responses and customer satisfaction. International Journal of Hospitality Management, 30(3), 542-550. https://doi.org/10.1016/j.ijhm.2010.09.005 
Kahle, E. (2002). Implications of "new economy" traits for the tourism industry. Journal of Quality Assurance in Hospitality \& Tourism, 3(3-4), 5-23. https://doi. org/10.1300/J162v03n03_02

Keyton, J. (2010). Communication and organizational culture. A key to understanding work experiences. SAGE Publications, Inc.

Khan, H., Halabi, A. K. y Sartorius, K. (2011). The use of multiple performance measures and the balanced scorecard (BSC) in Bangladeshi firms: an empirical investigation. Journal of Accounting in Emerging Economies, 1(2), 160-190. https://doi.org/10.1108/20421161111138512

King, R. C. y Xia, W. (1997). Media appropriateness: effects of experience on communication media choice. Decision Sciences, 28(4), 877-910. https://doi. org/10.1111/j.1540-5915.1997.tb01335.x

Krivonos, P. D. (1978). The relationship of intrinsic-extrinsic motivation and communication climate in organizations. International Journal of Business Communication, 15(4), 53-65. https://doi.org/10.1177/002194367801500405

Kuratko, D. F. (2009). The entrepreneurial imperative of the 21 st century. Business Horizons, 52(5), 421-428. https://doi.org/10.1016/j.bushor.2009.04.006

Kwofie, E. T., Adinyira, E. y Fugar, F. (2017). Theoretical and practical implications for engendering project team communication effectiveness in mass housing project delivery in Ghana. Journal of Engineering, Design and Technology, 15(6), 826-844. https://doi.org/10.1108/JEDT-09-2016-0064

Lievens, A. y Moenaert, R. K. (2000). Project team communication in financial service innovation. Journal of Management Studies, 37(5), 733-766. https://doi. org/10.1111/1467-6486.00201

Lundqvist, L. O. (2008). The relationship between the biosocial model of personality and susceptibility to emotional contagion: a structural equation modeling approach. Personality and Individual Differences, 45(1), 89-95. https://doi.org/10.1016/j.paid.2008.03.003

Malhotra, N. K. (2008). Investigación de mercados. Pearson - Prentice Hall.

Mantei, M. (1988). Capturing the capture concepts: a case study in the design of computer-supported meeting environments [ponencia]. ACM Conference on Computer-Supported Cooperative Work, San Francisco, Estados Unidos. 
Massey, G. y Kyriazis, E. (2007). Interpersonal trust between marketing and R\&D during new product development projects. European Journal of Marketing, 41(9-10), 1146-1172. https://doi.org/10.1108/03090560710773381

Mazzei, A. (2010). Promoting active communication behaviors through internal communication. Corporate Communications: an International Journal, 15(3), 221-234. https://doi.org/10.1108/13563281011068096

Mbatha, B. (2012). Exploring the potential of electronic commerce tools in South African SME tourism service providers. Information Development, 29(1), 1023. https://doi.org/10.1177/0266666912452270

Mohr, J. y Spekman, R. (1994). Characteristics of partnership success: partnership attributes, communication behavior, and conflict resolution techniques. Strategic Management Journal, 15(2), 135-152. https://doi.org/10.1002/ smj.4250150205

Nordin, S. M., Sivapalan, S., Bhattacharyya, E., Ahmad, H. H.W. F.W.y Abdullah, A. (2014). Organizational communication climate and conflict management: communications management in an oil and gas company. Procedia - Social and Behavioral Sciences, 109, 1046-1058. https://doi.org/10.1016/j.sbspro.2013.12.587

Nosnik, A. (1996). Comunicación y gestión organizacional: ciclo de conferencias. Universidad Autónoma de Bucaramanga.

Nosnik, A. (1998). ¿Por qué la comunicación es relevante a la empresa? En M. A. Rebeil y C. Ruiz (Coords.), El poder de la comunicación en las organizaciones (pp. 75-92). Plaza y Valdés Ediciones.

Park, J.-G., Lee, S. y Lee, J. (2014). Communication effectiveness on IT service relationship quality. Industrial Management \& Data Systems, 114(2), 321-336. https://doi.org/10.1108/IMDS-04-2013-0186

Patterson, P. (2016). Retrospective: tracking the impact of communications effectiveness on client satisfaction, trust, and loyalty in professional services. Journal of Services Marketing, 30(5), 485-489. https://doi.org/10.1108/JSM-052016-0190

Pentina, I. y Strutton, D. (2007). Information processing and new product success: a meta-analysis. European Journal of Innovation Management, 10(2), 149-175. https://doi.org/10.1108/14601060710745233 
Pérez-Rolo, M. (2012). Fundamentos teóricos metodológicos para realizar una campaña de relaciones públicas. Observatorio de la Economía Latinoamericana, 164, 13. https://bit.ly/3d0hyXR

Price, J. L. (1997). Handbook of organizational measurement. International Journal of Manpower, 18(4-6), 303-558. https://bit.ly/2F3RzT2

Ratna, S., Nayati Utami, H., Siti Astuti, E., Wilopo y Muflih, M. (2020). The technology tasks fit, its impact on the use of information system, performance, and users' satisfaction. VINE Journal of Information and Knowledge Management Systems, 50(3), 369-386. https://doi.org/10.1108/VJIKMS-10-2018-0092

Robbins, S. y Judge, T. (2013). Comportamiento organizacional. Pearson - Prentice Hall. https://bit.ly/3000Z7m

Segredo Pérez, A, García A., López, P., León, P. y Perdomo, I. (2017) Comunicación organizacional como dimensión necesaria para medir el clima en las organizaciones en salud pública. Horizonte Sanitario. https://doi.org/10.19136/ hs.v16i1.1256

Sharma, N. y Patterson, P. (1999). The impact of communication effectiveness and service quality on relationship commitment in consumer, professional services. Journal of Services Marketing, 13(2), 151-170. https://doi. org/10.1108/08876049910266059

Snyder R. A. y Morris J. H. (1984). Organizational communication and performance. Journal of Applied Psychology, 69(3), 461-465. https://doi.org/10.1037/00219010.69.3.461

Stenroos, L. A. y Jaakkola, E. (2010). Value co-creation within buyer-seller relationships in knowledge-intensive business services [ponencia]. IMP2010 Conference, Budapest, Hungría. https://bit.ly/3neW3Hs

Stiff, J., Corman, S., Krizek, B. y Snider, E. (1994). Individual differences and changes in nonverbal behavior: unmasking the changing faces of deception. Communication Research, 21(5), 555-581. https://doi.org/10.1177/009365094021005001

Taghavi, M., Bakhtiyari, K., Taghavi, H., Olyaee Attar, V. y Hussain, A. (2014). Planning for sustainable development in the emerging information societies. Journal of Science \& Technology Policy Management, 5(3), 178-211. https://doi. org/10.1108/JSTPM-04-2014-0013 
Thitthongkam, T., Walsh, J. C. y Banchapattanasakda, C. (2010). Language roles in internal and external communication in the Thai tourism industry competitiveness. Acta Universitatis Danubius. Fconomica, 6(2), 47-58. https://bit. ly/34r5KKi

Tjosvold, D. y McNeely, L. (1988). Innovation through communication in an educational bureaucracy. Communication Research, 15(5), 568-581. https://doi. org/10.1177/009365088015005004

Trelles, I. (Comp.) (2001). Comunicación organizacional. Selección de lecturas. Editorial Félix Varela.

Tucker,M.L.,Meyer,G.D.yWesterman,J.W.(1996).Organizational communication:development of internal strategic competitive advantage. The Journal of Business Communication, 33(1), 51-69. https://doi.org/10.1177/002194369603300106

Vimarlund, V., Olve, N.-G., Scandurra, I. y Koch, S. (2008). Organizational effects of information and communication technology (ICT) in elderly home care: a case study. Health Informatics Journal, 14(3), 195-210. https://doi. org/10.1177/1081180X08092830

Verčič, A., Verčič, D. y Sriramesh, K. (2012). Internal communication: definition, parameters, and the future. Public Relations Review, 38(2), 223-230. https://doi. org/10.1016/j.pubrev.2011.12.019

Wang, X. y Huang, Y. H. C. (2020). Uncovering the role of strategic orientation in translating communication strategies to organizational performance: an analysis of practitioners from two Chinese societies. International Journal of Business Communication. https://doi.org/10.1177/2329488420924839

Scott, W. G. y Mitchell, T. R. (1976). Organization theory a structural and behavioral analysis. R.D. Irwin. https://bit.ly/3j1bFfu

Yazici, H. J. (2002). The role of communication in organizational change: an empirical investigation. Information \& Management, 39(7), 539-552. https://doi. org/10.1016/S0378-7206(01)00110-0

Yildiz, Ö. (2015). Internal communication function and hotel productivity. A comparative study. American International Journal of Contemporary Research, 5(3), 45-54. https://bit.ly/32ReXw6 


\title{
ESTADO DEL CONOCIMIENTO SOBRE EL DESARROLLO SUSTENTABLE en Pueblos MáGICOS
}

\author{
ARELY ALCÁZAR GUZMÁN \\ arely_alcazar@hotmail.com \\ ELIZABETH OLMOS-MARTíNEZ \\ eolmosm.udo@gmail.com \\ Universidad Autónoma de Occidente, Sinaloa, México
}

El gobierno de México creó el programa de Pueblos Mágicos (PM), asociado al turismo sustentable. El objetivo de este trabajo es sintetizar y comparar el conocimiento científico sobre dicho desarrollo sustentable en los PM, mediante una búsqueda en 73 documentos académicos que cumplieron con los criterios de inclusión. Se encontró que gran parte de la literatura del tema en los PM se incluye en la dimensión sociocultural; la mayoría de los estudios corresponden al centro del país y no todos los PM han sido estudiados bajo la perspectiva del desarrollo sustentable.

Palabras clave: México, Pueblos Mágicos, desarrollo sostenible, desarrollo sustentable, turismo.

\section{STATE OF KNOWLEDGE ON SUSTAINABLE DEVELOPMENT in Pueblos MÁGICOS}

Mexican government created the program called Magical Towns (Pueblos Mágicos, PM in Spanish), which is associated to the sustainable tourism. The purpose of this research is to synthesize and compare the scientific knowledge about said sustainable development in the PM, throughout a review of 73 academic documents that accomplished the inclusion criteria. It was found that much of the literature on the theme about the PM is included in the sociocultural dimension; most of the studies correspond to the center of the country, and not all of the PM have been studied from the perspective of sustainable development.

Keywords: Mexico, Magical Towns, sustainable development, tourism. 


\section{Introducción}

e acuerdo con Orgaz y Moral (2016), el turismo forma parte de los principales sectores económicos a nivel mundial, además de fungir como fuente de oportunidades para la modernización socioeconómica y cultural de un área. La progresiva sensibilización de la opinión pública sobre la problemática ambiental, así como la toma de conciencia de las dificultades ecológicas, implican una valorización de los recursos naturales, con una tendencia a consumir un producto diferenciado respecto a dichos recursos, en buen estado de conservación, según afirma Bertoni (2008).

La demanda turística ha cambiado la motivación de los viajes, como lo mencionan Orgaz y Moral (2016) debido a que buscan experiencias que satisfagan sus necesidades a través de productos turísticos novedosos, distintos al turismo de masas, al ser la protección de la naturaleza y el conocimiento de la cultura local una de las nuevas tendencias.

Los cambios son innegables, ya sean culturales, ecológicos y económicos, lo que según los autores significa un reto hacia el turismo, encaminado a planear adecuadamente el aprovechamiento de los sitios, considerar los bienes y servicios dentro de un marco sustentable del ecosistema, todo sin dejar de lado las mejoras en las condiciones de vida de la población local y sin descuidar tampoco la experiencia recreativa de los visitantes para lograr un grado de satisfacción deseable. En ese sentido, en México se creó el programa de Pueblos Mágicos (PM), con características destinadas a fortalecer y atender dicha tendencia turística bajo la línea rectora del desarrollo sustentable (DS).

En este contexto, el objetivo y alcance de la presente investigación bibliográfica es sintetizar y comparar el conocimiento sobre el DS en los PM, así como identificar las aportaciones que permitan contextualizar, clasificar y categorizar los estudios bajo dicha temática, como contribución analítica.

Desde esta perspectiva, se presentan en un primer apartado los antecedentes que explican el DS y su relación con el turismo, además de la finalidad de los PM. Enseguida se describe la metodología utilizada en el estudio, que considera una búsqueda sistematizada en bases de datos para la detección de información pertinente dedicada al estudio del DS, específicamente en los destinos con la denominación de PM. De un total de 73 documentos revisados, destaca el estudio de la dimensión 
sociocultural como el enfoque más abordado para la realización de investigaciones; en contraparte, la medioambiental es la menos examinada.

\section{Antecedentes}

\subsection{Turismo y desarrollo sustentable}

Los principios de sustentabilidad refieren aspectos ambientales, económicos y socioculturales en equilibrio. De acuerdo con Liu (2003), el concepto de DS se dio a conocer en la década de los 70, haciendo énfasis precisamente en la conservación de la naturaleza y los recursos naturales. Para 1987, el Informe Brundtland de la Organización de las Naciones Unidas (ONU) definió el DS como aquel que satisface las necesidades propias del presente, sin comprometer la capacidad de las generaciones futuras; no se trata de un estado fijo de armonía, sino un proceso de cambios que están en concordia, para mejora del potencial actual y futuro de las necesidades y aspiraciones.

Años más tarde, en 1992, se llevó a cabo en Río de Janeiro la conferencia de las Naciones Unidas sobre Medio Ambiente y Desarrollo, llamada Cumbre de la Tierra (Velasco et al., 2011). Con la participación de diferentes países, personas y organizaciones no gubernamentales, se presentó el Programa 21 (también conocido como Agenda 21), en el cual se fijó la necesidad de reducir el desperdicio para fomentar un aprovechamiento más consciente de los recursos naturales, vista como una estrategia de desarrollo eficiente, equitativo, racional y duradero, basado en principios que implican la participación tanto de los sectores público y privado como de las comunidades locales.

Una década más tarde surge otra expresión del compromiso hacia el DS, a través de la Cumbre Mundial sobre el Desarrollo Sostenible, también conocida como Río+10, llevada a cabo en Johannesburgo, Sudáfrica, en el año 2002 y organizada por la ONU. Esta fue la oportunidad para adoptar nuevas medidas a fin de renovar la intención global del DS y hacer un balance a 10 años de implementación del Programa 21 (Díaz y Escárcega, 2009).

Los Objetivos del Milenio fueron publicados en el año 2000, derivados de la Cumbre del mismo nombre que tuvo lugar en Nueva York, con 189 representantes de diversas naciones, quienes realizaron un repaso de los compromisos adquiridos 
años atrás. Los ocho objetivos proponían tratar problemas de la vida cotidiana, de acuerdo con la ONU (2000): a) erradicar la pobreza extrema y el hambre, b) lograr la enseñanza primaria universal, c) promover la igualdad entre los géneros y la autonomía de la mujer, d) reducir la mortalidad infantil, e) mejorar la salud materna, f) combatir el VIH/SIDA, el paludismo y otras enfermedades, g) garantizar la sostenibilidad del medio ambiente, $\mathrm{y}$ h) fomentar una asociación mundial para el desarrollo.

En el año 2012, tuvo lugar la conferencia de las Naciones Unidas llamada Río+20, llevada a cabo en Río de Janeiro, Brasil, donde se dio como resultado un documento titulado El futuro que queremos. Allí se debatieron dos principales objetivos: a) el poder cimentar una economía verde, la cual logre un DS que erradique la pobreza y, b) buscar la forma de tener una mejor coordinación internacional tendiente a lograr el DS (Melón, 2016). Posteriormente, en el año 2015, se dio a conocer la Agenda 2030 para el DS, la cual consta de 17 objetivos, mismos que en el 2016 reemplazaron a los Objetivos del Milenio (Mariño et al., 2018).

A pesar de la gran relación del concepto de DS con términos económicos, Liu (2003) destaca que el desarrollo no implica necesariamente crecimiento, ya que es un proceso de realización de necesidades sociales, económicas y ambientales, por lo que se pueden sugerir cambios, reducción e incluso eliminación de productos ya existentes, empresas u otro tipo de factores.

El turismo ha sido visto tradicionalmente como una herramienta para el desarrollo, ya que tiene la virtud de crear gran cantidad de empleos e incentivar la economía de zonas rurales, en aprovechamiento del patrimonio cultural y ambiental que poseen (Ibáñez et al., 2015), por lo que los modelos alternativos de turismo son una oportunidad para impulsar las comunidades.

En ese contexto, Valverde y Benavides (2017) señalan que México es un país diverso en recursos naturales y culturales, encontrándose dentro de los líderes del turismo internacional receptivo. Es por ello que la industria turística sustentable debe tener en cuenta una participación social amplia para democratizar las decisiones y asumir las responsabilidades que implica la conservación del patrimonio territorial y paisajístico de una localidad o región, como lo mencionan Ibarra-Michel y Velarde (2016). 


\section{Pueblos Mágicos}

El programa de PM fue establecido por el gobierno federal en el año 2001, con el cual, de acuerdo con la Secretaría de Turismo (Sectur, 2014), se pretende revalorar los atractivos exclusivos y la diversificación de productos, con base en los atributos históricos, culturales y naturales, además de generar innovación que englobe los diversos segmentos de mercado en relación con la singularidad de una localidad, sin perder de vista la parte económica. Hoy en día, en México permanecen 121 poblaciones reconocidas como PM (Sectur, 2020).

Este programa fue creado para fomentar el desarrollo en localidades que tengan este nombramiento, en impulso al crecimiento de servicios relacionados directamente con el turismo para generar un efecto multiplicador (García y Guerrero, 2014). Además, en él se describen algunas estrategias en torno a la infraestructura de servicios e imagen urbana, el equipamiento turístico, creación y mejoramiento de sitios de interés, así como el desarrollo e innovación de productos afines. Domínguez et al. (2016) afirman que uno de los beneficios más importantes es su capacidad para fungir como un instrumento para promover el desarrollo regional.

A grandes rasgos, de acuerdo con Christian et al. (2011), a partir de la instauración de un entorno turístico dentro de un pueblo tradicional y costumbres arraigadas, se ven fortalecidos poco a poco los servicios a los que un turista está acostumbrado, con una actualización simultánea en cuestiones socioculturales, económicas y naturales. En este sentido, los autores mencionan que se genera una dinámica de cambios y es en ese aspecto donde sugieren implementar una cadena de valor que permita dar una funcionalidad más apropiada al turismo, sin dañar el patrimonio tanto arquitectónico como cultural y sin perder los valores únicos del pueblo.

\section{Metodología}

En el primer trimestre de 2019, se llevó a cabo una revisión sistemática en los siguientes buscadores: Redalyc, Latindex, Springerlink, EBSCO, Google Académico y Scielo, además de revistas como Turismo y Desarrollo Sostenible (Turydes), El Periplo Sustentable, y Turismo y Tecnología. Se seleccionaron documentos científicos publicados entre los años 2005 y 2019, que presentan en el título, el resumen y/o las palabras clave o sintaxis los siguientes conceptos: desarrollo sostenible, desarrollo sustentable, sustentabilidad, turismo y Pueblos Mágicos, que a su vez sirvieron como filtros de búsqueda. 
Solo se incluyeron en este documento aquellos textos que incorporaron una discusión de los elementos previamente mencionados en el cuerpo del estudio, puesto que en algunos casos el DS en los PM no era el tema principal, aunque estaba presente como parte de las palabras clave.

A través del análisis de la literatura académica se organizó una tabla de contenido bibliográfico con distintas categorías para clasificar la información, desde los datos de referencia (autor, año, título), los ejes de la sustentabilidad (económico, sociocultural y ambiental), tipos de indicadores utilizados, alcance geográfico, metodología y principales hallazgos.

Para identificar los indicadores de sustentabilidad en la tabla de contenido, se consideran los que propone Rohan (2016), quien a su vez retoma los recomendados por el Programa de las Naciones Unidas para el Medio Ambiente (PNUMA) y la Organización Mundial del Turismo (OMT, 2006) con una adaptación de estos (ver tabla 1).

En cuanto al alcance geográfico se consideraron cuatro categorías:

a) Internacional: se toman en cuenta dos o más destinos de diferentes países. Cabe mencionar que el programa de PM corresponde a México; sin embargo, en algunos estudios internacionales se realizan comparaciones con destinos pertenecientes a otro país, por lo que se incluyeron en el estudio.

b) Nacional: se consideran dos o más PM de diferentes estados de la República.

c) Regional: se engloban aquellos estudios que refieren dos o más PM de un mismo estado.

d) Local: en el cual la investigación hace referencia a un PM en específico.

Asimismo, las investigaciones en la base de datos se clasificaron por tipo de metodología utilizada, para lo cual se consideraron tres: a) cualitativa, que, de acuerdo con Hernández et al. (2014), se refiere al tipo de investigación enfocada en comprender un fenómeno desde la perspectiva de los participantes, en un ambiente natural y con relación a su contexto, b) cuantitativa, en la cual se recogen y analizan datos cuantificables de la relación entre las variables en contextos estructurales y situacionales y, c) mixta, en donde se mezclan los dos enfoques anteriores, ya sea centrándose más en uno de ellos o bien dándoles el mismo peso, al usar evidencia de datos numéricos, discursivos, textuales, visuales, simbólicos y de otras clases para entender problemas en la ciencia. 
Tabla 1. Indicadores de sustentabilidad

\begin{tabular}{|c|c|}
\hline Eje de sustentabilidad & Indicadores \\
\hline \multirow{10}{*}{ Sociocultural } & Satisfacción del residente \\
\hline & Protección del patrimonio cultural \\
\hline & Riqueza cultural \\
\hline & Gastronomía \\
\hline & Control local \\
\hline & Bienestar de la comunidad \\
\hline & Seguridad \\
\hline & Equidad de género \\
\hline & Gobernanza o política \\
\hline & Planeación de imagen urbana \\
\hline \multirow{6}{*}{ Económico } & Inversión \\
\hline & Prosperidad local \\
\hline & Equidad social \\
\hline & Viabilidad económica/Competitividad \\
\hline & Satisfacción del visitante \\
\hline & Calidad del empleo \\
\hline \multirow{6}{*}{ Ambiental } & Gestión del agua \\
\hline & Gestión del territorio \\
\hline & Gestión de la energía \\
\hline & Manejo de residuos sólidos \\
\hline & Calidad del aire \\
\hline & Conservación de la biodiversidad \\
\hline
\end{tabular}

Fuente: Rohan (2016), adaptado del PNUMA y la OMT (2006).

Adicionalmente, se organizaron las investigaciones conforme a la delimitación publicada en el Diario Oficial de la Federación (2013), en el cual se dividen los 32 estados de la República Mexicana en cinco regiones correspondientes a:

- Región Noroeste: Baja California, Baja California Sur, Chihuahua, Sinaloa y Sonora.

- Región Noreste: Coahuila, Durango, Nuevo León, San Luis Potosí y Tamaulipas.

- Región Centro: Ciudad de México, Estado de México, Guerrero, Hidalgo, Morelos, Puebla y Tlaxcala. 
- Región Occidente: Aguascalientes, Colima, Guanajuato, Jalisco, Michoacán, Nayarit, Querétaro y Zacatecas.

- Región Sureste: Campeche, Chiapas, Oaxaca, Quintana Roo, Tabasco, Veracruz y Yucatán.

\section{Resultados}

Se localizaron 102 documentos que contenían las palabras clave definidas en esta investigación dentro del título y/o en el resumen. No obstante, como se señaló líneas arriba, se encontró que en algunos casos los términos se mencionaban sin ser realmente el objetivo del estudio, por lo que estos trabajos fueron marcados como irrelevantes, siendo solamente 73 los que cumplieron con los requisitos establecidos.

\subsection{Tipo de publicación}

Entre los documentos seleccionados se encontraron cuatro tipos de producción científica: la mayoría fueron artículos (51), que representaron el 75\% de las publicaciones, seguido de 19 capítulos de libro (21\%), dos libros (3\%) y una tesis (1\%).

\subsection{Alcance geográfico}

Se determinó que solamente un trabajo es de alcance internacional, lo que refleja que los estudios relevantes al tema que relacionan los destinos de PM con sitios de otros países son una minoría. Siete de los documentos seleccionados abordan el tema de la sustentabilidad desde un alcance nacional, al generalizar algunos puntos sobre estos destinos y el programa de PM en sí. Además, se tienen 10 publicaciones de alcance regional en donde se hace referencia a dos o más PM. Finalmente, en su mayoría los trabajos son de alcance local, con un total de 55 , los cuales se enfocan solamente en un PM en específico. En la tabla 2 se enlistan los estudios, ordenados por su alcance geográfico. 
Tabla 2. Alcance geográfico de estudios sobre sustentabilidad en Pueblos Mágicos

\begin{tabular}{|c|c|}
\hline Alcance geográfico & Autor/es, año \\
\hline Internacional & Balslev y Velázquez, 2013. \\
\hline \multirow{6}{*}{ Nacional } & Valverde y Enciso, 2013. \\
\hline & Pulido-Fernández y Pulido-Fernández, 2014. \\
\hline & Equihua et al., 2015. \\
\hline & De la Rosa et al., 2016; Fernández, 2016. \\
\hline & Rodríguez et al., 2017. \\
\hline & López, 2018. \\
\hline \multirow{6}{*}{ Regional } & Hoyos y Hernández, 2008. \\
\hline & Covarrubias et al., 2010. \\
\hline & $\begin{array}{l}\text { Landeros et al., 2015; Rodríguez y Vargas, 2015; } \\
\text { Rodríguez et al., 2015; Treviño et al., } 2015 .\end{array}$ \\
\hline & García et al., 2016. \\
\hline & Sánchez y Barbosa, 2017. \\
\hline & Castillo et al., 2018; García y López, 2018. \\
\hline \multirow{9}{*}{ Local } & Almada, 2005. \\
\hline & Hernández, 2009; Velarde et al., 2009. \\
\hline & Muñoz, 2011. \\
\hline & $\begin{array}{l}\text { Fernández, 2013; Madrid, 2013; Martínez, 2013; Rodríguez, 2013; Rodríguez y Vargas, } \\
\text { 2013; Valenzuela et al., } 2013 .\end{array}$ \\
\hline & Barbosa y Santamaría, 2014a, 2014b; García y Guerrero, 2014; Velarde et al., 2014. \\
\hline & $\begin{array}{l}\text { Alvarado, 2015; Enciso, 2015; Estrella, 2015; Olivera y Fernández, 2015; Figueroa, 2015; } \\
\text { F. González, 2015; L. González, 2015; Gutiérrez, 2015; Guzmán, 2015; Hernández y } \\
\text { López, 2015; Levi, 2015; Martínez y Mínguez, 2015; Méndez y Rodríguez, 2015; Quiroz, } \\
\text { 2015; Rodríguez, 2015; Rodríguez y Rojo, 2015; Cruz et al., 2015; Royuela y Ramírez, } \\
\text { 2015; Sectur, 2015; Valverde y Sandoval, 2015; Velázquez y Aragón, } 2015 .\end{array}$ \\
\hline & $\begin{array}{l}\text { Coronado; 2016; Ibarra-Michel y Velarde, 2016; Luyando et al., 2016; Palafox-Muñoz, } \\
\text { 2016; Pérez-Ramírez y Antolín-Espinoza, } 2016 .\end{array}$ \\
\hline & $\begin{array}{l}\text { Alvarado et al., 2017; Álvarez-Quijada, 2017; Espinoza et al., 2017; Franco y Enciso, } \\
\text { 2017; Guillén et al., 2017; Hernández et al., 2017; López, 2017; Rojo et al., 2017; Rosas- } \\
\text { Jaco et al., 2017; Valenzuela, 2017; Vizcaíno-Suárez et al., } 2017 .\end{array}$ \\
\hline & Cornejo-Ortega et al., 2018; Fernández, 2018; Jiménez et al., 2018; Saiz-Álvarez, 2018. \\
\hline
\end{tabular}

\subsection{Tipo de metodología}

Tres tipos de metodologías se aplican en los estudios. La primera corresponde al tipo cualitativo, del cual se ubicaron 56 documentos (77\%). A la metodología cuantitativa corresponden nueve documentos (12\%), y ocho más se realizaron bajo un enfoque mixto, con un $11 \%$ (tabla 3 ). 
Tabla 3. Metodología abordada en estudios sobre sustentabilidad en Pueblos Mágicos

\begin{tabular}{|c|c|}
\hline Tipo de metodología & Número de publicaciones \\
\hline Cualitativa & 56 \\
\hline Cuantitativa & 9 \\
\hline Mixta & 8 \\
\hline Total & 73 \\
\hline
\end{tabular}

Fuente: Elaboración propia.

La mayor parte de las investigaciones sobre el DS en los PM tienen un enfoque cualitativo (77\%); ese tipo de estudios se caracterizan por ser interpretativos, al utilizar técnicas como la observación, anotaciones, grabaciones, elaboración de documentos, entre otros, lo cual deja en minoría a las investigaciones apoyadas en el enfoque cuantitativo, basadas en conteo o acotaciones, así como los estudios mixtos en los que confluyen ambos elementos.

\subsection{Año de publicación}

La gráfica 1 muestra que la mayor parte de las investigaciones que incluyen el tema del DS en los PM tuvieron lugar en el año 2015, con un total de 25 documentos, seguido por el año 2017 con 14; en los años 2005, 2008, 2010 y 2011 se localizó solo una publicación por cada uno, mientras que en el año 2012 y el primer trimestre del año 2019 no se encontraron estudios al respecto.

Gráfica 1. Publicaciones por año sobre desarrollo sustentable en Pueblos Mágicos

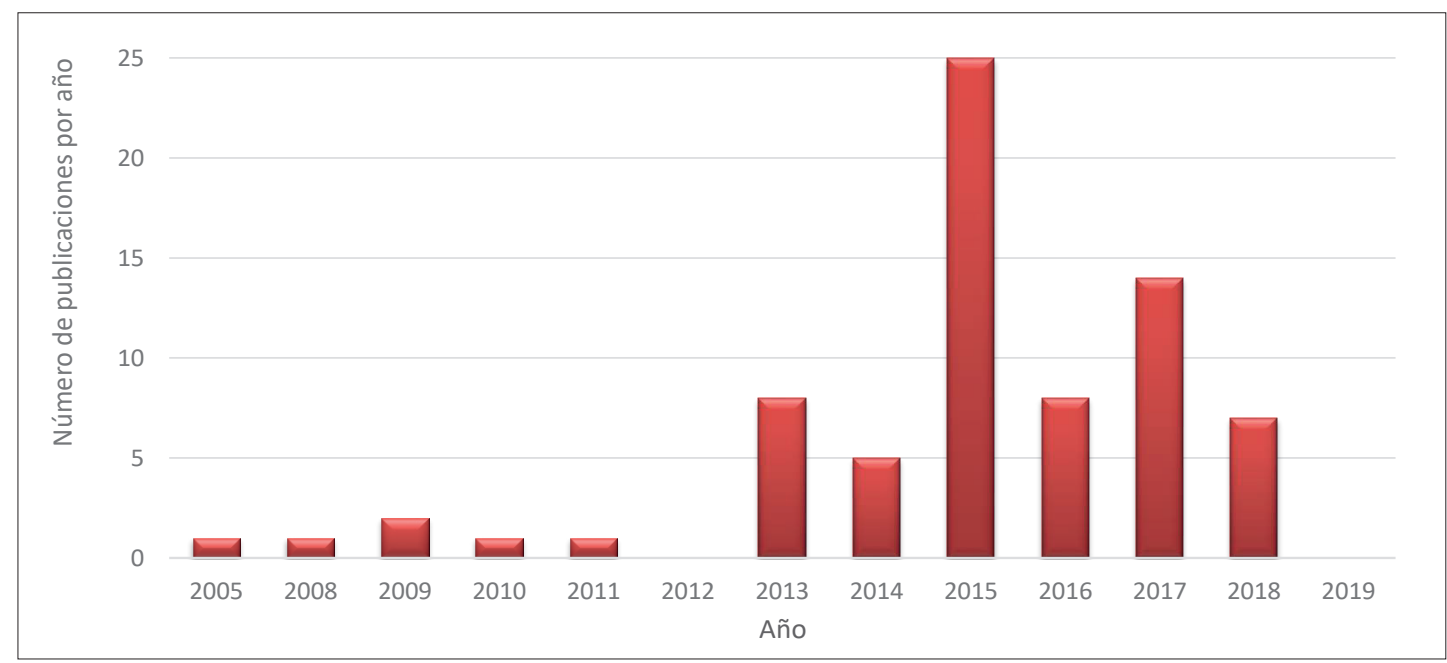

Fuente: Elaboración propia. 


\subsection{Categorías y ejes de sustentabilidad}

De acuerdo con los ejes de sustentabilidad, del total de las publicaciones $54 \%$ se inclinan hacia el eje sociocultural, seguido por el económico con $30 \%$, mientras que en tercer lugar se encuentra el ambiental con el 16\% (tabla 4). Así, los estudios acerca de los PM en donde se aborda el tema del DS, en su mayoría abordan aspectos relacionados con la parte sociocultural, con especial énfasis en las comunidades anfitrionas y la conservación de los activos culturales y arquitectónicos, además de los valores y tradiciones, por lo que se identifican menos trabajos sobre los recursos medioambientales.

Tabla 4. Número de publicaciones por eje de sustentabilidad

\begin{tabular}{|c|c|}
\hline Eje de sustentabilidad & Porcentaje \\
\hline Sociocultural & 54 \\
\hline Económico & 30 \\
\hline Ambiental & 16 \\
\hline \multicolumn{2}{|c|}{ Fuente: Elaboración propia. } \\
\hline
\end{tabular}

Cabe mencionar que se incluye más de un eje de la sustentabilidad en 54 de los documentos revisados. Un ejemplo de ello es el Diagnóstico sobre competitividad y sustentabilidad en El Fuerte, Sinaloa, realizado por Barbosa y Santamaría (2014b). Los autores recopilan indicadores relacionados con las tres dimensiones sustentables, para la propuesta de aplicación de un sistema afín, el cual se compone de temas como el medio ambiente, entorno socioeconómico, turismo (demanda turística y oferta) y desarrollo humano, derivado de ello se obtiene un diagnóstico que funge como herramienta de planeación pertinente para mejorar la toma de decisiones en torno a los PM.

\section{Eje sociocultural}

La gráfica 2 presenta los indicadores que se englobaron en el análisis de datos, donde el de gobernanza y política predomina como el más abordado, con 31 publicaciones. Posteriormente, se encuentra la protección del patrimonio cultural con 28 documentos que desarrollan este tema; en una tercera posición se presenta el indicador de riqueza cultural, con 22 investigaciones, seguido de los indicadores sobre gastronomía, equidad de género y seguridad en los PM del país. 
Devesa y Palacios (2005) presentan un estudio sobre las predicciones en el nivel de satisfacción percibido por los turistas de la ciudad de Segovia, España, a partir de las variables motivacionales y de la valoración de la experiencia. Explican el gusto de los viajeros por una ciudad declarada patrimonio de la humanidad a partir de un modelo predictivo, al mencionar tres grupos de variables y estimación de la vista. Los resultados muestran que la satisfacción depende de los factores humanos y la accesibilidad de los servicios.

Gráfica 2. Número de estudios del eje sociocultural por indicador

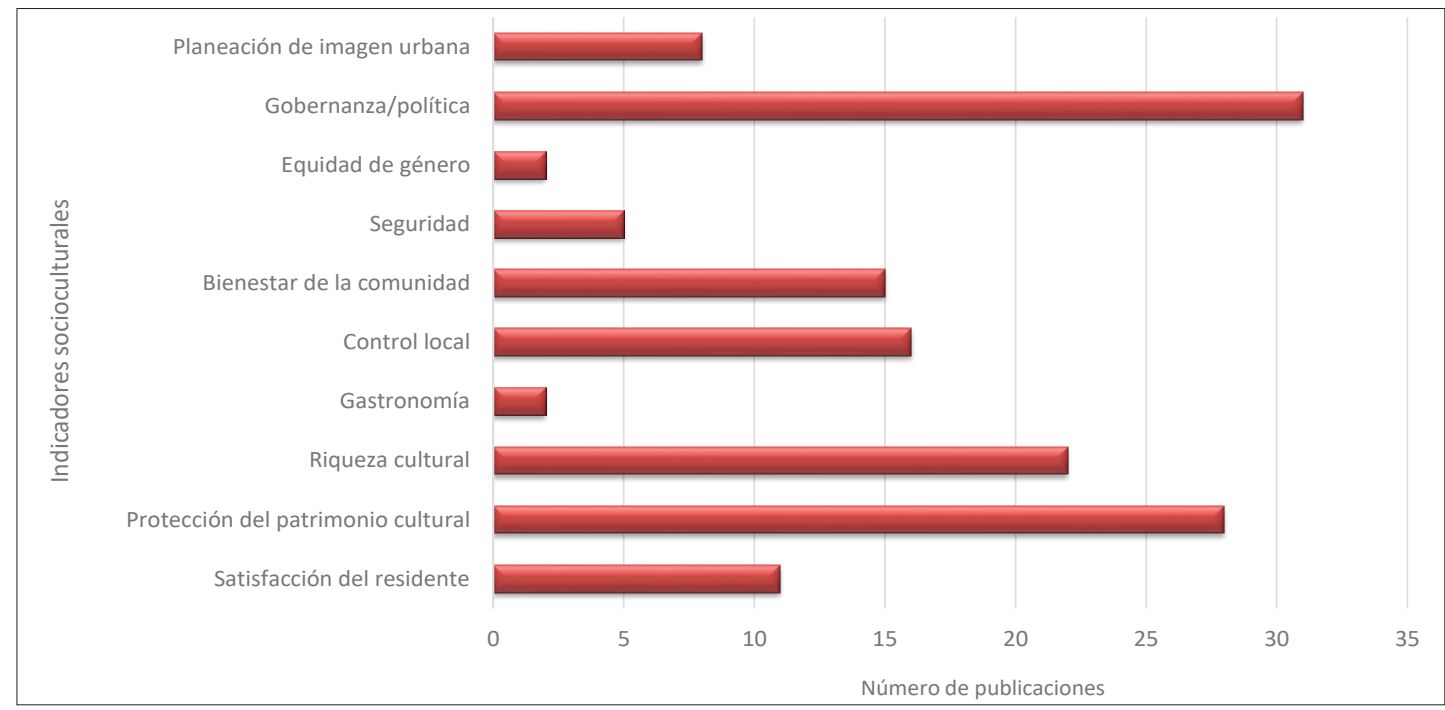

Fuente: Elaboración propia.

En los resultados del eje sociocultural, destaca también la investigación realizada por Covarrubias et al. (2010), quienes retoman la satisfacción de los residentes y cómo estos perciben los cambios en las localidades, a partir del nombramiento de PM en Comala, Colima y en Real de Asientos, Aguascalientes. Los autores concluyen que no solamente se debe tomar en cuenta la satisfacción del turista para lograr el equilibrio sustentable dentro de un destino, sino también considerar atributos y deficiencias en torno a la población local, en cuanto a la oferta turística. Para ello, señalan como imprescindible la consulta ciudadana a fin de tener un apego a la realidad y permitir la mejor elaboración de estrategias encaminadas al DS del destino.

Por su parte, Guillén et al. (2017) identifican y describen la participación ciudadana en la política de turismo asociada a los PM en El Fuerte, Sinaloa. El estudio se realizó en el centro histórico de este municipio; la idea fundamental consistió en analizar cómo los ciudadanos de El Fuerte entienden y practican su involucramiento dentro 
del programa, al considerar el carácter social del mismo y la importancia de la participación comunitaria para el logro de los objetivos.

Otro documento relevante para el eje sociocultural es el de Espinoza et al. (2017), acerca del PM de Mascota, Jalisco, en el cual indican que una de las estrategias se basa en la intervención y participación de la población local, para que se logre una distribución de riqueza a partir de las inversiones locales y la administración de recursos, lo que propicie un desarrollo endógeno. Además, se expresa que es necesario el análisis de cómo se desarrolla o se debe desarrollar el turismo a través de dicha denominación, para mejorar la calidad de vida de la población local, desde la percepción de los residentes acerca de la sustentabilidad de las actividades turísticas en los PM.

\section{Eje económico}

De acuerdo con la gráfica 3, se observa que tanto la prosperidad local, como la viabilidad económica y la competitividad, son los indicadores más relevantes en cuestión de temas económicos relacionados con el DS en los PM de México, pues en torno a ellos se registraron 21 documentos. En menor medida se encuentran las investigaciones que se inclinan por el indicador de la equidad social (a partir de aspectos económicos), con solo cuatro publicaciones relacionadas. Además, en cuanto a la inversión en estos destinos no se encuentra mucha información, ya que solamente se tienen siete trabajos que abordan el DS desde esta perspectiva.

Gráfica 3. Número de estudios del eje económico por indicador

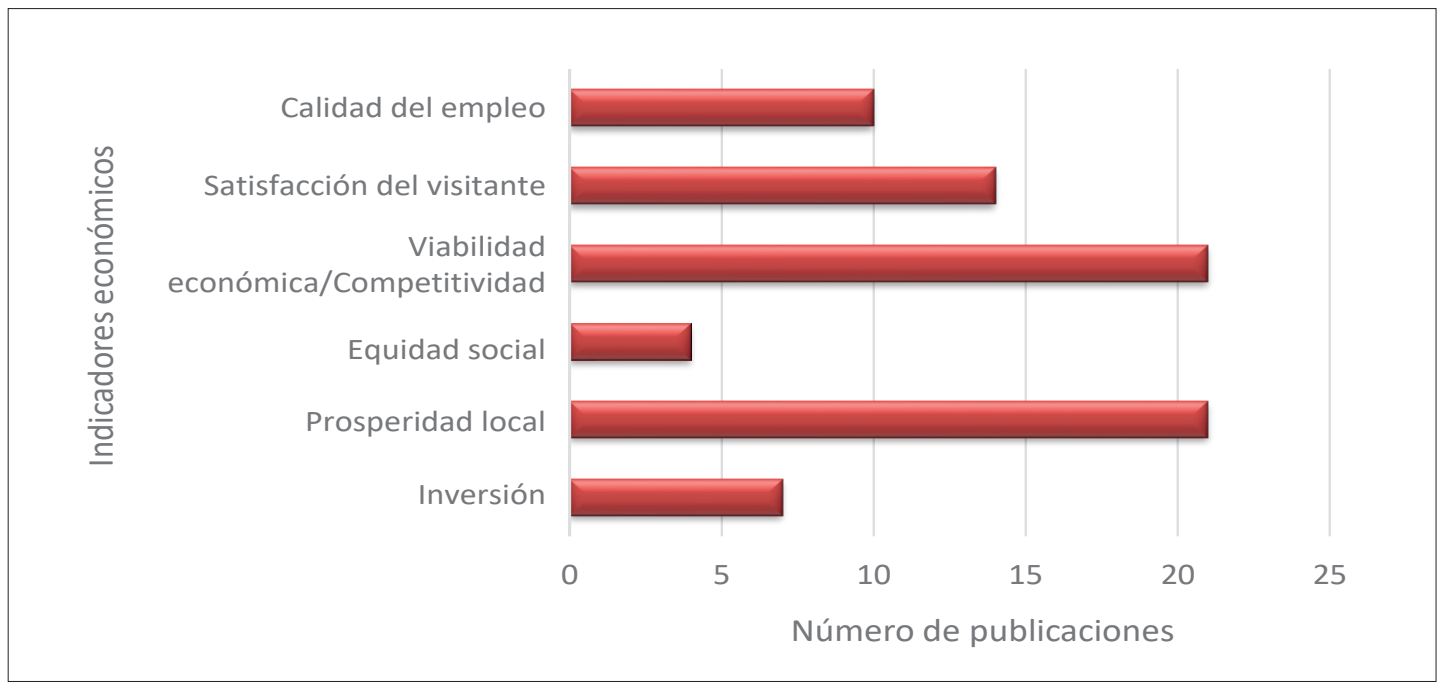

Fuente: Elaboración propia. 
Entre los hallazgos en este eje sustentable se encuentra el estudio realizado por Velarde et al. (2009), quienes hacen una aproximación a la realidad de dos comunidades, Cosalá y El Quelite, en Sinaloa y analizan los efectos derivados de las tareas realizadas para mejorar la imagen urbana, habilitar servicios y promover el involucramiento, la participación de las comunidades seleccionadas, así como la optimización del aprovechamiento racional de los recursos y atractivos tanto culturales como naturales, para el desarrollo turístico sustentable. Los resultados se conectan con la satisfacción del turista.

Se muestra que la llegada de turistas de mayor gasto está relacionada con el grado de satisfacción que experimentan durante su estancia, de ahí la importancia de que los prestadores de servicios conozcan los perfiles vinculados al turismo alternativo, que les ayude a tomar decisiones para incrementar el agrado del visitante.

Dentro del diagnóstico de competitividad y sustentabilidad en el PM de Cosalá, Sinaloa, elaborado por Velarde et al. (2014), se describen inversiones públicas realizadas para incentivar la diversificación de los servicios turísticos, como lo son museos, plazas, festivales de diferentes tipos (deportivos, gastronómicos, culturales, entre otros), así como la inversión en escuelas y conectividad; además, se encuentra la relación de los diferentes tipos de organismos públicos y privados que coadyuvan en la gestión de la actividad turística. En cuanto a la oferta del lugar, los autores sugieren que es necesario formar paquetes dirigidos al turista, donde se engloben diferentes actividades, a la par de fortalecer la calidad en la prestación de los servicios turísticos.

En este sentido, se encontró también el estudio de Treviño et al. (2015), quienes desarrollan un modelo econométrico con el fin de analizar el comportamiento del gasto de los visitantes en los PM de Guanajuato, dentro de un panorama turístico que incluye un análisis de las tendencias y competitividad de la actividad. Se destaca la importancia de ofrecer productos turísticos hechos a la medida y el hacer más atractivo el pernoctar en los PM. Igualmente, se sugiere la alianza estratégica entre destinos cercanos que fortalezcan la promoción de la marca PM aprovechando la proximidad geográfica.

Cruz et al. (2015) reconocen la importancia de la satisfacción del visitante del PM de Loreto, Baja California Sur como un indicador económico. A través de su estudio identifican la relación de este aspecto con otros como la seguridad pública, el paisaje y la fauna marina además de la gastronomía con que se cuenta, lo cual puede proporcionar mayores niveles de productividad. 
En la investigación realizada por Fernández (2016) se identifica a los PM como alternativa económica y social. Se profundiza en el discurso del gobierno, además de la visión de los inversionistas, empresarios turísticos y otros sectores que se ven beneficiados. Se menciona que los PM han servido para la rehabilitación del entorno arquitectónico e imagen urbana, recuperación de espacios, servicios y equipamiento; también, en menor escala, para impulsar el empleo, recursos comunitarios, diversificación económica y reorientación de actividades hacia la generación de ingresos en ciertos sectores sociales.

\section{Eje ambiental}

Relativo a las publicaciones en torno al eje ambiental del DS y su incidencia en los estudios publicados con relación a los PM, se encontró que la mayoría abordan el indicador de gestión del territorio, con 15 publicaciones. En segunda posición se encuentra el tema de la conservación de la biodiversidad, con un total de nueve trabajos; en comparación con los demás ejes del DS, este es el menos investigado (gráfica 4).

Gráfica 4. Número de estudios del eje ambiental por indicador

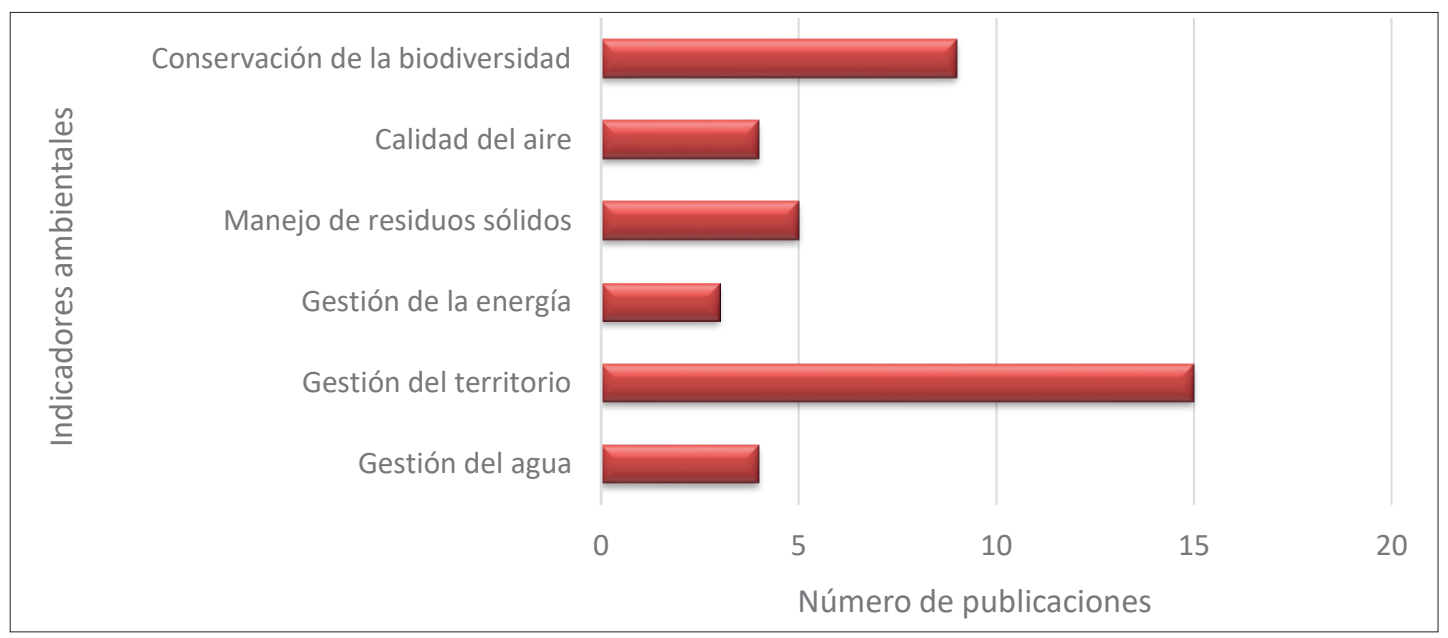

Fuente: Elaboración propia.

Entre los hallazgos de este eje se encuentra la investigación de Barbosa y Santamaría (2014a), en El Rosario, Sinaloa, mismo que a dos años de su nombramiento presentó una insuficiencia en el servicio del agua, ocasionada por problemas en el sistema de distribución y las malas condiciones de infraestructura, además de una falta de información respecto al uso del vital líquido por parte de los hoteles. Dentro del mismo diagnóstico, se plasma que la generación de basura representa un problema grave, ante la carencia de cultura ambiental, al no haber cooperación por parte de los habitantes. 
En la misma sintonía, en su revisión sobre la literatura relativa a los PM de Puebla y la sustentabilidad, García y López (2018) concluyen que las problemáticas ambientales han sido las menos atendidas. La sustentabilidad en los PM ha sido abordada en diferentes localidades. En su mayoría, el tema se desarrolló en alusión al programa de los pueblos en general, con un total de 10 publicaciones. Cosalá corresponde al PM más estudiado con seis documentos, seguido de Álamos, El Fuerte y El Rosario.

\subsection{Regiones de México}

La mayor parte de la investigación generada acerca de la sustentabilidad en los PM se concentra en la Región Centro del país, con 37 publicaciones (44\%), enseguida se tiene a la Región Noroeste como la segunda más estudiada, con 25 (30\%), en tercera posición se encuentra la Región Occidente con 16 documentos (19\%); para finalizar, con seis estudios (7\%), se ubica la Región Sureste. Cabe mencionar que del total de los documentos no se encontró alguno que pertenezca a la Región Noreste de México, como se puede observar en la gráfica 5.

Gráfica 5. Publicaciones por región del país

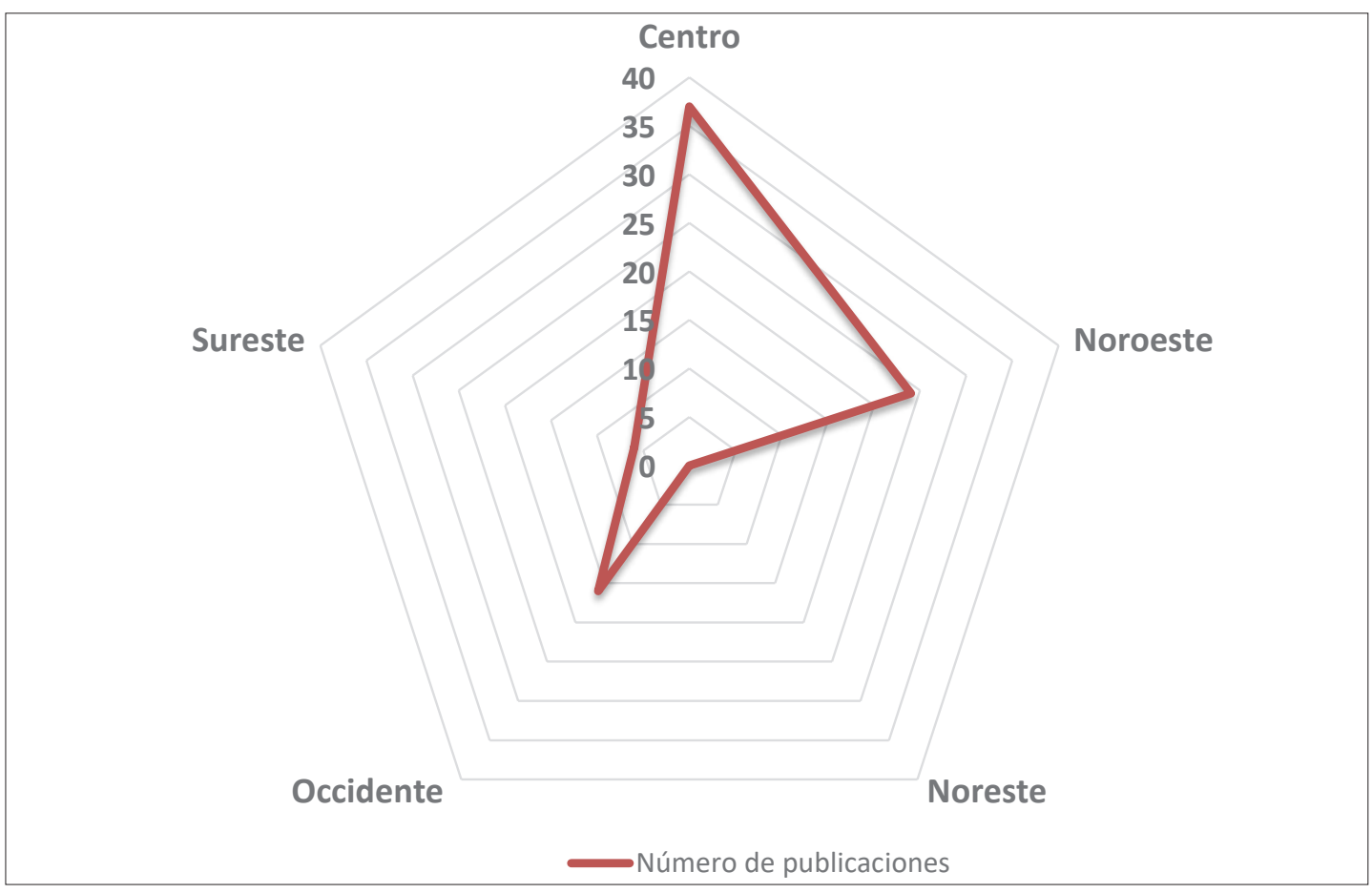

Fuente: Elaboración propia. 


\section{Región Noroeste}

La revisión realizada muestra que en la Región Noroeste del país se realizaron estudios en los siguientes siete destinos: Álamos, Cosalá, El Fuerte, El Rosario, Magdalena de Kino, Loreto y Todos Santos (gráfica 6). Cosalá es donde se centran la mayor parte de las investigaciones y Magdalena de Kino el menos estudiado; sin embargo, México cuenta con otros PM dentro de esta región de los cuales aún no se ha generado información relacionada con la sustentabilidad.

Gráfica 6. Número de publicaciones por Pueblo Mágico en la Región Noroeste

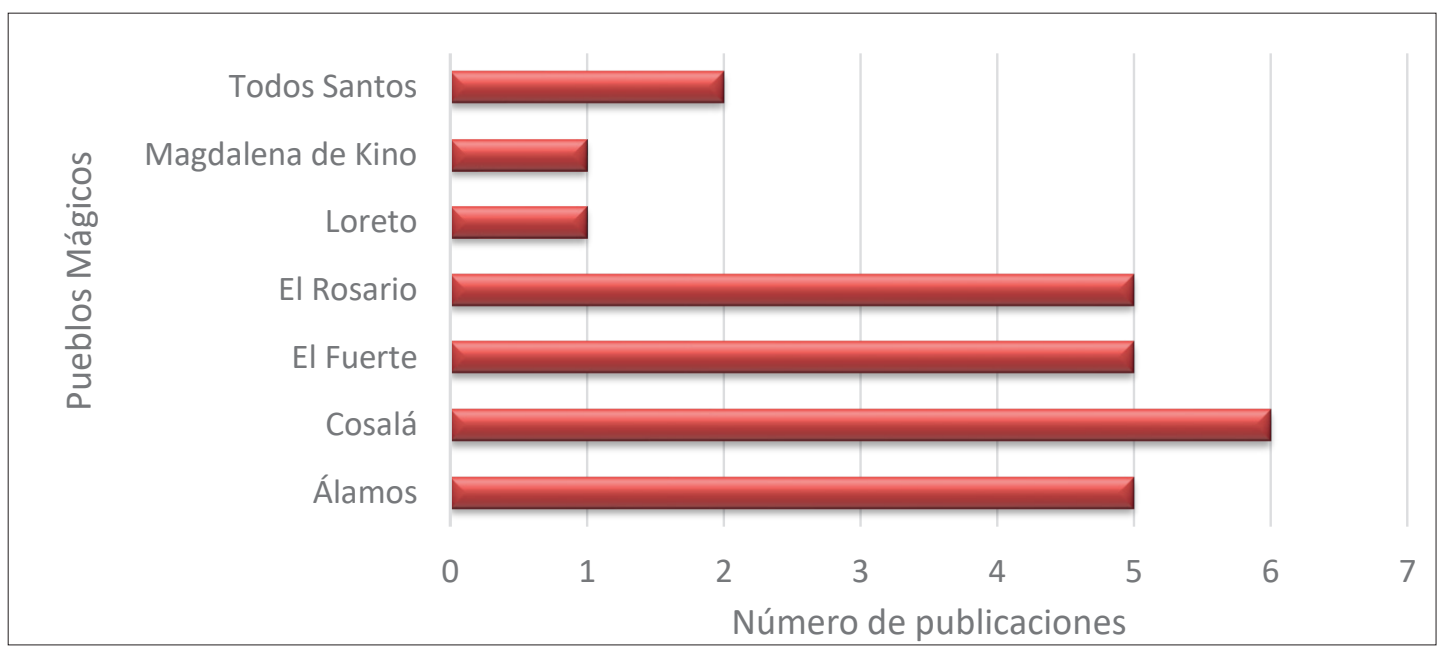

Fuente: Elaboración propia.

\section{Región Centro}

De acuerdo con los documentos analizados, los PM que se han estudiado desde una perspectiva sustentable son Atlixco, Chignahuapan, Cholula, Cuetzalan, El Oro de Hidalgo, Huauchinango, Huasca de Ocampo, Pahuatlán del Valle, Taxco, Tepotzotlán, Tepoztlán, Tlatlauquitepec, Tlayacapan, Valle de Bravo, Xicotepec y Zacatlán, de los cuales, Tepotzotlán y Tepoztlán son los que más estudios tienen con cuatro publicaciones cada uno, enseguida se encuentran El Oro de Hidalgo, Huasca de Ocampo, Xicotepec y Zacatlán con tres estudios respectivamente (gráfica 7). 
Gráfica 7. Número de publicaciones por Pueblo Mágico en la Región Centro

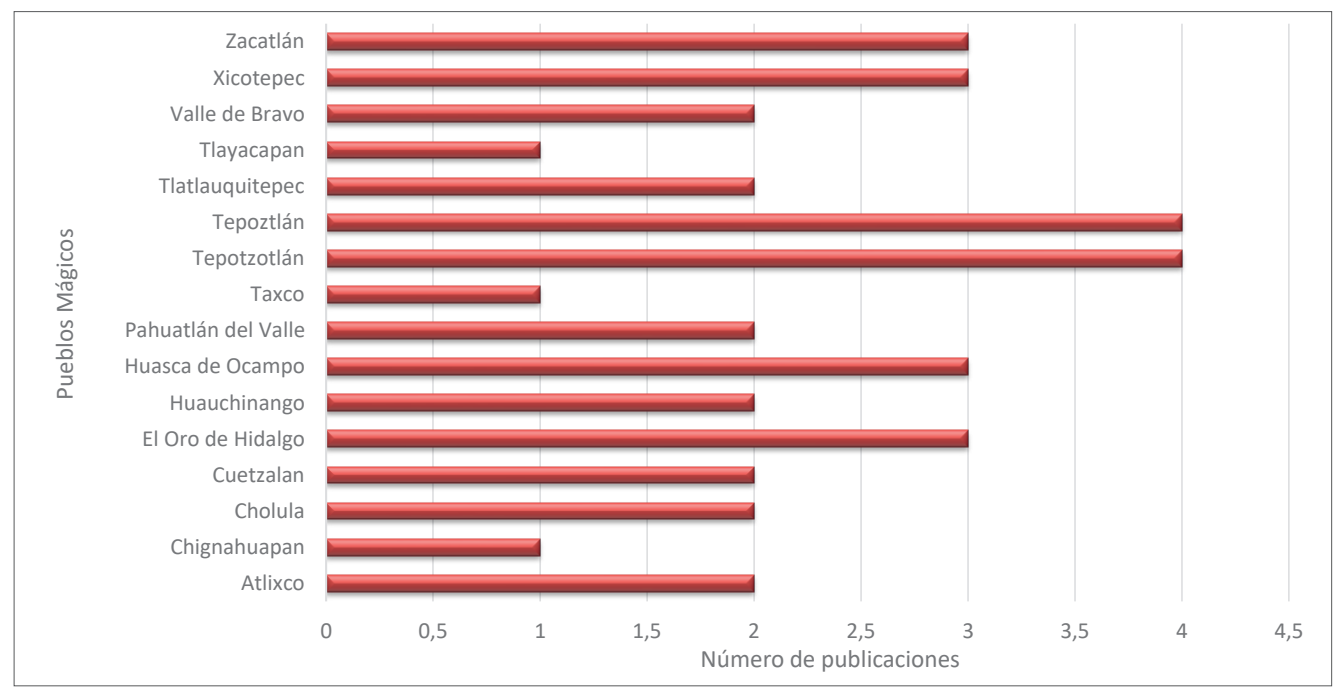

Fuente: Elaboración propia.

\section{Región Occidente}

En cuanto a la Región Occidente de México, se pueden rescatar 14 PM analizados desde la sustentabilidad, de los cuales Tequila y Comala aparecen como los más revisados, con dos publicaciones cada uno; los demás cuentan con una sola publicación cada uno: Calvillo, Celaya, Cuitzeo, Dolores Hidalgo, Irapuato, Jalostotitlán, León, Real de Asientos, Salamanca, San Miguel de Allende, Silao y Tlalpujahua (gráfica 8).

Gráfica 8. Número de publicaciones por Pueblo Mágico en la Región 0ccidente

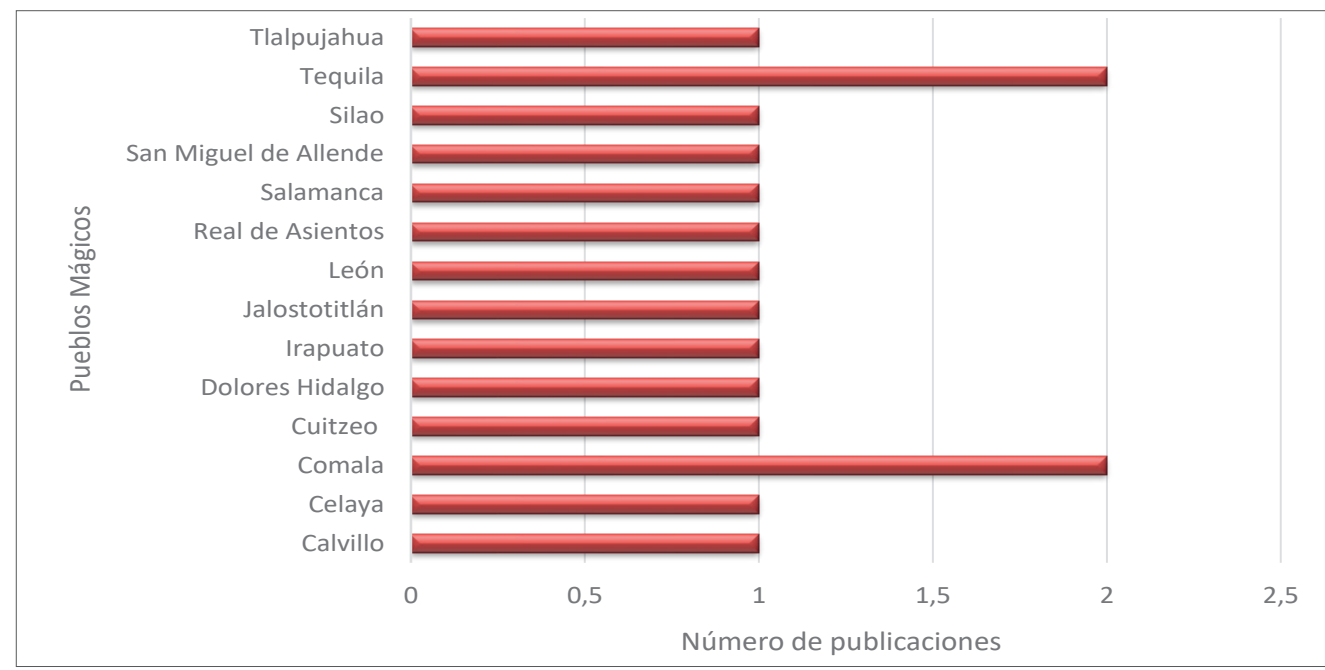

Fuente: Elaboración propia. 


\section{Región Sureste}

Dentro de la Región Sureste se localizaron solo cuatro PM con algún tipo de estudio publicado acerca del DS y de cómo su nombramiento tiene relevancia en el turismo. Con dos publicaciones se ubicó a los pueblos de Capulálpam y Tapijulapa como los más estudiados, y a Coatepec e Izamal con solo un estudio cada uno (gráfica 9).

Gráfica 9. Número de publicaciones por Pueblo Mágico en la Región Sureste

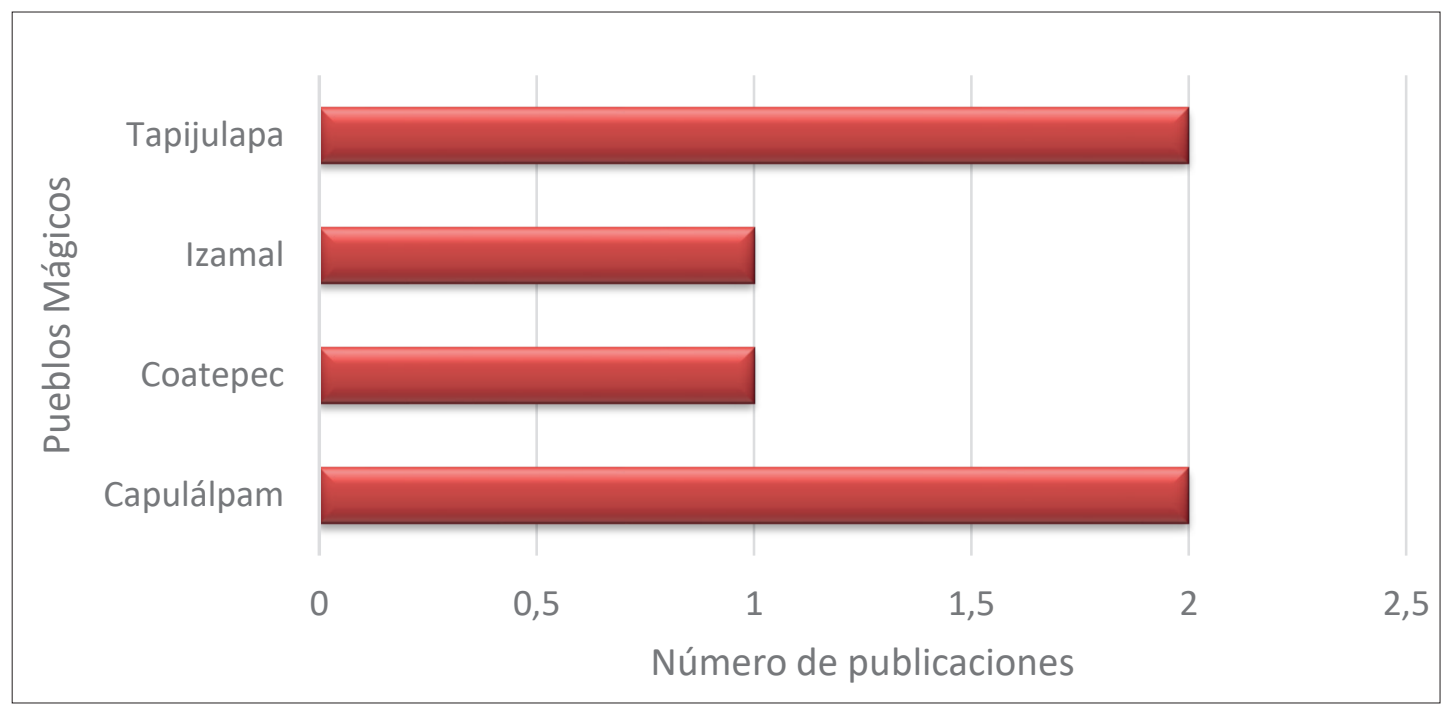

Fuente: Elaboración propia.

\section{Discusión}

De acuerdo con la revisión de la literatura mencionada, el programa de los PM, como estrategia para revalorar las localidades y contribuir al bienestar social, no ha concretado completamente su objetivo (Valverde y Benavides, 2017), por lo que es indispensable revisar y redirigir las estrategias con la perspectiva de las personas involucradas, es decir, de los actores que se ven incluidos dentro de las actividades turísticas de estos destinos.

Los autores coinciden en que la designación de los PM puede, en gran medida, impulsar el crecimiento de economías a través del turismo, pero no necesariamente el DS, ya que se perciben temas como la discriminación y el racismo, tal es el caso de los indígenas nativos de algunos de estos pueblos, lo que constituye un problema social que desequilibra el desarrollo. 
Adicionalmente, como lo mencionan Castillo et al. (2018), la relación turista-residente y el desarrollo de la misma industria son los dos hechos principales que impulsan los cambios en la calidad de vida de la comunidad local, lo cual contribuye también a la satisfacción de los habitantes en materia de la actividad turística y sus componentes específicos.

Sin embargo, los programas en estos temas mayormente presentan problemas que, lejos de seguir una tendencia hacia el desarrollo sustentable de las localidades asignadas como PM, desvían su mirada hacia la creación de imaginarios que distorsionan la imagen real de las comunidades, como lo menciona el estudio de Figueroa et al. (2015).

Los impactos que se desprenden del turismo, sobre las sociedades y el entorno, hacen imperantes los cambios hacia formas más sustentables; esto es, promover un equilibrio entre los tres ejes fundamentales que son la economía, la sociedad y el medioambiente, para caminar hacia un DS de las comunidades receptoras, que asegure tanto el bienestar social, económico y ambiental, incluyendo, claro está, la existencia de las actividades turísticas.

Por ejemplo, Equihua et al. (2015) detectan en la literatura afín el hecho de que en algunas localidades con dicho nombramiento se han producido efectos negativos, como lo es la aceleración de cambios sociales y actividades económicas, es decir, no se alcanza una derrama de divisas en el territorio, ni se aumentan los niveles de bienestar de la población, además del incremento demográfico en algunos casos. Por lo tanto, el programa de PM también trae consigo presión sobre la población vinculada al turismo y muestra como uno de los puntos más débiles el aspecto ambiental, lo que sugiere dar una mayor atención y seguimiento a la dimensión ecológica y sustentable de los PM.

La realidad es que no se brinda dicha atención y seguimiento, lo que se hace evidente en el total de publicaciones realizadas y analizadas en este trabajo, dado que solo un $16 \%$ alude a la dimensión ambiental de la sustentabilidad. A lo largo de este análisis acerca de la producción científica que aborda la sustentabilidad en los PM, se encontró que solo se han estudiado 41 de los 121 PM existentes en México en torno al tema del DS, de los cuales la mayoría se concentran en la Región Centro de la República (45\%). Se identifica de este modo la falta de investigación en otros destinos, mayormente en la Región Noreste del país, ya que no se localizaron documentos que diserten acerca de los ejes de sustentabilidad en esa zona. 
Asimismo, se identificó solamente un trabajo de alcance internacional, en donde se trata el tema del turismo cultural en una comparación entre Argentina, México y Brasil, en los que se describen los avances y desafíos de cada país. Ante ello, se observa como necesario el incremento de estudios de alcance global, para así enriquecer la información acerca de destinos similares a los PM y encontrar oportunidades que se ofrecen en diferentes lugares.

\section{Conclusiones}

El análisis de los estudios acerca de los PM como destinos turísticos, junto con el tema del DS, refiere que estos se concentran en el eje sociocultural con variables como la satisfacción del residente, patrimonio y riqueza cultural, gastronomía, bienestar, seguridad, equidad de género, gobernanza y planeación urbana, seguido del eje económico que contempla variables como la inversión, la prosperidad, la equidad social, la competitividad, la viabilidad económica, la satisfacción del visitante y la calidad del empleo. Finalmente, en menor medida, retoman el eje ambiental con variables como gestión del agua, territorio y energía, manejo de residuos, calidad del aire y conservación. Algunos trabajos que integran los tres ejes se analizaron y contabilizaron por separado en el eje correspondiente.

Cabe señalar que aunque existen publicaciones que analizan los PM y la sustentabilidad en todo el periodo observado (2005-2019), los resultados muestran un repunte significativo en el año 2015, con una disminución de investigaciones para el 2017, así como una reducción aún mayor en 2018 y el primer trimestre del 2019. Posiblemente se deba a los eventos históricos que despiertan el interés en el tema, como la nueva Agenda 2030 que se dio a conocer ese mismo año (2015).

De igual manera, no se encuentra producción sobre el DS en los PM en el año 2012, lo que nos lleva a relacionarlo con la actividad que tuvo lugar en la conferencia de las Naciones Unidas sobre el Desarrollo Sostenible (Río+20), en donde se debatieron los temas de economía verde para erradicar la pobreza y buscar la forma de tener una mejor coordinación internacional, por lo que se percibe una disminución en la importancia de los PM para el DS.

Los resultados muestran que es importante fortalecer los estudios de tipo cuantitativo, donde se aborden contextos estructurales y situacionales, además de los mixtos, que analicen datos numéricos, variables textuales, visuales y simbólicas, ya que 
dichas metodologías tienen el menor número de trabajos referidos en este texto, distinguiéndose con una gran mayoría (77\%) los estudios de corte cualitativo, los cuales se centran en el eje sociocultural.

Adicionalmente, la región del país menos favorecida con estudios de la sustentabilidad en PM es la Noreste, donde no se encontró investigación alguna. Lo anterior permite vislumbrar los huecos de información existentes para futuras exploraciones. Las regiones con mayor número de trabajos son la Centro: Ciudad de México, Estado de México, Guerrero, Hidalgo, Morelos, Puebla y Tlaxcala, y la Noroeste: Baja California, Baja California Sur, Chihuahua, Durango, Sonora y Sinaloa.

Los tipos de publicación analizados en su mayoría son artículos, seguidos de capítulos de libros y, en menor medida, libros completos. Asimismo, la generalidad de los estudios revisados se enfoca en la categoría geográfica local, con enfoque en un solo PM.

La importancia del DS en el sector turístico y algunos temas ambientales han marcado una fuerte tendencia, al pasar de un turismo que trae desgastes tanto sociales, económicos y ambientales, a un modelo alternativo que se preocupa por el equilibrio de estos tres ejes fundamentales; por ello, es necesario que las investigaciones del turismo sustentable se conjuguen cada vez más con los PM, los cuales tienen estrategias interesantes basadas en la sustentabilidad.

\section{Referencias}

Almada, R. (2005). Cultura, identidad política y multiculturalidad en Todos Santos, BCS. Espiral, Estudios sobre Estado y Sociedad, 11(32) 123-150. https://bit. ly/3kEYgKf

Alvarado, C. (2015). Conservación del patrimonio cultural en el Pueblo Mágico de Tepoztlán, Morelos (2001-2012). Territorios, 32, 15-33. https://doi.org/10.12804/ territ32.2015.01

Alvarado, C., Ruiz, C., Valenzuela, A. y Saldaña, M. (2017). El programa Pueblos Mágicos y el desarrollo sustentable en Tepoztlán. En J. Enríquez, M. Guillén y B. Valenzuela (Eds.), Patrimonio y turismo (pp. 175-199). QARTUPPI. https://bit. ly/3mMQPT5 
Álvarez-Quijada, R. (2017). Percepción ciudadana sobre el programa de Pueblos Mágicos. Estudio estadístico en Álamos, Sonora. En J. Enríquez, M. Guillén y B. Valenzuela (Eds.), Patrimonio y turismo (pp. 70-86). QARTUPPI. https://bit. ly/3mMQPT5

Balslev, H. y Velázquez, M. (2013). El turismo cultural en Argentina, México y Brasil. Avances y desafíos. Diálogos Latinoamericanos, 21, 9-30. https://bit.ly/2Z3X$\mathrm{cHz}$

Barbosa, A. y Santamaría, A. (2014a). Diagnóstico sobre competitividad y sustentabilidad de El Rosario, Sinaloa. Secretaría de Turismo. https://bit.ly/2WRyZ3B

Barbosa, A. y Santamaría, A. (2014b). Agenda de competitividad y sustentabilidad en El Fuerte, Sinaloa. Secretaría de Turismo. https://bit.ly/2YYMikA

Bertoni, M. (2008). Turismo sostenible: su interpretación y alcance operativo. Cuadernos de Geografía, 17, 155-163. https://doi.org/10.15446/rcdg.n17.10925

Castillo, E., Santoyo, V., Muñoz, M. y Rodríguez, B. (2018). Patrimonio gastronómico y desarrollo local en dos Pueblos Mágicos de México. RIVAR, Revista lberoamericana de Viticultura, Agroindustria y Ruralidad, 5(15), 22-38. https:// bit.ly/3iUCRwn

Christian, M., Fernandez-Stark, K., Ahmed, G. y Gereffi, G. (2011). The tourism global value chain. Center on Globalization, Governance y Competitiveness. https:// bit.ly/3i1 Kb8c

Cornejo-Ortega, J., Andrade-Romo, E., Chávez-Dagostino, R. y Espinoza-Sánchez, R. (2018). Percepción de la población local y turistas sobre los impactos del turismo en el Pueblo Mágico de Tapalpa, Jalisco, México. PASOS, Revista de Turismo y Patrimonio Cultural, 16(3), 745-754. https://doi.org/10.25145/j. pasos.2018.16.053

Coronado, Y. (2016). El ecoturismo como opción para el desarrollo local sustentable en el Pueblo Mágico de Tlalpujahua, Michoacán [tesis de maestría, Instituto Politécnico Nacional]. Repositorio Dspace. https://bit.ly/3cIZQO8

Covarrubias, R., Vargas, A. y Rodríguez, I. (2010). Satisfacción de residentes con el desarrollo de la actividad turística en los Pueblos Mágicos de México: un in- 
dicador de competitividad. Casos de Comala en Colima y de Real de Asientos en Aguascalientes. Gestión Turística, 14, 33-54. https://bit.ly/2XHmOXN

Cruz, P., Juárez, J., Cruz, G. y Urciaga, J. (2015). Evaluación del visitante en el Pueblo Mágico de Loreto. Revista Global de Negocios, 3(6), 89-97. https://bit.ly/3clJ4il

De la Rosa, B., Cruz, G. y Sánchez, F. (2016). Redes de política, élites y gobernanza. Marco teórico para el estudio de un caso turístico. PASOS, Revista de Turismo y Patrimonio Cultural, 14(3), 595-610. https://doi.org/10.25145/j. pasos.2016.14.039

Diario Oficial de la Federación (DOF). (2013). Acuerdos aprobados en la ll sesión extraordinaria del Consejo Nacional de Seguridad Pública. https://bit.ly/36ATBFt

Díaz, R. y Escárcega, S. (2009). Desarrollo sustentable, oportunidad para la vida. McGraw-Hill.

Devesa, M. y Palacios, A. (2005). Predicciones en el nivel de satisfacción percibida por los turistas a partir de las variables motivacionales y de la valoración de la vista. Informacion Comercial Española, Revista de Economía, 821, 241-256. https://bit.ly/3iX7jF5

Domínguez, M., Guzmán, M. y Sánchez, J. (2016). Indicadores de desarrollo: estudio de caso Pueblos Mágicos. Secretaría de Turismo. https://bit.ly/32U580f

Enciso, J. (2015). Real del Monte, Hidalgo ¿una experiencia de éxito? En L. López, C. Valverde y M. Figueroa (Coords.), Pueblos Mágicos, una visión interdisciplinaria (pp. 135-158). Universidad Autónoma Metropolitana.

Equihua, G., Messina, R. y Juan, R. (2015). Los Pueblos Mágicos: una visión crítica sobre su impacto en el desarrollo sustentable del turismo. Fuente Nueva Época, 6(22), 1-7. https://bit.ly/2IkIC7V

Espinoza, R., Barreras, V., Cornejo-Ortega, J. y Andrade, E. (2017). Percepción de la población local sobre los impactos del desarrollo turístico del Pueblo Mágico de Mascota, Jalisco. Turydes, Revista de Turismo y Desarrollo, 10(22) 1-20. https://bit.ly/2UJpHJO 
Estrella, J. (2015). Izamal, Yucatán ¿tradición o invención? En L. López, V. Carmen, y M. Figueroa (Coords.), Pueblos Mágicos, una visión interdisciplinaria (pp. 4561). Universidad Autónoma Metropolitana.

Fernández, A. (2013). Huasca de Ocampo: visitar, habitar, sentir, opinar. Topofilia, Revista de Arquitectura, Urbanismo y Ciencias Sociales, 4(3), 1-21. https://bit. ly/3clCVT8

Fernández, A. (2016). Una revisión del programa Pueblos Mágicos. Cultur, 10(1), 3-34. https://bit.ly/2FTnzt0

Fernández, A. (2018). Turismo, negocio o desarrollo: el caso de Huasca, México. PASOS, Revista de Turismo y Patrimonio Cultural, 16(1), 233-251. https://doi. org/10.25145/j.pasos.2018.15.015

Figueroa, M. (2015). Zacatlán de las Manzanas, Puebla. Configurando el modelo de Pueblo Mágico. En L. López, C. Valverde y M. Figueroa (Coords.), Pueblos Mágicos, una visión interdisciplinaria (pp. 299-321). Universidad Autónoma Metropolitana.

Franco, L. y Enciso, J. (2017). Turismo y patrimonio. Planeando la Imagen urbana: turismo y economía en los Pueblos Mágicos. En J. Enríquez, G. Manuela y B. Valenzuela (Eds.), Patrimonio y turismo (pp. 201-216). QARTUPPI. https://bit. ly/3mMQPT5

García, D. y Guerrero, H. (2014). El programa Pueblos Mágicos: análisis de los resultados de una consulta local ciudadana. El caso de Cuitzeo, Michoacán, México. Economía y Sociedad, 18(31), 71-94. https://bit.ly/2G0Qqvj

García, E. y López, V. (2018). Propuesta de una agenda para la investigación del turismo sustentable en los Pueblos Mágicos de Puebla. Regiones y Desarrollo Sustentable 18(34), 9-26. https://bit.ly/2U4XCbv

García, P., Gatica, M., Cruz, E., Vargas, R., Hernández, J., Luis, K. y De los Santos, S. (2016). Pueblos mágicos en Puebla y su aportación al desarrollo regional. Revista Iberoamericana de las Ciencias Sociales y Humanísticas, 5(10), 1-13. https://doi.org/10.23913/ricsh.v5i10.87 
González, F. (2015). Coatepec, Veracruz: turismo, patrimonio y territorio. En L. López, C. Valverde y M. Figueroa (Coords.), Pueblos Mágicos, una visión interdisciplinaria (pp.199-225). Universidad Autónoma Metropolitana.

González, L. (2015). Xico, Veracruz. Tapetes, danzas y sueños. En L. López, C. Valverde y M. Figueroa (Coords.), Pueblos Mágicos, una visión interdisciplinaria (pp. 357-371). Universidad Autónoma Metropolitana.

Guillén, M., Valenzuela, B. y Salas, I. (2017). Patrimonio y significación en ciudades turísticas de tradición agrícola: el caso de El Fuerte, Sinaloa. En J. Enríquez, M. Guillén y B. Valenzuela (Eds.), Patrimonio y turismo (pp. 37-49). QARTUPPI. https://bit.ly/3mMQPT5

Gutiérrez, C. (2015). Pahuatlán de Valle. Tradición y cultura en la Sierra Norte de Puebla. En L. López, C. Velarde y M. Figueroa (Coords.), Pueblos Mágicos, una visión interdisciplinaria (pp. 407-428). Universidad Autónoma Metropolitana.

Guzmán, V. (2015). El Oro de Hidalgo, Estado de México. Turismo y minería, juego de ensueños y desinformación. En L. López, C. Valverde y M. Figueroa (Coords.), Pueblo Mágicos, una visión interdisciplinaria (pp. 323-356). Universidad Autónoma Metropolitana.

Hernández, A. y López, R. (2015). Sombrerete, Zacatecas. Imaginario histórico de la minería colonial. En L. López, C. Valverde y M. Figueroa (Coords.), Pueblos Mágicos, una visión interdisciplinaria (pp. 373-405). Universidad Autónoma Metropolitana.

Hernández, D., Castrillo, M., Vargas, E. y Cruz, G. (2017). La transversalidad en la política turístico cultural del pueblo mágico de Metepec, México. Entreciencias: Diálogos en la Sociedad del Conocimiento, 5(13), 29-45. https://bit.ly/3iUhYkJ

Hernández, J. (2009). Tequila: centro mágico, pueblo tradicional ¿patrimonialización o privatización? Andamios, 6(12), 41-67. https://doi.org/10.29092/uacm. v6i12.134

Hernández, R., Fernández, C. y Baptista, L. (2014). Metodología de la investigación. McGraw-Hill. 
Hoyos, G. y Hernández, O. (2008). Localidades con recursos turísticos y el programa Pueblos Mágicos en medio del proceso de la nueva ruralidad. Los casos de Tepotzotlán y Valle de Bravo en el Estado de México. Quivera, 10(2), 111-130. https://bit.ly/2ZXhGlw

Ibáñez-Pérez, R., Vázquez-Hurtado, M. y Olmos-Martínez, E. (2015). Desenvolvimiento y características del turismo en dos destinos de playa. Estudio comparativo de La Paz, Baja California Sur, y Mazatlán, Sinaloa. En S. Flores y L. Flores (Eds.), Turismo en el sur de Sinaloa (pp. 25-49). Universidad Tecnológica de Escuinapa y el Instituto de apoyo a la investigación e innovación de Sinaloa.

Ibarra-Michel, J. y Velarde, M. (2016). El Programa Pueblos Mágicos y la sustentabilidad turística; el caso de Cosalá y los eventos "Cosaltazo" y "Cosalazo". El Periplo Sustentable, 31. https://bit.ly/3cjF41K

Jiménez, F., Muñoz, A. y Charneca, C. (2018). Modelo de turismo humano para el bienestar de Tapijulapa Pueblo Mágico, Tabasco, México. PASOS, Revista de Turismo y Patrimonio Cultural, 16(3), 685-700. https://doi.org/10.25145/j. pasos.2018.16.049

Landeros, H., Gomora, M. y Castañeda, T. (2015). Enfoques de análisis en Pueblos Mágicos: ¿eficacia o eficiancia? Asociación Mexicana de Ciencias para el DesarroIlo Regional.

Levi, S. (2015). Metepec, Estado de México. Entre la tradición y la modernidad. En L. López, C. Valverde y M. Figueroa (Coords.), Pueblos Mágicos una visión interdisciplinaria (pp. 429-449). Universidad Autónoma Metropolitana.

Liu, Z. (2003). Sustainable tourism development: a critique. Journal of Sustainable Tourism, 11(6), 459-475. https://doi.org/10.1080/09669580308667216

López, L. (2018). Las territorialidades del turismo: el caso de los Pueblos Mágicos en México. Atelié Geográfico, 12(1), 6-24. https://doi.org/10.5216/ag.v12i1.45803

López, O. (2017). Construcción de un índice de satisfacción del turismo en Capulálpam, Pueblo Mágico. PASOS, Revista de Turismo y Patrimonio Cultural, 15(4), 785-792. https://doi.org/10.25145/j.pasos.2017.4.002 
Luyando, J., Sandoval, L. y Ortega, E. (2016). El capital social como factor para el desarrollo en el Pueblo Mágico de Tapijulapa. El Periplo Sustentable, 31, 1-24. https://bit.ly/35WxhG7

Madrid, F. (2013). La gobernanza en turismo como un factor para alcanzar destinos turísticos exitosos: el caso de los Pueblos Mágicos de México. Universidad de Nebrija.

Mariño, J., Flores, S. y Bonilla, J. (2018). Sostenibilidad versus "sustentabilidad", una propuesta integradora que desvirtúa su uso homólogo. Opción, 34(87), 1-22. https://bit.ly/32OMZko

Martínez, C. (2013). Pueblos mágicos y nuevas ruralidades. El caso de Álamos, Sonora. Diálogos Latinoamericanos, 21, 31-45. https://bit.ly/2ZXidE2

Martínez, R. y Mínguez, M. (2015). El turismo religioso como elemento revalorizador de una tradición local: la incorporación de Jalostotitlán a los Pueblos Mágicos. International Journal of Scientific Management and Tourism, 2, 53-79. https://bit.ly/363DKyK

Melón, H. (2016). La protección constitucional del medio ambiente sano en Colombia. Colección Vítor, Ediciones Universidad de Salamanca.

Méndez, E. y Rodríguez, I. (2015). Álamos, Sonora, recreo para sus dioses. En L. López, C. Valverde y M. Figueroa (Coords.), Pueblos Mágicos, una visión interdisciplinaria (pp. 159-182). Universidad Autónoma Metropolitana.

Muñoz, E. (2011). Entre la vocación turística y la devoción. Percepciones sociales del patrimonio cultural en un contexto turístico. El caso de Malinalco, Estado de México. PASOS, Revista de Turismo y Patrimonio Cultural, 9(1), 115-568. https:// doi.org/10.25145/j.pasos.2011.09.010

Olivera, M. y Fernández, A. (2015). San Cristóbal de las Casas, Chiapas, colonial e ¿indígena? En L. López, C. Valverde y M. Figueroa (Coords.), Pueblos Mágicos, una visión interdisciplinaria (pp. 113-134). Universidad Autónoma Metropolitana.

Organización de las Naciones Unidas (ONU). (1987). Informe Brundtland. https:// bit.ly/34bONUa 
Organización de las Naciones Unidas (ONU). (2000). Objetivos de Desarrollo del Milenio. https://bit.ly/34dTcGh

Orgaz, F. y Moral, S. (2016). El turismo como motor potencial para el desarrollo económico de zonas fronterizas en vías de desarrollo. Un estudio de caso. El Periplo Sustentable, 31. https://bit.ly/2uOtcjt

Palafox-Muñoz, A. (2016). Nueva ruralidad y sustentabilidad social en el Pueblo Mágico de Calvillo, Aguascalientes. Revista Iberoamericana de Turismo, 6, 64-81. https://doi.org/10.2436/20.8070.01.14

Pérez-Ramírez, C. y Antolín-Espinoza, D. (2016). Programa Pueblos Mágicos y desarrollo local: actores y perspectivas en El Oro, México. Estudios Sociales, 25(47), 219-243. https://doi.org/10.24836/es.v25i47.315

Pulido-Fernández, M. y Pulido-Fernández, J. (2014). ¿Existe gobernanza en la actual gestión de los destinos turísticos? Estudio de casos. PASOS, Revista de Turismo y Patrimonio Cultural, 12(4), 685-705. https://bit.ly/32R2dFB

Quiroz, L. (2015). Taxco de Alarcón, Guerrero, un pueblo minero. En L. López, C. Valverde, y M. Figueroa (Coords.), Pueblos Mágicos, una visión interdisciplinaria (pp. 21-43). Universidad Autónoma Metropolitana.

Rodríguez, I. (2013). Desafío y dilema en la política pública del "Pueblo Mágico" mexicano. Topofilia, Revista de Arquitectura, Urbanismo y Ciencias Sociales, 4(3), 1-22. https://bit.ly/2ZU6shF

Rodríguez, S. (2015). Capulálpam de Méndez, Oaxaca. La magia y la comunidad. En L. López, C. Valverde, y M. Figueroa (Coords.), Pueblos Mágicos, una visión interdisciplinaria (pp. 249-271). Universidad Autónoma Metropolitana.

Rodríguez, S., Pulido-Fernández, J. y Rodríguez, I. (2017). El producto turístico en los Pueblos Mágicos de México. Un análisis crítico de sus componentes. Revista de Estudios Regionales, 108, 125-163. https://bit.ly/3mIOU1S

Rodríguez, S., Rojo, C. y Castañeda, E. (2015). La puesta de valor del patrimonio arquitectónico en Pueblos Mágicos sinaloenses. Topofilia, Revista de Arquitectura, Urbanismo y Territorios, 5(1), 1-17. https://bit.ly/35U44vm 
Rodríguez, S. y Rojo, S. (2015). Cosalá, Sinaloa, el imaginario cosalteco entre significados y representaciones. En L. López, C. Valverde, y M. Figueroa (Coords.), Pueblos Mágicos, una visión interdisciplinaria (pp. 183-197). Universidad Autónoma Metropolitana.

Rodríguez, S. y Vargas, R. (2013). Sistema turístico de pueblos mexicanos: oferta turística a través del programa Pueblos Mágicos. Topofilia, Revista de Arquitectura, Urbanismo y Ciencias Sociales, 4(3), 307-327. https://bit.ly/3iT5oCr

Rodríguez, S. y Vargas, R. (2015). Nuevas rutas en el sistema turístico de Pueblos Mágicos de Sonora y Sinaloa. Topofilia, Revista de Arquitectura, Urbanismo y Territorios, 5(1), 1-17. https://bit.ly/3cjGysQ

Rohan, I. (2016, 9 de octubre). Turismo responsable, sustentable, sostenible: ¿cuál es la diferencia? Travindy. https://bit.ly/2FTmlbM

Rojo, S., Rodríguez, S. y Castañeda, R. (2017). Del espacio vivido a los lugares de encuentro turístico: El Rosario Pueblo Mágico. En J. Enríquez, M. Guillén, y B. Valenzuela (Eds.), Patrimonio y turismo (pp. 51-68). QARTUPPI. https://bit. ly/3mMQPT5

Rosas-Jaco, I., Almeraya-Quintero, X. y Guajardo-Hernández, G. (2017). Los comités Pueblos Mágicos y el desarrollo turístico: Tepotzotlán y El Oro, Estado de México. Agricultura, Sociedad y Desarrollo, 14(1), 105-123. https://doi. org/10.22231/asyd.v14i1.525

Royuela, M. y Ramírez, I. (2015). Patrimonialización, desarrollo, gobernanza y gubernamentalidad en Malinalco, Pueblo Mágico. Revista de Cultura y Turismo, 9(2), 92-114. https://bit.ly/2FPVCT5

Saiz-Álvarez, J. (2018). Turismo sostenible y emprendimiento social. El Pueblo Mágico de Tequila, México. RETOS, Revista de Ciencias de la Administración y la Economía, 8(5), 51-67. https://doi.org/10.17163/ret.n15.2018.04

Sánchez, V. y Barbosa, A. (2017). Seguridad turística en los Pueblos Mágicos: El Fuerte y El Rosario, Sinaloa. Topofilia, Revista de Arquitectura, Urbanismo y Territorios, 10(14), 108-117. https://bit.ly/3cleGon 
Secretaría de Turismo (Sectur). (2014). Indicadores de competitividad y sustentabilidad de Pueblos Mágicos. https://bit.ly/2ZX3Lfy

Secretaría de Turismo (Sectur). (2015). Perfil y grado de satisfacción del turista. Secretaría de Turismo y Universidad de Colima.

Secretaría de Turismo (Sectur). (2020, 5 de junio). Pueblos mágicos de México. https://bit.ly/2FUAPOC

Treviño, E., Heald, J. y Guerrero, R. (2015). Un modelo del gasto con factores sociodemográficos y de hábitos de viaje en Pueblos Mágicos del Estado de Guanajuato, México. Investigaciones Turísticas, 10, 117-149. https://doi.org/10.14198/ INTURI2015.10.06

Valenzuela, A. (2017). Patrimonio, turismo y mercado inmobiliario en Tepoztlán, México. PASOS, Revista de Turismo y Patrimonio Cultural, 15(1), 181-193. https:// doi.org/10.25145/j.pasos.2017.15.011

Valenzuela, A., Saldaña, M. y Vélez, G. (2013). Territorios rebeldes: la puesta en valor del patrimonio cultural en Tepoztlán, México. PASOS, Revista de Turismo y Patrimonio Cultural, 11(4), 649-660. https://doi.org/10.25145/j.pasos.2013.11.057

Valverde, C. y Benavides, M. (2017). El turismo en México, una visión hacia el futuro. Planur-e, 9, 1-15. https://bit.ly/2YXCJCH

Valverde, M. y Enciso, J. (2013). La magia de los pueblos ¿atributo o designación? Topofilia, Revista de Arquitectura, Urbanismo y Ciencias Sociales, 4(1), 1-24. https://doi.org/10.22201/fa.2007252Xp.2013.7.43000

Valverde, C. y Sandoval, R. (2015). Tepotzotlán, Estado de México. La joya de la corona. En L. López, C. Valverde, y M. Figueroa (Coords.), Pueblos Mágicos, una visión interdisciplinaria (pp. 89-112). Universidad Autónoma Metropolitana.

Velarde, M., Maldonado, A. y Maldonado, M. (2009). Pueblos Mágicos. Estrategia para el desarrollo turístico sustentable: caso Sinaloa. Teoría y Praxis, 6, 79-93. https://doi.org/10.22403/UQROOMX/TYP06/04 
Velarde, M., Santillán, M. y Magio, K. (2014). Diagnóstico de competitividad y sustentabilidad del Pueblo Mágico de Cosalá. Secretaría de Turismo. https://bit.ly/ 2D07rBA

Velasco, G., Gómez, L., Hernández, F., Leo, J., Reyes, A., Romo, A., Urdapilleta, J. y Viguri, S. (2011). Guía para el desarrollo local sustentable. Banco Mundial, Ministerio de Economía y Hacienda del Gobierno de España, y Secretaría de Desarrollo Social. https://bit.ly/2SXshcA

Velázquez, M. y Aragón, J. (2015). Todos Santos, Baja California Sur, la experiencia de lo mexicano-americano: las misiones y el Hotel California. En L. López, C. Valverde, y F. María (Coords.), Pueblos Mágicos, una visión interdisciplinaria (pp. 227-248). Universidad Autónoma Metropolitana.

Vizcaíno-Suárez, L., Serrano-Barquín, R. y Cruz-Jiménez, G. (2017). Turismo, alfarería y trabajo femenino en el Pueblo Mágico de Metepec, México. PASOS, Revista de Turismo y Patrimonio Cultural, 15(2), 391-407. https://doi.org/10.25145/j. pasos.2017.15.025 


\title{
APROVECHAMIENTO DE LOS RECURSOS NATURALES EN LA COMUNIDAD EL PEÑóN, TEMASCALTEPEC: UNA RUTA ECOTURÍSTICA PARA LA DIVERSIFICACIÓN DE LA OFERTA
}

\author{
OMAR ISMAEL RAMÍREZ HERNÁNDEZ \\ omar.ramirez.hdez@hotmail.com \\ ROCÍO JARAMILLO JARAMILLO \\ rociojaramillojaramillo00@gmail.com \\ Centro Universitario UAEM Temascaltepec, \\ Universidad Autónoma del Estado de México
}

El uso de los recursos naturales ha constituido una nueva forma para los residentes de obtener ingresos; sin embargo, estos deben utilizarse de forma responsable. Por ello, el objetivo de este trabajo es generar una propuesta de ruta ecoturística en la comunidad de El Peñón, Temascaltepec, Estado de México, con el propósito de diversificar la oferta existente. A partir de un enfoque cualitativo, se desarrolló un estudio documental y descriptivo, dividido en dos etapas: la primera, contextualizó el destino e identificó la percepción de los residentes hacia proyectos turísticos; la segunda, realizó un ejercicio de planificación. Los resultados destacan que la comunidad percibe de buena manera al turismo y les gustaría participar en proyectos; asimismo, resaltan tres recursos naturales sobre los que basar la ruta: El Peñón del Diablo, la cascada y el lago.

Palabras clave: ecoturismo, ruta turística, diversificación, oferta, Temascaltepec.

\section{MANAGEMENT OF NATURAL RESOURCES IN THE COMMUNITY OF El PEÑón, TEMASCALTEPEC: AN ECOTOURISM ROUTE FOR THE DIVERSIFICATION OF THE OFFER}

The use of natural resources has become a new way for residents to obtain incomes; however, these must be used responsibly. Therefore, the objective of this work is to generate a proposal for an ecotourism route in the community of El Peñón, Temascaltepec, State of Mexico, with the purpose of diversifying the existing offer. Based on a qualitative approach, a documentary and descriptive study was developed, divided into two stages: the first contextualized the destination and identified the residents' perception towards tourism projects; while the second carried out a planning exercise. The results highlight that the community has a good perception of tourism and would like to participate in projects; they also remark three natural resources on which the route is based:The Devil's Rock, the waterfall and the lake.

Keywords: ecotourism, tourist route, diversification, offer, Temascaltepec.

Fecha de recepción: 9 de junio de 2020 Fecha de aceptación: 11 de septiembre de 2020.

CÓMO CITAR: Ramírez, O. y Jaramillo, R. (2020). Aprovechamiento de los recursos naturales en la comunidad El Peñón, Temascaltepec: una ruta ecoturística para la diversificación de la oferta. Dimensiones Turísticas, 4(7), 125-150. https://doi.org/10.47557/CTID4910 


\section{Introducción}

$\mathrm{H}$

oy en día, el turismo se ha convertido en una importante actividad a nivel mundial, principalmente por los beneficios económicos que implica. Sin embargo, se reconoce que también ha generado impactos negativos en los destinos, en su mayoría en el aspecto medioambiental (Camacho-Ruíz et al., 2016). Por ello, y como una manera de combatir los costos, surge el ecoturismo, el cual tiene por objetivo salvaguardar los recursos naturales y detonar el desarrollo sustentable de los sitios (Agaton-Lorenzo y Cruz-Vicente, 2013; Bringas-Rábago y Ojeda-Revah, 2000; Camacho-Ruíz et al., 2016; Obombo y Velarde, 2018; Orgaz y Cañero, 2015).

El ecoturismo es presentado como una opción para la diversificación de la oferta turística, con el aprovechamiento del entorno natural (Agaton-Lorenzo y Cruz-Vicente, 2013; Bringas-Rábago y Ojeda-Revah, 2000; Pinkus-Rendón y Pinkus-Rendón, 2015). En ese sentido, la finalidad de este trabajo es generar una propuesta de ruta ecoturística en la localidad de El Peñón, ubicada en el municipio de Temascaltepec, Estado de México. Cabe señalar que el lugar de estudio cuenta con una gran riqueza ambiental, la cual genera una incipiente pero constante afluencia de visitantes provenientes de Valle de Bravo, uno de los destinos consolidados del Estado de México.

Se elaboró este documento a fin de plasmar opciones tendientes a diversificar la oferta turística en la comunidad de El Peñón, centrada en la actualidad en eventos deportivos de ala delta y parapente. Adicionalmente, dicha propuesta se justifica en que existe una necesidad de formular proyectos de este tipo, donde los residentes tengan otras opciones de generar ingresos, al realizar actividades relacionadas con el turismo (Ramírez et al., 2020).

Para alcanzar el objetivo antes planteado, se diseñó una investigación documental y descriptiva que recupera la propuesta de Arredondo et al. (2013) y Ramírez (2019), quienes delinean una ruta y un proyecto turístico, respectivamente. La metodología es de enfoque cualitativo, aplicada en dos etapas: la primera, denominada preliminar, donde se contextualizó la comunidad en cuestión, al retomar fuentes secundarias e información proporcionada por los habitantes, y la segunda, denominada de planificación en la que se realizó el inventario y la propuesta de ruta ecoturística. Dicho esfuerzo es una oportunidad para hacer que los residentes valoren los recursos naturales, sensibilizándolos para su conservación y aprovechamiento sostenible. 


\section{Ecoturismo y las rutas turísticas}

En los últimos años, el ecoturismo se ha posicionado en el interés académico. De acuerdo con Weaver y Lawton (2007), diversos investigadores han realizado aportes a la comprensión del ecoturismo, motivados por la problemática del turismo de masas, el cual ha originado múltiples impactos en los aspectos sociales, económicos y medioambientales (Camacho-Ruíz et al., 2016; Wall y Mathieson, 2006). En este último aspecto, su premisa retoma fuerza ante la necesidad del uso responsable de los recursos naturales para la actividad turística.

De acuerdo con la bibliografía especializada, Ceballos Lascuráin es señalado como el padre del ecoturismo, al ser uno de los primeros en brindar una definición al respecto:

Es aquella modalidad turística ambientalmente responsable, consistente en viajar a o visitar áreas naturales relativamente sin disturbar, con el fin de disfrutar, apreciar y estudiar los atractivos naturales (paisaje, flora y fauna silvestres) de dichas áreas, así como cualquier manifestación cultural (del presente y del pasado) que pueda encontrarse ahí, a través de un proceso que promueve la conservación, tiene bajo impacto negativo ambiental y cultural, y propicia un involucramiento activo y socioeconómicamente benéfico de las poblaciones locales. (Ceballos, 1989, pp. 13-14).

De tal manera, el ecoturismo guarda estrecha relación con las actividades realizadas en la naturaleza, sin modificar los recursos o el medio ambiente donde se desarrollan. Si bien la definición de Ceballos propone una visión general del tema, de acuerdo con Fennell (2001), a principios del siglo XX existían más de 85 conceptos de ecoturismo, de los cuales se recuperan a continuación los más relevantes (ver tabla 1). 


\section{Tabla 1. Conceptos de ecoturismo}

\begin{tabular}{|l|l|}
\hline \multicolumn{1}{|c|}{ Autor y año } & \multicolumn{1}{c|}{ Definición } \\
\hline Lanquar (2001, p. 135) & $\begin{array}{l}\text { "Puede ser definido como un turismo de participación con la naturaleza, que se } \\
\text { diferencia de las demás modalidades (turismo rural y agroturismo)". }\end{array}$ \\
\hline $\begin{array}{l}\text { Organización Mundial del } \\
\text { Turismo }(2002, \text { p. 16) }\end{array}$ & $\begin{array}{l}\text { "Turismo en espacios poco actuados por el hombre, que debe contribuir a la } \\
\text { protección de la naturaleza y al bienestar de las poblaciones locales". }\end{array}$ \\
\hline Secretaría de Turismo (2004, p. 3) & $\begin{array}{l}\text { "Los viajes que tienen como fin el realizar actividades recreativas de apreciación y } \\
\text { conocimiento de la naturaleza, a través del contacto con la misma". }\end{array}$ \\
\hline Vanegas $(2006$, p. 1) & $\begin{array}{l}\text { "Es una actividad que combina la pasión por el viaje y lleva de la mano la } \\
\text { preocupación que se tiene por el medio ambiente". }\end{array}$ \\
\hline Jalani $(2012$, citado en Orgaz y & $\begin{array}{l}\text { "Aquel tipo de turismo que se desarrolla en áreas naturales y tiene como objetivo la } \\
\text { conservación de las zonas naturales y el desarrollo de las comunidades locales". }\end{array}$ \\
\hline Choral, s. f., párr. 23) & $\begin{array}{l}\text { "Se basa en el trabajo de la naturaleza, incluso en las áreas más sensibles y } \\
\text { restrictivas para el acceso humano y, al mismo tiempo, la preocupación por la } \\
\text { conservación/protección del medio ambiente". }\end{array}$ \\
\hline
\end{tabular}

Fuente: Elaboración propia con base en los autores citados.

Así, la tabla 1 retoma conceptos del ecoturismo, los cuales coinciden en el uso responsable de los recursos naturales para el aprovechamiento turístico. Las diferencias que presentan se deben a que fueron generadas para abordar contextos específicos, como las distintas actividades que se llevan a cabo bajo esta modalidad (Pinkus-Rendón y Pinkus-Rendón, 2015).

Algunos autores consideran que el ecoturismo se ha convertido en una actividad masificada (Bringas-Rábago y Ojeda-Revah, 2000; Mat y Baum, 2005; Pinkus-Rendón y Pinkus-Rendón, 2015); sin embargo, y desde un punto de vista optimista, otros investigadores postulan que el ecoturismo es visto como la actividad de mayor potencial en el sector para detonar el progreso local y regional, además de salvaguardar el medio ambiente (Ghorbani et al., 2015; Orgaz y Cañero, 2015). En particular, Ibarra-Michel y Velarde (2016) argumentan que favorece en el aspecto económico, ecológico y social de las regiones donde se lleva a cabo.

Por lo tanto, también es vinculado con la gestión comunitaria y el desarrollo sustentable, ante la necesidad de formular una planificación turística que involucre a los actores relacionados y las localidades (Ramírez, 2019; Suárez et al., 2013), lo cual ayuda a la generación de beneficios y la mitigación de impactos negativos, principalmente en el ámbito natural y social. Autores como Garduño y Guzmán (2012) y Ghorbani et al. (2015) comparten esta postura. 
Desde la perspectiva de aprovechar correctamente los elementos naturales, a fin de crear productos turísticos, la Secretaría de Turismo (Sectur, 2004) enlista aquellas actividades a realizar como parte del ecoturismo: talleres de educación ambiental, observación geológica, de ecosistemas y sideral, contemplación de fauna y fauna, safari fotográfico, avistamiento de fenómenos y atractivos especiales de la naturaleza, senderismo interpretativo, caminata recreativa, participación en programas de rescate de la vegetación y los animales, observación de fósiles y participación en proyectos de investigación biológica.

Por su parte, Drumm et al. (2004) proponen que un proyecto ecoturístico debe tener seis elementos básicos:

1) Bajo impacto natural en el área donde es llevado a cabo.

2) Involucrar en las fases de planeación, desarrollo, implementación y monitoreo a todos los actores relacionados directa o indirectamente.

3) Respetar las culturas y tradiciones locales.

4) Producir ingresos sostenibles y equitativos para todos los actores participantes.

5) Generar ingresos para la conservación de los recursos naturales utilizados.

6) Sensibilizar a los actores sobre su rol en la conservación de los recursos naturales.

Retomando lo anterior, es factible elaborar productos relacionados con el ecoturismo, tal es el caso de las rutas turísticas, que son identificadas como una de las actividades más sencillas y redituables, debido a que se requiere una inversión mínima, utilizando los recursos existentes (Arredondo et al., 2013; Baum, 1998; Bicudo et al., 2017). En este tenor, Hernández (2011) considera que su origen se encuentra en los recorridos históricos, realizados en lugares donde acontecieron hechos importantes que cuentan con un valor social distintivo.

Aunque existen diferentes definiciones sobre las rutas turísticas (Ibarra-Michel y Velarde, 2016; Obregón et al., 2016), de manera general son referidas como los productos en los cuales se realiza un traslado de un punto geográfico a otro, combinando tanto elementos naturales como culturales, donde los turistas son orientados sobre los lugares y duración del trayecto.

En este tenor, se distinguen diferentes tipos (Alpízar y Maldonado, 2009; Arredondo et al., 2013; Barragán, 2017; Jeambey, 2016; Kraftchick et al., 2014), que surgen del espacio geográfico y los recursos que predominan en el espacio de acción (tabla 2). 
Tabla 2. Tipos de rutas turísticas

\begin{tabular}{|l|l|}
\multicolumn{1}{|c|}{ Tipo } & \multicolumn{1}{c}{ Recursos utilizados } \\
\hline Cultural & Recursos culturales intangibles y tangibles, monumentos, museos. \\
\hline Gastronómica & Alimentos típicos o distintivos. \\
\hline Del vino & Plantíos de vid, instalaciones vitivinícolas. \\
\hline Cervecera & Fábricas, comercializadoras de cerveza, bares y restaurantes especializados. \\
\hline Ecoturística & Recursos naturales. \\
\hline
\end{tabular}

Fuente: Elaboración propia con base en la literatura revisada.

De esta forma, la ruta cultural está basada precisamente en los elementos culturales tangibles e intangibles (Arredondo et al., 2013); la gastronómica emplea la elaboración y degustación de alimentos típicos o distintivos de un lugar o región (Jeambey, 2016); la del vino realiza recorridos en haciendas productoras de esta bebida (Alpízar y Maldonado, 2009); la cervecera se especializa en la cata y procesos de elaboración de esta bebida (Kraftchick et al., 2014); y la ecoturística se enfoca en el aprovechamiento sustentable de los recursos naturales (Barragán, 2017). Cabe destacar que estos tipos de ninguna manera constituyen la totalidad, pues actualmente es posible encontrar otros elementos que pueden fungir como atractivos para organizar recorridos.

\section{Diversificación de la oferta a partir de la elaboración de rutas turísticas}

Distintos autores reconocen que la generación de productos novedosos ayuda a la captación de turistas, al incrementar la derrama económica y el tiempo de estadía de los visitantes (García y Doumet, 2017; Luján et al., 2016; Urquiola y Lalangui, 2016). Asimismo, existen trabajos que realizan la propuesta de actividades ecoturísticas para la diversificación de la oferta; tal es el caso de Agaton-Lorenzo y Cruz-Vicente (2013), quienes evidencian que los recorridos ecoturísticos en la Laguna de Tres Palos, Acapulco, aportan variantes a un destino conocido por el turismo de sol y playa.

En el mismo sentido, García y Doumet (2017) diseñan un producto de turismo basado en la gestión comunitaria en el cantón Bolívar, Ecuador, en donde estructuran dos rutas con base en actividades relacionadas al entorno natural de seis comunidades. Adicionalmente, los autores proponen las estrategias de comercialización y promoción de dichas rutas, con el fin de aprovechar los recursos existentes y contribuir al desarrollo de la región. 
De igual forma, Luján et al. (2016), en su intención de lograr un manejo integral costero de las comunidades, identifican alternativas que promueven la diversificación de la economía en la localidad de Pehuen-Co, provincia de Buenos Aires, Argentina. Con la zonificación del área de estudio, se determinó su grado de avance turístico y se detectaron nuevos sitios con potencial, los cuales podrían aprovecharse a través de recorridos.

Gonzaga et al. (2015) proponen una ruta ecoturística a través de la gestión comunitaria en la provincia de Zamora Chinchipe, Ecuador. Al plantear este proyecto, los autores buscan mejorar la calidad de vida de los residentes, con el objeto de generar mayores oportunidades económicas que fomenten su participación.

Visto desde un enfoque empresarial, las rutas diversifican los productos en un destino (Urquiola y Lalangui, 2016), pues aprovechan los recursos para establecer actividades atractivas y frescas (Garduño y Guzmán, 2012; Gonzaga et al., 2015). Esta nueva oferta igualmente trata de mitigar problemáticas sociales, económicas y medioambientales en los diferentes sitios. Por ello, resulta de vital importancia planear adecuadamente las rutas ecoturísticas, con el fin de alcanzar el desarrollo sustentable (Pinkus-Rendón y Pinkus-Rendón, 2015).

\section{Metodología para la generación de rutas turísticas}

La elaboración de productos turísticos no tiene una metodología aceptada en lo general; existen diversas posturas que consideran las necesidades y características de las regiones, algunas de ellas son elaboradas por el sector público, privado o académico. En este sentido, Ramírez (2019) realiza una revisión de diferentes formas de estructurar dichos productos presentando 15 metodologías. El autor expone la poca participación de la comunidad en cada una de ellas, por lo que sugiere que los habitantes en conjunto sean el pilar fundamental en la creación y gestión, situación que es apoyada por Reyes et al. (2017), quienes argumentan que en muchas ocasiones los residentes se limitan a prestar servicios o incorporarse a empresas foráneas, situación que complica alcanzar una mejora local.

En la abundancia de metodologías sin un consenso al respecto, García y Doumet (2017) exponen su propuesta, dividida en tres grandes fases: a) diagnóstico, b) estudio del mercado, c) diseño y comercialización. Este proceso es usado específicamente para la gestión comunitaria en el cantón Bolívar, Ecuador. 
Arredondo et al. (2013) realizan otro planteamiento enfocado en crear rutas turísticas que den valor al patrimonio cultural en el sur del estado de Jalisco. Su documento contiene 11 pasos a seguir, en donde los autores analizan factores de accesibilidad, apertura, oferta turística, patrimonio cultural, actores relacionados y la disponibilidad temporal del turista. La aplicación de la metodología incluye sugerencias para la comercialización y posicionamiento de la ruta como producto turístico cultural en la región.

Por su parte, Gonzaga et al. (2015) proponen que para este fin son necesarias tres etapas: la primera, dirigida a la generación de un intercambio entre actores y autoridades locales, al establecer un camino de cooperación mutua; la segunda, centrada en realizar un prediagnóstico del lugar, con un inventario de recursos para su aprovechamiento turístico; por último, la tercera etapa que consiste en la evaluación técnica y la propuesta de actividades a realizar en el área.

De esta forma, la planeación de rutas y en general de los productos turísticos, es un trabajo heterogéneo, el cual consiste en la búsqueda de beneficios económicos, medioambientales y sociales (Machado y Hernández, 2007); asimismo, el éxito de cada uno depende de diversos factores, como los recursos, la inversión, los objetivos, la gestión, las políticas públicas y la participación de la comunidad local (Hernández, 2011; Ibarra-Michel y Velarde, 2016; Ramírez, 2019).

Por lo hasta aquí argumentado, se decide proponer un nuevo producto turístico con el fin de diversificar la oferta del destino en cuestión, orientado a la generación de otras actividades de turismo, lo cual conllevará a la creación de empleo en la zona, a la par del aprovechamiento y la conservación de los recursos naturales, con elementos de participación de la población local, pues de acuerdo con Ramírez (2019) este factor es fundamental para el éxito de los proyectos turísticos.

\section{Proceso metodológico}

Para cumplir con el objetivo antes planteado de diseñar una propuesta de ruta ecoturística y atendiendo las propuestas de Arredondo et al. (2013) y Ramírez (2019), se estableció un planteamiento para el caso de la localidad, basado en sus características sociodemográficas y turísticas. De esta forma, la metodología fue establecida como un proceso dividido en dos etapas: a) preliminar y b) de planificación (figura 1). 
En preparación para la segunda etapa de la ruta ecoturística, se realizó en primer lugar un trabajo documental a través de la búsqueda de información sobre el área, seguido de un análisis descriptivo donde se identificaron las características generales de los recursos, las percepciones de la comunidad local hacia el turismo y la propuesta de ruta.

Para llevar a cabo el proyecto se utilizó un enfoque cualitativo y valiéndose de la experiencia de uno de los autores del presente texto, quien reside en la zona, fue posible contactar informantes y obtener datos relevantes sobre la comunidad y su dinámica turística. En contraparte, otro de los autores no estaba familiarizado con el contexto local, lo que contribuyó a incrementar la objetividad del estudio. A continuación, se describe cada etapa con los pasos, técnicas e instrumentos utilizados para el trabajo de campo.

Figura 1. Proceso metodológico

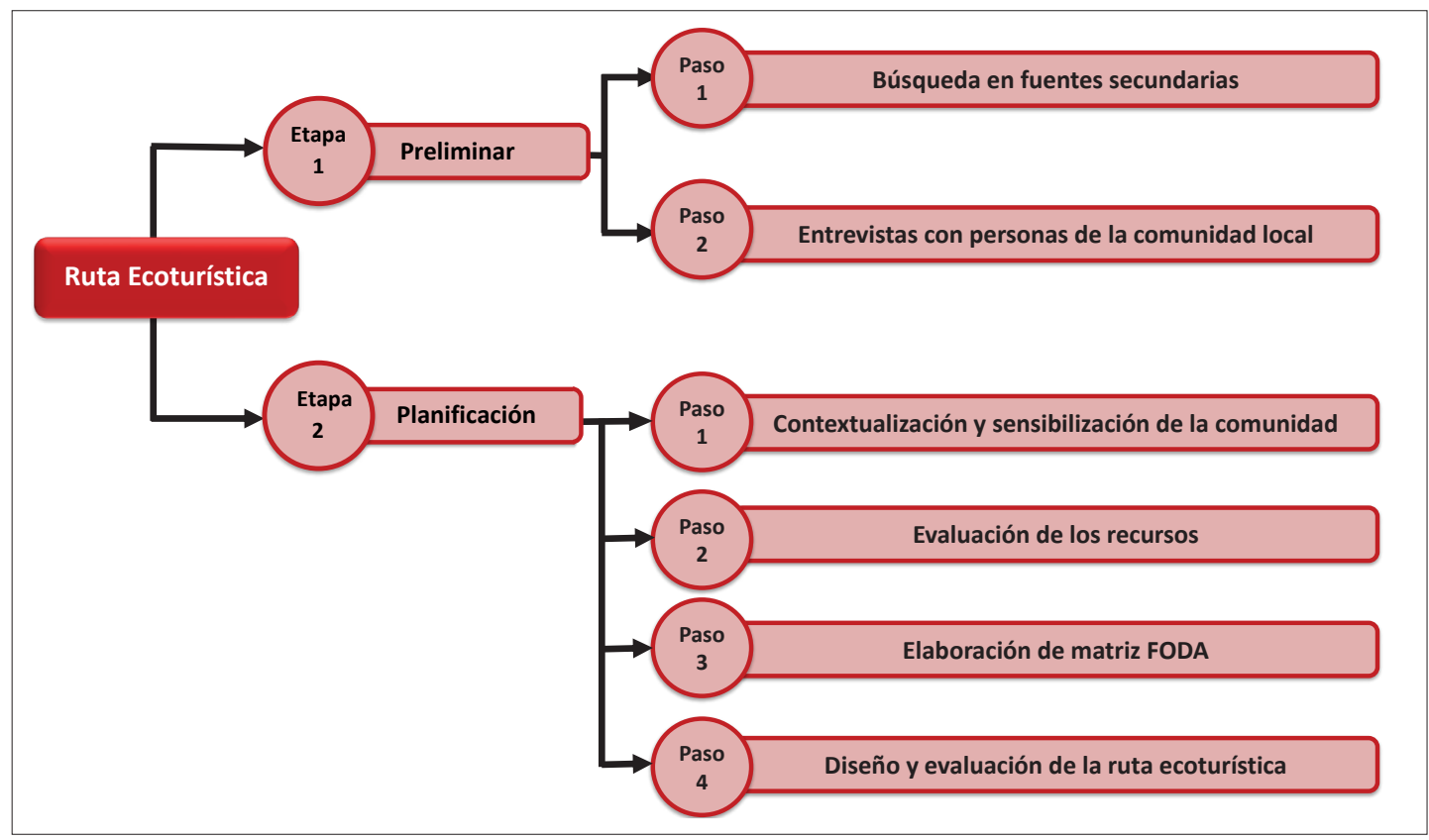

Fuente: Elaboración propia.

\subsection{Etapa preliminar}

Esta fase consistió en la búsqueda de información sobre la comunidad de El Peñón, dividida en dos pasos: 
Paso 1. Fuentes secundarias. Se indagó en documentos tales como planes de desarrollo municipal, artículos científicos, páginas web y la observación de campo en la propia comunidad.

Paso 2. Fuentes primarias. Radicó en preguntar directamente a los habitantes de la comunidad El Peñón sobre aspectos propios de la localidad; para ello, fue elaborado un guion de entrevista semiestructurada, el cual es un instrumento técnico para la obtención de información mediante la interacción verbal entre dos personas (entrevistador y entrevistado) (Bryman, 2012). Dicho documento contenía 12 preguntas, directamente las tres primeras ahondaban respecto a elementos sociodemográficos, las restantes versaban sobre la dinámica turística y social en el lugar, la postura hacia el turismo y nuevos proyectos turísticos, así como la evaluación de los recursos naturales y culturales existentes.

El muestreo utilizado fue por saturación teórica, el cual consiste en detener la actividad cuando las personas repiten los mismos datos y no proporcionan detalles nuevos (Bryman, 2012). La aplicación de las entrevistas se realizó durante los meses de octubre y diciembre de 2018, periodo en el que se buscó obtener respuestas de residentes de la comunidad de El Peñón con diferentes perfiles. Así, de 35 posibles participantes fueron 30 las personas entrevistadas, ya que cinco de ellas se negaron a colaborar en el estudio (tabla 3).

Tabla 3. Perfil de los informantes

\begin{tabular}{|c|c|c|c|c|c|}
\hline Variable & Categoría & Número & Variable & Categoría & Número \\
\hline \multirow{2}{*}{ Sexo } & Femenino & 10 & \multirow{4}{*}{ Edad } & 18 a 30 años & 12 \\
\hline & Masculino & 20 & & 31 a 45 años & 5 \\
\hline \multirow{6}{*}{ Ocupación } & Agricultor & 9 & & 46 a 60 años & 7 \\
\hline & Ama de casa & 8 & & 60 o más años & 6 \\
\hline & Comerciante & 5 & \multirow{4}{*}{ Nivel de estudios } & Primaria & 6 \\
\hline & Arquitecto & 1 & & Secundaria & 8 \\
\hline & Fotógrafo & 1 & & Preparatoria & 7 \\
\hline & Estudiante & 6 & & Universidad & 9 \\
\hline
\end{tabular}

Nota: Por motivos de confidencialidad y anonimato, los nombres de los entrevistados fueron modificados. Fuente: Elaboración propia con base en la investigación de campo. 
De esta manera, el grupo de informantes se integró con 10 hombres y 20 mujeres, de entre 18 y 78 años. Dentro de sus ocupaciones se ubican las de ama de casa (nueve) y agricultor (ocho), le siguen estudiante (seis) y comerciante (cinco). Las menos referidas son las de arquitecto (uno) y fotógrafo (uno).

Cabe resaltar que 22 individuos mencionaron dedicarse ocasionalmente a actividades turísticas durante la temporada de vuelo (noviembre a febrero), en la cual se desempeñan como choferes (cinco), vendedoras de alimentos y bebidas (seis) y ayudantes generales (11). Asimismo, es importante resaltar que todos los entrevistados han vivido siempre en el lugar de estudio.

\subsection{Etapa de planificación}

Con el análisis de la información recabada en la primera etapa, se prosiguió a la planificación de la ruta ecoturística, por medio de cuatro pasos:

Paso 1. Contextualización y percepción de la comunidad. Se caracterizó la comunidad de El Peñón, además se analizó la información obtenida en las entrevistas individuales con integrantes de la localidad, sobre la percepción de la actividad turística.

Paso 2. Evaluación de recursos. Se valoraron aquellos recursos susceptibles de aprovechamiento ecoturístico mediante fichas de inventario. Para ello, fue adaptada la propuesta elaborada por el Ministerio de Comercio, Industria y Turismo de Colombia (Mincit, 2010), con puntos como: datos del recurso, descripción, actividades desempeñadas, vías de acceso, estado de conservación, señalética, seguridad, equipamiento y fotografías; asimismo, fueron incorporados aspectos como actividades turísticas potenciales a realizar, tiempo para llegar al recurso y si recibe actualmente visitantes.

Igualmente, fue retomada información de la primera etapa, donde se cuestionó a las personas de la comunidad si los recursos eran susceptibles de uso turístico. Los factores que influyeron en la elección fueron el reconocimiento e importancia para los residentes, la accesibilidad, y que los locales aceptaran utilizar dichos elementos para el destino. Así, se determinó cuáles eran aprovechables para la actividad ecoturística.

Paso 3. Elaboración de matriz de Fortalezas, Oportunidades, Debilidades y Amenazas (FODA). Se realizó un análisis FODA en torno a la comunidad de El Peñón, Temascaltepec, considerando los datos recabados durante la etapa 1 y el trabajo de campo. 
Paso 4. Diseño y evaluación de la ruta ecoturística. Derivado de los pasos previos, se procedió a confeccionar la ruta, con fundamento en los recursos aprovechables desde el punto de vista de la comunidad local, además de establecer los posibles servicios y actividades a ofertar. De igual manera, se realizó una propuesta de actores (residentes y patrocinadores potenciales) susceptibles de identificar su pertinencia.

\section{Resultados}

Los resultados obtenidos a raíz de la metodología planteada se dividen en cuatro apartados: el primero está relacionado con la etapa preliminar (contextualización y percepción de la comunidad El Peñón, Temascaltepec), los otros tres fueron generados en la etapa de planificación (evaluación de recursos, matriz FODA, diseño y evaluación de la ruta ecoturística).

\subsection{Contextualización y percepción de la comunidad El Peñón, Temascaltepec}

Temascaltepec es un municipio del sur del Estado de México, colinda al noreste con Zinacantepec, al noroeste con Valle de Bravo, al norte con Amanalco, al oeste con Zacazonapan, al sur con San Simón de Guerrero y Texcaltitlán, al sureste con Coatepec Harinas y al suroeste con Tejupilco ( $\mathrm{H}$. Ayuntamiento de Temascaltepec, 2016) (figura 2). De acuerdo con la Gaceta Municipal, la entidad tiene una superficie total de $546.79 \mathrm{~km}^{2}$ y su población total es de 35 mil 904 habitantes.

Los climas predominantes a lo largo del municipio son el subhúmedo (54\%), el Iluvioso tropical (28\%), el semifrío subhúmedo (14\%) y el cálido subhúmedo (2\%) (H. Ayuntamiento de Temascaltepec, 2016). Asimismo, sin contar la cabecera municipal, el lugar es considerado como zona rural. En cuanto a su economía, Temascaltepec desarrolla la agricultura, la ganadería y la floricultura. Adicionalmente, es reconocida su histórica producción minera; en la actualidad, la compañía First Majestic Silver Corp. tiene concesionada la mina llamada La Guitarra, en la localidad de La Albarrada, donde existen yacimientos de vetas y mantos de sulfuros masivos (Subsecretaría de Minería, 2018).

De igual manera, el turismo ha tratado de posicionarse como una actividad relevante en el lugar, el cual desde el año 2009 ostenta el nombramiento de Pueblo con encan- 
to, reconocimiento otorgado por la Secretaría de Turismo Estatal debido a sus atractivos y recursos con vocación turística (H. Ayuntamiento de Temascaltepec, 2016).

Figura 2. Ubicación de Temascaltepec

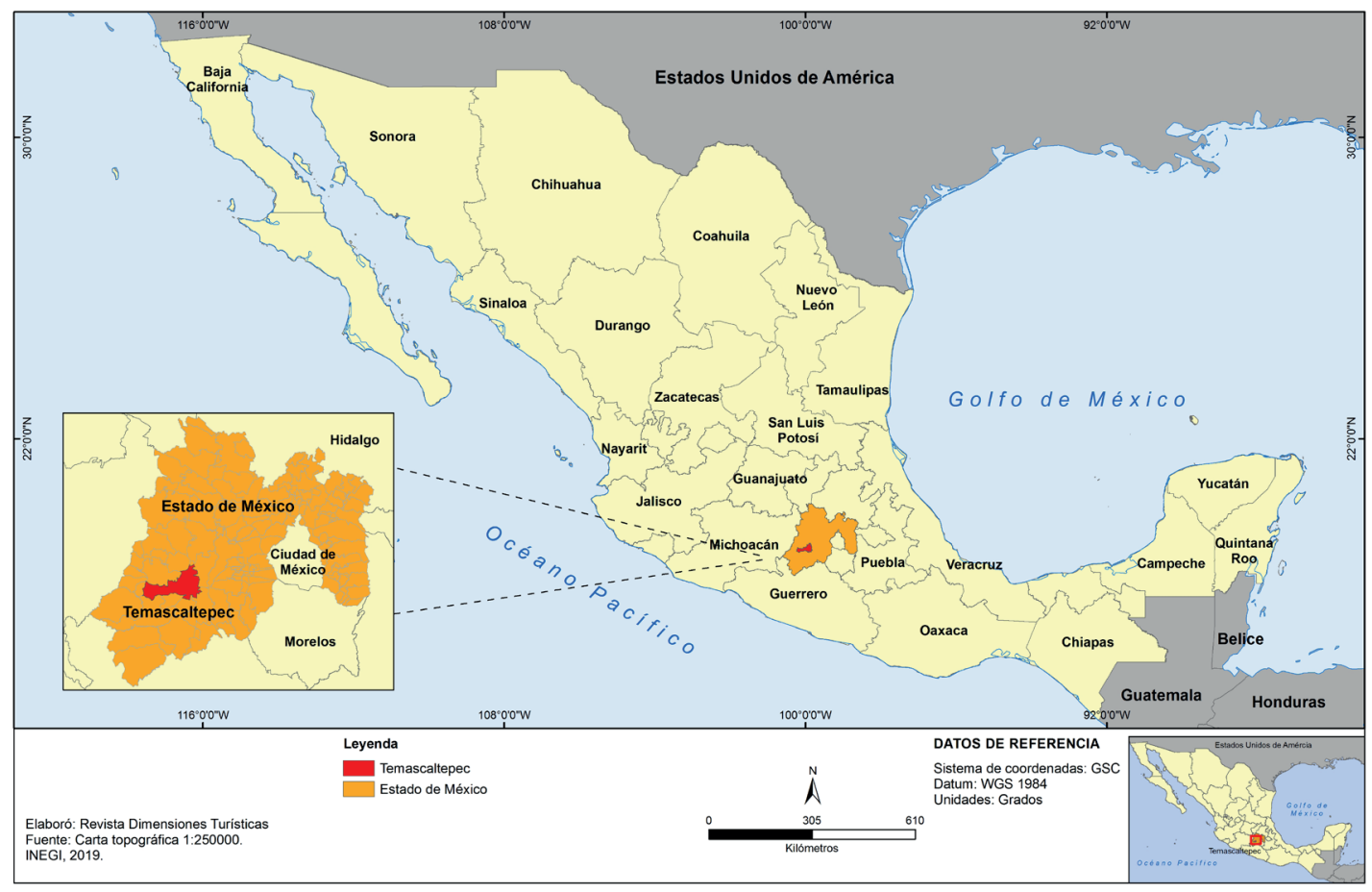

Fuente: Ver interior figura 2.

La comunidad de El Peñón se localiza en el municipio de Temascaltepec. De acuerdo con datos de la Secretaría de Desarrollo Social (Sedesol, 2015), el lugar cuenta con 533 habitantes, de los cuales 274 son hombres y 259 mujeres. Al igual que el municipio al que pertenece, las principales actividades en la localidad son la agricultura y ganadería de traspatio, ya que no se cuenta con actividades industriales o de manufactura.

Es de considerar que el nivel de marginación social y de rezago es alto (Sedesol, 2015). Durante las entrevistas, y por experiencia del autor que reside en la zona, no fue notoria una fuerte migración a Estados Unidos como en épocas pasadas, pero las personas han dejado la comunidad para ir a ciudades cercanas como Toluca y la Ciudad de México. 
En el ámbito turístico, en El Peñón son llevadas a cabo diferentes actividades, entre las que destacan el vuelo en ala delta y parapente, deportes por los que es conocida la comunidad a nivel internacional. De igual manera, existe la práctica de rappel, ciclismo y campismo, aunque de forma incipiente. Aunado a esto, la infraestructura turística es limitada, pues en la actualidad solo existen dos hoteles que brindan sus servicios únicamente de noviembre a febrero.

Si bien la localidad representa un punto de interés para el sector turismo, no se tienen datos oficiales sobre el número de visitantes que arriban. Sin embargo, los informantes mencionan que en temporada alta o de vuelo (noviembre a febrero) llegan alrededor de 50 a 60 turistas a la semana, mientras que en temporada baja (marzo a octubre) los visitantes llegan hasta 25. Además, los locales observan que los turistas son jóvenes con gusto por las actividades que posibilitan el contacto con la naturaleza y la práctica deportiva.

Adicionalmente, la mayoría de los entrevistados (24) coincide en que los turistas que arriban lo hacen procedentes de Valle de Bravo, el destino más reconocido de la región, e indican que muchos de los visitantes solo están un periodo de tiempo corto en la comunidad de El Peñón. En este sentido, Joaquín, comerciante, comenta que:

La generación de nuevos productos turísticos en la comunidad ayudaría a que los visitantes no solo vengan a volar (parapente o ala delta) y se regresen a Valle, que es donde ellos hacen todo lo demás (actividades turísticas). (Comunicación personal).

Por lo anterior, de acuerdo con las entrevistas se infiere la razón principal de que 23 de los 30 informantes consideran relevante crear nuevos proyectos turísticos en la comunidad, lo cual coincide con otras investigaciones (García y Doumet, 2017; Garduño y Guzmán, 2012; Gonzaga et al., 2015), donde los residentes son capaces de visualizar el beneficio económico de este tipo de actividad. A la par, algunos de los participantes mencionan que esto combatiría la estacionalidad de visitantes, tal como lo dice Ximena, ama de casa:

Algunos de los que nos dedicamos en nuestros tiempos libres al turismo, o como una actividad complementaria, solo vemos más ingresos cuando es temporada de vuelo, pues en otra época son pocos los que vienen y de ellos casi nadie se queda. (Comunicación personal). 
Existen algunos ejemplos donde la nueva oferta turística ayuda a cambiar la estacionalidad de la demanda en los destinos (Alpízar y Maldonado, 2009; Bicudo et al., 2017; Calçada, 2017); no obstante, esos lugares ya tienen una afluencia importante de turistas, por lo que no podría esperarse un comportamiento similar en la comunidad de El Peñón, debido a sus características. Sin embargo, sí podrían integrarse servicios novedosos para los turistas que llegan y detonar de esta manera una derrama económica adicional a la presente.

Por su parte, los entrevistados identifican que la actividad turística trae otros beneficios, como la enseñanza de los deportes practicados por los turistas. En este sentido, Jesús, fotógrafo de profesión, señala que:

La escuela de vuelo que está en la comunidad enseña a los chavos a volar de forma gratuita (parapente), les proporciona todo, el equipo y los instructores; clases que son muy caras... más o menos 30 mil pesos o a veces hasta más. (Comunicación personal).

Por lo anterior, se asume la responsabilidad social de las empresas turísticas en la comunidad, uno de los puntos que también ayuda a detonar el desarrollo en el lugar, con bienestar para los residentes (Pinkus-Rendón y Pinkus-Rendón, 2015; Soares et al., 2015).

\subsection{Evaluación de recursos}

En las entrevistas realizadas a los integrantes de la comunidad El Peñón, ellos reconocen ocho recursos, de los cuales tres son naturales y cinco culturales (tabla 4). 


\section{Tabla 4. Recursos de la comunidad El Peñón}

\begin{tabular}{|c|c|c|c|}
\hline Recurso & Descripción & Evaluación & $\begin{array}{l}\text { Posibles actividades } \\
\text { por realizar }\end{array}$ \\
\hline $\begin{array}{l}\text { Canales y } \\
\text { subestación } \\
\text { eléctrica }\end{array}$ & $\begin{array}{l}\text { Es una extensión cercana a los } 600 \mathrm{~m} \\
\text { de longitud, que en un inicio fue creada } \\
\text { para la generación de electricidad en } \\
\text { la comunidad, pertenece al régimen de } \\
\text { propiedad comunal. }\end{array}$ & $\begin{array}{l}\text { No aprovechable: debido } \\
\text { a que actualmente se } \\
\text { encuentra abandonada y } \\
\text { no existe infraestructura, ni } \\
\text { señalamientos en el lugar. }\end{array}$ & Paseos a pie o en bicicleta. \\
\hline La capilla & $\begin{array}{l}\text { Iglesia católica construida } \\
\text { aproximadamente hace } 50 \text { años, donde } \\
\text { son celebrados eventos religiosos en } \\
\text { torno a San Antonio de Padua y misas } \\
\text { dominicales. }\end{array}$ & $\begin{array}{l}\text { No aprovechable: a pesar de } \\
\text { encontrarse en buen estado, } \\
\text { no cuenta con el interés de los } \\
\text { visitantes. }\end{array}$ & $\begin{array}{l}\text { Asistencia a fiesta patronal } \\
\text { en el mes de junio. }\end{array}$ \\
\hline Pan artesanal & $\begin{array}{l}\text { Es un alimento elaborado } \\
\text { artesanalmente, el cual puede } \\
\text { adquirirse en dos establecimientos de } \\
\text { la comunidad, el más reconocido es el } \\
\text { llamado "lasloyo". }\end{array}$ & $\begin{array}{l}\text { Aprovechable: cuenta con } \\
\text { potencial latente; sin embargo, } \\
\text { al ser un recurso cultural, no } \\
\text { tendría lugar protagónico en } \\
\text { la ruta. }\end{array}$ & $\begin{array}{l}\text { Degustación durante los } \\
\text { recorridos. }\end{array}$ \\
\hline Deshilados & $\begin{array}{l}\text { Es una fina artesanía creada con cortes } \\
\text { en la tela, su elaboración data de hace } \\
\text { más de } 60 \text { años en la comunidad. } \\
\text { Aún existen talleres donde enseñan a } \\
\text { realizarlos. }\end{array}$ & $\begin{array}{l}\text { Aprovechable: es un recurso } \\
\text { cultural, por lo que no sería } \\
\text { incluido en la ruta como una } \\
\text { actividad principal. }\end{array}$ & Souvenirs. \\
\hline La comunidad & $\begin{array}{l}\text { Es el espacio donde se encuentran } \\
\text { los habitantes; además, cuenta con } \\
\text { instalaciones que facilitan la reunión } \\
\text { de personas y es el lugar donde llega } \\
\text { el transporte público y particular con } \\
\text { visitantes. }\end{array}$ & $\begin{array}{l}\text { Aprovechable: no es un } \\
\text { recurso natural; sin embargo, } \\
\text { será incluido por sus } \\
\text { características, debido a las } \\
\text { posibles actividades a realizar. }\end{array}$ & $\begin{array}{l}\text { Talleres de educación } \\
\text { ambiental, de conservación } \\
\text { y aprovechamiento de } \\
\text { recursos. }\end{array}$ \\
\hline El Peñón & $\begin{array}{l}\text { El Peñón del Diablo es el nombre que le } \\
\text { da la comunidad a la formación rocosa } \\
\text { situada en el lugar; existe una gran } \\
\text { variedad de flora y fauna, entre la que } \\
\text { se puede encontrar árboles de encino y } \\
\text { ocote, así como ardillas, lagartijas, aves } \\
\text { e iguanas. }\end{array}$ & $\begin{array}{l}\text { Aprovechable: es el recurso } \\
\text { natural más importante de } \\
\text { la zona, cuenta con algunos } \\
\text { caminos no señalados para } \\
\text { llegar a él. }\end{array}$ & $\begin{array}{l}\text { Senderismo para llegar } \\
\text { hacia el recurso, rappel, } \\
\text { escalada, fotografía, } \\
\text { observación de fauna y } \\
\text { flora. }\end{array}$ \\
\hline La cascada & $\begin{array}{l}\text { Es una caída de agua de alrededor } \\
\text { de } 5 \mathrm{~m} \text { de alto, con un espacio de } 6 \mathrm{~m}^{2} \\
\text { donde se estanca el agua, con salida al } \\
\text { río. }\end{array}$ & $\begin{array}{l}\text { Aprovechable: es uno } \\
\text { de los recursos naturales } \\
\text { mencionados por la } \\
\text { comunidad y cuenta con } \\
\text { acceso en buen estado. }\end{array}$ & Actividades recreativas. \\
\hline El lago & $\begin{array}{l}\text { Es un cuerpo de agua con superficie } \\
\text { aproximada de } 45 \mathrm{~m}^{2} \text {. Su estado de } \\
\text { conservación es bueno y se encuentran } \\
\text { aves y peces. }\end{array}$ & $\begin{array}{l}\text { Aprovechable: a pesar de no } \\
\text { contar con señalamientos y } \\
\text { seguridad, son factibles las } \\
\text { actividades turísticas. }\end{array}$ & Pesca recreativa y kayak. \\
\hline
\end{tabular}

Fuente: Elaboración propia con base en el trabajo de campo. 
Dentro de los recursos naturales identificados, se destaca El Peñón como el de mayor atractivo. Pedro, agricultor, relata:

Lo más importante a visitar aquí es El Peñón, en primer lugar, porque así se llama la comunidad y, en segundo, por sus condiciones naturales, pues permite practicar diversas actividades, no solo en el sitio, sino en el camino tomado para llegar ahí. (Comunicación personal).

Adicionalmente, testimonios mencionan que la cascada y el lago tienen un gran valor comunitario, ya que en ellos los habitantes desarrollan actividades recreativas como la pesca y las caminatas. Llama la atención que los entrevistados subrayan con énfasis los paisajes naturales, los cuales, al igual que en el trabajo de Orgaz y Cañero (2015), podrían fungir como un atractivo cuando se realicen los recorridos.

Los informantes también señalaron cuatro recursos culturales; sin embargo, algunos de ellos explican que no resultan de interés para los turistas, tal es el caso de Lucía, ama de casa, quien comenta:

Los turistas visitan poco otros lugares aparte del despegue, el aterrizaje y El Peñón, pues ellos lo que quieren es practicar deporte o tener contacto con la naturaleza, lo que se puede hacer con toda tranquilidad aquí. (Comunicación personal).

Así, los elementos naturales utilizados para la propuesta serán El Peñón, la cascada, el lago y el centro de la comunidad; dejando a un lado los elementos culturales que, si bien son relevantes para los habitantes, en este caso fungirán como elementos complementarios de la ruta, pues al tener la temática ecoturística no es posible incorporarlos como principales.

\subsection{Matriz FODA}

A raíz de la información reunida en la revisión documental y el trabajo de campo, se marcaron las fortalezas, oportunidades, debilidades y amenazas de la comunidad El Peñón (tabla 5). 


\section{Tabla 5. Análisis FODA de El Peñón}

\section{Fortalezas}

Recibe afluencia de turistas en búsqueda de realizar actividades deportivas, de aventura y contacto con la naturaleza.

Cuenta con recursos naturales y culturales de importancia regional, que pueden ser aprovechados para la actividad turística.

Es reconocido el valor natural por los turistas que visitan el lugar.

Son celebradas competencias nacionales e internacionales en la comunidad.

Elaboración de productos de forma artesanal.

La población ve de forma positiva la actividad turística y le gustaría participar en proyectos.

Aprovechar los recursos naturales y culturales para implementar proyectos turísticos.

Existe el apoyo de las autoridades municipales para financiar proyectos productivos en la región.

Cercanía con el pueblo mágico de Valle de Bravo.

\section{Oportunidades}

Creciente interés de los turistas por desarrollar actividades en contacto con la naturaleza.

Incremento de actividades de turismo alternativo a nivel mundial.

La comunidad empieza a ser reconocida por los pilotos internacionales de parapente y ala delta.

Posibilidad para la diversificación de la economía local.

Existe la posibilidad de proponer políticas de conservación turística.

\section{Debilidades}

Los residentes tienen una escasa iniciativa emprendedora.

Solo cuenta con una escuela de vuelo en el lugar.

Ningún proyecto turístico está enfocado en el aprovechamiento adecuado de los recursos naturales.

Insuficiente infraestructura, señalización y servicios turísticos especializados.

No existe red de celular e Internet en la mayor parte de la localidad.

Insuficiente transporte público para llegar a la comunidad.

La población no está capacitada para recibir el turismo y no existen guías de turistas locales capacitados.

No existe una planificación para el desarrollo del turismo.

Casi todos los turistas que visitan la localidad lo hacen por empresas turísticas de Valle de Bravo.

Poca capacidad financiera de los residentes para invertir en proyectos turísticos.

\section{Amenazas}

Deterioro de recursos naturales debido a causas externas, como el cambio climático.

Imagen de inseguridad causada por el narcotráfico en la región.

Migración de la comunidad local hacia otros puntos geográficos.

Existen otros destinos consolidados en la región.

Incremento de la exigencia del turista.

Poco adiestramiento para afrontar factores relacionados con la salud, como epidemias o pandemias.

Crisis y recesión económica a nivel mundial.

Fuente: Elaboración propia con base en el trabajo de campo. 
De esta forma, es posible establecer la cercanía de la comunidad con el municipio de Valle de Bravo como una de las características que más influye en el análisis FODA, ya que la mayor cantidad de turistas provienen de ese sitio, lo que ocasiona una dependencia del mercado emisor. Esta situación podría beneficiar a la comunidad de El Peñón, como un referente en la planificación y gestión turística (Soares et al., 2015).

Una amenaza que podría influir en el desarrollo del destino y la ruta propuesta, es la imagen de inseguridad que mantiene la zona sur del Estado de México. Esta situación puede provocar que los turistas no arriben como se esperaría, toda vez que algunos autores destacan la seguridad del sitio turístico como una de las condicionantes que el visitante privilegia (Hernández y De la Torre, 2016; Martínez y Trejoluna, 2017).

\subsection{Diseño de la ruta ecoturística y propuesta de evaluación}

Con la información recolectada en la etapa preliminar y los pasos anteriores, se generó el diseño de la ruta ecoturística (figura 3), la cual contempla los recursos identificados con las características necesarias para ser aprovechados.

Figura 3. Diseño de ruta ecoturística

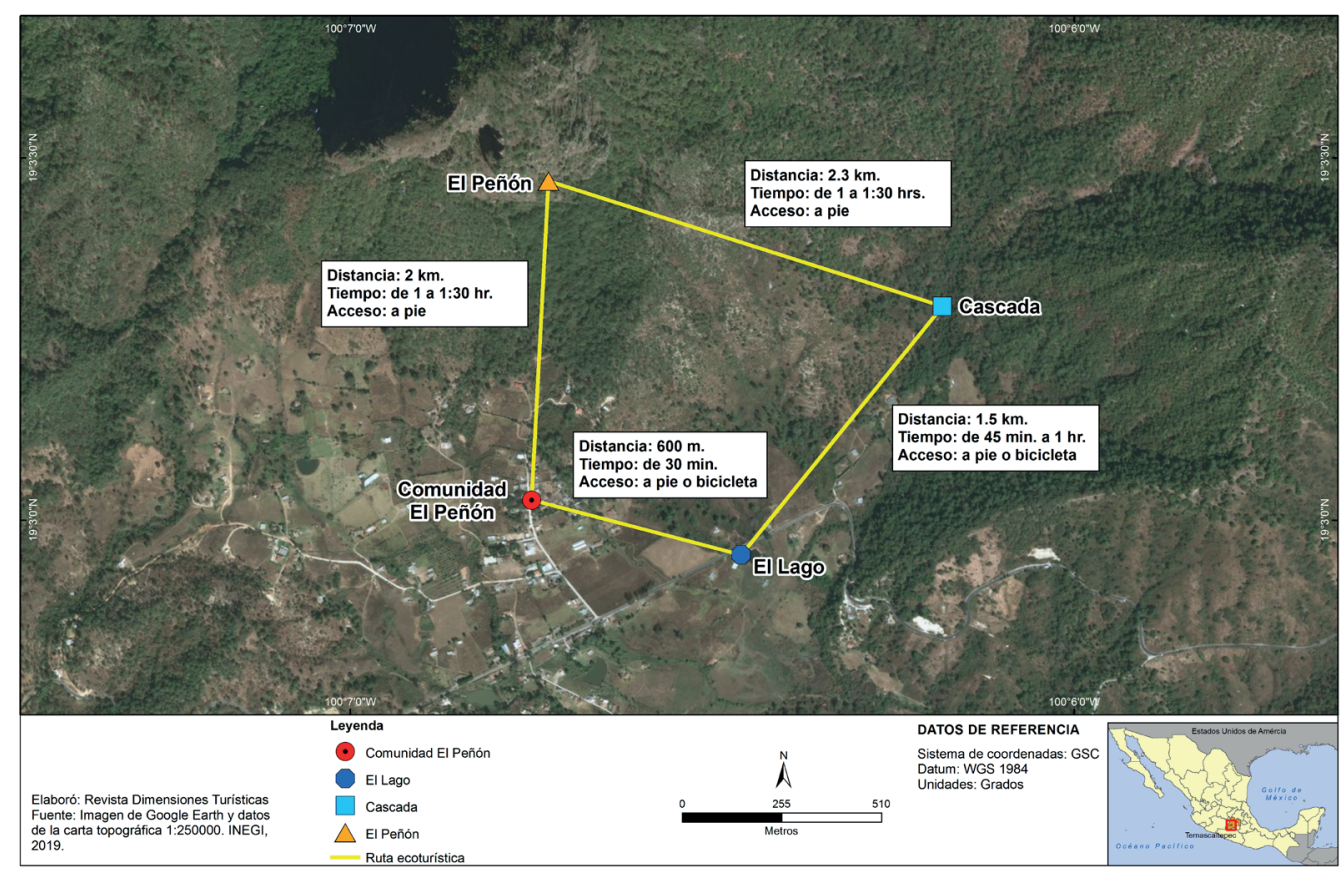

Fuente: Ver interior figura 3. 
De esta manera, la ruta daría comienzo en el centro de la comunidad, para después visitar el lago, la cascada y, por último, El Peñón; aunque también puede ser de forma inversa. Cabe mencionar que el acceso a los atractivos es posible a pie o en bicicleta, en donde se distingue que la distancia entre los puntos va de los $600 \mathrm{~m}$ hasta los $2.3 \mathrm{~km}$. El tiempo para llegar a los lugares es de 30 minutos a hora y media.

Al no contar con señalización de tránsito, es necesario que los turistas realicen el recorrido con integrantes de la comunidad local, pues son ellos quienes conocen el trayecto y los senderos específicos; así, los residentes se incorporarían a estas actividades. De acuerdo con Suárez et al. (2013), una de las primeras acciones para la inclusión de la comunidad en proyectos turísticos es hacerla partícipe en la operatividad, para que puedan darle seguimiento. Adicionalmente, una situación por atender es la profesionalización de los habitantes, ya que, según se reconoce en el trabajo de campo, solo algunos cuentan con las competencias necesarias para la atención al turista.

En cuanto a las actividades a realizar en la ruta establecida y su duración, estas dependerán del espacio donde se encuentren los turistas (tabla 6). Adicionalmente, los recursos culturales pueden aprovecharse cuando el visitante se encuentre en el centro de la comunidad El Peñón, pero no formarán parte del recorrido.

Tabla 6. Actividades y materiales dentro de la ruta

\begin{tabular}{|l|l|l|}
\hline \multicolumn{1}{|c|}{ Lugar } & \multicolumn{1}{|c|}{ Actividades } & \multicolumn{1}{c|}{ Materiales } \\
\hline El Peñón & $\begin{array}{l}\text { Observación de flora y fauna } \\
\text { Observación sideral }\end{array}$ & Binoculares \\
\hline Safari fotográfico & Telescopio astronómico \\
\hline Cascada & Actividades recreativas acuáticas & Cámara fotográfica \\
\hline Lago & Pesca recreativa & Traje de baño \\
\hline Ruta de tránsito & $\begin{array}{l}\text { Senderismo interpretativo y caminata } \\
\text { recreativa }\end{array}$ & Caña de pescar, anzuelos, carnada, red \\
\hline Comunidad El Peñón & $\begin{array}{l}\text { Talleres de educación ambiental y rescate } \\
\text { de flora y fauna }\end{array}$ & $\begin{array}{l}\text { Papelería (hojas, lápices, marcadores, } \\
\text { plumones), fotografías }\end{array}$ \\
\hline
\end{tabular}

Fuente: Elaboración propia.

De esta forma, las acciones son propuestas conforme a la literatura revisada, específicamente lo postulado por Sectur (2004), que ayudaría a generar un bajo impacto en la zona, premisa fundamental del ecoturismo. Además, a través del planteamiento se intenta producir ingresos sostenibles y equitativos para los participantes, así 
como la conservación de los recursos naturales, lo cual coincide con lo establecido por Drumm et al. (2004).

El proyecto de ruta ecoturística debe evaluarse por la comunidad local, instituciones públicas y posibles inversionistas/colaboradores, con el fin de que se ajusten elementos para la puesta en marcha de las acciones (Arredondo et al., 2013; Ramírez, 2019). De esta forma, durante el trabajo de campo fueron vislumbrados actores sociales, públicos y privados que pueden apoyar, entre los que destacan la Dirección de Turismo del Municipio de Temascaltepec, las escuelas de vuelo (Vuelo libre y Sky Riders), escuelas similares en Valle de Bravo, además de la comunidad local. Así, los elementos que se tendrían que evaluar son la pertinencia, la logística, las actividades a implementar $y$, de ser viable, realizar una prueba de mercado.

Adicionalmente, uno de los elementos que no cubre esta propuesta es identificar un camino a seguir, a fin de propiciar la participación de la comunidad y actores interesados en todas las fases de planificación, porque solo se centra en lo operativo y en la evaluación de recursos naturales. Atender este vacío es vital para el éxito de los productos turísticos, debido a que, como algunos autores evidencian (Garduño y Guzmán, 2012; Ghorbani et al., 2015; Ramírez, 2019), es importante conformar un grupo de trabajo que se haga cargo del proyecto y con ello fortalecer el trabajo comunitario.

\section{Conclusiones}

El ecoturismo se ha convertido en una práctica consolidada en los últimos años; principalmente debido a que promueve el desarrollo sustentable (Ghorbani et al., 2015; Orgaz y Cañero, 2015). De esta manera, los destinos han visto una oportunidad de innovar en su oferta, por medio del aprovechamiento de los recursos naturales (Agaton-Lorenzo y Cruz-Vicente, 2013; Calçada, 2017; Pinkus-Rendón y Pinkus-Rendón, 2015). Uno de los productos más utilizados para ello son las rutas turísticas (Ibarra-Michel y Velarde, 2016; Fernández y Guzmán, 2005), las cuales necesitan poca inversión y aprovechan los recursos poco utilizados para la recepción de turistas (Urquiola y Lalangui, 2016).

La contribución de este documento se observa a través de dos aspectos: a) la elaboración de una metodología para diseñar rutas ecoturísticas, y b) la propuesta de proyecto en la comunidad El Peñón, Temascaltepec, la cual busca diversificar la 
oferta en la temporada de vuelo. También se identificó que los residentes están de acuerdo en que se generen productos turísticos, lo cual para Ramírez (2019) es de vital importancia, si se pretende detonar el desarrollo sustentable.

En cuanto a las limitantes del estudio, la propuesta contempla solo en algunas etapas a la comunidad local, por lo que es indispensable trabajar con los residentes y los actores interesados a fin de llevarla a cabo. Además, una debilidad del proyecto es que no todos los habitantes están capacitados para la oferta de los servicios, además de que la infraestructura es limitada y se necesitaría un plan estratégico para su implementación.

Lo anterior constituye una oportunidad para futuras investigaciones, tal es el caso de la gestión comunitaria destinada a establecer el proyecto, planes de negocios, análisis de mercado, estudios del costo-beneficio y capacidad de carga, entre otros, que contribuyan a que se favorezca el desarrollo sustentable, local y turístico en la zona.

Por último, los resultados obtenidos ratifican que la ruta ecoturística puede diversificar la oferta de la comunidad de El Peñón, dando valor al aprovechamiento de los recursos naturales; sin embargo, y de acuerdo con Calderón-Puerta et al. (2018) es necesario plantear, desarrollar y evaluar la forma de gestión e implementación de los nuevos proyectos de turismo en las comunidades, con el fin de que los beneficios sean mayores a los costos generados por la actividad turística.

\section{Referencias}

Agaton-Lorenzo, D. y Cruz-Vicente, M. (2013). Propuesta de diversificación de la oferta turística en Acapulco: paseos ecoturísticos en la Laguna de Tres Palos. Turydes, Revista de Turismo y Desarrollo, 6(14). https://bit.ly/36NrVgl

Alpízar, V. y Maldonado, M. (2009). Integración de la ruta del vino en Querétaro, un producto innovador. Quivera, Revista de Estudios Territoriales, 11(2), 97-109. https://bit.ly/360JnBx

Arredondo, P., Hernández, C. y Mendoza, T. (2013). Propuesta para el diseño de rutas turísticas culturales: el caso del sur del estado de Jalisco, México. Turismo \& Sociedade, 6(2), 324-344. https://doi.org/10.5380/tes.v6i2.31931

Barragán, J. (2017). Diseño de una ruta ecoturística en el municipio de Coloso - Sucre: senderismo y biodiversidad [tesis de maestría, Universidad Tecnológica de Bolívar]. Biblioteca de la Universidad Tecnológica de Bolívar. https://bit.ly/2GHXqOB 
Baum, T. (1998). Taking the exit route: extending the tourism area life cycle model. Current Issues in Tourism, 1(2), 167-175. https://doi. org/10.1080/13683509808667837

Bicudo, R., Alves, M., Aparecida, S., Batistella, M. y Farinaci, J. (2017). Perspectives for environmental conservation and ecosystem services on coupled rural-urban systems. Perspectives in Ecology and Conservation, 15(2), 74-81. https://doi.org/10.1016/j.pecon.2017.05.005

Bringas-Rábago, N. L. y Ojeda-Revah, L. (2000). El ecoturismo: ¿una nueva modalidad del turismo de masas? Economía, Sociedad y Territorio, 2(7), 373-403. https://doi.org/10.22136/est002000436

Bryman, A. (2012). Social Research Methods. Oxford University Press. https://bit.ly/ 3nEXzCT

Calçada, F. (2017). La diversificación de la oferta turística como alternativa para minimizar la estacionalidad: el caso de los eventos en Balneário Camboriú (Santa Catarina, Brasil). Cuadernos de Turismo, 39, 91-112. https://bit.ly/2FifBcU

Calderón-Puerta, D. M., Arcila-Garrido, M. L. y López-Sánchez, J. A. (2018). Las rutas e itinerarios turístico-culturales en los portales oficiales de turismo de las comunidades autónomas españolas. Revista de Estudios Andaluces, 35, 123-145. https://doi.org/10.12795/rea.2018.i35.05

Camacho-Ruiz, E., Carrillo-Reyes, A., Rioja-Paradela, T. y Espinoza-Medinilla, E. (2016). Indicadores de sostenibilidad para el ecoturismo en México: estado actual. LiminaR, Estudios Sociales y Humanísticos, 14(1), 156-168. https://doi. org/10.29043/liminar.v14i1.429

Ceballos, H. (1989). The future of ecotourism. Mexico Journal, 1(17), 13-14.

Cheia, G. (2013). Ecotourism: definition and concepts. Revista de Turism: Studii si Cercetari in Turism, 15, 56-60. https://bit.ly/3ILHcmD

Drumm, A., Moore, A., Terborgh, J., Patterson, C. y Soles, A. (2004). Desarrollo del ecoturismo: un manual para los profesionales de la conservación (Vol. 2). Nature Conservancy United States. Agency for International Development. https:// bit.ly/2SWogF6

Fennell, D. (2001). A content analysis of ecotourism definitions. Current Issues in Tourism, 4(5), 403-421. https://doi.org/10.1080/13683500108667896

Fernández, G. y Guzmán, A. (2005). Patrimonio industrial y rutas turísticas culturales: algunas propuestas para Argentina. Cuadernos de Turismo, 15, 97-112. https://bit.ly/36XjQpA 
García, N. y Doumet, N. (2017). El producto turístico comunitario como estrategia para diversificar las economías locales del cantón Bolívar, provincia de Manabí, Ecuador. Revista Interamericana de Ambiente y Turismo, 13(1), 105-116. https://doi.org/10.4067/S0718-235X2017000100105

Garduño, M. y Guzmán, C. (2012). El turismo rural y la participación comunitaria en Ranchería Las Palomas, Estado de México. Revista Rosa Dos Ventos, 4(2), 235249. http://hdl.handle.net/20.500.11799/79539

Ghorbani, A., Raufirad, V., Rafiaani, P. y Azadi, H. (2015). Ecotourism sustainable development strategies using SWOT and QSPM model: a case study of Kaji Namakzar Wetland, South Khorasan Province, Iran. Tourism Management Perspectives, 16, 290-297. https://doi.org/10.1016/j.tmp.2015.09.005

Gonzaga, C., Moncayo, A., Cortés, S. y Suasnavas, G. (2015). Ruta ecoturística: una oportunidad para promover la acción comunitaria, base del desarrollo sustentable en la Amazonia Sur del Ecuador. Revista Cultura y Turismo, 67, 199227. https://bit.ly/3dftVzs

H. Ayuntamiento de Temascaltepec. (2016, 31 de marzo). Gobierno municipal de Temascaltepec 2016-2018. https://bit.ly/33ICwrl

Hernández, E. y De la Torre, M. (2016). Turismo y violencia. Los nuevos imaginarios del miedo. Opción, 32(13), 203-227. https://bit.ly/2GJD3QY

Hernández, J. (2011). Los caminos del patrimonio. Rutas turísticas e itinerarios culturales. PASOS, Revista de Turismo y Patrimonio Cultural, 9(2), 225-236. https:// doi.org/10.25145/j.pasos.2011.09.021

Ibarra-Michel, J. y Velarde, M. (2016). Rutas turísticas sustentables como alternativa para el desarrollo de comunidades rurales. En R. Espinoza, R. Chávez, y E. Andrade (Eds.), Estudios turísticos en regiones de México (pp. 179-209). Universidad de Guadalajara, Centro Universitario de la Costa.

Jeambey, Z. (2016). Rutas gastronómicas y desarrollo local: un ensayo de conceptualización en Cataluña. PASOS, Revista de turismo y patrimonio cultural, 14(5), 1187-1198. https://doi.org/10.25145/j.pasos.2016.14.079

Kraftchick, J. F., Byrd, E. T., Canziani, B. y Gladwell, N. J. (2014). Understanding beer tourist motivation. Tourism Management Perspectives, 12, 41-47. https://doi. org/10.1016/j.tmp.2014.07.001

Lanquar, R. (2001). Marketing turístico: de lo global a lo local. Ariel Turismo. 
Luján, M., Ferrelli, F. y Piccolo, M. (2016). Diversificación de la actividad turística de balnearios: el caso de Pehuen-Co, Argentina. Cuadernos de Turismo, 38, 245261. https://doi.org/10.6018/turismo.38.271441

Machado, E. y Hernández, Y. (2007). Procedimiento para el diseño de un producto turístico integrado en Cuba. Teoría y Praxis, 3(4), 161-174. https://doi. org/10.22403/uqroomx/typ04/10

Martínez, R. y Trejoluna, O. (2017). La percepción de seguridad de los turistas en un sitio de turismo religioso. International Journal of Scientific Management and Tourism, 3(4), 255-274. https://bit.ly/2SGHuys

Mat, A. y Baum, T. (2005). Mass-ecotourism: an alternative to sustainable tourism development in developing countries. TEAM, Journal of Hospitality \& Tourism, 2(1), 81-91. https://bit.ly/2SIMgLO

Ministerio de Comercio, Industria y Turismo (Mincit). (2010). Metodología para la elaboración del inventario de atractivos turísticos. https://bit.ly/3dl93GV

Obombo, K. y Velarde, M. (2018). Ecoturismo y conservación: Perspectivas y prácticas en las reservas de la biósfera de Los Tuxtlas, México y Maasai Mara, Kenia. Dimensiones Turísticas, 2(2), 53-78. https://doi.org/10.47557/PMQQ9256

Obregón, S. A., Sánchez, J. y Somohano, M. de L. (2016). Planificación de rutas turísticas para autobús a través de indicadores de accesibilidad integral y de dotación de bienes materiales e inmateriales. Transporte y Territorio, 14, 144166. https://bit.ly/3300GAU

Organización Mundial del Turismo (OMT). (2002). El mercado francés del ecoturismo. https://bit.ly/3nBldAo

Orgaz, F. y Cañero, P. (2015). El ecoturismo como motor de desarrollo en zonas rurales: un estudio de caso en República Dominicana. Ciencia y Sociedad, 40(1), 47-76. https://doi.org/10.22206/cys.2015.v40i1.pp47-76

Orgaz, F. y Moral, S. (s. f.). Las áreas protegidas como espacios para fomentar el desarrollo sostenible y el turismo comunitario. Un estudio de caso exitoso. Revista DELOS, Desarrollo Local Sostenible. https://bit.ly/3IsJ03F

Pinkus-Rendón, M. A. y Pinkus-Rendón, M.J. (2015). El ecoturismo: quimera o realidad de desarrollo en la reserva de la biosfera Ría Celestún, México. Revista LiminaR, Estudios Sociales y Humanísticos, 13(1), 69-80. https://doi.org/10.29043/ liminar.v13i1.367 
Ramírez, O. (2019). Propuesta metodológica para la generación de productos turísticos a partir de la comunidad local. RETOS, Revista de Ciencias de Administración y Economía, 9(17), 127-143. https://doi.org/10.17163/ret.n17.2019.08

Ramírez, O., Serrano, R. y Palmas, Y. (2020). Impactos socioculturales del turismo deportivo en la comunidad de El Peñón, Temascaltepec Methaodos, Revista de Ciencias Sociales, 8(1), 62-76. https://doi.org/10.17502/m.rcs.v8i1.338

Reyes, M., Ortega, Á. y Machado, E. (2017). Modelo para la gestión integrada del turismo comunitario en Ecuador, caso de estudio Pastaza. Revesco, Revista de Estudios Cooperativos, 123, 250-275. https://doi.org/10.5209/REVE.53242

Secretaría de Desarrollo Social (Sedesol). (2015). Catálogo de localidades. https://bit. ly/2GHkqNG

Secretaría de Turismo (Sectur). (2004). Turismo alternativo. Una nueva forma de hacer turismo (Fascículo 1). https://bit.ly/3jYBNIO

Soares, J., Ivars, J. y Gândara, J. (2015). La evolución de destinos turísticos litorales consolidados. Análisis comparado de Balneario Camnoriú (Brasil) y Benidorm (España). Anales de Geografía de la Universidad Complutense, 35(2), 143-166. https://doi.org/10.5209/rev_aguc.2015.v35.n2.50118

Suárez, R., Bribiescas, F. y Villanueva, J. (2013). Gestión y fortalecimiento de proyectos comunitarios: una opción para el desarrollo turístico sustentable en comunidades rurales del Estado de Chihuahua (Caso Ejido Ojo de la Casa). European Scientific Journal, 9(8), 270-283. https://bit.ly/3iOMNGT

Subsecretaría de Minería. (2018). Panorama minero del Estado de México. Secretaría de Economía. https://bit.ly/2laa2yd

Urquiola, O. y Lalangui, J. (2016). La ruta agro turística y de naturaleza Banagua de la provincia El Oro. Revista Universidad y Sociedad, 8(3), 128-134. https://bit. ly/3iMAMI8

Vanegas, G. (2006). Ecoturismo instrumento de desarrollo sostenible [monografía, Universidad de Antioquia]. Biblioteca Digital de la Universidad de Antioquía. https://bit.ly/3jNSaai

Wall, G. y Mathieson, A. (2006). Tourism: change, impacts and opportunities. Pearson - Prentice Hall.

Weaver, D. y Lawton, L. (2007). Twenty years on: the state of contemporary ecotourism research. Tourism Management, 28(5), 1168-1179. https://doi. org/10.1016/j.tourman.2007.03.004 


\title{
EXPECTATIVAS LABORALES DE LOS CENTENNIALS PARA LOS NEGOCIOS TURÍSTICOS DE CANCÚN. ENFOQUE BASADO EN LA TEORÍA DE LAS NECESIDADES DE MCCLELLAND
}

\author{
RICARDO SONDA DE LA ROSA \\ rsonda@ucaribe.edu.mx \\ DAMAYANTI ESTOLANO CRISTERNA \\ destolano@ucaribe.edu.mx \\ SANDRA GUERRA MONDRAgÓN \\ sguerra@ucaribe.edu.mx \\ Universidad del Caribe
}

La creciente participación de trabajadores conocidos como centennials, obliga a los negocios turísticos a implementar nuevas estrategias para reclutar y retener a su personal. Este trabajo identifica las expectativas laborales bajo la teoría de las necesidades de McClelland, desde un enfoque cuantitativo de alcance correlacional, utilizando el análisis factorial de componentes, a través de la aplicación de una encuesta a la población estudiantil próxima a egresar, del programa educativo de Turismo Sustentable y Gestión Hotelera de la Universidad del Caribe, ubicada en Cancún, Quintana Roo, México. Los hallazgos declarados como motivadores fueron la infraestructura, el balance de vida, el clima laboral y los programas de sustentabilidad característicos de esta generación.

Palabras clave: centennials, contratación, expectativas, negocio turístico.

\section{CENTENNIALS JOB EXPECTATIONS FOR CANCUN TOURISM BUSINESSES. APPROACH BASED ON MCCLELLAND'S THEORY OF NEEDS}

The growing participation of young workers known as centennials, compels tourism businesses to implement new strategies to recruit and retain their staff. This paper identifies labor expectations under McClelland's theory of needs, from a quantitative approach of correlational scope using the factorial analysis of components, applied through a survey to the student population about to graduate from the educational program of Sustainable Tourism and Hotel Management at the Universidad del Caribe, located in Cancun, Quintana Roo, Mexico. The findings declared as motivators are infrastructure, life balance, work environment and sustainability programs hallmarks of this generation.

Keywords: centennials, recruitment, expectations, tourist business.

Fecha de recepción: 15 de julio de 2020 Fecha de aceptación: 9 de octubre de 2020.

CÓMO CITAR: Sonda, R., Estolano, D. y Guerra, S. (2020). Expectativas laborales de los centennials para los negocios turísticos de Cancún. Enfoque basado en la teoría de las necesidades de McClelland. Dimensiones Turísticas, 4(7), 151-180. https://doi.org/10.47557/KJLU44449 


\section{Introducción}

as diferencias y confrontaciones entre generaciones, en aspectos sociales y culturales, han sido siempre una constante en el entorno laboral; sin embargo, se han agudizado en los últimos años debido a que, por primera vez en la historia contemporánea, las organizaciones emplean hasta cuatro de ellas en un mismo contexto empresarial (Bennett et al., 2012; Costanza et al., 2012; Kuron et al., 2015).

Los denominados Baby boomers, Generación X (o xennials), Generación Y (más conocidos como millennials), y ahora los Generación Z (también llamados centennials), en conjunto, desarrollan una equilibrada fuerza de trabajo en muchos negocios turísticos, cada uno con motivaciones que es útil determinar, para distintos fines.

Se designa como centennials a los jóvenes que nacieron a mediados de los años 90 y hasta el 2005, en una época caracterizada por lo digital (Magallón, 2016). Autores como Boschma y Groen (2008) los describen con atributos fortalecidos en el sentido de la autenticidad, el crecimiento personal, la rapidez y la socialización. Bajo este paradigma, tales individuos se incorporan hoy en día al mercado, de forma gradual, razón por la que se ha hablado respecto a sus motivaciones y expectativas.

Autores como Guillot-Soulez y Soulez (2014), Golik (2013), Ng et al. (2010), y Smith (2010), coinciden en que estos perfiles buscan prioritariamente un equilibrio entre su vida personal y el desempeño profesional; motivación que deben contemplar las empresas en busca de resultar atractivas para ellos.

Wilton (2008) plantea que los centennials, antes de ingresar en una organización, anteponen variables como el desarrollo de habilidades, proyectos de vida y retos innovadores, por encima del factor retribución económica. Según Smith (2010), esta generación es la primera en reducir las diferencias entre hombres y mujeres; además, se les considera incluyentes y abiertos a otras preferencias de género, distintas a las conservadoras.

Thompson y Gregory (2012) afirman que estas actitudes han tenido impacto en los procesos tradicionales de selección, reclutamiento y contratación, mismos que requieren evolucionar a corto y mediano plazo, a fin de que disminuyan los índices de rotación. Esto parece demandar el establecimiento de estrategias de prospección diversas para los nuevos colaboradores (Al-Emadi et al., 2015; Kultalahti y Viitala, 2015; Rani y Samuel, 2016). 
Moreno et al. (2015) describen que el mayor índice de rotación se presenta durante los primeros seis meses después de incorporar al empleado a una organización. Esto ocasiona cuantiosos costos en el proceso de reclutamiento, selección, contratación, inducción y capacitación al puesto; además, provoca una percepción negativa de los demás trabajadores y supervisores, traducida en incertidumbre, cansancio, frustración y estrés, a causa de la baja. Esta situación puede detonar un efecto dominó y hacer que los colaboradores de planta evalúen sus alternativas, en busca de otro espacio para la obtención de una estabilidad mayor.

El índice de rotación es multifactorial; sin embargo, una de las principales causas es el incumplimiento de las expectativas laborales. Autores como Boschma y Groen (2008), Ferri-Reed (2014), y Herbison y Boseman (2009), afirman que es responsabilidad de las empresas migrar a innovadores y más atractivos paquetes integrales (no solo salariales), dirigidos a satisfacer dichas expectativas.

Una de las teorías más conocidas, en camino a entender qué mueve a los trabajadores, es la de David McClelland, la cual ha sido utilizada para disminuir los índices de rotación y atraer a futuros colaboradores. En el libro titulado The achieving society (1961), el autor define los tres tipos de motivaciones compartidas por todas las personas, sin importar su origen, sexo o edad, que influyen en la toma de decisiones en cuanto a mantenerse o dejar sus puestos: necesidad de afiliación, necesidad de logro y necesidad de poder.

En este contexto, la presente investigación tiene como objetivo identificar qué esperan los centennials del mercado laboral, con base en la teoría de McClelland (1961), para considerar emplearse en una organización turística, así como los elementos de retención más atractivos, englobados en estrategias, planes y programas, que las empresas deberán priorizar y ofrecer en el corto plazo, a fin de convertirse en espacios atractivos que cubran las necesidades del perfil de interés.

Lo anterior lleva a las siguientes reflexiones: ¿cuáles son las principales motivaciones laborales de los estudiantes de turismo, próximos a insertarse en su primera experiencia profesional en una organización turística?, ¿cuáles son las variables que determinan su estabilidad en una empresa?, y ¿cómo se relacionan esas motivaciones con la teoría de David McClelland? 


\section{Antecedentes}

La literatura relacionada con las motivaciones, gustos, principios y expectativas de los centennials es tan nueva como limitada. A continuación, se expresan los hallazgos de algunos autores que han estudiado sus características, basados en diversos acontecimientos que forman parte de esta generación, así como de las precedentes.

Los Baby boomers (1946-1964), también llamados Alfa boomers o Golden boomers, son descendientes de la Segunda Guerra Mundial. Se caracterizan por ser pioneros de revoluciones sociales, en busca de un mundo de paz y armonía, rechazando los conflictos bélicos. Priorizan el respeto y la disciplina, son ahorradores y acumuladores, los que más leen, comen en casa y evitan caer en compras de impulso. Su motivación principal es la familia (Boschma y Groen, 2008; Hershatter y Epstein, 2010).

Los individuos de la Generación X (1965-1979), conocida igualmente como Peter Pan o Gen X, reciben su nombre de los Baby boomers, debido a la dificultad para entenderlos, pues no tenían rumbo o sentido. Crecieron en una época marcada por el escepticismo y la reforma social; se convirtieron en grandes impulsores de la tecnología, transformándose en seres consumistas que dejaron los aparatos electrónicos (fijos), para sustituirlos por los dispositivos portátiles (móviles). Son ambiciosos, buscan estudiar y escalar posiciones cuanto antes sea posible (Karriker y Hartman, 2018; Parry y Urwin, 2017).

La Generación Y (1980-2000) está compuesta por personas con una actitud desafiante y retadora, cuestionan todo. El internet ha sido parte de su vida y están inmersos en una sociedad con acceso a la información en todo momento. Jonsen et al. (2012), en su libro Cómo gestionar a los nativos digitales, comentan al respecto: "asumiendo que tienen derecho a ciertas cosas, creen que el mundo les debe algo, esto los convierte en personajes instantáneos que han desarrollado mentes con hipertexto prefiriendo el acceso sencillo, rápido y aleatorio de la información" (p. 62).

A la par, en su pensamiento se vuelven dictaminadores que pueden castigar o hacer populares a las organizaciones dependiendo de cómo se sienten tratados, por medio de las redes sociales (Bialik y Fry, 2019; Bizzi, 2017; Bosch et al., 2019; Espinoza y Ukleja, 2016; Fischer y Espejo, 2018; Karriker y Hartman, 2018; Holland et al., 2016; Murillo, 2017). 
La Generación Z, también denominada centennials, son nativos digitales, personas que nacieron y están creciendo con los avances tecnológicos, son impulsivos, lo que se refleja en un mayor empoderamiento. Están llenos de entretenimientos y se consideran hábiles en técnicas sociales de conexión tecnológica. La mayoría creció sin preocupaciones y confía en la prosperidad material e intelectual (Boschma y Groen, 2008).

Para Jonsen et al. (2012), los centennials han creado un perfil de personalidad basado más en la diversión que en las obligaciones y responsabilidades, son liberales en muchos sentidos, les gusta establecer sus propios horarios y reglas, evitan realizar tareas que no les satisfacen, y los retos y el reconocimiento en público les producen placer.

Asimismo, esta generación es la primera que ve a la tecnología como parte de su mundo. No tuvieron que adecuarse a los cambios técnicos y consideran a las actualizaciones algo normal de su vida (Carter y Walker, 2018). Tener dominio digital puede ser una ventaja, pues gracias a esta característica la incorporación al mundo laboral y la adaptación a las nuevas tecnologías les es natural (Ferri-Reed, 2014). También, aumentan su confianza para obtener ayuda, crear ideas o retroalimentación sincrónica, gracias al acceso a la información que en otras épocas no tendrían a su alcance (Jonsen et al., 2012).

Herbison y Boseman (2009) los describen como individuos que han estado rodeados por familiares, quienes les apoyan sobremanera en cualquier aspecto de sus vidas, alentándolos y motivándolos permanentemente en actividades extraacadémicas. Los estudios complementarios han logrado que tengan una habilidad superior en la solución de problemas y enfoque a resultados. Estos contextos de familia crean un sujeto que no se preocupa con facilidad, arraigado a casa de sus padres y creador de ambientes de respeto en sus espacios (Gibson et al., 2009).

Al hablar de organizaciones se entiende igualmente que se habla de personas, ambas se benefician unas de otras. Mientras que las primeras obtienen sus objetivos por medio de los individuos, las segundas logran sus metas a través de una estabilidad que se identifica como sinergia empresarial, donde los esfuerzos resultan en un ganar-ganar entre la organización y sus colaboradores. Cuando alguna de estas dos entidades obtiene más provecho sobre la otra, se pierde el equilibrio y surge la llamada rotación de personal. 
Como se indicó líneas arriba, dicha rotación es multivariable. Entre las distintas razones para que un empleado opte por abandonar una organización y contratarse en otra están: los cambios de entornos empresariales, la falta de comunicación o clarificación en metas y objetivos, la inadaptabilidad a normas y procedimientos, la diferencia del perfil de puestos versus el perfil del trabajador, o un ámbito competitivo con ofertas superiores (Boschma y Groen, 2008; Ferri-Reed, 2014; Golik, 2013; Haserot, 2009; Jonsen et al., 2012; Kowske et al., 2010; Meister, 2012; Thompson y Gregory, 2012).

En la actualidad, los jóvenes y su interés por encontrar un equilibrio entre la vida profesional y la personal son un tema abordado por varios investigadores (Bialik y Fry, 2019), por lo que muchas instancias ven este asunto como un elemento clave para reducir el índice de rotación, al afinar sus procesos en la gestión del capital humano y lograr con ello una mejor retención de los perfiles centennial.

En cuanto a la rotación, de acuerdo con las generaciones que convivan en una organización, deberán identificarse las variables principales que provocan este efecto, lo cual ha de entenderse como que el comportamiento humano, con relación a lo psicológico y lo tecnológico, hará que los procesos varíen, impactando en que se logre o no una retención de la fuerza de trabajo (Twenge, 2010).

Golik (2013) afirma que, a ojos de los centennials, el hecho de que los Baby boomers dediquen toda su existencia a una empresa, consumidos en lo personal y con sacrificios hacia sus familias, para ser despedidos luego de años de esfuerzo, es una situación que no están dispuestos a vivir (Solnet et al., 2012).

Tyler (2013) comenta que la Generación Z tiene una opinión puntual y directa respecto a la importancia de un empleo, que dista de las otras. El tema de la movilidad a corto o mediano plazo les es natural, inclusive satisfactoria; así, la decisión de retirarse de una empresa para buscar otras alternativas les produce un sentimiento de reto (Ertas, 2015; George y Wallio, 2017; Rani y Mukherjee, 2017).

Otras características de este perfil, que destacan Jonsen et al. (2012), son: a) quieren reconocimiento inmediato, por más mínimo que sea, b) desean que sus opiniones sean escuchadas, c) rechazan la lectura y presentan problemas de concentración, d) cuentan con una iniciativa mayor, así como capacidad para resolución de conflictos, e) se motivan por medio de retos y desafíos, y f) gustan de ser parte de un equipo, 
pero que las metas y logros se establezcan de manera abierta y consensuada (González, 2011).

En México, la media del índice de rotación de personal es de $16.75 \%$, el más alto de Latinoamérica (Meza, 2019). Dentro de la industria de servicios, especialmente en el sector restaurantero, puede llegar hasta el 50\% (Kelly Mercadotenia, 2017). Para Carter y Walker (2018), la atracción y la retención de recursos humanos son factores que adquieren mayor importancia ante la escasez de talento y afirman que es mejor y más barato conservar que reclutar nuevos candidatos.

Con lo anterior, se considera importante invertir lo que sea necesario en procesos adecuados de selección, complementados con un paquete atractivo de prestaciones para los trabajadores, quienes no resultaban tan críticos antes, pero ahora muestran cambios en la forma de valorar un puesto desde la perspectiva del significado y aporte que puede traer a sus vidas.

En ese tenor, los responsables de capital humano enfrentan grandes retos con las generaciones actuales, en particular por sus altas expectativas, la falta de arraigo para mantenerse por largo tiempo en un mismo departamento, la poca tolerancia, así como los deseos de superación inmediata, lo que juega un rol común en los centennials y provoca que su retención sea más complicada (Torrado, 2015).

Es en este punto donde los postulados de motivación son útiles para los profesionales del reclutamiento, como los siguientes:

a) Teoría de la jerarquía de necesidades, de Maslow (1943);

b) Teoría de la motivación e higiene, de Herzberg y Mausiner (1959);

c) Teorías X y Y, de McGregor (1985);

d) Modelo jerárquico ERC, de Alderfer (1969), en el que ERC son las siglas de existencia, relación y crecimiento;

e) Teoría de valencias y expectativas, de Vroom (1994), con las aportaciones de Porter y Lawler;

f) Teoría del establecimiento de metas, de Locke et al. (1990);

g) Teoría de la equidad, de Adams (1963; 1965); y

h) Teoría de las necesidades aprendidas, de McClelland (1961). 
Este último sustenta sus estudios en torno a las necesidades humanas que tienen los trabajadores, mediante la comparación y análisis de diversos colaboradores operativos y ejecutivos de distintas empresas. Concluye que existen tres grandes necesidades que destacan a la hora de motivarse para desempeñar una actividad laboral. Según McClelland estas se entienden como procesos inconscientes y se dividen en tres categorías:

a) Necesidad de afiliación. Personas que tienen fuertes deseos de ser parte de un grupo social, ávidas de gustar a los demás miembros, con un sentimiento de empatía. Prefieren la colaboración a la competición, no les agradan las situaciones riesgosas o de incertidumbre.

b) Necesidad de logro. Estos individuos buscan de manera intensa alcanzar metas, que involucren un nivel superior de desafío. Anhelan tomar riesgos controlados para lograr sus objetivos, y ansían retroalimentación sobre las actividades que desempeñan.

c) Necesidad de poder. Son aquellos que pretenden controlar a otros e influir en su comportamiento. Este punto se divide en dos: los del poder socializado (preocuparse más por los demás), y los del poder personal (la obtención de autoridad para su propio beneficio).

La teoría de las necesidades aprendidas de McClelland es el eje conductual de este documento, en el que se propone evaluar y diagnosticar las necesidades que expresan los centennials a la hora de elegir un proyecto laboral. La situación actual obliga a que las empresas propongan novedosos esquemas de empleo, que transformen los procesos y estructuras de gestión del capital humano a través de objetivos claros e innovadores, con la finalidad de poder reclutar y dinamizar a los próximos egresados de las universidades, para involucrarlos en una vida profesional sin que sacrifiquen sus expectativas personales.

Bussin y Brigman (2019) enlistan una serie de variables relevantes en las técnicas de atracción de personal en las organizaciones, dirigidas a perfiles centennials, así como la estrategia de retención de personal Employer Branding, conformada para satisfacer y promover la lealtad entre los empleados. Aquí pueden entrar en sinergia valores, comportamientos, al potenciar talentos de los presentes y futuros colaboradores en los negocios turísticos, con la satisfacción de sus necesidades de afiliación, logro y poder. 
El objetivo es lograr la identificación de las principales motivaciones laborales entre los jóvenes, hacia su primera experiencia profesional, lo cual implica establecer relaciones entre múltiples variables. Para ello, se contempla pertinente hacer uso del análisis factorial exploratorio, una técnica multivariante de aproximación estadística que permitirá revelar las interrelaciones de las variables de interés, a través de encontrar dimensiones (factores) subyacentes, comunes entre ellas. Es decir, dicho análisis será la manera de condensar la información recolectada y organizarla en un número más pequeño, sin perder datos valiosos (Hair et al., 1999).

En este método multivariable, se considera el supuesto de que las variables observadas, en lo individual, tienen una parte común al resto y otra parte que es específica. Es en esta última donde, además de la especificidad propia, se aprecian los errores de medida (Barbero, 2013). Lo que importa entonces es que la parte común pueda explicarse por una serie de factores, que son los que se calcularán como resultado de la investigación.

El análisis factorial exploratorio es útil debido a que se está en la búsqueda de una estructura entre una serie de variables cuantitativas, de ahí que se obtenga la información de los datos mismos, sin restricciones a priori sobre la estimación de los componentes o el número de ellos a ser extraído. En resumen, no hay preconcepciones sobre la estructura de los datos.

Además, se establece bajo esta técnica que los factores (latentes) pueden estar correlacionados o bien ser independientes. Más de un factor podría afectar a las variables, pero los errores no se correlacionan entre sí. Dichas variables están afectadas por un único término de error y los factores o las variables latentes no se correlacionan con los términos de error (Barbero, 2013).

\section{Metodología}

El objetivo se centró en identificar las expectativas laborales que tienen los próximos egresados de la carrera de turismo, como parte de la Generación Z, dispuestos a insertarse a corto plazo en empresas de servicios turísticos. La perspectiva teórica aplicada fue la de las necesidades aprendidas de McClelland (1961), que orienta hacia las motivaciones para emplearse en una organización; asimismo, se observaron los elementos de retención más atractivos que las compañías tienen por ofrecer. 
Ante ello, se diseñó una investigación no experimental de alcance correlacional, en la que se estableció la relación entre variables (U.S. Department of Education, 2005) que se hipotetiza conforman las perspectivas que poseen los futuros colaboradores (de perfil centennial) para unirse o permanecer en una organización, con el fin de valorar su importancia (o prioridad) entre la población estudiada.

Robbins (1999) y Schultz (1992) describen como factor de rotación la insatisfacción del trabajador, definida como la discrepancia entre la cantidad de recompensas que espera de las que, efectivamente, recibe. Ello se comprende como que un empleado debe estar satisfecho (con recompensas justas y equitativas) para tener una estabilidad, y que la mayoría de los individuos descontentos son jóvenes solteros, quienes cuentan con mayor libertad de abandonar sus puestos que los colaboradores de más de 50 años, ello invita a plantear la primera hipótesis:

H1: la combinación de actividades laborales y personales impacta de manera directa en el índice de rotación de personal.

Cabe señalar que en ocasiones dichas actividades encuentran un balance. Al respecto, Kahn (2017) estipula que los individuos en toda organización juegan roles distintos, conviviendo y desarrollándose en sus puestos en tres niveles: el físico, el cognitivo y el emocional. En cuanto a este último, existen estudios que profundizan en el concepto de salario emocional, como las de Espinoza y Toscano (2020), quienes afirman que a los colaboradores no solo los mueve la remuneración económica, sino que buscan más allá, teniendo intereses heterogéneos de satisfacción personal, como el de integrar un equipo que sea percibido como sólido y dinámico.

Es por ello, de acuerdo con Cloninger (2002), que la pertenencia a un colectivo, ya sea pequeño o grande, ayuda a aportar sentido a lo que se hace en el día a día; además, el contacto personal y las relaciones sociales favorecen estos lazos de pertenencia, por lo que, aunado al fundamento anterior, se plantea la siguiente hipótesis:

H2: la necesidad de afiliación laboral es un factor determinante para que personas con perfil centennial se mantengan en una organización.

Este estudio transversal se define en un momento en el tiempo (Ato et al., 2013). El levantamiento de datos se realizó entre febrero y marzo del año 2020. El marco de población estuvo compuesto por los estudiantes de la Licenciatura de Turismo Sustentable y Gestión Hotelera de la Universidad del Caribe, ubicada en Cancún, 
Quintana Roo, próximos a egresar en el periodo de otoño e invierno del 2020, nacidos entre los años 1994 y 1999.

La representatividad de la población elegida radicó no solo en que cumplen con fechas de nacimiento previas al 2005, según Magallón (2016), sino en su actitud desafiante y retadora, la conectividad de la que gozan en esta época digital, el empoderamiento que perciben en los distintos ámbitos de sus vidas, las motivaciones y expectativas laborales que mantienen en el corto plazo, los diversos estratos sociales a los que pertenecen, y sus dinámicas de núcleos familiares múltiples.

Fue posible realizar un censo a través de la plataforma Google Forms, utilizando el correo institucional de dicha población. Este proceso virtual permitió crear una liga vinculada al cuestionario, que sería alimentado por los sujetos bajo análisis. El llenado individual de este instrumento no implicó más de 10 minutos. La tasa de respuesta obtenida fue de 9 de cada 10 inscritos en esta cohorte, pues 10 de los estudiantes (contactados en la última semana de marzo, cuando inició la contingencia por la pandemia del COVID-19), no respondieron al formulario.

Las razones por las que no participaron fueron variadas: a) no abrieron el correo con la invitación a la encuesta en línea, b) tuvieron nulo o limitado acceso a internet, c) regresaron a sus lugares de origen (fuera de Cancún), y d) experimentaron condiciones que dificultaron la conectividad. Así, la tasa de no respuesta fue de 1:10.

Las variables seleccionadas en el instrumento fueron tomadas parcialmente de la propuesta de Madero y De la Garza (2017) y de Madero et al. (2016), englobados en los planteamientos de McClelland.

Tabla 1. Variables de expectativas laborales

\begin{tabular}{|l|l|l|l|l|}
\hline 1. Liderazgo & 2. Ubicación & 3. Alimentos & 4. Infraestructura & 5. Bienestar \\
\hline 6. Salud & 7. Balance & 8. Desarrollo & 9. Transporte & 10. Clima laboral \\
\hline 11. Sustentabilidad & 12. Certificaciones & 13. Salario & 14. Procedimientos & 15. Movilidad \\
\hline
\end{tabular}

Fuente: Elaboración propia.

El instrumento consistió en un cuestionario formado en su mayoría por preguntas cerradas y algunas abiertas, para recolectar los valores de las 15 variables (tabla 1), y 12 de perfil demográfico (año de nacimiento, género, situación de empleo, conocimientos informáticos, idiomas) y psicográfico (motivación, habilidades, au- 
topercepción, principales distracciones, cuidados personales, gustos personales e intereses).

Dichas variables se detallan a continuación, de acuerdo con las categorías de necesidades aprendidas que propone McClelland (1961).

Necesidades de afiliación:

1) Liderazgo: que el supervisor o jefe inmediato sea considerado un líder.

2) Ubicación: que la localización de la empresa donde se desarrollan las actividades laborales sea importante para elegirla.

3) Alimentos: contar con un comedor y alimentos saludables e higiénicos.

4) Infraestructura: acceso a materiales, equipos, herramientas, espacios y suministros a fin de desarrollar las funciones del puesto.

5) Bienestar: tener instalaciones de descanso, entretenimiento y ejercicio para colaboradores.

6) Salud: ofrecer servicios de salud y bienestar integral.

Necesidades de logro:

7) Balance: que las actividades laborales permitan tener un equilibrio entre la vida personal y la vida profesional.

8) Desarrollo: que la empresa presente un plan de crecimiento, capacitación y adiestramiento.

9) Transporte: contar con transporte de personal para traslados.

10) Clima laboral: promover un ambiente positivo.

11) Sustentabilidad: que se implementen (o estén en planeación) programas de sustentabilidad y manejo adecuado de recursos.

12) Certificaciones: impulsar reconocimientos, certificaciones o galardones.

Necesidades de poder:

13) Salario: contar con un ingreso adecuado.

14) Procedimientos: que la empresa opere con reglamentos, manuales y procedimientos establecidos.

15) Movilidad: que se ofrezcan programas de movilidad nacional o internacional. 
Para las respuestas se utilizó una escala Likert de medición del 1 al 5, siendo totalmente en desacuerdo (1), en desacuerdo (2), neutro (3), de acuerdo (4), y totalmente de acuerdo (5). Para el bloque del perfil se combinaron escalas de medición nominales y ordinales.

El instrumento presentó una consistencia interna válida, ya que el coeficiente Alfa de Cronbach resultó en 0.86 . En la evaluación de la confiabilidad se aplicó este método, por ser el más utilizado para la estimación de este dato, mismo que permite señalar la magnitud de la covarianza de los ítems que se incluyen en el instrumento, y la medida en la que el constructo (o tema de estudio) está presente en ellos (Ventura-León y Caycho-Rodríguez, 2017).

En este análisis factorial tipo $\mathrm{R}$ (el diseño más común dentro de esta técnica), se siguió un método de cinco pasos, que explican Hair et al. (1999), con la serie de variables de investigación para identificar sus dimensiones latentes:

Paso 1. Diseño del análisis factorial, en el que se calculó una matriz de correlación. Se delineó en términos del número de variables (15, seleccionadas para explicar el supuesto de contratación), sus propiedades de medición y los tipos, así como el tamaño de muestra adecuado, pues en el censo que se realizó se eligieron a conveniencia 100 casos, lo que permitió respetar la ratio aceptable de 10 a uno, con relación a las variables finales que se procesaron; el criterio para conservar una de ellas con significancia estadística, fue que su coeficiente de correlación ( $r$ ) fuera mayor a $|0.5|$. El nivel de significancia (a) utilizado en las pruebas de hipótesis fue de 0.05 .

Paso 2. Revisión de los supuestos del análisis factorial, que tienen que ver con la distribución de normalidad, homocedasticidad y linealidad.

Paso 3. Estimación de los factores y valoración del ajuste, para el que se utilizó el análisis de componentes principales, que permitiría ponderar la varianza total y la referida estimación de los factores, los cuales presentan proporciones bajas de varianza única. Asimismo, el interés en este estudio fue la predicción y el obtener una única solución.

Paso 4. Interpretación de los factores, que inició con:

a) El cálculo de la matriz de factores no rotados, lo cual permitió conocer de manera preliminar cuántos factores extraer para el modelo. Esta matriz despliega 
las cargas de cada variable por factor; además, con ella es posible visualizar la mejor combinación lineal y las subsecuentes;

b) Rotación de factores con el método ortogonal de aproximación Varimax, que maximiza la suma de varianzas de las cargas de la matriz de factores; por tanto, lo conveniente es que estas sean cercanas a $-10+1$, pues eso indicaría que hay una clara asociación negativa o positiva, respectivamente, entre la variable y el factor;

c) Valoración de la significación de cargas factoriales, asegurando la significación práctica. Esto se resumió en que cualquier factor con carga de 0.55 o más (en términos absolutos) sería por demás significativo, pues la cantidad de casos lo permite. Lo anterior posibilitó expresar la carga como el porcentaje de varianza explicada debida al factor, elevando al cuadrado y multiplicando por 100;

d) Valoración de la comunalidad, que representa la proporción de varianza con la que contribuye cada variable a la solución final. Así pues, si la comunalidad es menor a 0.5 se considera que esa variable está carente de explicación suficiente; $y$

e) Etiquetación de los factores, que está muy relacionada con el conocimiento especializado del material por parte del investigador, pues se fabricaron intuitivamente, a partir de las asociaciones y cargas obtenidas.

Paso 5. Validación del análisis factorial, con mecanismos como el de la división de grupos, para evaluar el grado para generar nuevos resultados.

En la examinación de los datos y la elaboración de recursos visuales (tablas y gráficos) se utilizó GNU PSPP v.1.2.0 y Excel v.365. Una vez hecha la validación del modelo, se concluiría sobre las hipótesis planteadas.

\section{Resultados}

Este apartado se organizó en tres partes:

1) Análisis descriptivo de las variables demográficas y psicográficas, para identificar la composición de la población centennial, entre los estudiantes de la Licenciatura de Turismo Sustentable y Gestión Hotelera de la Universidad del 
Caribe, quienes se perfilan a egresar e insertarse en empresas de vocación turística.

2) Análisis descriptivo ponderado, que permite ubicar las variables de mayor relevancia para contratación entre los sujetos de estudio.

3) Análisis factorial exploratorio, dirigido a validar las correlaciones entre variables y determinar los factores de constructos.

\section{Análisis demográfico y psicográfico}

En la tabla 2 se muestra la información relacionada con los 100 sujetos que contestaron el instrumento, en cuanto a género, situación de empleo, nivel de conocimientos informáticos y dominio de idiomas extranjeros (cantidad). Predomina el género femenino. Por lo menos 80 de ellos han tenido experiencia de trabajo formal, la mayoría domina la paquetería Office y otro software que se utiliza en organizaciones de servicios turísticos y más de 90 estudiantes hablan inglés.

Tabla 2. Características demográficas de los sujetos de estudio

\begin{tabular}{|l|c|c|}
\hline \multicolumn{1}{|c|}{ Variable $y$ amplitud } & Número & Porcentaje \\
\hline 1. Sexo & & \\
\hline Masculino & 37 & $37 \%$ \\
\hline Femenino & 63 & $63 \%$ \\
\hline 2. Situación laboral & & \\
\hline Se encuentra laborando & 23 & $23 \%$ \\
\hline No está laborando, pero ha trabajado & 60 & $60 \%$ \\
\hline Nunca ha trabajado & 6 & $6 \%$ \\
\hline Solo ha realizado prácticas & 11 & $11 \%$ \\
\hline 3. Conocimientos informáticos & & \\
\hline Maneja solo Office & 40 & $40 \%$ \\
\hline Domina Office y otro software turístico & 60 & $60 \%$ \\
\hline 4. Nivel de idiomas & & $82 \%$ \\
\hline Solo habla español & 0 & $0 \%$ \\
\hline Habla español e inglés & & \\
\hline Habla más de dos idiomas & & \\
\hline
\end{tabular}

Fuente: Elaboración propia. 
En la tabla 3 se observan las principales motivaciones, habilidades, descripción propia y sus principales intereses. Algunos sujetos son motivados por la familia, reconocen que tienen habilidades de socialización, de ahí que se describan a sí mismos como amistosos, y a la tercera parte de ellos le gustaría viajar.

Tabla 3. Principales motivaciones de los sujetos de estudio

\begin{tabular}{|c|c|c|}
\hline Variable y amplitud & Número & Porcentaje \\
\hline \multicolumn{3}{|l|}{ 5. Motivación principal } \\
\hline Familia & 40 & $40 \%$ \\
\hline Superación personal & 19 & $19 \%$ \\
\hline Tener un mejor empleo & 13 & $13 \%$ \\
\hline Tener una vida estable & 9 & $9 \%$ \\
\hline Otros & 19 & $19 \%$ \\
\hline \multicolumn{3}{|l|}{ 6. Habilidades } \\
\hline Socialización & 38 & $38 \%$ \\
\hline Aprendizaje & 25 & $25 \%$ \\
\hline Creatividad & 18 & $18 \%$ \\
\hline Trabajo en equipo & 5 & $5 \%$ \\
\hline Otras & 14 & $14 \%$ \\
\hline \multicolumn{3}{|l|}{ 7. Descripción de ellos mismos } \\
\hline Amistoso & 23 & $23 \%$ \\
\hline Inteligente & 16 & $16 \%$ \\
\hline Honesto & 11 & $11 \%$ \\
\hline Proactivo & 10 & $10 \%$ \\
\hline Responsable & 9 & $9 \%$ \\
\hline Otras & 31 & $31 \%$ \\
\hline \multicolumn{3}{|l|}{ 8. Intereses } \\
\hline Viajar & 33 & $33 \%$ \\
\hline Conocer gente & 24 & $24 \%$ \\
\hline Estudiar más & 14 & $14 \%$ \\
\hline Apoyar a otros & 5 & $5 \%$ \\
\hline Otros & 24 & $24 \%$ \\
\hline
\end{tabular}

Fuente: Elaboración propia.

La tabla 4 muestra las principales distracciones, cuidados personales, gustos e intereses que tienen en la vida. Se destaca el gusto por la lectura y el arte (cerca de la cuarta parte) y la buena alimentación, en más del 50\%. 
Tabla 4. Entretenimiento, cuidado y gustos de los sujetos de estudio

\begin{tabular}{|c|c|c|}
\hline Variable y amplitud & Número & Porcentaje \\
\hline \multicolumn{3}{|l|}{ 9. Principales distracciones } \\
\hline Lectura & 26 & $26 \%$ \\
\hline Música & 17 & $17 \%$ \\
\hline Series & 14 & $14 \%$ \\
\hline Videojuegos & 12 & $12 \%$ \\
\hline Otros & 31 & $31 \%$ \\
\hline \multicolumn{3}{|l|}{ 10. Cuidados personales } \\
\hline Buena alimentación & 52 & $52 \%$ \\
\hline Ejercicio/Deporte & 31 & $31 \%$ \\
\hline Higiene & 9 & $9 \%$ \\
\hline Otras & 8 & $8 \%$ \\
\hline \multicolumn{3}{|l|}{ 11. Gustos personales } \\
\hline Arte & 23 & $23 \%$ \\
\hline Comida & 19 & $19 \%$ \\
\hline Naturaleza & 15 & $15 \%$ \\
\hline Otros & 43 & $43 \%$ \\
\hline \multicolumn{3}{|l|}{ 12. Intereses en la vida } \\
\hline Viajar & 36 & $36 \%$ \\
\hline Buen empleo & 25 & $25 \%$ \\
\hline Aprender & 19 & $19 \%$ \\
\hline Otros & 20 & $20 \%$ \\
\hline
\end{tabular}

Fuente: Elaboración propia.

\section{Análisis descriptivo ponderado}

La encuesta permitió recolectar información para el procesamiento y análisis descriptivo, planteando una relación entre las variables de expectativas laborales, con la finalidad de identificar cuáles son las que más influyen al momento de tomar la decisión de ingresar a una empresa o no, así como seguir en ella o dejarla para buscar un nuevo espacio para laborar.

Después de obtener los estadísticos descriptivos sobre la dispersión (tabla 5), se pudo apreciar que tanto ubicación (V5), salario (V4), transporte (V8), así como bienestar (V14), son las que mayor variabilidad registraron (SD > 0.75), con respecto al resto. 
Tabla 5. Estadísticos de dispersión de las variables de expectativas laborales

\begin{tabular}{|c|c|c|c|c|c|}
\hline \multicolumn{2}{|c|}{ Variable } & $\begin{array}{l}\text { Media } \\
\text { (M) }\end{array}$ & $\begin{array}{l}\text { Err. Est. Media } \\
\text { (EEM) }\end{array}$ & $\begin{array}{l}\text { Desv. Estd. } \\
\text { (SD) }\end{array}$ & $\begin{array}{l}\text { Coef. Variación } \\
\text { (CV) }\end{array}$ \\
\hline Balance & (V1) & 4.72 & 0.05 & 0.51 & $10.89 \%$ \\
\hline Desarrollo & (V2) & 4.72 & 0.06 & 0.55 & $11.69 \%$ \\
\hline Liderazgo & (V3) & 4.66 & 0.06 & 0.61 & $13.02 \%$ \\
\hline Salario & (V4) & 4.51 & 0.08 & 0.77 & $17.12 \%$ \\
\hline Ubicación & (V5) & 4.30 & 0.08 & 0.82 & $19.13 \%$ \\
\hline Alimentos & (V6) & 4.68 & 0.06 & 0.65 & $13.88 \%$ \\
\hline Infraestructura & (V7) & 4.81 & 0.04 & 0.44 & $9.20 \%$ \\
\hline Transporte & (V8) & 4.50 & 0.08 & 0.76 & $16.86 \%$ \\
\hline Clima laboral & (V9) & 4.81 & 0.05 & 0.51 & $10.53 \%$ \\
\hline Procedimientos & (V10) & 4.59 & 0.07 & 0.70 & $15.20 \%$ \\
\hline Certificaciones & (V11) & 4.46 & 0.07 & 0.70 & $15.75 \%$ \\
\hline Sustentabilidad & (V12) & 4.77 & 0.05 & 0.49 & $10.26 \%$ \\
\hline Movilidad & (V13) & 4.57 & 0.07 & 0.67 & $14.67 \%$ \\
\hline Bienestar & (V14) & 4.39 & 0.08 & 0.76 & $17.40 \%$ \\
\hline Salud & (V15) & 4.78 & 0.05 & 0.52 & $10.96 \%$ \\
\hline
\end{tabular}

Nota: Casos válidos $=100$; casos con valor(es) perdido(s) $=0$.

Fuente: Elaboración propia.

En la figura 1 se visualizan las variables que los jóvenes consideran prioritarias:

1) Contar con infraestructura, herramientas y equipos aptos para desarrollar las funciones - $V 7$ - $(M=4.81 ; S D=0.44)$;

2) Tener un balance de vida personal y profesional -V1- $(M=4.72 ; S D=0.51)$;

3) Contar con un clima laboral positivo -V9- $(\mathrm{M}=4.81$; $\mathrm{SD}=0.51)$;

4) Implementar programas de sustentabilidad y de manejo adecuado de recursos $-V 12-(M=4.77 ; S D=0.49)$;

5) Ser parte de un plan de crecimiento, capacitación y adiestramiento -V2- (M $=4.72 ; \mathrm{SD}=0.55) ; \mathrm{y}$

6) Tener servicios de salud y bienestar integral para colaboradores -V14- ( $M=$ 4.39; DS = 0.79).

En el semáforo que se muestra abajo de la figura 1, se enlista la totalidad de las variables de expectativas laborales. De acuerdo con la intensidad del color, el verde fue el mejor ponderado (se sumaron los puntos 4 y 5 , que expresaban acuerdo con 
el ítem descrito), y el rojo el menor calificado. Destaca que 23 de los 100 encuestados dijeron no estar interesados en la localización de la empresa que seleccionarán para trabajar, pues evaluaron ese punto como neutral (3 puntos en escala de Likert).

Figura 1. Ponderación de variables de expectativas laborales

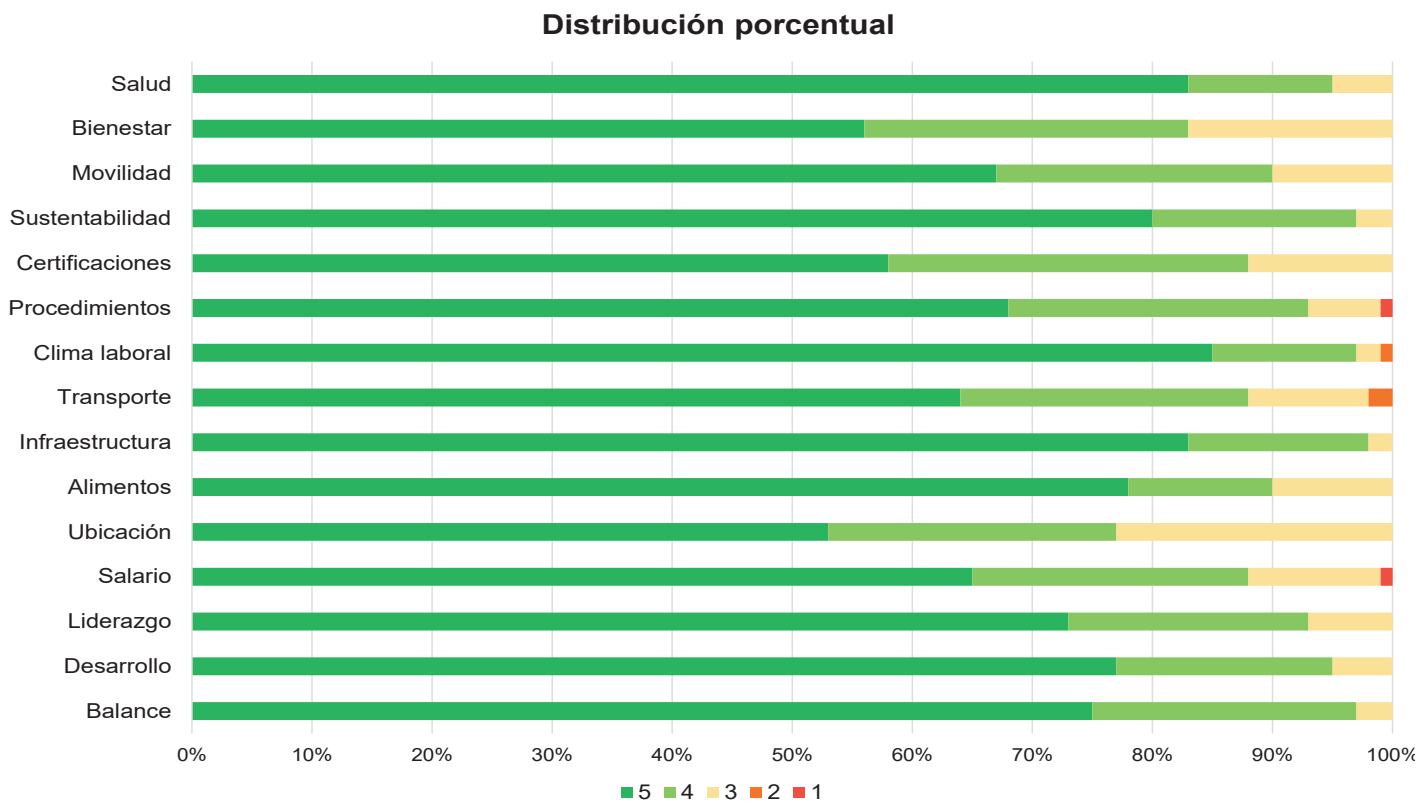

\begin{tabular}{l|c}
\multicolumn{1}{c|}{ Variable } & $\begin{array}{c}\text { \% positivo } \\
\text { (pesos de 4 y 5) }\end{array}$ \\
\hline Infraestructura & 98 \\
\hline Balance & 97 \\
\hline Clima laboral & 97 \\
\hline Sustentabilidad & 97 \\
\hline Desarrollo & 95 \\
\hline Salud & 95 \\
\hline Liderazgo & 93 \\
\hline Procedimientos & 93 \\
\hline Alimentos & 90 \\
\hline Movilidad & 90 \\
\hline Salario & 88 \\
\hline Transporte & 88 \\
\hline Certificaciones & 88 \\
\hline Bienestar & 83 \\
\hline Ubicación & 77
\end{tabular}

Fuente: Elaboración propia. 


\section{Análisis factorial exploratorio}

Junto con el análisis descriptivo, se asociaron las variables para la obtención del coeficiente de correlación ( $r$ ). La tabla 6 solo muestra aquellas en las que se registró un $r \geq|0.5|$ que fue significativo. Así, vemos que son 10 asociaciones lineales bivariadas las que aparecen como aceptables en el análisis factorial.

Tabla 6. Coeficiente de correlación

\begin{tabular}{|c|c|c|c|c|c|c|c|c|}
\hline Variable & Liderazgo & Alimentos & $\begin{array}{l}\text { Infra- } \\
\text { estructura }\end{array}$ & $\begin{array}{l}\text { Clima } \\
\text { laboral }\end{array}$ & $\begin{array}{l}\text { Proce- } \\
\text { dimientos }\end{array}$ & $\begin{array}{l}\text { Susten- } \\
\text { tabilidad }\end{array}$ & Bienestar & Salud \\
\hline Liderazgo & 1 & & & & & & & \\
\hline Alimentos & $0.34^{*}$ & 1 & & & & & & \\
\hline Infraestructura & $0.47^{*}$ & $0.63^{*}$ & 1 & & & & & \\
\hline Clima laboral & $0.38^{*}$ & $0.37^{*}$ & $0.38^{*}$ & 1 & & & & \\
\hline Procedimientos & $0.38^{*}$ & $0.55^{*}$ & $0.50^{*}$ & $0.43^{*}$ & 1 & & & \\
\hline Sustentabilidad & $0.31^{*}$ & $0.47^{*}$ & $0.45^{*}$ & $0.56^{*}$ & $0.52^{*}$ & 1 & & \\
\hline Bienestar & $0.35^{*}$ & 0.19 & $0.31^{*}$ & 0.19 & $0.32^{*}$ & $0.38^{*}$ & 1 & \\
\hline Salud & $0.53^{*}$ & $0.47^{*}$ & $0.65^{*}$ & $0.45^{*}$ & $0.52^{*}$ & $0.51^{*}$ & $0.52^{*}$ & 1 \\
\hline
\end{tabular}

Para este análisis se establecieron dos factores: F1 y F2. El primero, compuesto por variables de los tres tipos de necesidades (afiliación, logro y poder), y el segundo, integrado solamente por las que se enfocan en necesidades de afiliación. Después de la rotación ortogonal, los resultados se muestran en la tabla 7. 
Tabla 7. Matriz de factores del análisis de componentes Varimax

\begin{tabular}{|r|l|c|c|c|}
\hline \multicolumn{1}{|c|}{ Variable } & F1 & F2 & Comunalidades \\
\hline V3- & Liderazgo & 0.37 & 0.61 & 0.51 \\
\hline V6- & Alimentos & 0.82 & 0.08 & 0.67 \\
\hline V7- & Infraestructura & 0.70 & 0.37 & 0.62 \\
\hline V9- & Clima laboral & 0.73 & 0.27 & 0.60 \\
\hline V10- & Procedimientos & 0.69 & 0.16 & 0.50 \\
\hline V12- & Sustentabilidad & 0.69 & 0.31 & 0.56 \\
\hline V14- & Bienestar & 0.05 & 0.90 & 0.81 \\
\hline V15- & Salud & 0.54 & 0.66 & 0.74 \\
\hline & Suma de cuadrados & & & Total \\
\hline & Autovalor & 3.08 & 1.96 & 5.03 \\
\hline & \% de traza* & Fuente: Elaboración propia. & & 62.93 \\
\hline
\end{tabular}

Por tanto, el F1 se compondrá de las variables alimentos (V6), infraestructura (V7), clima laboral (V9), procedimientos (V10) y sustentabilidad (V12); y el F2, por liderazgo (V3), bienestar (V14) y salud (V15). Con ello, al F1 se le puede denominar bloque $A$, y al F2 bloque $B$.

Asimismo, el modelo multivariante factorial exploratorio presentó una varianza explicada de casi $63 \%$ (porcentaje de traza), y la carga de cada factor solo se diferenció por 14 puntos porcentuales, en discrepancia con lo que se había registrado antes de la rotación (39 puntos, donde el F1 tenía una carga de 51\%). El Alfa de Cronbach para el instrumento con las variables de F1 resultó en 0.82, y el F2 en 0.70, ambos aceptables.

Hacia la validación del modelo, se fraccionó la base de datos con la mitad de los casos $(n / 2)$ componiendo la muestra de división 1 (D1) del registro 1 al 50, y la muestra de división 2 (D2) del 51 al 100. Los resultados se despliegan en la tabla 8. Al observar ambas, se percibe que las cargas entre factores se mantuvieron casi en la misma proporción, así como su varianza explicada; no sucedió así con variables como liderazgo (V3), bienestar (V14) y salud (V15), cuyos valores en la D1 fueron de $0.34,0.04$ y 0.56 , respectivamente, y en la $D 2$, se aprecian igual a $0.52,0.56$ y 0.87 , esto es que marcan más carga hacia el F1 en la muestra D2, que en el F1 de la D1. 
Clima laboral (V9) y sustentabilidad (V12) son las únicas variables que se cargan al F2, de la D1 a la D2. Así, también las comunalidades varían en dos de las variables (V3 y V14). Liderazgo, por su parte, descendió de 0.56 a 0.31 , y bienestar, de 0.80 a 0.35 . Tales cambios son grandes. Las tres puntuaciones no son convenientes para obtener un resultado concluyente.

Tabla 8. Validación del análisis de componentes por estimación de división de los casos Varimax

\begin{tabular}{|c|c|c|c|c|}
\hline & Variable & F1 & F2 & Comunalidades \\
\hline Muest & ra de división 1 ( & & & \\
\hline V3- & Liderazgo & 0.34 & 0.67 & 0.56 \\
\hline V6- & Alimentos & 0.84 & 0.1 & 0.72 \\
\hline V7- & Infraestructura & 0.65 & 0.52 & 0.70 \\
\hline V9- & Clima laboral & 0.69 & 0.43 & 0.65 \\
\hline V10- & Procedimientos & 0.82 & 0.15 & 0.69 \\
\hline V12- & Sustentabilidad & 0.64 & 0.38 & 0.56 \\
\hline V14- & Bienestar & 0.04 & 0.89 & 0.80 \\
\hline V15- & Salud & 0.56 & 0.68 & 0.77 \\
\hline Muest & ra de división 2 ( & & & \\
\hline V3- & Liderazgo & 0.52 & 0.21 & 0.31 \\
\hline V6- & Alimentos & 0.62 & 0.46 & 0.6 \\
\hline V7- & Infraestructura & 0.71 & 0.27 & 0.57 \\
\hline V9- & Clima laboral & -0.14 & 0.89 & 0.8 \\
\hline V10- & Procedimientos & 0.75 & 0.23 & 0.61 \\
\hline V12- & Sustentabilidad & 0.43 & 0.69 & 0.66 \\
\hline V14- & Bienestar & 0.56 & -0.19 & 0.35 \\
\hline V15- & Salud & 0.87 & -0.05 & 0.76 \\
\hline
\end{tabular}

Nota: Los cuadros resaltados se han dejado como referencia de las variables del modelo original, mostrado en la tabla 7. Fuente: Elaboración propia.

\section{Discusión}

En congruencia con el objetivo de esta investigación, se establecieron dos hipótesis cuyo cuestionamiento tuvo el siguiente resultado:

La hipótesis 1 es real. Relacionada con la premisa de que el balance entre las actividades laborales y las personales impacta de manera directa en el índice de rotación de personal, se observa que el equilibrio entre estas dos dimensiones es lo que más importa a los futuros trabajadores turísticos. 
Esta hipótesis no se refuta pues la variable balance (V1) fue la segunda más ponderada con $97 \%$ de peso, es decir, en el análisis descriptivo en el cual se utilizó la escala de Likert, los mayores valores (entre 5 y 4) fueron otorgados a la pregunta que representaba esta variable. Además, la $V 1$ resultó consistente en las respuestas de los sujetos bajo estudio, con un CV cercano al $10 \%$.

La hipótesis 2 fue rechazada. Afirmaba que la necesidad de afiliación laboral es un factor de retención para personas con perfil centennial; no obstante, con el análisis factorial exploratorio, las variables liderazgo (V3) y bienestar (V14) no permitieron la reducción de los factores considerados (F1 y F2), pues ambas presentan un cambio evidente al momento de realizar la validación del modelo. Es decir, para evitar el rechazo de la hipótesis, lo ideal sería que V3 y V14 no mostraran diferencias en sus comunalidades en el análisis de componentes, por estimación de división de los casos (D1 y D2).

En particular, en el caso de la hipótesis 2 se esperaba que se cumpliera a cabalidad la afirmación de que las necesidades de afiliación laboral, según la teoría de McClelland (1961), serían en conjunto los motivadores principales de retención. En el esfuerzo de buscar una reducción de variables a través del análisis factorial exploratorio, y de acuerdo con sus comportamientos específicos y de interdependencia, se pensaba que las variables de liderazgo (V3), ubicación (V5), alimentos (V6), infraestructura (V7), bienestar (V14) y/o salud (V15), todas o algunas de ellas conformarían un factor (F1 o F2), lo cual no sucedió.

Ante los resultados exploratorios derivados de la evidencia empírica, se contempla necesario conseguir una muestra adicional para validar dicha hipótesis; sin embargo, en el año en curso no será viable la obtención de dicha muestra, pues se requiere esperar a que la siguiente cohorte de estudiantes próximos a egresar, en el mismo programa educativo, esté cursando el periodo primavera 2021, con el fin de replicar las condiciones de la población referida.

Destaca aquí una de las variables que no se esperaba fuera atractiva para el perfil centennial: la de infraestructura (V7), siendo la más ponderada de las 15, con 98 puntos, al evidenciar que sí es de interés de los jóvenes contar con materiales, herramientas, equipos, espacios y suministros aptos para desarrollar sus funciones. Por el contrario, la variable salario (V4) (con 88), que pudiera pensarse sería la más atractiva, obtuvo 10 puntos menos que la más alta (V7). 
En resumen, el salario (V4) no es una prioridad entre los encuestados, por lo que no se recomienda que se le relacione con la rotación de personal en una próxima investigación. No obstante, sí se sugiere abrir una línea que valore elementos tales como materiales, herramientas, equipos, espacios y suministros para desarrollar tareas, a fin de determinar su influencia en la retención de los recursos humanos.

En un acto de reflexión práctica, el tema de expectativas laborales se ha abordado desde diversas posturas; sin embargo, sigue sin encontrarse la clave para la disminución de la rotación de personal, al ser una cuestión multifactorial (Boschma y Groen, 2008; Ferri-Reed, 2014). Conscientes de ello, el análisis aquí desarrollado es una exploración más, que pretende contribuir en esta área de oportunidad.

Los indicadores de rotación de personal, evaluaciones de desempeño y el alcance de los objetivos y metas establecidas, son aspectos que los gerentes generales, y en sí todo el comité ejecutivo de las empresas turísticas, deben fortalecer (Smith, 2010).

Proporcionar herramientas, equipos y espacios aptos para el desarrollo de tareas, permitir tener un equilibrio entre la vida personal y profesional, promover un clima laboral positivo, e implementar programas de sustentabilidad y manejo adecuado de recursos, con fines de potenciar a sus colaboradores, será la diferencia entre ser una empresa en peligro de cierre, o ser competitiva y atractiva para clientes internos y externos.

\section{Conclusiones}

Este trabajo se enfocó en identificar las expectativas laborales que tiene la Generación Z, según la teoría de McClelland (1961), con el propósito de entender mejor el fenómeno y las implicaciones de contratación en empresas turísticas, así como plantear esquemas de retención mayor, a través de estrategias, planes y programas de gestión de capital humano, para ser más atractivas a los ojos de las nuevas generaciones, como lo sugieren Thompson y Gregory (2012).

El análisis realizado permitió reconocer los intereses que priorizan los próximos egresados de turismo de la Universidad del Caribe (trabajadores potenciales en Cancún), con perfil de centennials, que son las necesidades de logro (balance, desarrollo, clima laboral y sustentabilidad) y de afiliación (infraestructura, bienestar y salud), antes de las de poder (procedimientos, salario y movilidad). 
Es indudable que la investigación puede tener un alcance más amplio, contemplando poblaciones universitarias que estudian turismo en otras Instituciones Educativas de nivel Superior (IES) en Cancún, pues todas atienden la oferta laboral de dicho destino turístico.

Con lo anterior, se considera pertinente suscitar una revisión de la oferta y demanda de relaciones contractuales, con un enfoque en las características demográficas de los centennials, que se adecúe al panorama turístico en curso. Esto permitirá, de acuerdo con Paradinas (2020), diseñar acercamientos en el ámbito que aborden la gestión del conflicto, para identificarlo, minimizarlo y utilizarlo como herramienta de retención.

El plantear propuestas de empleo acordes a las tendencias del mercado, como lo sugiere Golik (2013), sin duda facilitará la incorporación efectiva de esta generación y con ello contar con una herramienta más para contribuir a la reducción de la rotación de personal, al ampliar la integración e impulsar una adecuada inclusión en las empresas turísticas.

Por último, los resultados obtenidos alimentan la reflexión de que los centennials manifiestan sin limitaciones sus expectativas laborales, lo que invita a repensar la oferta ideal en las empresas turísticas. Los estudios de Espinoza y Toscano (2020), por ejemplo, confirman que el salario emocional es perfectamente compatible con estos trabajadores y que, si es gestionado de manera adecuada, el tan anhelado equilibrio de vida personal y profesional puede ser posible en un sector tan controversial.

\section{Referencias}

Adams, J. S. (1963). Towards an understanding of inequity. Journal of Abnormal Psychology, 67(5), 422-436. https://doi.org/10.1037/h0040968

Adams, J. S. (1965). Inequity in social exchange. Advances in Experimental Social Psychology, 2, 267-299. https://doi.org/10.1016/S0065-2601(08)60108-2

Alderfer, C. P. (1969). An empirical test of a new theory of human needs. Organizational Behavior and Human Performance, 4(2), 142-175. https://doi. org/10.1016/0030-5073(69)90004-X 
Al-Emadi, A., Schwabenland, C. y Wei, Q. (2015). The vital role of employee retention in human resource management: a literature review. The IUP Journal of Organizational Behavior, 14(3), 7-32. https://bit.ly/3j5QPuC

Ato, M., López, J. y Benavente, A. (2013). Un sistema de clasificación de los diseños de investigación en psicología. Anales de Psicología, 29(3), 1038-1059. https:// bit.ly/3nXzelT

Barbero, M. I. (2013). Introducción básica al análisis factorial. Universidad Nacional de Educación a Distancia.

Bennett, J., Pitt, M. y Price, S. (2012). Understanding the impact of generational issues in the workplace. Facilities, 30(7-8), 278-288. https://doi. org/10.1108/02632771211220086

Bialik, K. y Fry, R. (2019, 14 de febrero). Millennial life: how young adulthood today compares with prior generations. Pew Research Center. https://pewrsr. $\mathrm{ch} / 2 \mathrm{~T} 3 \mathrm{WNSa}$

Bizzi, L. (2017). Should HR managers allow employees to use social media at work? Behavioral and motivational outcomes of employee blogging. The International Journal of Human Resource Management, 31(10), 1285-1312. https:// doi.org/10.1080/09585192.2017.1402359

Boschma, J. y Groen, I. (2008). Generación Einstein: más listos, más rápidos y más sociales. Comunicar con los jóvenes del siglo XXI. Gestión 2000.

Bosch, O., Revilla, M. y Paura, E. (2019). Do millennials differ in terms of survey participation? International Journal of Market Research, 61(4). https://doi. org/10.1177/1470785318815567

Bussin, M. y Brigman, N. (2019). Evaluation of remuneration preferences of knowledge workers. SA Journal of Human Resource Management, 10. https://doi. org/10.4102/sajhrm.v17i0.1075

Carter, T. y Walker, W. (2018). Retaining, cultivating, and investing strategies for leading millennial managers. The Journal of Government Financial Management, 67(2), 20-25. https://bit.ly/2HdlTtl

Cloninger, S. (2002). Teorías de la personalidad. Pearson - Prentice Hall.

Costanza, D. P., Badger, J. M., Fraser, R. L., Severt, J. y Gade, P. (2012). Generational differences in work-related attitudes: a meta-analysis. Journal of Business and Psychology, 27, 375-394. https://doi.org/10.1007/s10869-012-9259-4 
Ertas, N. (2015). Turnover intentions and work motivations of millennial employees in federal service. Public Personnel Management, 44(3), 401-423. https://doi. org/10.1177/0091026015588193

Espinoza, A. y Toscano, J. A. (2020). Salario emocional: una solución alternativa para la mejora del rendimiento laboral. Nova Rua, 12(20), 72-89. http://dx.doi. org/10.20983/novarua.2020.20.5

Espinoza, C. y Ukleja, M. (2016). Managing the millennials: discover the core competencies for managing today's workforce. Wiley.

Ferri-Reed, J. (2014). Are millennial employees changing how managers manage? The Journal for Quality \& Participation, 37(2), 15-35. https://bit.ly/2T8qOjr

Fischer, L. y Espejo, J. (2018). Are young university millennials compulsive in their purchase? Horizonte Sanitario, 17(3), 189-196. https://doi.org/10.19136/ hs.a17n3.2244

George, J. y Wallio, S. (2017). Organizational justice and millennial turnover in public accounting. Employee Relations, 39(1), 112-126. https://doi.org/10.1108/ER11-2015-0208

Gibson, J., Greenwood, R. y Murphy, E. (2009). Generational differences in the workplace: personal values, behaviors, and popular beliefs. Journal of Diversity Management, 4(3), 1-7. https://doi.org/10.19030/jdm.v4i3.4959

Golik, M. (2013). Las expectativas de equilibrio entre vida laboral y vida privada y las elecciones laborales de la nueva generación. Cuadernos de Administración, 26(46), 107-133. https://bit.ly/3ka9CGu

González, R. (2011). La incorporación de la Generación Y al mercado laboral. El caso de una entidad financiera de la ciudad de Resistencia. Palermo Business Review, 5(1), 67-93. https://bit.ly/2IDBW6a

Guillot-Soulez, C. y Soulez, S. (2014). On the heterogeneity of Generation Y job preferences. Employee Relations, 36(4), 319-332. https://doi.org/10.1108/ER-072013-0073

Hair, J., Anderson, R., Tatham, R. y Black, W. (1999). Análisis multivariante. Prentice Hall Iberia.

Haserot, P. (2009). The keys to maintaining professionalism and harmony across the generations at work. The Professional Lawyer, 19(3), 3-5, 17. 
Herbison, G. y Boseman, G. (2009). Here they come - Generation Y. Are you ready? Journal of Financial Service Professional, 63(3), 33-34. https://bit.ly/2Hd0AKd

Hershatter, A. y Epstein, M. (2010). Millennials and the world of work: an organization and management perspective. Journal of Business \& Psychology, 25, 211223. https://doi.org/10.1007/s10869-010-9160-y

Herzberg, F. y Mausiner, B. S. (1959). The motivation to work. Wiley.

Holland, P., Cooper, B. y Hecker, R. (2016). Use of social media at work: a new form of employee voice? The International Journal of Human Resource Management, 27(21), 2621-2634. https://doi.org/10.1080/09585192.2016.1227867

Jonsen, K., Weg, S. y Martin, R. (2012). Cómo gestionar a los nativos digitales. Capital Humano, 266, 60-65. https://bit.ly/3IVDUNq

Kahn, W. (2017). Psychological conditions of personal engagement and disengagementat work.Academy ofManagement,33(4). https://doi.org/10.5465/256287

Karriker, J. y Hartman, N. (2018). Social media and dynamic capabilities: mining millennial resources. Journal of Organizational Psychology, 18(4), 43-56. https:// doi.org/10.33423/jop.v18i4.84

Kelly Mercadotenia. (2017, 15 de mayo). Índices de rotación a nivel nacional. https:// bit.ly/3m7spTt

Kowske, B., Rasch, R. y Wiley, J. (2010). Millennials' (lack of) attitude problem: an empirical examination of generational effects on work attitudes. Journal of Business and Psychology, 25(2), 265-279. https://doi.org/10.1007/s10869-0109171-8

Kultalahti, S. y Viitala, R. (2015). Generation Y - Challenging clients for HRM. Journal of Managerial Psychology, 30(1), 101-114. https://doi.org/10.1108/JMP-082014-0230

Kuron, L., Lyons, S., Schweitzer, L. y Ng, E. (2015). Millennials' work values: differences across the school to work transition. Personnel Review, 44(6), 991-1009. https://doi.org/10.1108/PR-01-2014-0024

Locke, E. A., Latham, G., Smith, K. y Wood, R. (1990). A theory of goal setting and task performance. Prentice Hall.

Madero, S. y De la Garza, J. (2017, junio). Validación del modelo de las prácticas de atracción y retención laboral desde la perspectiva del trabajador joven. Gestión de la innovación para el desarrollo sostenible de los negocios 
[ponencia]. 3er. Congreso Internacional de Investigación en Escuelas y Facultades de Negocios, Nuevo León, México.

Madero, S., Díaz, P. y Núñez, F. (2016, mayo). Análisis exploratorio de las prácticas de atracción y retención en ambientes de trabajo desde la perspectiva de la Generación Y. Gestión social: organizaciones humanas para una sociedad incluyente [ponencia]. XX Congreso Anual de la Academia de Ciencias Administrativas AC (Acacia), Yucatán, México.

Magallón, R. (2016). El ADN de la Generación Z. Entre la economía colaborativa y la economía disruptiva. Revista de Estudios de Juventud, 114, 29-44. https://bit. ly/2lyJRS1

Maslow, A. (1943). A theory of human motivation. Psychological Review, 50(4), 370396. https://doi.org/10.1037/h0054346

McClelland, D. C. (1961). The achieving society. Van Nostrand.

McGregor, D. (1985). The human side of enterprise. McGraw-Hill Education.

Meister, J. (2012, 5 de octubre). Tree reasons you need to adopt a millennial mindset regardless of your age. Forbes. https://bit.ly/2H6Y87T

Meza, A. (2019, 20 de marzo). Rotación de personal: cinco tips para reducirla. Forbes. https://bit.ly/2T3D3he

Moreno, L., López, V. y Marín, M. (2015). Comportamiento de la tasa de rotación laboral en la industria maquiladora en Mexicali, Baja California, 2009 - 2013. Revista Global de Negocios, 3(4), 11-26. https://bit.ly/37gcBt1

Murillo, E. (2017). Attitudes toward mobile search ads: a study among mexican millennials. Journal of Research in Interactive Marketing, 11(1), 91-108. https:// doi.org/10.1108/JRIM-06-2016-0061

Ng, E., Schweitzer, L. y Lyons, S. (2010). New generation, great expectations: a field study of the Millennial Generation. Journal of Business and Psychology, 25, 281-292. https://doi.org/10.1007/s10869-010-9159-4

Paradinas, M. C. (2020). La gestión del conflicto en el ámbito laboral de las organizaciones turísticas: una herramienta de marketing interno. Holos, 1, 1-12. https://doi.org/10.15628/holos.2020.8260

Parry, E. y Urwin, P. (2017). The evidence-base for generational differences: where do we go from here? Work, Aging and Retirement, 3(2), 140-148. https://doi. org/10.1093/workar/waw037 
Rani, N. y Samuel, A. (2016). A study on generational differences in work values and person-organization fit and its effect on turnover intention of generation Y in India. Management Research Review, 39(12), 1695-1719. https://doi. org/10.1108/MRR-10-2015-0249

Rani, S. y Mukherjee, S. (2017). Development of a causal framework linking work values, perceived organisational support, and job attitudes. Journal of Strategic Human Resource Management, 6(3), 6-16. https://bit.ly/31e7uWA

Robbins, S. (1999). Comportamiento organizacional. Pearson - Prentice Hall.

Schultz, D. (1992). Psicología industrial. McGraw-Hill.

Smith, T. (2010). Work-life balance perspectives of marketing professionals in Generation Y. Services Marketing Quarterly, 31(4), 434-447. https://doi.org $/ 10.1080 / 15332969.2010 .510724$

Solnet, D., Kralj, A. y Kandampully, J. (2012). Generation Y employees: an examination of work attitude differences. Journal of Applied Management and Entrepreneurship, 17(3), 36-54. https://bit.ly/301Muwb

Thompson, C. y Gregory, J. B. (2012). Managing millennials: a framework for improving attraction, motivation, and retention. The Psychologist-Manager Journal, 15(4), 237-246. https://doi.org/10.1080/10887156.2012.730444

Torrado, S. (2015, 31 de enero). Empresas para los jóvenes. Latin Trade Magazine. https://bit.ly/3jONH2Y

Twenge, J. (2010). A review of the empirical evidence on generational differences in work attitudes. Journal of Business and Psychology, 25, 201-210. http://dx.doi. org/10.1007/s10869-010-9165-6

Tyler, K. (2013). Organizational and employee development: new kids on the block. HR Magazine, 59(10), 34-40.

U.S. Department of Education. (2005). What is scientifically based research? A guide for teachers. https://bit.ly/3IZI8F7

Ventura-León, J. L. y Caycho-Rodríguez, T. (2017). El coeficiente Omega: un método alternativo para la estimación de la confiabilidad. Revista Latinoamericana de Ciencias Sociales, Niñez y Juventud, 15(1), 625-627. https://bit.ly/2HgE2s4

Vroom, V. (1994). Work and motivation. Wiley.

Wilton, P. (2008). Unlocking the talent of Generation Y. Engineering \& Technology, 3(14), 80-83. http://dx.doi.org/10.1049/et:20081421 


\title{
TURISMO RURAL: DESAFÍOS DE LAS COMUNIDADES RURALES EN EL CONTEXTO DEL COVID-19
}

\author{
Jesús ANTONIO Madera PACHeCo \\ jmadera@uan.edu.mx \\ Universidad Autónoma de Nayarit
}

En este texto se revisa el concepto de turismo rural, partiendo de los supuestos y equívocos que en torno a él se manejan. Se expresa cómo ha sido vendida la idea de un espacio idílico, casi una panacea en tiempos del COVID-19. Asimismo, se revisa la postura de los actores locales, ante los retos por venir en la búsqueda por romper los paradigmas.

Palabras clave: turismo rural, COVID-19, territorios, retos, ruralidad.

\section{RURAL TOURISM: CHALLENGES OF RURAL COMMUNITIES IN THE CONTEXT OF COVID-19}

In this text, the concept of rural tourism is reviewed, starting from the assumptions and misunderstandings that are handled around it. It expresses how the idea of an idyllic space has been sold, almost a panacea in times of COVID-19. Likewise, the position of local actors is reviewed, given the challenges to come in the search to break paradigms.

Keywords: rural tourism, COVID-19, territories, challenges, rurality. 
Entre alternatividades nos veamos...

Cómo entender las ruralidades hoy?, ¿cómo le están haciendo frente las comunidades rurales a los turismos alternativos, entre ellos, el turismo rural?, ¿alternativos para quién/es y desde dónde?, ¿cómo entender las ruralidades y el turismo rural en el contexto del COVID-19?

En el entendido de que los espacios rurales no son homogéneos, y las problemáticas que les aquejan son necesariamente diferenciadas y en intensidades distintas, Zamudio et al. (2008) proponen diversas definiciones, identificando incluso gradientes al respecto.

En gran medida, la noción que se tiene de lo rural está basada en una percepción primaria, a partir de las imágenes que proyectan las películas o las novelas, presentado como un ente estático y homogéneo, "atrasado", contrario a las urbes, desde las cuales se planifica y decide lo que "necesitan" esos territorios.

Sin embargo, las realidades de/desde lo rural se muestran complejas, heterogéneas, diversas, dinámicas, persistentes y propositivas; con intensidades y niveles distintos y únicos para cada caso. Rompen con el antiguo estigma de que se reducen exclusivamente a lo agrícola. Nada más alejado de la realidad.

A partir del cansancio que la ciudad y sus ajetreados ritmos provocan, lo rural se concibe también como un remanso verde, al que se puede volver para descansar y recuperar energías. Ante las necesidades de dichas ciudades (alimenticias, comerciales, de ocio y recreación, entre otras), se ha visto al territorio fuera de sus muros como el lugar que debe subsanarlas o abastecerlas; no obstante, tales necesidades son igualmente las que promueven, de manera directa o indirecta, megaproyectos que dan cumplimiento a las demandas gestadas desde lo urbano. Históricamente, se le ha caracterizado como el patio trasero de la metrópoli.

El turismo rural, entre otras variantes "alternativas", emerge o se plantea como la panacea para muchas comunidades, especialmente aquellas que cuentan con atractivos turísticos, una especie de "modelo ideal". Sin embargo, en la realidad no existen modelos perfectos $y$, más bien, lo que se encuentra son localidades y territorialidades con características heterogéneas, que pueden acercarse a esa imagen de ruralidad idílica. 
En el contexto anterior surge la pregunta: ¿panacea para quiénes? o ¿desde dónde? De hecho, en muy pocos casos lo es para quienes desde esos territorios viven, piensan, reconstruyen y sienten sus proyectos de vida en/desde lo rural. De tal forma, en el caso mexicano, este tipo de turismo ha sido una medida paliativa arbitrada/ implementada de manera vertical desde el Estado, buscando aminorar el éxodo rural o retener a las juventudes de esas zonas; además, con una idea de "empresarializar" a las comunidades receptoras (Garduño et al., 2009), para responder a los requerimientos de los visitantes. La mirada reciente, que atiende a una coyuntura específica generada por el COVID-19, no dista mucho de la anterior.

Así, desde instancias gubernamentales, principalmente, se detectan poblaciones indígenas y/o campesinas con atractivos naturales y culturales donde promueven la creación de microempresas que puedan recibir al turismo para explotar su potencial. Desde dichas instancias se crean o adecúan reglas de operación, se diseña formatería y se "capacita" para el llenado de tales documentos, también se generan figuras con reconocimiento ante el sistema tributario.

Se niega, una vez más, que los actores que dan vida a esos territorios y comunidades puedan decidir y ejecutar por sí solos sus proyectos de vida en lo rural. Los apoyos son escasos, pero se pretende que su mentalidad sea la de emprendedores de alto nivel, cualquier cosa que se entienda por ello.

En términos de Huizer (1998), para los actores locales ese tipo de propuestas o proyectos, más que un problema técnico, desde fuera implican un asunto político que debe ser construido al interior, a partir del encuentro de intereses colectivos comunes, buscando evitar que los beneficiados sean "principalmente los poderosos (por ejemplo, los terratenientes y la élite local) [...] frecuentemente en detrimento de la mayoría pobre" (Huizer, 1998, p. 53).

\section{Lo rural permanentemente disputado}

Lo rural vive y se (re)construye en una permanente disputa. Desde el exterior está en constante pugna por la urbanización y la metropolización, a la par de actividades extractivas y megaproyectos (minería y geotermia, solo por enunciar algunos); en el interior, es reñido por la agricultura intensiva y agroindustrial, $y$, más recientemente, por la transgénica, que forman parte de esas territorialidades complejas, múltiples, en las que los actores locales construyen y dan sentido a sus vidas. 
El turismo, en específico el denominado rural, también entra en conflicto, por muy alternativo que sea, especialmente cuando es una actividad impuesta. Se quiera o no, "modificando pautas de comportamiento e incitando a la (re)construcción, estéticamente aceptada, de paisajes, patrimonios y culturas" (Santana, 2002, p. 1), esta industria puede convertirse en artificializadora de la vida fuera de las ciudades (Cànoves y Villarino, 2000) y extractivista.

El turismo [rural] es una actividad que se verá beneficiada de los excedentes sociales producidos por el campesino, una vez que este ha satisfecho sus necesidades vitales con el mínimo posible, acumula fondos ceremoniales, que son parte sustantiva del atractivo turístico y que generalmente no son pagados por el turista, como por ejemplo el viajero que destina su tiempo a "pueblear" y disfruta de la fiesta de un pueblo pero no paga ninguna remuneración por dicho goce estético, sino, por el contrario, aprovecha el excedente que el campesino ha generado para tal fin. (Thomé, 2008, p. 247).

Cualquier área, expresión cultural o entorno natural puede hoy promocionarse como destino y producto turístico, existiendo ya una demanda (pre)configurada para el mismo [... o bien,] los promotores rara vez toman en consideración otros elementos que intervienen y representan, en mayor o menor medida, costos que deben asumir los residentes. (Santana, 2002, pp. 1-2).

La urbe o los megaproyectos, la agricultura industrial o transgénica, e incluso el turismo rural, son actividades, en lo general, no construidas desde dentro. Al final, todas disputan los territorios campesinos e indígenas.

El turismo rural se convierte en una actividad pensada desde las ciudades, en la que los habitantes urbanos se proponen disfrutar de los remansos de un mundo pasado, que las sociedades industriales avanzadas no pueden satisfacer con sus modelos turísticos masivos. (Thomé, 2008, p. 239).

Disputas constantes, una tras otra, varias a la vez; pareciera que casi siempre van de la mano -con aval, por acción u omisión- del Estado, en un juego de relaciones de poder donde lo rural con mayor frecuencia se ve disminuido; pero, al mismo tiempo, donde estas zonas y sus actores cada vez se reinventan y crean nuevas alianzas, que les permiten innovar la diversidad de estrategias socio-organizativas y productivas para continuar en la pelea. 
En un juego de aparentes antagonismos... se fortalecen cultivos "tradicionales", en producción orgánica o convencional; se dejan algunos, al menos temporalmente, y se añaden otros nuevos; se juega con lo colectivo-individual y se refuerzan o flexibilizan las identidades que revelan a un actor colectivo en permanente reconstrucción. En la aparente disputa de proyectos socioculturales y productivos, lo que se resalta es la plasticidad social de la agricultura campesina y familiar que, al reinventarse, nos muestra actores inmersos en una multiplicidad de estrategias de combinación y juego con los recursos que tienen a la mano (aun cuando parezcan antagónicos), que han aprendido a sortear los embates de la política agrícola y a negociar (inclusive desde las diferencias) al interior de la comunidad, pero también con agentes externos que incluyen desde el ámbito académico, gubernamental, organizaciones civiles, etcétera. (Madera y Vargas, 2015, p. 102).

En esas disputas no solo se transforman el territorio y las territorialidades, sino que también se (re)construyen nuevos procesos identitarios, y se incide en la pérdida (o modificación, en el menor de los males) de producción de alimentos. Es en lo rural donde aún siguen cultivándose los insumos para las urbes y a donde se va a recargar energías que la ciudad drena. Desde sus luchas y persistencias, paradójicamente, de manera continua siguen surgiendo opciones para mejorar las condiciones de vida en las metrópolis, a partir de la alimentación saludable y culturalmente apropiada, que permiten hacer frente a situaciones como la actual pandemia generada por el virus COVID-19.

\section{Turismo rural tras bambalinas: ¿y los actores locales?}

Como concepto, el turismo rural en México existe desde hace alrededor de cinco décadas, aunque en los últimos años hay una cierta moda de estudios y publicaciones en torno al tema, con predominio de aquellos con una visión restringida a la "demanda" potencial de lo que el turista "necesita" (Korstanje, 2020), incentivando una mirada empresarial y, por si fuera poco, que asocian dicha actividad con el ámbito de lo doméstico, donde "las mujeres ejercen su papel de acogida a los turistas en las casas rurales" (Cànoves y Villarino, 2000, p. 64), lo cual reproduce estereotipos de género: 
Las mujeres entienden que el trabajo del turismo rural es una extensión de las tareas domésticas y una extensión hacia los huéspedes del cuidado de los miembros de la familia [...]. Es habitual que sea la mujer la que se encargue de atender a los turistas, de servir las comidas y de tener a punto las habitaciones, mientras que suele ser el hombre el que informa de las actividades que se pueden realizar en la zona y los lugares para visitar. (Cànoves y Villarino, 2000, pp. 64-65).

También se maneja al turismo rural con una acepción técnico-operativa, visto como estrategia de intervención (Gómez-Carreto et al., 2018), generalmente pensada verticalmente, a veces bajo el disfraz de proceso participativo y desde el exterior.

Existen contradicciones durante la instrumentación de proyectos participativos que tienen como estrategia conformar cooperativas de base comunitaria en el medio rural. En este sentido, los proyectos de turismo rural en Chiapas [aunque puede aplicar para cualquier otro sitio, por ejemplo, para el caso de Nayarit se puede ver Aranda (2020)], son bienintencionados en el discurso, aunque denotan vacíos en el método y que se perciben particularmente en la fase instrumental. El interés de los habitantes locales por agruparse en cooperativas es ficticio en lo general, pues atiende a una lógica de no contraponerse a sus autoridades locales. (Gómez-Carreto et al., 2018, p. 73).

Abona aún más a dicho auge e interés la designación del 2020 como el Año del turismo y el desarrollo rural, por parte de la Organización Mundial del Turismo (OMT), así como los efectos de la pandemia del COVID-19 en el sector. Esa será la disputa sobre la que lo rural y sus actores habrán de dar la batalla en lo sucesivo, ¿lo quieren?, ¿están preparados?

En el caso de México, no obstante la retórica gubernamental que busca "dejar en el pasado el modelo de crecimiento depredador, inequitativo y sin justicia social" (Secretaría de Turismo, Sectur, 2020, p. 33), llama la atención que en el Programa sectorial 2020-2024 (Prosectur) no se menciona a los denominados turismos alternativos, ni alternativas al turismo. El "turismo rural" solo se menciona una vez y para la gestión: "4.2.2. Contribuir a la realización y permanencia de iniciativas de turismo rural, ante diferentes instancias público, privadas, nacionales e internacionales" (Sectur, 2020, p. 46). 
A cuenta de los efectos de la pandemia del COVID-19 sobre el sector turístico mundial, nunca el turismo y el desarrollo rural han revestido tanta importancia como ahora. El turismo en zonas rurales ofrece importantes oportunidades de recuperación. (OMT, 2020).

En la actualidad, el turismo rural brinda una salida o escape para miles de turistas citadinos, y una oportunidad para revitalizar -o recuperar- las economías domésticas de la crisis que deja el COVID-19. En momentos de incertidumbre, como los que ha suscitado la pandemia, el turismo rural se presenta como un destino obligado para miles de personas. (Korstanje, 2020, p. 190).

Tal como lo refiere Korstanje (2020), ante la incertidumbre y la crisis, los turistas buscarán destinos menos peligrosos: las zonas rurales. Pero ¿qué sucede con las poblaciones receptoras?, ¿o es que no deberán preocuparse de la peligrosidad que implica acoger a los visitantes?, como los contagiados de COVID-19, vinculados a actividades ilícitas u otras. De nuevo, se piensa en el turista o excursionista, pero no en los residentes.

Promover el turismo rural como la panacea para hacer frente a los retos y desafíos pos-COVID-19, parece evidenciar que no se ha entendido el mensaje de la naturaleza respecto a la situación que provocó la actual pandemia. Es decir, impulsar las actividades turísticas para aprovechar los recursos de lo rural, pensando solo en los turistas y en la dinamización económica para la reproducción del modelo vigente, es aceptar la continua depredación de la naturaleza.

Finalmente, aunque la atención hacia ella sea menor, existe una dimensión más holística y crítica del turismo rural (Thomé, 2008; Santana, 2002; Madera y Vargas, 2015; entre otros), "en coexistencia con múltiples realidades que suceden en un mismo espacio" (Thomé, 2008, p. 242), que es precisamente por la que abogaríamos que se hiciera mayor eco en lo sucesivo.

Es importante plantear la concepción de turismo rural no solo desde la perspectiva puramente turística [...] Es necesario atender las características específicas de América Latina y, a partir de ello, articular nuevos elementos enriquecedores de la definición como son: proceso turístico, aprovechamiento de recursos, motivaciones de viaje, necesidades del desarrollo local en comunidades rurales y la definición de los impactos de la actividad turística. (Thomé, 2008, p. 240). 
Se trata de una nueva articulación, que parte del reconocimiento de los actores locales y la comprensión de lo rural en su complejidad; que permita reconocer al turismo, como señala Thomé (2008), no solo como ente central sino impulsor del desarrollo, o incluso un complemento, que posibilite a su vez:

Reconocer y revalorar sus saberes y conocimientos, sus formas de pensarse y de entender el mundo, además de entender sus dinámicas de organización y de manejo de conflictos, para comprender su versatilidad para adaptarse a las dificultades que históricamente se les han presentado. (Madera y Vargas, 2015, p. 99).

Es decir, comprender sus lógicas de vida, con perspectiva de género y generaciones, sus especificidades socio-productivas e identitarias, así como la diversidad de actividades, de formas de ser y de hacer. En ese sentido, habremos de estar atentos y abiertos también a repensar nuestras propias formas de aproximarnos (epistémica y metodológicamente) a su comprensión, y a buscar respuestas que permitan construir otras formas de relación sociedad-naturaleza, más empáticas y justas.

\section{Agradecimiento:}

Agradezco los atinados comentarios y sugerencias críticas, con que me han obsequiado en la lectura del texto los colegas Karla Barrón, Laura Cayeros, Dagoberto de Dios y Jorge Marín.

Las incoherencias que se mantienen siguen siendo mías.

\section{Referencias}

Aranda, L. (2020). Participación comunitaria del Ejido Colorado de la Mora, en el contexto de la construcción de la presa Aguamilpa [tesis de maestría, Universidad Autónoma de Nayarit]. Repositorio Institucional Aramara. https://bit. $\mathrm{ly} / 2 \mathrm{H} 2 \mathrm{i} 4 \mathrm{sU}$

Cànoves, G. y Villarino, M. (2000). Turismo en espacio rural en España: actrices e imaginario colectivo. Documents d'Anàlisi Geogràfica, 37, 51-77. https://bit. ly/3IS4MOk 
Garduño, M., Guzmán, C. y Zizumbo, L. (2009). Turismo rural: participación de las comunidades y programas federales. El Periplo Sustentable, 17, 5-30. https:// bit.ly/3iYCMqp

Gómez-Carreto, T., Zarazúa, J. A., Guillén, L. y Castellanos, A. C. (2018). Innovación social, turismo rural y empresas sociales. Evidencias desde el Sur-Sureste de México. El Periplo Sustentable, 34, 44-81. https://bit.ly/2FBbkl6

Huizer, G. (1998). La imposición de los valores occidentales y la lucha campesina por la equidad. En R. Menchú, R. Boelens y G. Dávila (Eds.), Buscando la equidad. Concepciones sobre justicia y equidad en el riego campesino (pp. 48-59). Van Gorcum Publishers.

Korstanje, M. E. (2020). El COVID-19 y el turismo rural: una perspectiva antropológica. Dimensiones Turísticas [Número especial: Turismo y COVID-19], 4, 179196. https://doi.org/10.47557/CKDK5549

Madera, J. y Vargas, J. (2015). Miradas desde la agroecología a aparentes proyectos antagónicos en la comunidad indígena de Puerta de Platanares, Nayarit, México. Nóesis, Revista de Ciencias Sociales y Humanidades, 24(47-2), 94-104. https://doi.org/10.20983/noesis.2015.13.7

Organización Mundial del Turismo (OMT). (2020). Turismo y el desarrollo rural: nota técnica. https://bit.ly/2H115bG.

Santana, A. (2002, 14-16 de mayo). Desarrollos y conflictos en torno al turismo rural: claves y dilemas desde la antropología social [ponencia]. III Congresso Internacional sobre Turismo Rural e Desenvolvimento Sustentável - Citurdes, Estado do Rio Grande do Sul, Brasil. https://bit.ly/3nU4gBi

Secretaría de Turismo (Sectur). (2020). Programa sectorial de turismo 2020-2024. https://bit.ly/344swZM

Thomé, H. (2008). Turismo rural y campesinado, una aproximación social desde la ecología, la cultura y la economía. Convergencia, 15(47), 237-261. https://bit. ly/3561MHx 
Varisco, C. A. (2016). Turismo rural: propuesta metodológica para un enfoque sistémico. PASOS, Revista de Turismo y Patrimonio Cultural, 14(1), 153-167. https:// bit.ly/3IU2fTI

Zamudio, F., Corona, A. y López, I. (2008). Un índice de ruralidad para México. Espiral, Estudios sobre Estado y Sociedad, 14(42), 179-214. https://bit.ly/3du5BtG 


\section{Reseña bibliográfica / Book review}

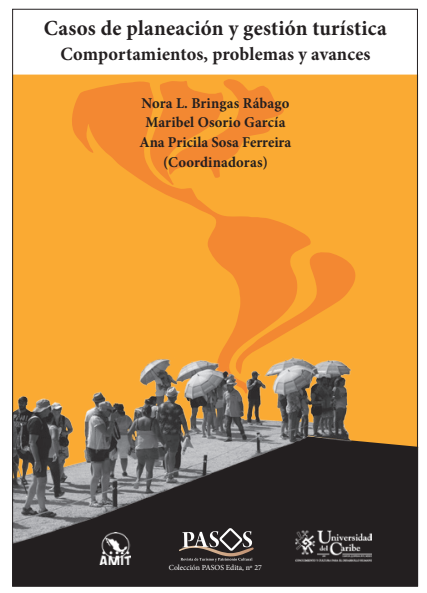

Bringas-Rábago, N. L., Osorio-García, M. y Sosa-Ferreira, A. P. (Coords.). (2020). CASOS DE PLANEACIÓN Y GESTIÓN TURÍSTICA. COMPORTAMIENTOS, PROBLEMAS Y AVANCES. Colección PASOS Edita, No. 27. https://bit.ly/3ddROra

$\square$ I libro Casos de planeación y gestión turística. Comportamientos, problemas y avances, de la editora PASOS, Revista de Turismo y Patrimonio Cultural, fue publicado en el mes de junio del año 2020 bajo el sello de la Colección PASOS Edita, N²7. Las coordinadoras de esta obra son tres destacadas investigadoras de México: Nora L. Bringas Rábago, Maribel Osorio García y Ana Pricila Sosa Ferreira. Esta primera edición cuenta con la colaboración de la Academia Mexicana de Investigación Turística (AMIT) y la Universidad del Caribe, México.

Se trata de un notable esfuerzo de compilación del conocimiento científico actual del turismo en Latinoamérica, específicamente en el campo de los estudios socioespaciales. Es un compendio de textos realizados por investigadores de la región, quienes comparten los resultados de sus trabajos desde una perspectiva teórica, metodológica y empírica, aplicados en México, Chile, Argentina y Brasil.

Un total de 352 páginas se distribuyen en una introducción, 15 capítulos organizados en cuatro secciones, conclusiones generales, listado de evaluadores e información de los autores. Cada capítulo cuenta con la estructura propia de un artículo científico, incluyendo referencias; en ellos se hace una invitación a reflexionar de manera informada y focalizada, explorando diversos aspectos de la planeación y gestión turística en distintos tipos de espacios, en particular los urbanos (sección 2), litorales (sección 3) y regionales (sección 4).

CÓMO CITAR: Inostroza, G. (2020). Reseña del libro Casos de planeación y gestión turística. Comportamientos, problemas y avances. Dimensiones Turísticas, 4(7), 191-194. https://doi.org/10.47557/XWFW7352 
En 13 de sus 15 apartados se distribuye el análisis de ocho casos de estudio en México, dos en Chile y Argentina respectivamente y uno en Brasil. A esto se añade un capítulo de apertura, dirigido al análisis bibliográfico del estado de conocimiento en los estudios socioespaciales del turismo en Iberoamérica (sección 1) y un último texto, a modo de ensayo, acerca de los efectos globales del sector en el patrimonio.

En la introducción se expresa claramente el interés que ha tenido la comunidad científica del turismo en Latinoamérica por los temas espaciales. En efecto, las 13 investigadoras y 11 investigadores que publican sus trabajos en este libro han abordado los ejes temáticos de la sostenibilidad y el desarrollo local, con un fuerte énfasis social. En la referida introducción, el lector podrá encontrar un resumen de los capítulos de cada sección, así como la identificación de los grandes temas tratados, que son: imaginarios, paisaje, patrimonio, impactos del turismo, implicancias de la planificación turística y estudios críticos del turismo.

Dicho esto, la producción social del espacio turístico es el eje transversal, al reincorporar el rol protagónico de los sujetos en la construcción social de los espacios. Se observan referencias a autores clásicos en la temática, como Henri Lefebvre, Milton Santos, David Harvey y Doreen Massey, que aparecen mencionados principalmente en aquellos apartados que han asumido un enfoque crítico.

De este modo, la mayoría de los capítulos tiene como propósito desvelar las subjetividades, sentidos y significados simbólicos de los actores locales en torno al turismo, es por ello que el tema de los imaginarios sociales es recurrente en gran parte de la obra. Aquí asoma con fuerza un referente contemporáneo: Daniel Hiernaux; al respecto, es interesante observar cómo el capítulo 10 establece las asociaciones entre los distintos tipos de imaginarios del turismo residencial (Hiernaux, 2009; 2010) y las representaciones de los actores locales, en cinco destinos turísticos del Caribe mexicano.

Asimismo, no deja de sorprender la manera en que nuevos modelos de negocio turístico, tales como los food truck o furgonetas que ofrecen comida urbana o gourmet en las calles de ciudades como Tijuana, en México, se constituyen en lugares simbólicos de la identidad de una metrópoli, tema del apartado 4.

El enfoque crítico se aprecia en varios de los capítulos, en el sentido de ubicar al turismo ya sea como un re-productor del sistema capitalista neoliberal en un contexto de globalización, o bien como una estrategia de desarrollo local por parte de las 
comunidades receptoras de turistas. En este sentido, se evidencia la lucha, las tensiones y los conflictos que se suscitan, a partir del interés de control del espacio por distintos tipos de actores, ya sea empresarios, trabajadores, gobiernos, o turistas.

Es ahí cuando emergen aspectos tales como la gentrificación (capítulo 1); la capacidad de agencia de ciertos actores de la élite empresarial local en León, México (capítulo 5); la protección y defensa del patrimonio histórico a través del poder social de las comunidades locales en Valparaíso, Chile (capítulo 6); el modelo turístico tipo enclave capitalista y el modelo local de base comunitaria, con una interesante reconstrucción histórica en cuanto a los esfuerzos del Estado por institucionalizar este sector en Chile, tomando como caso de estudio el sur de dicho país (capítulo 12); $y$, finalmente, el turismo como factor de dependencia o de desarrollo en la carretera Parque Transpantaneira, Brasil (capítulo 13).

Otra temática relevante en los textos es el análisis de las políticas públicas en torno al patrimonio. Para lectores interesados en la planeación estatal, en algunos apartados se aborda la experiencia de los Centros Integralmente Planeados (CIP) de México (Dávila, 2014), como Cancún y Nayarit (capítulos 8 y 9 respectivamente), o la valoración de las políticas públicas y la gestión del patrimonio histórico en Morelia, México (capítulos 2 y 3 respectivamente).

El libro incluye también dos textos centrados en Argentina, con enfoques más tradicionales en los estudios del turismo, en cuanto al relevamiento del patrimonio natural para el uso turístico, y la propuesta de nuevos circuitos del sector en Mar del Plata (capítulo 7), así como la evaluación de experiencias turísticas rurales en Neuquén (capítulo 14).

Las metodologías empleadas en los trabajos son principalmente de tipo cualitativo o mixto, utilizando como instrumento principal las entrevistas semiestructuradas, la observación y, por supuesto, la revisión documental. Hay un capítulo que es la excepción, al emplear técnicas preferentemente cuantitativas, con el propósito de analizar la influencia del capital social en la calidad de vida de la población local, en un destino turístico maduro como lo es Cozumel, en el Caribe mexicano (capítulo 11).

Finalmente, el apartado de conclusiones generales señala que los trabajos publicados reflejan distintos enfoques teórico-epistemológicos, como lo es el estructuralismo, los estudios críticos y los culturales (Hiernaux 2008a; 2008b), y asienta que la 
mayoría se ubica en este último rubro, particularmente en la corriente de la geografía humana y cultural del turismo.

Es resumen, el libro resulta ser un producto atractivo, estructurado y ordenado. Un notable esfuerzo de coordinación y difusión de diversas investigaciones realizadas en países de Latinoamérica. Una obra relevante para la ciencia y para la profesión, porque contribuye a generar nuevo conocimiento científico en torno a la producción social de los espacios turísticos, y porque puede llegar a orientar, con base en su lectura, a los tomadores de decisiones en los procesos de planificación y gestión turística, en distintos tipos de espacios, bajo un enfoque de sostenibilidad.

\section{Referencias}

Dávila, A. (2014, junio). Centros Integralmente Planeados en México: las piezas del proyecto turístico de Fonatur [conferencia]. VI Seminario Internacional de Investigación en Urbanismo, Barcelona-Bogotá.

Hiernaux, D. (2008a). Una década de cambios: la geografía humana y el estudio del turismo. Scripta Nova: Revista Electrónica de Geografía y Ciencias Sociales, 12(270). https://bit.ly/2MaTci5

Hiernaux, D. (2008b). El giro cultural y las nuevas interpretaciones geográficas del turismo. Geousp-Espaço e Tempo, 23, 177-187. https://doi.org/10.11606/ issn.2179-0892.geousp.2008.74088

Hiernaux, D. (2009). Los imaginarios del turismo residencial: experiencias mexicanas. En T. Mazón, R. Huete y A. Mantecón (Eds.), Turismo, urbanización y estilos de vida. Las nuevas formas de movilidad residencial (pp. 109-125). Icaria.

Hiernaux, D. (2010). Las segundas residencias, un abordaje geográfico. En D. Hiernaux (Coord.), Las segundas residencias en México: un balance. Universidad del Caribe, Universidad Autónoma del Estado de México, y Plaza y Valdés. 


\title{
Reseña de libro / Book review
}

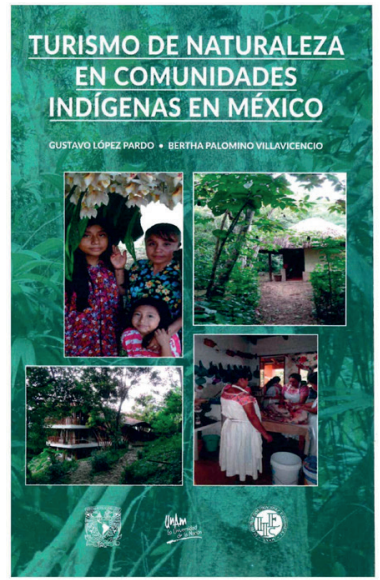

López Pardo, G. y Palomino Villavicencio, B. (2019).

TURISMO DE NATURALEZA EN COMUNIDADES

INDÍGENAS EN MÉXICO. Universidad Nacional Autónoma

de México. https://bit.ly/30U0qyq

\author{
VÍCTOR MANUEL LÓPEZ GUEVARA \\ victorlopez@coltlax.edu.mx \\ El Colegio de Tlaxcala, A. C.
}

as primeras iniciativas gubernamentales para promover el desarrollo turístico en espacios rurales e indígenas de México se registraron a finales de los años 70, de forma aislada y circunstancial, en los estados de Nayarit y Quintana Roo (Juárez y Ramírez, 2007). Dos décadas después, como consecuencia de los ajustes estructurales, diversos programas federales impulsaron la implantación de la función turística en ejidos y comunidades; esto dio lugar a la expresión de una nueva geografía del turismo que, por el hecho de encontrarse en proceso de construcción, generó rápido interés en la comunidad académica.

Durante los últimos 20 años, la vasta literatura científica generada alrededor del tema ha buscado responder a multiplicidad de interrogantes, con encuadres disciplinares diversos y análisis usualmente contextualizados a escala local y regional. Hasta el momento, no son comunes los trabajos que ofrezcan una visión de conjunto desde una perspectiva longitudinal; justamente esa es la característica que distingue a la contribución que ofrecen Gustavo López Pardo y Bertha Palomino Villavicencio en el libro Turismo de naturaleza en comunidades indígenas en México.

A lo largo de los cuatro capítulos que dan forma al documento, los autores desarrollan un abordaje progresivo sobre el tema, que inicia con el manejo de desafíos y precisiones conceptuales, para luego describir la relación del turismo de naturaleza (TN) con el desarrollo y las políticas públicas.

CÓMO CITAR: López Guevara, V. M. (2020). Reseña del libro Turismo de naturaleza en comunidades indígenas en México. Dimensiones Turísticas, 4(7), 195-198. https://doi.org/10.47557/KQKX2780 
La parte final del libro presenta un minucioso análisis de la situación que guardan las empresas indígenas de TN, financiadas a lo largo de las dos últimas décadas por los programas gubernamentales. Esta sección es de especial interés para orientar futuras líneas de investigación, así como agendas que busquen promover la apropiación social del conocimiento. A continuación se detalla el contenido de los diferentes apartados de la obra.

El primer capítulo describe el contexto que ha propiciado la progresiva implantación de la función turística en los espacios rurales e indígenas, desde finales del siglo pasado. Junto a los cambios en la orientación de la política económica, los autores destacan dos causas adicionales: la primera, es el cambio en las preferencias de los consumidores que, cada vez más, buscan experiencias de viaje diferenciadas (respecto a las ofrecidas por el turismo convencional), en las cuales haya aprendizajes novedosos derivados del contacto intercultural; la segunda, se refiere al cambio en los sujetos rurales, quienes han logrado integrar sus prácticas socio-organizativas en la gestión de los emprendimientos de TN, para concretar así una nueva arena social, desde la cual es posible ejercer y fortalecer la autodeterminación y el fomento al etnodesarrollo.

López y Palomino advierten que los intereses gubernamentales incorporados en las políticas públicas y en las reglas de operación de los programas oficiales, han significado un notable contrapeso a la agencia de los sujetos sociales, a tal grado que es posible percibir en los espacios indígenas la conformación de proyectos turísticos descontextualizados del entorno cultural y natural, en los cuales la orientación hacia la mercantilización implica el riesgo latente de banalizar al patrimonio, además de generar, a través de la experiencia ofrecida, imaginarios sociales que se muestran más próximos al turismo convencional que al alternativo. Por lo tanto, recomiendan que las políticas públicas promotoras de TN fomenten la participación local permanente, como vía para evitar tensiones e incoherencias entre el corpus conceptual y la praxis del turismo.

El segundo capítulo presenta una panorámica alrededor de las acciones gubernamentales, mismas que sentaron las bases para definir una política turística enfocada en los espacios rurales. A este respecto, los autores dan cuenta de los primeros convenios interinstitucionales formulados para apuntalar la acción pública. El primero de ellos, firmado en 2004, asoció metas y acciones a los referentes del ecoturismo y 
el turismo rural; el segundo, formalizado en 2007, ajustó los intereses gubernamentales y la acción pública a los términos asociados a un nuevo concepto: el TN.

Así, entre 2006 y 2012, ambos convenios dieron pauta al diseño y ejecución de 57 programas, de los cuales cinco fueron de orientación turística específica, 29 manejaron objetivos afines al turismo, en tanto que 23 (aun sin guardar relación con el sector) financiaron acciones que brindaron soporte al desarrollo de la actividad.

La ejecución de los programas propició la revalorización del patrimonio por parte de las poblaciones locales, el fortalecimiento de las identidades, la articulación de iniciativas de conservación ambiental y la diversificación productiva. No obstante, los autores reconocen que la acción pública generó un conjunto de inconsistencias, atribuidas a la insuficiente transversalidad institucional, a saber: 1) escaso énfasis en la construcción de capacidades para la operación de las empresas, 2) financiamiento de acciones ambientales, sociales y empresariales, carentes de una visión sistémica, y 3) operación discrecional de los programas.

En el tercer capítulo se describen los alcances de la política turística en los espacios indígenas de México. El análisis parte de una premisa, en la cual se establece que las políticas públicas son proyectos y actividades que buscan atender necesidades sociales. Debido al fin que persiguen, su diseño demanda el encuentro entre la racionalidad estatal y la voluntad de la sociedad. En el caso del TN, los autores señalan una inconsistente convergencia entre los intereses del Estado y los pueblos indígenas, lo cual ha derivado en la instrumentación de políticas públicas desequilibradas, a pesar de las continuas modificaciones que han recibido durante tres etapas, desde 1985 al 2012.

Los desajustes en la política pública del TN han dado pauta a un escenario dual: por un lado, se muestra positivo en cuanto a la gestión del patrimonio y del medio ambiente, así como en el fortalecimiento al capital social y al bienestar de las comunidades; por otro, se revela negativo, debido a la manifestación de conflictos asociados al control de los emprendimientos, al abandono de los proyectos y a la pérdida de la inversión ejercida. El reto que se requiere superar para evitar el fracaso de las empresas, según apuntan los autores, reside en el desarrollo y adecuación de capacidades para la operación del TN.

Con la intención de valorar la efectividad de los programas públicos, en el cuarto capítulo se analiza la situación de 998 empresas indígenas de TN. Para tal efecto 
López y Palomino aplican una metodología basada en la medición de variables de gestión, identificadas como indispensables para poder operar en el mercado turístico y competir con la oferta privada. Los hallazgos revelan que el $51.8 \%$ de las empresas se ubicaron en el rango del desempeño bajo, $44.99 \%$ en el medio y $3.21 \%$ en el alto, con lo cual se evidencia la necesidad de proponer cambios a las políticas públicas, con la intención de tornarlas más efectivas.

En este orden de ideas, la discusión elaborada en los capítulos precedentes cobra sentido, cuando los autores corroboran que algunas variables asociadas al desempeño alto de las empresas guardan relación con la práctica de procesos participativos, mediante los cuales es posible asegurar: 1) la contextualización de las acciones promovidas por los programas públicos, 2) la activación de redes colaborativas para reducir costos de inversión, 3) el aprovechamiento en favor de la gestión, de habilidades y saberes detentados por diferentes grupos y generaciones, y 4) la representación de la identidad local durante la puesta en valor de los bienes y espacios patrimoniales, con lo cual se evita la estandarización y la reproducción de imaginarios, que limitan la operación de experiencias diferenciadas.

El libro apunta a la necesidad de mantener un análisis minucioso y sistemático del TN en los espacios indígenas del país, para perfilar una mejor comprensión del tema y del funcionamiento de los instrumentos de política pública asociados a este. A lo anterior, se debe sumar el llamado a la comunidad académica para incursionar en el acompañamiento a las empresas, en aras de fortalecer los procesos de apropiación social del conocimiento.

Este último asunto reclama especial atención, al tener en cuenta que México, además de ser un país multicultural, ha ratificado en diversas ocasiones las convenciones internacionales que aseguran a los pueblos originarios el derecho a la libre determinación, a la consulta y cooperación con el Estado y sus instituciones, a la participación, a la capacitación y al adiestramiento profesional.

\section{Referencia}

Juárez, J. y Ramírez, B. (2007). El turismo rural como complemento al desarrollo territorial rural en zonas indígenas de México. Scripta Nova, Revista Electrónica de Geografía y Ciencias Sociales, 11(236). https://bit.ly/3lwqN5f 


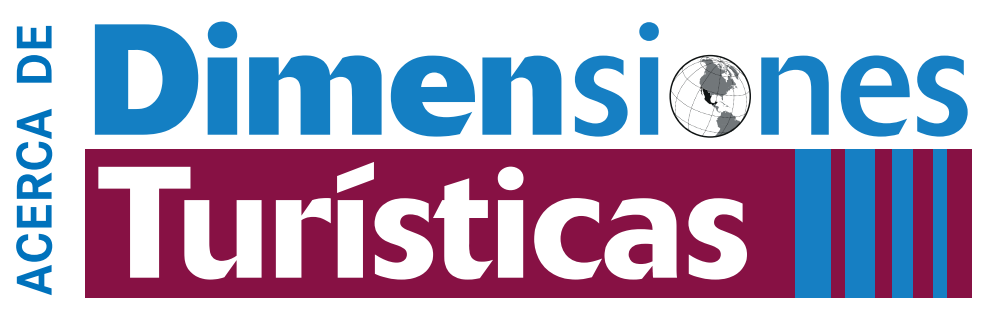

\section{POLÍTICAS}

\section{Enfoque y alcance}

Dimensiones Turísticas es una publicación científica, digital y de distribución gratuita que publica y difunde trabajos originales de investigación que abordan temáticas turísticas en México y en otros contextos internacionales. Dimensiones Turísticas se especializa en el estudio de los distintos procesos sociales, culturales, económicos, políticos, ambientales y territoriales vinculados con la actividad turística a través de investigaciones analíticas, críticas y reflexivas desde una perspectiva inter y multidisciplinaria con el propósito de difundir los principales hallazgos de investigación tanto entre la comunidad académica, como con el sector gubernamental, empresarial y la sociedad en su conjunto.

Su objetivo es constituirse en un espacio que permita exponer nuevos enfoques, teorías, metodologías, estudios, experiencias y hallazgos de investigación que posibiliten avanzar en la construcción y difusión del conocimiento acerca del turismo, así como contribuir al enriquecimiento de debates actuales sobre la investigación turística.

\section{Políticas de sección}

Dimensiones Turísticas publica textos inéditos de carácter científico que analicen teorías, metodologías o procesos sociales, culturales, económicos, administrativos, políticos, ambientales y territoriales vinculados con la actividad turística desde una perspectiva inter y multidisciplinaria.

Se publicarán tres tipos de trabajos: artículos, notas críticas y reseñas bibliográficas.

Artículo: Se refiere a trabajos originales que expongan los principales hallazgos teóricos, empíricos o metodológicos de investigaciones concluidas o en curso que analicen desde distintas disciplinas procesos vinculados a la actividad turística.

Nota crítica: Es una reflexión académica sobre temas actuales o avances de investigación.

Reseña bibliográfica: Es un texto breve que refiere o analiza publicaciones en formato físico o electrónico recientes que aborden temáticas de turismo o de investigación. El Comité editorial será el responsable de sugerir los libros a reseñar. 


\section{Proceso de evaluación por pares}

Los trabajos académicos serán sometidos a un proceso de evaluación anónima por pares. Las notas críticas serán sometidas al mismo proceso de evaluación que los artículos. Las publicaciones reseñadas no deberán tener una fecha de publicación mayor a dos años anteriores al año de envío de la propuesta.

Debido al proceso editorial anónimo, los datos de autores/as como adscripción, currículo sucinto, dirección electrónica y postal figurarán en una hoja aparte. Los trabajos serán sometidos a la revisión de un comité de expertos para avalar la calidad científica y deberán enviarse en su versión final y completa, ya que no se permitirán modificaciones posteriores una vez iniciado el proceso de evaluación.

El proceso para la revisión blindada de artículos es el siguiente:

Recepción del manuscrito y aviso de recepción al autor en un plazo no mayor a 72 horas. Posteriormente, inicia el proceso que consta de las siguientes fases:

Primera fase: Envío de la propuesta al Comité editorial para realizar una preevaluación de la calidad del manuscrito, la pertinencia temática y la conformidad de las normas editoriales. El manuscrito podrá ser aceptado o rechazado por el Comité, que basa su decisión en criterios de calidad académica, aportación al campo científico y a la temática y normatividad. Si el manuscrito es aceptado, pasa a la segunda fase; en caso contrario, se envía un aviso de rechazo al/la autor/a.

Segunda fase: en caso de que el predictamen sea favorable, el manuscrito anónimo se enviará a dos evaluadores/as externos/as, con especialidad en la línea de investigación, temática o materia de la propuesta. En caso de contar con dictámenes contradictorios, el manuscrito se envía a un tercer evaluador/a, también especialista, cuya decisión será determinante para el dictamen final.

Los dictámenes podrán tener los siguientes resultados:

Dictamen positivo: indica un resultado favorable; el manuscrito puede ser evaluado como:

a) Publicar sin cambios;

b) Publicar cuando se hayan cumplido con modificaciones menores;

c) Publicar una vez que se haya efectuado una revisión a fondo.

No publicable: el escrito se rechaza de forma definitiva.

En caso de que el dictamen final solicite cambios o modificaciones, los/as autores/ as disponen de cuatro semanas para incorporarlos y volver someter el manuscrito para su revisión. La revisión la realiza el Comité editorial. Si los cambios se incorpo- 
ran adecuadamente, el manuscrito se acepta finalmente; si se considera que no se han hecho las modificaciones requeridas se pedirá a los/las autores/as que revisen su propuesta y se contará con un plazo no mayor a dos semanas para incorporar los cambios solicitados. Si los cambios se incorporan, será aceptado para su publicación; si los cambios no se incorporan en este segundo periodo, el manuscrito se rechaza.

Para que las propuestas sean enviadas al Comité editorial deberán cumplir con las Normas editoriales de AMIT (APA 7). En caso contrario, serán devueltas a los/las autores/as para que ajusten sus propuestas a las directrices.

Una vez aceptado el trabajo para su publicación, los/as autores/as conceden a la revista Dimensiones Turísticas los derechos de los artículos publicados, conservando sus derechos morales conforme lo establece la Ley de derechos de autor.

Frecuencia de publicación

Dimensiones Turísticas es una publicación semestral. Se publica en junio y diciembre. La convocatoria para recepción de trabajos se mantiene abierta durante todo el año. Cada número incluye un mínimo de cinco artículos.

Política de acceso abierto

Dimensiones Turísticas brinda un acceso abierto y gratuito al contenido de sus investigaciones con la finalidad de difundir y garantizar un intercambio amplio y directo del conocimiento generado.

No se cobrarán cuotas por el envío, gestión o publicación de los trabajos enviados a evaluar.

Derechos de los/las autores/as

Los/las autores/as serán responsables únicos de las ideas, afirmaciones y opiniones expresadas en su texto, por lo que la revista no asume responsabilidad alguna en este sentido. Los/las autores/as conserva/n sus derechos morales conforme lo establece la Ley de derechos de autor. Dimensiones Turísticas autoriza la reproducción de su material a través de medios magnéticos, electrónicos y de reprografía siempre y cuando no se alteren los contenidos, sea sin fines de lucro y se cite la fuente completa. 


\section{Directrices para autores}

Los trabajos serán sometidos a evaluación por un comité de expertos. Todas las propuestas pasarán por un proceso editorial que se desarrollará en varias fases, por lo que es necesario que la presentación de los escritos siga una serie de normas que faciliten la edición y eviten el retraso de la publicación.

Los escritos enviados a Dimensiones Turísticas para su publicación deberán ser originales y académicos, no haber sido publicados en otros medios impresos, ni electrónicos. Tampoco deberán haber sido sometidos de manera simultánea a otras revistas u órganos editoriales. Deberán atender de manera estricta la presente guía para autores.

Los textos deberán enviarse en su versión final y completa, ya que no se admitirán modificaciones posteriores una vez iniciado el proceso de evaluación.

La revista publicará tres tipos de trabajos: artículos, notas críticas y reseñas bibliográficas.

Todos los trabajos serán revisados para verificar que se ajusten estrictamente a la presente guía para autores, en caso contrario, se remitirán a los/las autores/ as para que realicen los ajustes correspondientes. Una vez establecido que el trabajo cumple con los requisitos solicitados por la revista, será enviado a dos árbitros, quienes determinarán en forma anónima:

a) Dictamen positivo: indica un resultado favorable; el manuscrito puede ser evaluado:

Publicar sin cambios;

Publicar cuando se hayan cumplido modificaciones menores;

Publicar una vez que se haya efectuado una revisión a fondo.

b) No publicable: el escrito se rechaza de forma definitiva.

En caso de discrepancia entre ambos resultados, el texto será enviado a un tercer árbitro, cuyo dictamen será determinante para decidir si se acepta o no. Los resultados del proceso de evaluación serán inapelables en todos los casos.

Los trabajos enviados por académicos/as adscritos/as a alguna institución serán sometidos a consideración de árbitros externos a la misma.

Los dictámenes serán enviados a los/las autores/as oportunamente. 


\section{Elementos para considerar}

Los trabajos enviados deberán estar escritos de manera clara, sencilla y bien estructurada, omitiendo la redacción en primera persona, ya sea en singular o plural (yo o nosotros).

Los párrafos adoptarán el estilo de párrafo moderno (sin sangría). Los trabajos podrán estar escritos en español o en inglés.

No se aceptarán escritos que presenten un abuso de citas textuales por cada página; utilizándose de preferencia solo para conceptos y definiciones.

\section{Requisitos para los artículos}

Todos los trabajos deberán estar escritos en el programa Word 2011 o anterior, en hojas tamaño carta, en una sola faz, a espacio y medio y con márgenes de tres centímetros. Tipo de letra Calibri de 12 puntos.

La extensión mínima del artículo será de 20 cuartillas y la máxima de 25, tamaño carta, a espacio y medio, incluyendo resumen, tablas, gráficos y figuras (mapas, ilustraciones, diagramas, fotografías) y referencias.

En la primera página deberá aparecer el título del trabajo (redactado en alta y bajas, en negritas y en español e inglés), que deberá ser breve y referir claramente el contenido. Enseguida se incluirá un resumen en español e inglés (abstract) con una extensión máxima de 500 caracteres, en el que se destaque el objetivo, la relevancia del análisis, el método utilizado, los principales resultados o hallazgos más relevantes. Es responsabilidad del autor proveer una traducción correcta del resumen.

Asimismo, se requieren cinco palabras clave en español e inglés (keywords). Se sugiere que estas palabras sean: una geográfica, dos disciplinarles y dos temáticas, con su respectiva traducción al inglés o español que permitan identificar el contenido del artículo. Incluir seguidamente el texto principal y las referencias.

El texto deberá organizarse como sigue (los títulos de secciones son indicativos, las propuestas pueden llevar otro título, pero respetar los contenidos):
a. Título
b. Resumen (español e inglés) y palabras clave en ambos idiomas
c. Introducción
d. Cuerpo del trabajo: antecedentes, metodología, resultados, discusión y/o ha- llazgos.
e. Conclusiones
f. Referencias 
Los títulos o subtítulos deberán diferenciarse entre sí, para ello se recomienda el uso del sistema decimal progresivo, cuidando que la numeración de los subtemas o secciones no sea excesiva o mayor a dos órdenes (2., 2.1, 2.1.1, 2.1.2).

Las siglas y acrónimos deberán ser claramente definidos en su primer uso en el texto. No se aceptan abreviaturas, excepto las referidas en el Manual de estilo.

Todas las referencias al material previamente publicado y a fuentes estadísticas deberán estar identificadas en el texto utilizando el sistema de citas autor y fecha de APA 7, colocando el apellido del autor (o autores), anotando entre paréntesis el primer apellido del autor/a o autores, seguido del año de publicación y página(s) de referencia precedida por la letra p. Por ejemplo: (Hiernaux, 2010, p.63) o (Hiernaux y Lindón, 2015, pp.231-235).

Las notas de pie de página deberán ser las estrictamente necesarias, estar numeradas sucesivamente en números arábigos y estar situadas a pie de página. Se utilizarán solo para hacer comentarios puntuales o aclaraciones del autor y no para referencias bibliográficas. Deberán presentarse con letra Calibri de 9 puntos evitando anexos 0 apéndices.

Las tablas y gráficos deberán incluir información estadística concisa, en formato de hoja de cálculo, preferiblemente en Microsoft Excel. Igualmente deberán colocarse en formato editable en el lugar propuesto en el documento, con el título colocado en la parte superior del objeto, con tipología Calibri 10 puntos y con su respectiva fuente de referencia colocada en la parte inferior.

Las figuras deberán incluirse en archivos separados, en formato de imagen jpeg (.jpg) o tiff (.tif) con una resolución de 300 dpi y preferentemente en color y un archivo por cada objeto. También deberán colocarse en formato editable en el lugar propuesto en el documento, con el título colocado en la parte superior de la figura, con tipología Calibri 10 puntos y con su respectiva fuente de referencia colocada en la parte inferior.

Tanto las tablas, gráficos y demás figuras serán numerados con el sistema arábigo (tabla 1, 2, 3, y más). Las fotografías son consideradas como figuras (figura 1, 2, 3, etcétera). Estas últimas deberán manejarse en formato JPG a 300 dpi como mínimo y deberán especificar como pie de foto, el autor y el año en que fueron tomadas, con tipología Calibri 10 puntos y con su respectiva fuente de referencia, colocada en la parte inferior.

Cada archivo debe ir titulado en primer lugar por el tipo de objeto, su número consecutivo y la página en que queda ubicado (graf1p8.jpg; mapa1p15.tif; fig1 p12.jpg; fig2p16.xls; etcétera). En el cuerpo del texto deberá incluirse cada objeto en el lugar correspondiente, en formato editable. 
Las referencias se incluirán al final del artículo ordenadas alfabéticamente por autor, incluyendo exclusivamente las obras citadas en el cuerpo del texto como libros, capítulos de libros, artículos en revistas digitales o impresas, notas periodísticas, archivos de Internet, películas, entre otros.

\section{Requisitos para las notas críticas}

Las notas críticas son reflexiones sobre temas de actualidad o avances de investigación. Deberán tener una extensión mínima de ocho cuartillas tamaño carta y un máximo de 10, a espacio y medio, en Calibri de 12 puntos, con márgenes de tres centímetros.

Las notas críticas serán seleccionadas por el Comité editorial de la revista considerando su calidad, originalidad en el análisis, actualidad y pertinencia temática.

Las notas críticas deberán atender las mismas indicaciones con respecto al título y el resumen (bilingüe), así como para citar referencias.

Requisitos para las reseñas bibliográficas

Las reseñas deben referirse a libros relevantes publicados dentro de los dos años anteriores a la fecha de publicación de la revista y su extensión máxima deberá ser de cuatro páginas tamaño carta, a espacio y medio, en Calibri de 12 puntos, con márgenes de tres centímetros en todos los lados.

La reseña deberá contener la referencia completa de la obra (formato APA 7), seguida de los datos de quien hace la reseña y los datos de identificación (nombre y apellidos, correo electrónico e institución).

Normas para citar las referencias

Las referencias a fuentes consultadas deberán incluirse al final en orden alfabético, sin distinguir el tipo de fuente y en formato APA 7 (Para información más completa ver sección 38 de la Guía para autores y Manual de estilo de la RDT).

Artículos y publicaciones periódicas impresas

Apellido, A. A., Apellido, B. B. y Apellido, C. C. (Año). Título del artículo (en redondas). Nombre de la revista (en cursivas), volumen(en cursivas)(número), pp.-pp.

Ejemplo:

Bertoncello, R. (2002). Turismo y territorio, otras prácticas, otras miradas. Aportes y transferencias, 6(2), 29-50 
Artículo y publicaciones digitales o electrónicas

Apellido, A. A., Apellido, B. B. y Apellido, C. C., (Año). Título del artículo (en redondas). Nombre de la revista (en cursivas), volumen(en cursivas)(número), pp.-pp. http://URL

Ejemplo:

Rodríguez Herrera, I. M. y Vargas Vázquez, A. (2018). Aproximación reticular a la producción científica sobre turismo realizada por investigadores mexicanos. Dimensiones Turísticas, 2(2), 9-26. https://dimensionesturisticas.amiturismo.org/wp-content/ uploads/2020/03/2018-DT-V2N2-03_09-26-Rodriguez-Vargas.pdf

Artículo con doi

Apellido, A. A., Apellido, B. B. y Apellido, C. C. (Año). Título del artículo (en redondas). Nombre de la revista (en cursivas), volumen(en cursivas)(número), pp.-pp. http://doi: XXX-YYYY

Ejemplo:

Valcuende del Río, J. M. (2012). Turismo y poblaciones indígenas: Espacios, tiempos y recursos. Scripta Nova. Revista Electrónica de Geografía y Ciencias Sociales, XVI(410), 28-55. http://doi.1138-9788

Libros

Apellido, A. A. (Año). Título (en cursivas). Editorial.

Ejemplos:

Santana, A. (1997). Antropología y Turismo. ¿Nuevas hordas, viejas culturas? Ariel.

Casez, G. (1992a). Fondements pour une géographie du tourisme et des loisirs. Bréal Editions.

Casez, G. (1992b). Tourisme et tiers-monde, un bilan controversé. L'Harmattan (Tome II).

Libros con editor, compilador o coordinador

Apellido, A. A. (Ed.). (Año). Título (en cursivas). Editorial.

Ejemplo:

Vera Rebollo, J. F. (Coord.) (2011). Análisis territorial del turismo y planificación de destinos turísticos. Tirant Lo Blanch. 
Versión electrónica o digital de libro impreso

Apellido, A. A. (Año). Título (en cursivas). Editorial. http://URL

Ejemplo:

Ascanio, A. (2013). Economía del turismo. Ediciones de la U. http://economia.com

Capítulo de libro

Apellido, A. A. y Apellidos, B. B. (Año). Título del capítulo (en redondas). En A. A.

Apellido (Ed.), Título del libro (en cursivas) (p. nn-nn). Editorial.

Ejemplos:

Luka, N. (2011). Del espacio al lugar y al paisaje cultural: segundas residencias a orillas de ríos y lagos en Canadá central. En T. Mazón y A. Mantecón (eds.), Construir una nueva vida. Los espacios del turismo y la migración residencial (pp. 21-46). Milrazones.

Salvat, J., Meritxell S., y Olmos, P. (1998). Evaluación del potencial turístico: las montañas de Prades. En J. Oliveras y A. Salvador (eds.), Turismo y planificación del territorio en la España de fin de siglo (pp. 107-115). Universitat Rovira I Virgili.

Videos, grabaciones y otros soportes digitales

Apellido, A. A. (productor) y Apellido, B. B. (director). (Año). Título (en cursivas) [descripción]. Estudio/compañía productora/sello discográfico.

Ejemplo:

Marvin, N. (productora) y Darabont, F. (director). (1994). Sueños de fuga [película cinematográfica]. Columbia Pictures.

Secretaría de Turismo de México (2015). Compendio estadístico del turismo en México 2016 [disco compacto].

Videos, podcast y otras fuentes en línea

Apellido, A. A. (año, día y mes). Nombre del programa o evento (en cursivas) [tipo de archivo]. http://URL

Ejemplo:

Hiernaux, D. (2019, 2 de octubre). La entrevista de John Urry en el Congreso Internacional de Investigación AMIT 2019 [audio en podcast]. http://bitly.ws/9Q6R 
Páginas web

Apellido, A. A. (Año). Título del contenido (en redondas). Nombre del sitio (cursivas) http://URL

Ejemplo:

Cañada, E. (2020, 8 de julio). Turismos de proximidad, un plural en disputa. Alba Sud. http://www.albasud.org

Simposios y conferencias

Apellido, A., y Apellido, B. (año, día y mes). Título de la presentación (en redondas). En A. Apellido del Presidente/organizador del Congreso (Presidencia), Título del simposio (en cursivas). Simposio dirigido por Nombre de la Institución Organizadora, Lugar.

Ejemplo:

Ibáñez, R. (2013, 31 de octubre). Retos en materia de turismo y sustentabilidad en pequeñas localidades costeras de Baja California Sur (BCS). 7mo. Congreso Internacional de la Academia Mexicana de Investigación Turística. Simposio dirigido por la Academia Mexicana de Investigación Turística y la Universidad Autónoma de Chiapas, San Cristóbal de las Casas, Chiapas, México.

Tesis

Apellido, A. (Año). Título de la tesis (en cursivas) [tesis de (grado), Nombre de la Institución]. Repositorio.

Ejemplo:

Gaxiola Aldama, R. (2010). Turismo sexual masculino y las prácticas sociales de uso del espacio urbano en la ciudad de Tijuana [tesis de doctorado, El Colegio de la Frontera Norte]. Repositorio institucional.

Comunicaciones personales y entrevistas

Si bien las comunicaciones personales (correos, cartas privadas, memorandos, entrevistas telefónicas) deberán aparecer referidas en el cuerpo del texto según lo sugerido por las normas APA 7, no se incluyen en las referencias, por no considerarse fuentes consultables. 


\section{ENVÍOS}

Los trabajos podrán enviarse atendiendo cualquiera de las dos opciones:

Enviar el archivo digital del trabajo directamente a la dirección: amit.dimentur@ gmail.com, asegurándose de eliminar del mismo las referencias de autoría y filiación.

Subir el archivo digital del trabajo directamente en el siguiente enlace: https://dimensionesturisticas.amiturismo.org/envio-de-archivos

\section{Información adicional}

Para asegurar el anonimato, además del texto completo del artículo o reseña, es necesario enviar en hoja independiente o capturar directamente en el siguiente enlace https://dimensionesturisticas.amiturismo.org/envio-de-archivos.

Tipo de colaboración

Título de la colaboración.

Nombre completo del/la autor/a.

Correo electrónico del/la autor/a.

Institución y dependencia de adscripción.

Dirección postal

País

Currículo abreviado de el/la autor/a o autores/as (máximo 600 caracteres), que incluya el último grado académico y la institución donde obtuvo el grado, ocupación actual, líneas de investigación y título de los últimos tres trabajos publicados.

\section{Lista de comprobación de preparación de envíos}

Como parte del proceso de envío se requiere que los autores indiquen que el mismo cumple puntualmente con las siguientes características:

- Que la propuesta no ha sido publicada previamente, ni se ha enviado simultáneamente a otra revista.

- Que el archivo enviado está en formato de Microsoft Word.

- Que se han añadido direcciones web para las referencias donde sea posible.

- Tipografía Calibri a 12 puntos para el texto y de 10 para títulos de tablas, gráficas y figuras y para notas de pie de página el tamaño es 9.

- Texto interlineado a espacio y medio.

- Que el texto cumple con los requisitos bibliográficos y de estilo indicados en la Guía para autores y manual de estilo de la RDT. 
Los trabajos que no cumplan con estas indicaciones pueden ser devueltos al/la autor/a, quien podrá enviar de nuevo su escrito siempre y cuando cumpla con los puntos solicitados.

Aviso de derechos de autor

Los/as autores/as conceden a Dimensiones Turísticas el permiso para que su material se difunda en la revista y medios magnéticos, electrónicos y fotográficos. Los derechos de autor de los artículos publicados en Dimensiones Turísticas son cedidos a la Academia Mexicana de Investigación Turística, A.C. (AMIT) tras la aceptación del original para que este se publique y distribuya en versión electrónica; asimismo, los/las autores/as conserva(n) sus derechos, morales conforme lo establece la Ley de derechos de autor.

El/la autor/a principal recibirá una forma de Declaración de originalidad y cesión de derechos de autor que deberá firmar y remitir a Dimensiones Turísticas (amit. dimentur@gmail.com) conjuntamente con la versión final del trabajo. Será su responsabilidad obtener la firma y consentimiento de los/las demás autores/ as si los hubiere.

Por otra parte, los/as autores/as podrán usar el material de su artículo en otros trabajos o libros publicados por ellos mismos, con la condición de citar a Dimensiones Turísticas como la fuente original de los textos.

Es responsabilidad de los/las autores/as obtener por escrito la autorización correspondiente para todo aquel material que forme parte de su artículo (fotografías o mapas satelitales) y que se encuentre protegido por la Ley de derechos de autor.

Todos los contenidos de Dimensiones Turísticas se publican bajo la licencia Creative Commons Atribución no comercial, sin derivadas 4.0 Internacional, y pueden ser usados gratuitamente para fines no comerciales, dando el crédito a los autores y a la revista Dimensiones Turísticas.

\section{(c) (i) (5) $\Theta$}

Declaración de privacidad

Los nombres y direcciones de correos administrados por la revista Dimensiones Turísticas se usarán exclusivamente para los fines declarados por la revista y no estarán disponibles para ningún otro propósito u otra persona. 


\section{OTROS}

Dimensiones Turísticas suscribe el código de conducta del Committee on Publication Ethics (COPE), que adopta las siguientes recomendaciones de la Guía de Buenas Prácticas revisada y aprobada por el COPE en 2011:

- La dirección de la revista y demás miembros del equipo editorial son responsables de garantizar un proceso de evaluación anónimo entre autores y evaluadores. La información sobre el manuscrito se mantendrá en estricta confidencialidad y solo se informará a autores/as responsables de la propuesta y al equipo editorial.

- La dirección de la revista mantendrá anónima la identidad de los/as evaluadores/as.

- La revista Dimensiones Turísticas se compromete a elegir evaluadores/as calificados/as según la temática y con capacidad probada para evaluar de forma ética y profesional, evitando conflictos de intereses.

- Se cuidará la calidad académica y ética de la comunicación con los/las evaluadores/as. Cualquier falta, descortesía o mala conducta de un/a dictaminador/a será revisada y la revista se compromete a no recurrir a evaluadores/as que realicen tales prácticas.

- Las propuestas serán sometidas a dictamen considerando su contenido intelectual, sin sesgos ni discriminación de edad, género, creencias políticas o religiosas y respetando la libertad de expresión.

- Las decisiones editoriales de aceptación o rechazo estarán basadas en la importancia, originalidad y claridad del manuscrito, en la validez del estudio científico y en su vínculo con la línea editorial de la revista. El/la directora/a solo podrán revocar propuestas o contribuciones en caso de que se identifiquen problemas serios con las mismas, como plagio, faltas éticas, entre otras, aunque estuvieran previamente aprobadas para su publicación.

- En caso de ser necesario y estar comprobado, la revista Dimensiones Turísticas puede hacer públicas cuestiones de mala conducta vinculadas a la investigación y a las propuestas incluyendo prácticas de plagio y duplicidad por parte de los/as autores/as.

- La dirección de la revista y el Consejo editorial recomiendan a sus revisores/ as el uso de software para detectar plagios. Algunos en versión pago son Turnitin, Paper Rater, Viper, entre otros. De igual manera, en el espectro gratuito se destacan plag.es o bien plagiarisma.net/es las cuales brindan opciones premium con el simple registro o señalar la pertenencia a la academia. 
En cuanto a los/las evaluadores/as, estos deberán comprometerse a lo siguiente:

- Revisar las propuestas de forma confidencial y no utilizar la información de la revisión para otros fines distintos a la evaluación del trabajo.

- Informar a la dirección de la revista en caso de existir algún conflicto de cualquier tipo (de interés o vinculado con la metodología, contenidos o procedimientos de la investigación, los/las evaluadores/as deberán informar a la dirección).

- Informar a la dirección de la revista cuestiones de mala ética vinculadas a la investigación y a las propuestas incluyendo prácticas de plagio y duplicidad por parte de los/as autores/as.

En cuanto a los/las autores/as, deberán comprometerse a lo siguiente:

- Las propuestas son responsabilidad de quien sustenta la autoría; los/las autores/as se comprometen a someter obras académicas inéditas y originales elaboradas por ellos mismos.

- Las propuestas no deberán ser sometidas a otros procedimientos editoriales ni haber sido objeto de plagio, falsificación o manipulación.

- Todo material no producido por quien sustenta la autoría, deberá estar claramente citado de acuerdo a la Guía para autores y Manual de estilo editorial de la revista Dimensiones Turísticas.

- Los/las autores/as tienen la obligación de no incurrir en falsificación de participación de autoría, por lo que deberán equilibrar su participación a fin de que no aparezcan autorías o colaboraciones fantasmas. 